\title{
Carbon and Other Biogeochemical Cycles
}

\author{
Coordinating Lead Authors: \\ Philippe Ciais (France), Christopher Sabine (USA)

\section{Lead Authors:} \\ Govindasamy Bala (India), Laurent Bopp (France), Victor Brovkin (Germany/Russian Federation), \\ Josep Canadell (Australia), Abha Chhabra (India), Ruth DeFries (USA), James Galloway (USA), \\ Martin Heimann (Germany), Christopher Jones (UK), Corinne Le Quéré (UK), Ranga B. Myneni \\ (USA), Shilong Piao (China), Peter Thornton (USA)
}

\section{Contributing Authors:}

Anders Ahlström (Sweden), Alessandro Anav (UK/Italy), Oliver Andrews (UK), David Archer (USA), Vivek Arora (Canada), Gordon Bonan (USA), Alberto Vieira Borges (Belgium/Portugal), Philippe Bousquet (France), Lex Bouwman (Netherlands), Lori M. Bruhwiler (USA), Kenneth Caldeira (USA), Long Cao (China), Jérôme Chappellaz (France), Frédéric Chevallier (France), Cory Cleveland (USA), Peter Cox (UK), Frank J. Dentener (EU/Netherlands), Scott C. Doney (USA), Jan Willem Erisman (Netherlands), Eugenie S. Euskirchen (USA), Pierre Friedlingstein (UK/Belgium), Nicolas Gruber (Switzerland), Kevin Gurney (USA), Elisabeth A. Holland (Fiji/ USA), Brett Hopwood (USA), Richard A. Houghton (USA), Joanna I. House (UK), Sander Houweling (Netherlands), Stephen Hunter (UK), George Hurtt (USA), Andrew D. Jacobson (USA), Atul Jain (USA), Fortunat Joos (Switzerland), Johann Jungclaus (Germany), Jed O. Kaplan (Switzerland/Belgium/USA), Etsushi Kato (Japan), Ralph Keeling (USA), Samar Khatiwala (USA), Stefanie Kirschke (France/Germany), Kees Klein Goldewijk (Netherlands), Silvia Kloster (Germany), Charles Koven (USA), Carolien Kroeze (Netherlands), Jean-François Lamarque (USA/Belgium), Keith Lassey (New Zealand), Rachel M. Law (Australia), Andrew Lenton (Australia), Mark R. Lomas (UK), Yiqi Luo (USA), Takashi Maki (Japan), Gregg Marland (USA), H. Damon Matthews (Canada), Emilio Mayorga (USA), Joe R. Melton (Canada), Nicolas Metzl (France), Guy Munhoven (Belgium/Luxembourg), Yosuke Niwa (Japan), Richard J. Norby (USA), Fiona O'Connor (UK/Ireland), James Orr (France), Geun-Ha Park (USA), Prabir Patra (Japan/ India), Anna Peregon (France/Russian Federation), Wouter Peters (Netherlands), Philippe Peylin (France), Stephen Piper (USA), Julia Pongratz (Germany), Ben Poulter (France/USA), Peter A. Raymond (USA), Peter Rayner (Australia), Andy Ridgwell (UK), Bruno Ringeval (Netherlands/ France), Christian Rödenbeck (Germany), Marielle Saunois (France), Andreas Schmittner (USA/Germany), Edward Schuur (USA), Stephen Sitch (UK), Renato Spahni (Switzerland), Benjamin Stocker (Switzerland), Taro Takahashi (USA), Rona L. Thompson (Norway/New Zealand), Jerry Tjiputra (Norway/Indonesia), Guido van der Werf (Netherlands), Detlef van Vuuren (Netherlands), Apostolos Voulgarakis (UK/Greece), Rita Wania (Austria), Sönke Zaehle (Germany), Ning Zeng (USA)

\section{Review Editors: \\ Christoph Heinze (Norway), Pieter Tans (USA), Timo Vesala (Finland)}

This chapter should be cited as:

Ciais, P., C. Sabine, G. Bala, L. Bopp, V. Brovkin, J. Canadell, A. Chhabra, R. DeFries, J. Galloway, M. Heimann, C. Jones, C. Le Quéré, R.B. Myneni, S. Piao and P. Thornton, 2013: Carbon and Other Biogeochemical Cycles. In: Climate Change 2013: The Physical Science Basis. Contribution of Working Group I to the Fifth Assessment Report of the Intergovernmental Panel on Climate Change [Stocker, T.F., D. Qin, G.-K. Plattner, M. Tignor, S.K. Allen, J. Boschung, A. Nauels, Y. Xia, V. Bex and P.M. Midgley (eds.)]. Cambridge University Press, Cambridge, United Kingdom and New York, NY, USA. 


\section{Executive Summary} 467

\subsection{Introduction} 470

$$
6.1 .1
$$$$
\text { Global Carbon Cycle Overview }
$$

Box 6.1: Multiple Residence Times for an Excess of Carbon Dioxide Emitted in the Atmosphere.

6.1.2 Industrial Era.......................................................... 474

6.1.3 Connections Between Carbon and the Nitrogen and Oxygen Cycles

Box 6.2: Nitrogen Cycle and Climate-Carbon Cycle Feedbacks.

\subsection{Variations in Carbon and Other Biogeochemical} Cycles Before the Fossil Fuel Era.

6.2.1 Glacial-Interglacial Greenhouse Gas Changes.......... 480

6.2.2 Greenhouse Gas Changes over the Holocene ........... 483

6.2.3 Greenhouse Gas Changes over the Last Millennium

6.3 Evolution of Biogeochemical Cycles Since the Industrial Revolution

6.3.1 Carbon Dioxide Emissions and Their Fate Since 1750

6.3.2 Global Carbon Dioxide Budget. 488

Box 6.3: The Carbon Dioxide Fertilisation Effect 502

6.3.3 Global Methane Budget...... 508

6.3 .4 Global Nitrogen Budgets and Global Nitrous Oxide Budget in the 1990s.

\subsection{Projections of Future Carbon and Other}

Biogeochemical Cycles. 514

6.4.1 Introduction 514

\section{4 .2}

Carbon Cycle Feedbacks in Climate Modelling Intercomparison Project Phase 5 Models . 514

Box 6.4: Climate-Carbon Cycle Models and Experimental Design 516

6.4.3 Implications of the Future Projections for the Carbon Cycle and Compatible Emissions ...

6.4.4 Future Ocean Acidification 528

6.4.5 Future Ocean Oxygen Depletion 532

6.4.6 Future Trends in the Nitrogen Cycle and Impact on Carbon Fluxes 535

6.4.7 Future Changes in Methane Emissions ..... 539

6.4.8 Other Drivers of Future Carbon Cycle Changes ......... 542

6.4.9 The Long-term Carbon Cycle and Commitments....... 543
6.5 Potential Effects of Carbon Dioxide Removal Methods and Solar Radiation Management on the Carbon Cycle 546

6.5.1 Introduction to Carbon Dioxide Removal Methods 546

6.5.2 Carbon Cycle Processes Involved in Carbon Dioxide Removal Methods 547

6.5.3 Impacts of Carbon Dioxide Removal Methods on Carbon Cycle and Climate. 550

6.5.4 Impacts of Solar Radiation Management on the Carbon Cycle ............................................................. 551

6.5.5 Synthesis 552

References 553

\section{Frequently Asked Questions}

FAQ 6.1 Could Rapid Release of Methane and Carbon Dioxide from Thawing Permafrost or Ocean Warming Substantially Increase Warming? 530

FAQ 6.2 What Happens to Carbon Dioxide After It Is Emitted into the Atmosphere? 544

\section{Supplementary Material}

Supplementary Material is available in online versions of the report. 


\section{Executive Summary}

This chapter addresses the biogeochemical cycles of carbon dioxide $\left(\mathrm{CO}_{2}\right)$, methane $\left(\mathrm{CH}_{4}\right)$ and nitrous oxide $\left(\mathrm{N}_{2} \mathrm{O}\right)$. The three greenhouse gases (GHGs) have increased in the atmosphere since pre-industrial times, and this increase is the main driving cause of climate change (Chapter 10). $\mathrm{CO}_{2}, \mathrm{CH}_{4}$ and $\mathrm{N}_{2} \mathrm{O}$ altogether amount to $80 \%$ of the total radiative forcing from well-mixed GHGs (Chapter 8). The increase of $\mathrm{CO}_{2}, \mathrm{CH}_{4}$ and $\mathrm{N}_{2} \mathrm{O}$ is caused by anthropogenic emissions from the use of fossil fuel as a source of energy and from land use and land use changes, in particular agriculture. The observed change in the atmospheric concentration of $\mathrm{CO}_{2}, \mathrm{CH}_{4}$ and $\mathrm{N}_{2} \mathrm{O}$ results from the dynamic balance between anthropogenic emissions, and the perturbation of natural processes that leads to a partial removal of these gases from the atmosphere. Natural processes are linked to physical conditions, chemical reactions and biological transformations and they respond themselves to perturbed atmospheric composition and climate change. Therefore, the physical climate system and the biogeochemical cycles of $\mathrm{CO}_{2}, \mathrm{CH}_{4}$ and $\mathrm{N}_{2} \mathrm{O}$ are coupled. This chapter addresses the present human-caused perturbation of the biogeochemical cycles of $\mathrm{CO}_{2}, \mathrm{CH}_{4}$ and $\mathrm{N}_{2} \mathrm{O}$, their variations in the past coupled to climate variations and their projected evolution during this century under future scenarios.

\section{The Human-Caused Perturbation in the Industrial Era}

$\mathrm{CO}_{2}$ increased by $40 \%$ from $278 \mathrm{ppm}$ about 1750 to $390.5 \mathrm{ppm}$ in 2011. During the same time interval, $\mathrm{CH}_{4}$ increased by $150 \%$ from 722 ppb to 1803 ppb, and $\mathrm{N}_{2} \mathrm{O}$ by $20 \%$ from $271 \mathrm{ppb}$ to $324.2 \mathrm{ppb}$ in 2011. It is unequivocal that the current concentrations of atmospheric $\mathrm{CO}_{2}, \mathrm{CH}_{4}$ and $\mathrm{N}_{2} \mathrm{O}$ exceed any level measured for at least the past 800,000 years, the period covered by ice cores. Furthermore, the average rate of increase of these three gases observed over the past century exceeds any observed rate of change over the previous 20,000 years. $\{2.2,5.2,6.1,6.2\}$

Anthropogenic $\mathrm{CO}_{2}$ emissions to the atmosphere were $555 \pm 85$ $\mathrm{PgC}\left(1 \mathrm{PgC}=10^{15} \mathrm{gC}\right)$ between 1750 and 2011. Of this amount, fossil fuel combustion and cement production contributed $375 \pm 30$ $\mathrm{PgC}$ and land use change (including deforestation, afforestation and reforestation) contributed $180 \pm 80 \mathrm{PgC}$. $\{6.3 .1$, Table 6.1 $\}$

With a very high level of confidence ${ }^{1}$, the increase in $\mathrm{CO}_{2}$ emissions from fossil fuel burning and those arising from land use change are the dominant cause of the observed increase in atmospheric $\mathrm{CO}_{2}$ concentration. About half of the emissions remained in the atmosphere $(240 \pm 10 \mathrm{PgC})$ since 1750 . The rest was removed from the atmosphere by sinks and stored in the natural carbon cycle reservoirs. The ocean reservoir stored $155 \pm 30 \mathrm{PgC}$. Vegetation biomass and soils not affected by land use change stored 160 \pm 90 PgC. $\{6.1,6.3,6.3 .2 .3$, Table 6.1, Figure 6.8 $\}$

Carbon emissions from fossil fuel combustion and cement production increased faster during the 2000-2011 period than during the 1990-1999 period. These emissions were $9.5 \pm 0.8 \mathrm{PgC}$ $\mathrm{yr}^{-1}$ in 2011, 54\% above their 1990 level. Anthropogenic net $\mathrm{CO}_{2}$ emissions from land use change were $0.9 \pm 0.8 \mathrm{PgC} \mathrm{yr}^{-1}$ throughout the past decade, and represent about $10 \%$ of the total anthropogenic $\mathrm{CO}_{2}$ emissions. It is more likely than not ${ }^{2}$ that net $\mathrm{CO}_{2}$ emissions from land use change decreased during 2000-2011 compared to 1990-1999. $\{6.3$, Table 6.1, Table 6.2, Figure 6.8\}

Atmospheric $\mathrm{CO}_{2}$ concentration increased at an average rate of $2.0 \pm 0.1 \mathrm{ppm} \mathrm{yr}^{-1}$ during 2002-2011. This decadal rate of increase is higher than during any previous decade since direct atmospheric concentration measurements began in 1958. Globally, the size of the combined natural land and ocean sinks of $\mathrm{CO}_{2}$ approximately followed the atmospheric rate of increase, removing $55 \%$ of the total anthropogenic emissions every year on average during 1958-2011. \{6.3, Table 6.1\}

After almost one decade of stable $\mathrm{CH}_{4}$ concentrations since the late 1990s, atmospheric measurements have shown renewed $\mathrm{CH}_{4}$ concentrations growth since 2007. The drivers of this renewed growth are still debated. The methane budget for the decade of 2000 2009 (bottom-up estimates) is 177 to $284 \mathrm{Tg}\left(\mathrm{CH}_{4}\right) \mathrm{yr}^{-1}$ for natural wetlands emissions, 187 to $224 \mathrm{Tg}\left(\mathrm{CH}_{4}\right) \mathrm{yr}^{-1}$ for agriculture and waste (rice, animals and waste), 85 to $105 \mathrm{Tg}\left(\mathrm{CH}_{4}\right) \mathrm{yr}^{-1}$ for fossil fuel related emissions, 61 to $200 \mathrm{Tg}\left(\mathrm{CH}_{4}\right) \mathrm{yr}^{-1}$ for other natural emissions including, among other fluxes, geological, termites and fresh water emissions, and 32 to $39 \mathrm{Tg}\left(\mathrm{CH}_{4}\right) \mathrm{yr}^{-1}$ for biomass and biofuel burning (the range indicates the expanse of literature values). Anthropogenic emissions account for 50 to $65 \%$ of total emissions. By including natural geological $\mathrm{CH}_{4}$ emissions that were not accounted for in previous budgets, the fossil component of the total $\mathrm{CH}_{4}$ emissions (i.e., anthropogenic emissions related to leaks in the fossil fuel industry and natural geological leaks) is now estimated to amount to about $30 \%$ of the total $\mathrm{CH}_{4}$ emissions (medium confidence). Climate driven fluctuations of $\mathrm{CH}_{4}$ emissions from natural wetlands are the main drivers of the global interannual variability of $\mathrm{CH}_{4}$ emissions (high confidence), with a smaller contribution from the variability in emissions from biomass burning during high fire years. $\{6.3 .3$, Figure 6.2, Table 6.8$\}$

The concentration of $\mathrm{N}_{2} \mathrm{O}$ increased at a rate of $0.73 \pm 0.03 \mathrm{ppb}$ $\mathrm{yr}^{-1}$ over the last three decades. Emissions of $\mathrm{N}_{2} \mathrm{O}$ to the atmosphere are mostly caused by nitrification and de-nitrification reactions

\footnotetext{
In this Report, the following summary terms are used to describe the available evidence: limited, medium, or robust; and for the degree of agreement: low, medium, or high. A level of confidence is expressed using five qualifiers: very low, low, medium, high, and very high, and typeset in italics, e.g., medium confidence. For a given evidence and agreement statement, different confidence levels can be assigned, but increasing levels of evidence and degrees of agreement are correlated with increasing confidence (see Section 1.4 and Box TS.1 for more details).

2 In this Report, the following terms have been used to indicate the assessed likelihood of an outcome or a result: Virtually certain 99-100\% probability, Very likely 90-100\%, Likely $66-100 \%$, About as likely as not 33-66\%, Unlikely 0-33\%, Very unlikely $0-10 \%$, Exceptionally unlikely $0-1 \%$. Additional terms (Extremely likely: 95-100\%, More likely than not $>50-100 \%$, and Extremely unlikely $0-5 \%$ ) may also be used when appropriate. Assessed likelihood is typeset in italics, e.g., very likely (see Section 1.4 and Box TS.1 for more details).
} 
of reactive nitrogen in soils and in the ocean. Anthropogenic $\mathrm{N}_{2} \mathrm{O}$ emissions increased steadily over the last two decades and were 6.9 (2.7 to 11.1) $\left.\mathrm{TgN}_{(\mathrm{N}} \mathrm{O}\right) \mathrm{yr}^{-1}$ in 2006. Anthropogenic $\mathrm{N}_{2} \mathrm{O}$ emissions are 1.7 to $4.8 \mathrm{TgN}\left(\mathrm{N}_{2} \mathrm{O}\right) \mathrm{yr}^{-1}$ from the application of nitrogenous fertilisers in

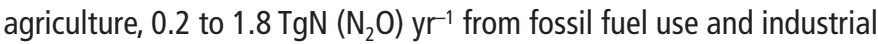
processes, 0.2 to $1.0 \mathrm{TgN}\left(\mathrm{N}_{2} \mathrm{O}\right) \mathrm{yr}^{-1}$ from biomass burning (including

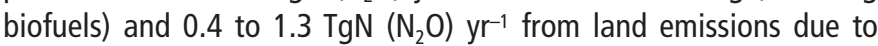
atmospheric nitrogen deposition (the range indicates expand of literature values). Natural $\mathrm{N}_{2} \mathrm{O}$ emissions derived from soils, oceans and a

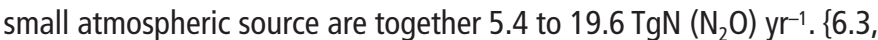
6.3.4, Figure 6.4c, Figure 6.19, Table 6.9\}

The human-caused creation of reactive nitrogen in 2010 was at least two times larger than the rate of natural terrestrial creation. The human-caused creation of reactive nitrogen is dominated by the production of ammonia for fertiliser and industry, with important contributions from legume cultivation and combustion of fossil fuels. Once formed, reactive nitrogen can be transferred to waters and the atmosphere. In addition to $\mathrm{N}_{2} \mathrm{O}$, two important nitrogen compounds emitted to the atmosphere are $\mathrm{NH}_{3}$ and $\mathrm{NO}_{\mathrm{x}}$ both of which influence tropospheric $\mathrm{O}_{3}$ and aerosols through atmospheric chemistry. All of these effects contribute to radiative forcing. It is also likely that reactive nitrogen deposition over land currently increases natural $\mathrm{CO}_{2}$ sinks, in particular forests, but the magnitude of this effect varies between regions. $\{6.1 .3,6.3,6.3 .2 .6 .5,6.3 .4,6.4 .6$, Figures $6.4 a$ and 6.4b, Table 6.9, Chapter 7\}

\section{Before the Human-Caused Perturbation}

During the last 7000 years prior to 1750 , atmospheric $\mathrm{CO}_{2}$ from ice cores shows only very slow changes (increase) from 260 ppm to $280 \mathrm{ppm}$, in contrast to the human-caused increase of $\mathrm{CO}_{2}$ since pre-industrial times. The contribution of $\mathrm{CO}_{2}$ emissions from early anthropogenic land use is unlikely sufficient to explain the $\mathrm{CO}_{2}$ increase prior to 1750 . Atmospheric $\mathrm{CH}_{4}$ from ice cores increased by about 100 ppb between 5000 years ago and around 1750. About as likely as not, this increase can be attributed to early human activities involving livestock, human-caused fires and rice cultivation. \{6.2, Figures 6.6 and 6.7$\}$

Further back in time, during the past 800,000 years prior to 1750, atmospheric $\mathrm{CO}_{2}$ varied from 180 ppm during glacial (cold) up to $300 \mathrm{ppm}$ during interglacial (warm) periods. This is well established from multiple ice core measurements. Variations in atmospheric $\mathrm{CO}_{2}$ from glacial to interglacial periods were caused by decreased ocean carbon storage (500 to $1200 \mathrm{PgC}$ ), partly compensated by increased land carbon storage (300 to $1000 \mathrm{PgC}$ ). \{6.2.1, Figure $6.5\}$

\section{Future Projections}

With very high confidence, ocean carbon uptake of anthropogenic $\mathrm{CO}_{2}$ emissions will continue under all four Representative Concentration Pathways (RCPs) through to 2100, with higher uptake corresponding to higher concentration pathways. The future evolution of the land carbon uptake is much more uncertain, with a majority of models projecting a continued net carbon uptake under all RCPs, but with some models simulating a net loss of carbon by the land due to the combined effect of climate change and land use change. In view of the large spread of model results and incomplete process representation, there is low confidence on the magnitude of modelled future land carbon changes. $\{6.4 .3$, Figure 6.24$\}$

There is high confidence that climate change will partially offset increases in global land and ocean carbon sinks caused by rising atmospheric $\mathrm{CO}_{2}$. Yet, there are regional differences among Climate Modelling Intercomparison Project Phase 5 (CMIP5) Earth System Models, in the response of ocean and land $\mathrm{CO}_{2}$ fluxes to climate. There is a high agreement between models that tropical ecosystems will store less carbon in a warmer climate. There is medium agreement between models that at high latitudes warming will increase land carbon storage, although none of the models account for decomposition of carbon in permafrost, which may offset increased land carbon storage. There is high agreement between CMIP5 Earth System models that ocean warming and circulation changes will reduce the rate of carbon uptake in the Southern Ocean and North Atlantic, but that carbon uptake will nevertheless persist in those regions. \{6.4.2, Figures 6.21 and 6.22$\}$

It is very likely, based on new experimental results $\{6.4 .6 .3\}$ and modelling, that nutrient shortage will limit the effect of rising atmospheric $\mathrm{CO}_{2}$ on future land carbon sinks, for the four RCP scenarios. There is high confidence that low nitrogen availability will limit carbon storage on land, even when considering anthropogenic nitrogen deposition. The role of phosphorus limitation is more uncertain. Models that combine nitrogen limitations with rising $\mathrm{CO}_{2}$ and changes in temperature and precipitation thus produce a systematically larger increase in projected future atmospheric $\mathrm{CO}_{2}$, for a given fossil fuel emissions trajectory. $\{6.4 .6,6.4 .6 .3,6.4 .8 .2$, Figure 6.35$\}$

Taking climate and carbon cycle feedbacks into account, we can quantify the fossil fuel emissions compatible with the RCPs. Between 2012 and 2100, the RCP2.6, RCP4.5, RCP6.0, and RCP8.5 scenarios imply cumulative compatible fossil fuel emissions of 270 (140 to 410) PgC, 780 (595 to 1005) PgC, 1060 (840 to 1250$) \mathrm{PgC}$ and 1685 (1415 to 1910$) \mathrm{PgC}$ respectively (values quoted to nearest $5 \mathrm{PgC}$, range derived from CMIP5 model results). For RCP2.6, an average 50\% (range 14 to $96 \%$ ) emission reduction is required by 2050 relative to 1990 levels. By the end of the 21 st century, about half of the models infer emissions slightly above zero, while the other half infer a net removal of $\mathrm{CO}_{2}$ from the atmosphere. $\{6.4 .3$, Table 6.12 , Figure 6.25$\}$

There is high confidence that reductions in permafrost extent due to warming will cause thawing of some currently frozen carbon. However, there is low confidence on the magnitude of carbon losses through $\mathrm{CO}_{2}$ and $\mathrm{CH}_{4}$ emissions to the atmosphere, with a range from 50 to $250 \mathrm{PgC}$ between 2000 and 2100 under the RCP8.5 scenario. The CMIP5 Earth System Models did not include frozen carbon feedbacks. $\{6.4 .3 .4$, Chapter 12$\}$

There is medium confidence that emissions of $\mathrm{CH}_{4}$ from wetlands are likely to increase under elevated $\mathrm{CO}_{2}$ and a warmer climate. But there is low confidence in quantitative projections of these changes. The likelihood of the future release of $\mathrm{CH}_{4}$ from marine 
gas hydrates in response to seafloor warming is poorly understood. In the event of a significant release of $\mathrm{CH}_{4}$ from hydrates in the sea floor by the end of the 21st century, it is likely that subsequent emissions to the atmosphere would be in the form of $\mathrm{CO}_{2}$, due to $\mathrm{CH}_{4}$ oxidation in the water column. $\{6.4 .7$, Figure 6.37$\}$

It is likely that $\mathrm{N}_{2} \mathrm{O}$ emissions from soils will increase due to the increased demand for feed/food and the reliance of agriculture on nitrogen fertilisers. Climate warming will likely amplify agricultural and natural terrestrial $\mathrm{N}_{2} \mathrm{O}$ sources, but there is low confidence in quantitative projections of these changes. $\{6.4 .6$, Figure 6.32$\}$

It is virtually certain that the increased storage of carbon by the ocean will increase acidification in the future, continuing the observed trends of the past decades. Ocean acidification in the surface ocean will follow atmospheric $\mathrm{CO}_{2}$ while it will also increase in the deep ocean as $\mathrm{CO}_{2}$ continues to penetrate the abyss. The CMIP5 models consistently project worldwide increased ocean acidification to 2100 under all RCPs. The corresponding decrease in surface ocean $\mathrm{pH}$ by the end of the 21 st century is 0.065 (0.06 to 0.07 ) for RCP2.6, 0.145 (0.14 to 0.15$)$ for RCP4.5, $0.203(0.20$ to 0.21$)$ for RCP6.0, and 0.31 ( 0.30 to 0.32 ) for RCP8.5 (range from CMIP5 models spread). Surface waters become seasonally corrosive to aragonite in parts of the Arctic and in some coastal upwelling systems within a decade, and in parts of the Southern Ocean within 1 to 3 decades in most scenarios. Aragonite undersaturation becomes widespread in these regions at atmospheric $\mathrm{CO}_{2}$ levels of 500 to 600 ppm. \{6.4.4, Figures 6.28 and 6.29\}

It is very likely that the dissolved oxygen content of the ocean will decrease by a few percent during the 21st century. CMIP5 models suggest that this decrease in dissolved oxygen will predominantly occur in the subsurface mid-latitude oceans, caused by enhanced stratification, reduced ventilation and warming. However, there is no consensus on the future development of the volume of hypoxic and suboxic waters in the open-ocean because of large uncertainties in potential biogeochemical effects and in the evolution of tropical ocean dynamics. $\{6.4 .5$, Figure 6.30$\}$

\section{Irreversible Long-Term Impacts of Human-Caused Emissions}

With very high confidence, the physical, biogeochemical carbon cycle in the ocean and on land will continue to respond to climate change and rising atmospheric $\mathrm{CO}_{2}$ concentrations created during the 21 st century. Ocean acidification will very likely continue in the future as long as the oceans take up atmospheric $\mathrm{CO}_{2}$. Committed land ecosystem carbon cycle changes will manifest themselves further beyond the end of the 21st century. In addition, it is virtually certain that large areas of permafrost will experience thawing over multiple centuries. There is, however, low confidence in the magnitude of frozen carbon losses to the atmosphere, and the relative contributions of $\mathrm{CO}_{2}$ and $\mathrm{CH}_{4}$ emissions. $\{6.4 .4,6.4 .9$, Chapter 12$\}$

The magnitude and sign of the response of the natural carbon reservoirs to changes in climate and rising $\mathrm{CO}_{2}$ vary substantially over different time scales. The response to rising $\mathrm{CO}_{2}$ is to increase cumulative land and ocean uptake, regardless of the time scale. The response to climate change is variable, depending of the region considered because of different responses of the underlying physical and biological mechanisms at different time scales. $\{6.4$, Table 6.10 , Figures 6.14 and 6.17$\}$

The removal of human-emitted $\mathrm{CO}_{2}$ from the atmosphere by natural processes will take a few hundred thousand years (high confidence). Depending on the RCP scenario considered, about 15 to $40 \%$ of emitted $\mathrm{CO}_{2}$ will remain in the atmosphere longer than 1,000 years. This very long time required by sinks to remove anthropogenic $\mathrm{CO}_{2}$ makes climate change caused by elevated $\mathrm{CO}_{2}$ irreversible on human time scale. $\{$ Box 6.1\}

\section{Geoengineering Methods and the Carbon Cycle}

Unconventional ways to remove $\mathrm{CO}_{2}$ from the atmosphere on a large scale are termed Carbon Dioxide Removal (CDR) methods. CDR could in theory be used to reduce $\mathrm{CO}_{2}$ atmospheric concentrations but these methods have biogeochemical and technological limitations to their potential. Uncertainties make it difficult to quantify how much $\mathrm{CO}_{2}$ emissions could be offset by $\mathrm{CDR}$ on a human time scale, although it is likely that CDR would have to be deployed at large-scale for at least one century to be able to significantly reduce atmospheric $\mathrm{CO}_{2}$. In addition, it is virtually certain that the removal of $\mathrm{CO}_{2}$ by $\mathrm{CDR}$ will be partially offset by outgassing of $\mathrm{CO}_{2}$ from the ocean and land ecosystems. \{6.5, Figures 6.39 and 6.40, Table 6.15, Box 6.1, FAQ 7.3

The level of confidence on the side effects of CDR methods on carbon and other biogeochemical cycles is low. Some of the climatic and environmental effects of CDR methods are associated with altered surface albedo (for afforestation), de-oxygenation and enhanced $\mathrm{N}_{2} \mathrm{O}$ emissions (for artificial ocean fertilisation). Solar Radiation Management (SRM) methods (Chapter 7) will not directly interfere with the effects of elevated $\mathrm{CO}_{2}$ on the carbon cycle, such as ocean acidification, but will impact carbon and other biogeochemical cycles through their climate effects. $\{6.5 .3,6.5 .4,7.7$, Tables 6.14 and 6.15$\}$ 


\subsection{Introduction}

The radiative properties of the atmosphere are strongly influenced by the abundance of well-mixed GHGs (see Glossary), mainly carbon dioxide $\left(\mathrm{CO}_{2}\right)$, methane $\left(\mathrm{CH}_{4}\right)$ and nitrous oxide $\left(\mathrm{N}_{2} \mathrm{O}\right)$, which have substantially increased since the beginning of the Industrial Era (defined as beginning in the year 1750), due primarily to anthropogenic emissions (see Chapter 2). Well-mixed GHGs represent the gaseous phase of global biogeochemical cycles, which control the complex flows and transformations of the elements between the different components of the Earth System (atmosphere, ocean, land, lithosphere) by biotic and abiotic processes. Since most of these processes are themselves also dependent on the prevailing environment, changes in climate and human impacts on ecosystems (e.g., land use and land use change) also modify the atmospheric concentrations of $\mathrm{CO}_{2}, \mathrm{CH}_{4}$ and $\mathrm{N}_{2} \mathrm{O}$. During the glacial-interglacial cycles (see Glossary), in absence of significant direct human impacts, long variations in climate also affected $\mathrm{CO}_{2}, \mathrm{CH}_{4}$ and $\mathrm{N}_{2} \mathrm{O}$ and vice versa (see Chapter 5, Section 5.2.2). In the coming century, the situation would be quite different, because of the dominance of anthropogenic emissions that affect global biogeochemical cycles, and in turn, climate change (see Chapter 12). Biogeochemical cycles thus constitute feedbacks in the Earth System.

This chapter summarizes the scientific understanding of atmospheric budgets, variability and trends of the three major biogeochemical greenhouse gases, $\mathrm{CO}_{2}, \mathrm{CH}_{4}$ and $\mathrm{N}_{2} \mathrm{O}$, their underlying source and sink processes and their perturbations caused by direct human impacts, past and present climate changes as well as future projections of climate change. After the introduction (Section 6.1), Section 6.2 assesses the present understanding of the mechanisms responsible for the variations of $\mathrm{CO}_{2}, \mathrm{CH}_{4}$ and $\mathrm{N}_{2} \mathrm{O}$ in the past emphasizing glacial-interglacial changes, and the smaller variations during the Holocene (see Glossary) since the last glaciation and over the last millennium. Section 6.3 focuses on the Industrial Era addressing the major source and sink processes, and their variability in space and time. This information is then used to evaluate critically the models of the biogeochemical cycles, including their sensitivity to changes in atmospheric composition and climate. Section 6.4 assesses future projections of carbon and other biogeochemical cycles computed, in particular, with CMIP5 Earth System Models. This includes a quantitative assessment of the direction and magnitude of the various feedback mechanisms as represented in current models, as well as additional processes that might become important in the future but which are not yet fully understood. Finally, Section 6.5 addresses the potential effects and uncertainties of deliberate carbon dioxide removal methods (see Glossary) and solar radiation management (see Glossary) on the carbon cycle.

\subsubsection{Global Carbon Cycle Overview}

\subsubsection{Carbon Dioxide and the Global Carbon Cycle}

Atmospheric $\mathrm{CO}_{2}$ represents the main atmospheric phase of the global carbon cycle. The global carbon cycle can be viewed as a series of reservoirs of carbon in the Earth System, which are connected by exchange fluxes of carbon. Conceptually, one can distinguish two domains in the global carbon cycle. The first is a fast domain with large exchange fluxes and relatively 'rapid' reservoir turnovers, which consists of carbon in the atmosphere, the ocean, surface ocean sediments and on land in vegetation, soils and freshwaters. Reservoir turnover times, defined as reservoir mass of carbon divided by the exchange flux, range from a few years for the atmosphere to decades to millennia for the major carbon reservoirs of the land vegetation and soil and the various domains in the ocean. A second, slow domain consists of the huge carbon stores in rocks and sediments which exchange carbon with the fast domain through volcanic emissions of $\mathrm{CO}_{2}$, chemical weathering (see Glossary), erosion and sediment formation on the sea floor (Sundquist, 1986). Turnover times of the (mainly geological) reservoirs of the slow domain are 10,000 years or longer. Natural exchange fluxes between the slow and the fast domain of the carbon cycle are relatively small $\left(<0.3 \mathrm{PgC} r^{-1}, 1 \mathrm{PgC}=10^{15} \mathrm{gC}\right)$ and can be assumed as approximately constant in time (volcanism, sedimentation) over the last few centuries, although erosion and river fluxes may have been modified by human-induced changes in land use (Raymond and Cole, 2003).

During the Holocene (beginning 11,700 years ago) prior to the Industrial Era the fast domain was close to a steady state, as evidenced by the relatively small variations of atmospheric $\mathrm{CO}_{2}$ recorded in ice cores (see Section 6.2), despite small emissions from human-caused changes in land use over the last millennia (Pongratz et al., 2009). By contrast, since the beginning of the Industrial Era, fossil fuel extraction from geological reservoirs, and their combustion, has resulted in the transfer of significant amount of fossil carbon from the slow domain into the fast domain, thus causing an unprecedented, major human-induced perturbation in the carbon cycle. A schematic of the global carbon cycle with focus on the fast domain is shown in Figure 6.1. The numbers represent the estimated current pool sizes in $\mathrm{PgC}$ and the magnitude of the different exchange fluxes in $\mathrm{PgC} \mathrm{yr}^{-1}$ averaged over the time period 2000-2009 (see Section 6.3).

In the atmosphere, $\mathrm{CO}_{2}$ is the dominant carbon bearing trace gas with a current (2011) concentration of approximately 390.5 ppm (Dlugokencky and Tans, 2013a), which corresponds to a mass of $828 \mathrm{PgC}$ (Prather et al., 2012; Joos et al., 2013). Additional trace gases include methane $\left(\mathrm{CH}_{4}\right.$, current content mass $\left.\sim 3.7 \mathrm{PgC}\right)$ and carbon monoxide (CO, current content mass $\sim 0.2 \mathrm{PgC})$, and still smaller amounts of hydrocarbons, black carbon aerosols and organic compounds.

The terrestrial biosphere reservoir contains carbon in organic compounds in vegetation living biomass (450 to $650 \mathrm{PgC}$; Prentice et al., 2001) and in dead organic matter in litter and soils (1500 to $2400 \mathrm{PgC}$; Batjes, 1996). There is an additional amount of old soil carbon in wetland soils (300 to $700 \mathrm{PgC}$; Bridgham et al., 2006) and in permafrost soils (see Glossary) ( 1700 PgC; Tarnocai et al., 2009); albeit some overlap with these two quantities. $\mathrm{CO}_{2}$ is removed from the atmosphere by plant photosynthesis (Gross Primary Production (GPP), $123 \pm 8 \mathrm{PgC} \mathrm{yr}^{-1}$, (Beer et al., 2010)) and carbon fixed into plants is then cycled through plant tissues, litter and soil carbon and can be released back into the atmosphere by autotrophic (plant) and heterotrophic (soil microbial and animal) respiration and additional disturbance processes (e.g., sporadic fires) on a very wide range of time scales (seconds to millennia). Because $\mathrm{CO}_{2}$ uptake by photosynthesis occurs only during the growing season, whereas $\mathrm{CO}_{2}$ release by respiration occurs nearly yearround, the greater land mass in the Northern Hemisphere $(\mathrm{NH})$ imparts 


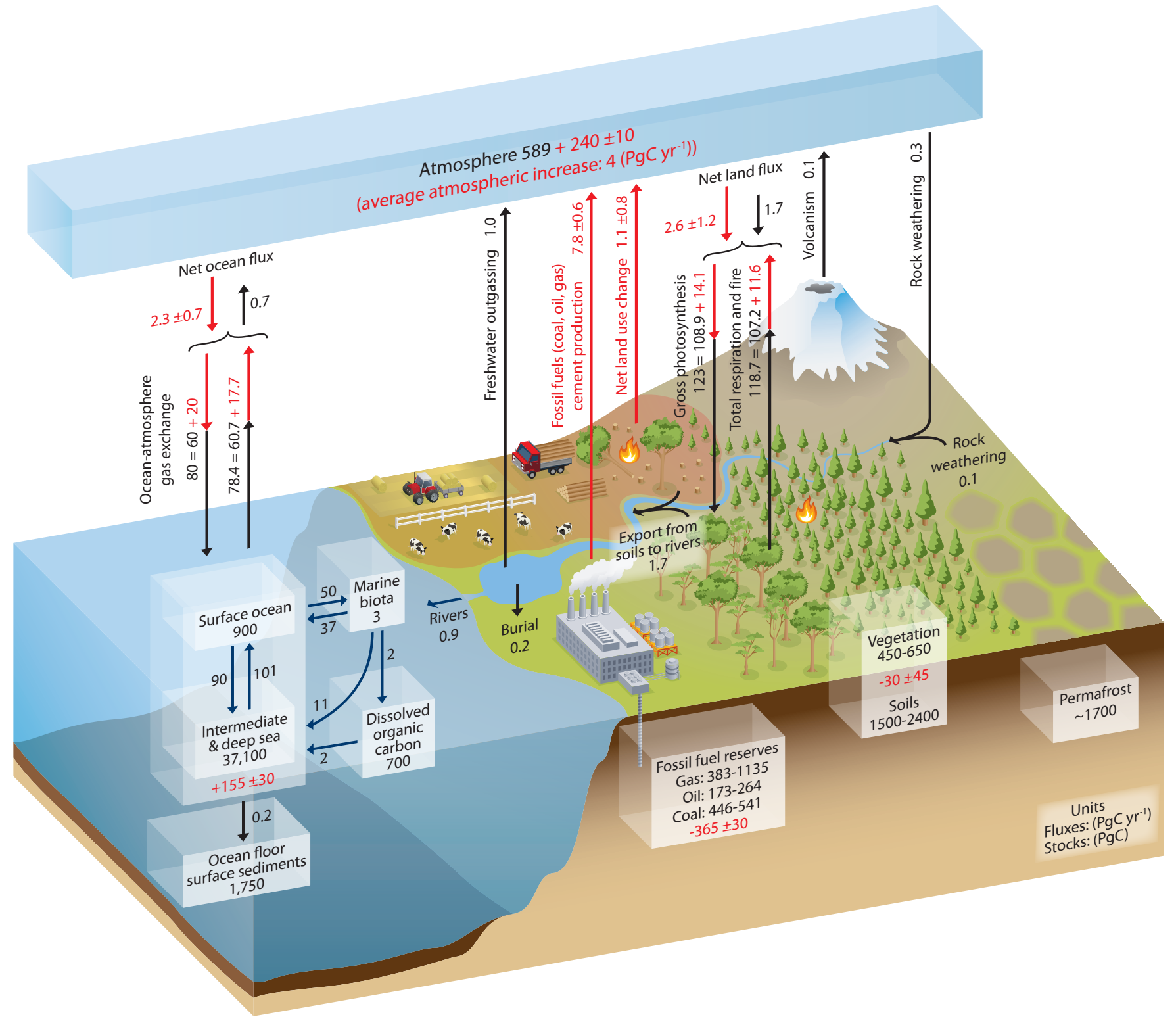

Figure 6.1 | Simplified schematic of the global carbon cycle. Numbers represent reservoir mass, also called 'carbon stocks' in $\mathrm{PgC}\left(1 \mathrm{PgC}=10^{15} \mathrm{gC}\right)$ and annual carbon exchange fluxes (in $\mathrm{PgC} \mathrm{yr}^{-1}$ ). Black numbers and arrows indicate reservoir mass and exchange fluxes estimated for the time prior to the Industrial Era, about 1750 (see Section 6.1 .1 .1 for references). Fossil fuel reserves are from GEA (2006) and are consistent with numbers used by IPCC WGIII for future scenarios. The sediment storage is a sum of 150 PgC of the organic carbon in the mixed layer (Emerson and Hedges, 1988) and $1600 \mathrm{PgC}$ of the deep-sea $\mathrm{CaCO}_{3}$ sediments available to neutralize fossil fuel $\mathrm{CO}_{2}$ (Archer et al., 1998). Red arrows and numbers indicate annual 'anthropogenic' fluxes averaged over the 2000-2009 time period. These fluxes are a perturbation of the carbon cycle during Industrial Era post 1750. These fluxes (red arrows) are: Fossil fuel and cement emissions of $\mathrm{CO}_{2}$ (Section 6.3.1), Net land use change (Section 6.3.2), and the Average atmospheric increase of $\mathrm{CO}_{2}$ in the atmosphere, also called ' $\mathrm{CO}_{2}$ growth rate' (Section 6.3). The uptake of anthropogenic $\mathrm{CO}_{2}$ by the ocean and by terrestrial ecosystems, often called 'carbon sinks' are the red arrows part of Net land flux and Net ocean flux. Red numbers in the reservoirs denote cumulative changes of anthropogenic carbon over the Industrial Period 1750-2011 (column 2 in Table 6.1). By convention, a positive cumulative change means that a reservoir has gained carbon since 1750. The cumulative change of anthropogenic carbon in the terrestrial reservoir is the sum of carbon cumulatively lost through land use change and carbon accumulated since 1750 in other ecosystems (Table 6.1). Note that the mass balance of the two ocean carbon stocks Surface ocean and Intermediate and deep ocean includes a yearly accumulation of anthropogenic carbon (not shown). Uncertainties are reported as $90 \%$ confidence intervals. Emission estimates and land and ocean sinks (in red) are from Table 6.1 in Section 6.3. The change of gross terrestrial fluxes (red arrows of Gross photosynthesis and Total respiration and fires) has been estimated from CMIP5 model results (Section 6.4). The change in air-sea exchange fluxes (red arrows of ocean atmosphere gas exchange) have been estimated from the difference in atmospheric partial pressure of $\mathrm{CO}_{2}$ since 1750 (Sarmiento and Gruber, 2006). Individual gross fluxes and their changes since the beginning of the Industrial Era have typical uncertainties of more than $20 \%$, while their differences (Net land flux and Net ocean flux in the figure) are determined from independent measurements with a much higher accuracy (see Section 6.3). Therefore, to achieve an overall balance, the values of the more uncertain gross fluxes have been adjusted so that their difference matches the Net land flux and Net ocean flux estimates. Fluxes from volcanic eruptions, rock weathering (silicates and carbonates weathering reactions resulting into a small uptake of atmospheric $\mathrm{CO}_{2}$ ), export of carbon from soils to rivers, burial of carbon in freshwater lakes and reservoirs and transport of carbon by rivers to the ocean are all assumed to be pre-industrial fluxes, that is, unchanged during 1750-2011. Some recent studies (Section 6.3) indicate that this assumption is likely not verified, but global estimates of the Industrial Era perturbation of all these fluxes was not available from peer-reviewed literature. The atmospheric inventories have been calculated using a conversion factor of $2.12 \mathrm{PgC}$ per ppm (Prather et al., 2012). 
a characteristic 'sawtooth' seasonal cycle in atmospheric $\mathrm{CO}_{2}$ (Keeling, 1960) (see Figure 6.3). A significant amount of terrestrial carbon (1.7 $\mathrm{PgC} \mathrm{yr}^{-1}$; Figure 6.1) is transported from soils to rivers headstreams. A fraction of this carbon is outgassed as $\mathrm{CO}_{2}$ by rivers and lakes to the atmosphere, a fraction is buried in freshwater organic sediments and the remaining amount $\left(\sim 0.9 \mathrm{PgC} \mathrm{yr}^{-1}\right.$; Figure 6.1) is delivered by rivers to the coastal ocean as dissolved inorganic carbon, dissolved organic carbon and particulate organic carbon (Tranvik et al., 2009).

Atmospheric $\mathrm{CO}_{2}$ is exchanged with the surface ocean through gas exchange. This exchange flux is driven by the partial $\mathrm{CO}_{2}$ pressure difference between the air and the sea. In the ocean, carbon is available predominantly as Dissolved Inorganic Carbon (DIC, 38,000 PgC; Figure 6.1), that is carbonic acid (dissolved $\mathrm{CO}_{2}$ in water), bicarbonate and carbonate ions, which are tightly coupled via ocean chemistry. In addition, the ocean contains a pool of Dissolved Organic Carbon (DOC, $\sim 700 \mathrm{PgC}$ ), of which a substantial fraction has a turnover time of 1000 years or longer (Hansell et al., 2009). The marine biota, predominantly phytoplankton and other microorganisms, represent a small organic carbon pool $(\sim 3 \mathrm{PgC})$, which is turned over very rapidly in days to a few weeks.

Carbon is transported within the ocean by three mechanisms (Figure 6.1): (1) the 'solubility pump' (see Glossary), (2) the 'biological pump' (see Glossary), and (3) the 'marine carbonate pump' that is generated by the formation of calcareous shells of certain oceanic microorganisms in the surface ocean, which, after sinking to depth, are re-mineralized back into DIC and calcium ions. The marine carbonate pump operates counter to the marine biological soft-tissue pump with respect to its effect on $\mathrm{CO}_{2}$ : in the formation of calcareous shells, two bicarbonate ions are split into one carbonate and one dissolved $\mathrm{CO}_{2}$ molecules, which increases the partial $\mathrm{CO}_{2}$ pressure in surface waters (driving a release of $\mathrm{CO}_{2}$ to the atmosphere). Only a small fraction $\left(\sim 0.2 \mathrm{PgC} \mathrm{yr}^{-1}\right)$ of the carbon exported by biological processes (both soft-tissue and carbonate pumps) from the surface reaches the sea floor where it can be stored in sediments for millennia and longer (Denman et al., 2007).

\section{Box 6.1 | Multiple Residence Times for an Excess of Carbon Dioxide Emitted in the Atmosphere}

On an average, $\mathrm{CO}_{2}$ molecules are exchanged between the atmosphere and the Earth surface every few years. This fast $\mathrm{CO}_{2}$ cycling through the atmosphere is coupled to a slower cycling of carbon through land vegetation, litter and soils and the upper ocean (decades to centuries); deeper soils and the deep sea (centuries to millennia); and geological reservoirs, such as deep-sea carbonate sediments and the upper mantle (up to millions of years) as explained in Section 6.1.1.1. Atmospheric $\mathrm{CO}_{2}$ represents only a tiny fraction of the carbon in the Earth System, the rest of which is tied up in these other reservoirs. Emission of carbon from fossil fuel reserves, and additionally from land use change (see Section 6.3) is now rapidly increasing atmospheric $\mathrm{CO}_{2}$ content. The removal of all the human-emitted $\mathrm{CO}_{2}$ from the atmosphere by natural processes will take a few hundred thousand years (high confidence) as shown by the timescales of the removal process shown in the table below (Archer and Brovkin, 2008). For instance, an extremely long atmospheric $\mathrm{CO}_{2}$ recovery time scale from a large emission pulse of $\mathrm{CO}_{2}$ has been inferred from geological evidence when during the Paleocene-Eocene thermal maximum event about 55 million years ago a large amount of $\mathrm{CO}_{2}$ was released to the atmosphere (Mclnerney and Wing, 2011). Based on the amount of $\mathrm{CO}_{2}$ remaining in the atmosphere after a pulse of emissions (data from Joos et al. 2013) and on the magnitude of the historical and future emissions for each RCP scenario, we assessed that about 15 to $40 \%$ of $\mathrm{CO}_{2}$ emitted until 2100 will remain in the atmosphere longer than 1000 years.

Box 6.1, Table 1 | The main natural processes that remove $\mathrm{CO}_{2}$ consecutive to a large emission pulse to the atmosphere, their atmospheric $\mathrm{CO}_{2}$ adjustment time scales, and main (bio)chemical reactions involved.

\begin{tabular}{|l|c|l|}
\hline Processes & Time scale (years) & Reactions \\
\hline Land uptake: Photosynthesis-respiration & $1-10^{2}$ & $\begin{array}{l}6 \mathrm{CO}_{2}+6 \mathrm{H}_{2} \mathrm{O}+\text { photons } \rightarrow \mathrm{C}_{6} \mathrm{H}_{12} \mathrm{O}_{6}+6 \mathrm{O}_{2} \\
\mathrm{C}_{6} \mathrm{H}_{12} \mathrm{O}_{6}+6 \mathrm{O}_{2} \rightarrow 6 \mathrm{CO}_{2}+6 \mathrm{H}_{2} \mathrm{O}+\text { heat }\end{array}$ \\
\hline Ocean invasion: Seawater buffer & $10-10^{3}$ & $\mathrm{CO}_{2}+\mathrm{CO}_{3}{ }^{2-}+\mathrm{H}_{2} \mathrm{O} \rightleftharpoons 2 \mathrm{HCO}_{3}^{-}$ \\
\hline Reaction with calcium carbonate & $10^{3}-10^{4}$ & $\mathrm{CO}_{2}+\mathrm{CaCO}_{3}+\mathrm{H}_{2} \mathrm{O} \rightarrow \mathrm{Ca}^{2+}+2 \mathrm{HCO}_{3}^{-}$ \\
\hline Silicate weathering & $10^{4}-10^{6}$ & $\mathrm{CO}_{2}+\mathrm{CaSiO}_{3} \rightarrow \mathrm{CaCO}_{3}+\mathrm{SiO}_{2}$ \\
\hline
\end{tabular}

These processes are active on all time scales, but the relative importance of their role in the $\mathrm{CO}_{2}$ removal is changing with time and depends on the level of emissions. Accordingly, the times of atmospheric $\mathrm{CO}_{2}$ adjustment to anthropogenic carbon emissions can be divided into three phases associated with increasingly longer time scales.

Phase 1. Within several decades of $\mathrm{CO}_{2}$ emissions, about a third to half of an initial pulse of anthropogenic $\mathrm{CO}_{2}$ goes into the land and ocean, while the rest stays in the atmosphere (Box 6.1, Figure 1a). Within a few centuries, most of the anthropogenic $\mathrm{CO}_{2}$ will be in the form of additional dissolved inorganic carbon in the ocean, thereby decreasing ocean $\mathrm{pH}$ (Box 6.1, Figure 1b). Within a thousand years, the remaining atmospheric fraction of the $\mathrm{CO}_{2}$ emissions (see Section 6.3.2.4) is between 15 and $40 \%$, depending on the amount of carbon released (Archer et al., 2009b). The carbonate buffer capacity of the ocean decreases with higher $\mathrm{CO}_{2}$, so the larger the cumulative emissions, the higher the remaining atmospheric fraction (Eby et al., 2009; Joos et al., 2013). (continued on next page) 
Box 6.1 (continued)

Phase 2. In the second stage, within a few thousands of years, the $\mathrm{pH}$ of the ocean that has decreased in Phase 1 will be restored by reaction of ocean dissolved $\mathrm{CO}_{2}$ and calcium carbonate $\left(\mathrm{CaCO}_{3}\right)$ of sea floor sediments, partly replenishing the buffer capacity of the ocean and further drawing down atmospheric $\mathrm{CO}_{2}$ as a new balance is re-established between $\mathrm{CaCO}_{3}$ sedimentation in the ocean and terrestrial weathering (Box 6.1, Figure 1c right). This second phase will pull the remaining atmospheric $\mathrm{CO}_{2}$ fraction down to 10 to $25 \%$ of the original $\mathrm{CO}_{2}$ pulse after about 10 kyr (Lenton and Britton, 2006; Montenegro et al., 2007; Ridgwell and Hargreaves, 2007; Tyrrell et al., 2007; Archer and Brovkin, 2008).

Phase 3. In the third stage, within several hundred thousand years, the rest of the $\mathrm{CO}_{2}$ emitted during the initial pulse will be removed from the atmosphere by silicate weathering, a very slow process of $\mathrm{CO}_{2}$ reaction with calcium silicate $\left(\mathrm{CaSiO}_{3}\right)$ and other minerals of igneous rocks (e.g., Sundquist, 1990; Walker and Kasting, 1992).

Involvement of extremely long time scale processes into the removal of a pulse of $\mathrm{CO}_{2}$ emissions into the atmosphere complicates comparison with the cycling of the other GHGs. This is why the concept of a single, characteristic atmospheric lifetime is not applicable to $\mathrm{CO}_{2}$ (Chapter 8).
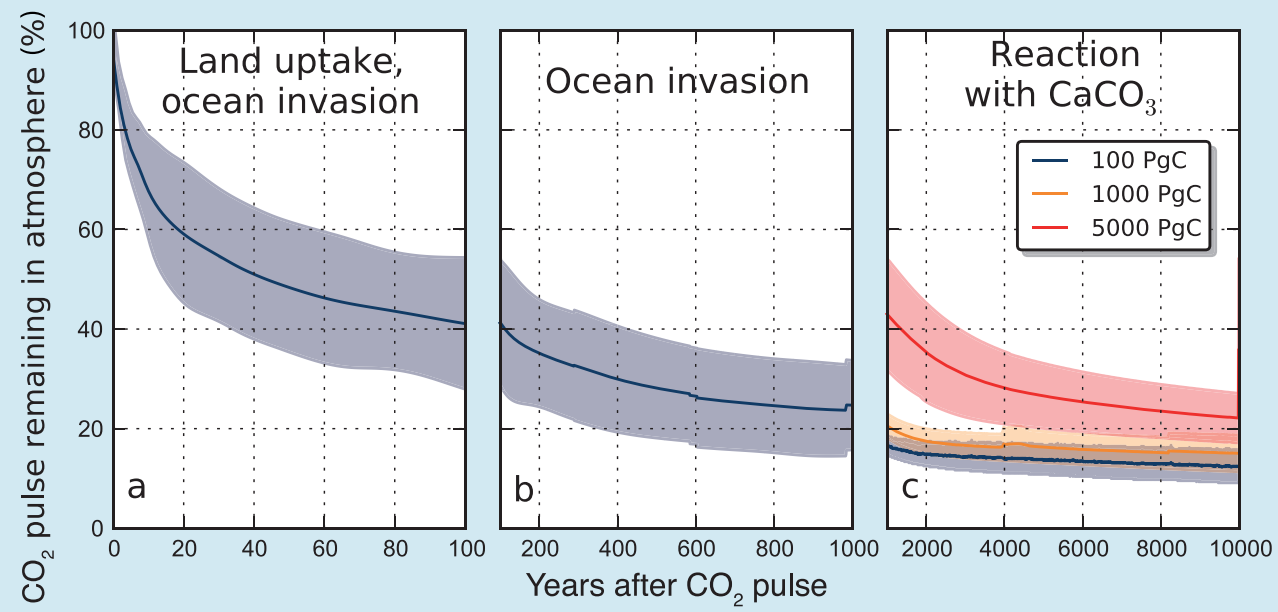

Box 6.1, Figure $1 \mid$ A percentage of emitted $\mathrm{CO}_{2}$ remaining in the atmosphere in response to an idealised instantaneous $\mathrm{CO}_{2}$ pulse emitted to the atmosphere in year 0 as calculated by a range of coupled climate-carbon cycle models. (Left and middle panels, a and b) Multi-model mean (blue line) and the uncertainty interval ( \pm 2 standard deviations, shading) simulated during 1000 years following the instantaneous pulse of $100 \mathrm{PgC}$ (Joos et al., 2013). (Right panel, c) A mean of models with oceanic and terrestrial carbon components and a maximum range of these models (shading) for instantaneous $\mathrm{CO}_{2}$ pulse in year 0 of $100 \mathrm{PgC}$ (blue), $1000 \mathrm{PgC}$ (orange) and $5000 \mathrm{PgC}$ (red line) on a time interval up to $10 \mathrm{kyr}$ (Archer et al., 2009b). Text at the top of the panels indicates the dominant processes that remove the excess of $\mathrm{CO}_{2}$ emitted in the atmosphere on the successive time scales. Note that higher pulse of $\mathrm{CO}_{2}$ emissions leads to higher remaining $\mathrm{CO}_{2}$ fraction $(\mathrm{Section} 6.3 .2 .4)$ due to reduced carbonate buffer capacity of the ocean and positive climate-carbon cycle feedback (Section 6.3.2.6.6).

\subsubsection{Methane Cycle}

$\mathrm{CH}_{4}$ absorbs infrared radiation relatively stronger per molecule compared to $\mathrm{CO}_{2}$ (Chapter 8), and it interacts with photochemistry. On the other hand, the methane turnover time (see Glossary) is less than 10 years in the troposphere (Prather et al., 2012; see Chapter 7). The sources of $\mathrm{CH}_{4}$ at the surface of the Earth (see Section 6.3.3.2) can be thermogenic including (1) natural emissions of fossil $\mathrm{CH}_{4}$ from geological sources (marine and terrestrial seepages, geothermal vents and mud volcanoes) and (2) emissions caused by leakages from fossil fuel extraction and use (natural gas, coal and oil industry; Figure 6.2). There are also pyrogenic sources resulting from incomplete burning of fossil fuels and plant biomass (both natural and anthropogenic fires). The biogenic sources include natural biogenic emissions predominantly from wetlands, from termites and very small emissions from the ocean (see Section 6.3.3). Anthropogenic biogenic emissions occur from rice paddy agriculture, ruminant livestock, landfills, man-made lakes and wetlands and waste treatment. In general, biogenic $\mathrm{CH}_{4}$ is produced from organic matter under low oxygen conditions by fermentation processes of methanogenic microbes (Conrad, 1996). Atmospheric $\mathrm{CH}_{4}$ is removed primarily by photochemistry, through atmospheric chemistry reactions with the $\mathrm{OH}$ radicals. Other smaller removal processes of atmospheric $\mathrm{CH}_{4}$ take place in the stratosphere through reaction with chlorine and oxygen radicals, by oxidation in well aerated soils, and possibly by reaction with chlorine in the marine boundary layer (Allan et al., 2007; see Section 6.3.3.3).

A very large geological stock (globally 1500 to $7000 \mathrm{PgC}$, that is $2 \mathrm{x}$ $10^{6}$ to $9.3 \times 10^{6} \mathrm{Tg}\left(\mathrm{CH}_{4}\right)$ in Figure 6.2; Archer (2007); with low confidence in estimates) of $\mathrm{CH}_{4}$ exists in the form of frozen hydrate deposits ('clathrates') in shallow ocean sediments and on the slopes of continental shelves, and permafrost soils. These $\mathrm{CH}_{4}$ hydrates are stable 
under conditions of low temperature and high pressure. Warming or changes in pressure could render some of these hydrates unstable with a potential release of $\mathrm{CH}_{4}$ to the overlying soil/ocean and/or atmosphere. Possible future $\mathrm{CH}_{4}$ emissions from $\mathrm{CH}_{4}$ released by gas hydrates are discussed in Section 6.4.7.3.

\subsubsection{Industrial Era}

\subsubsection{Carbon Dioxide and the Global Carbon Cycle}

Since the beginning of the Industrial Era, humans have been producing energy by burning of fossil fuels (coal, oil and gas), a process that is releasing large amounts of $\mathrm{CO}_{2}$ into the atmosphere (Rotty, 1983; Boden et al., 2011; see Section 6.3.2.1). The amount of fossil fuel $\mathrm{CO}_{2}$ emitted to the atmosphere can be estimated with an accuracy of about 5 to $10 \%$ for recent decades from statistics of fossil fuel use (Andres et al., 2012). Total cumulative emissions between 1750 and 2011 amount to $375 \pm 30 \mathrm{PgC}$ (see Section 6.3.2.1 and Table 6.1), including a contribution of $8 \mathrm{PgC}$ from the production of cement.

The second major source of anthropogenic $\mathrm{CO}_{2}$ emissions to the atmosphere is caused by changes in land use (mainly deforestation), which causes globally a net reduction in land carbon storage, although recovery from past land use change can cause a net gain in in land

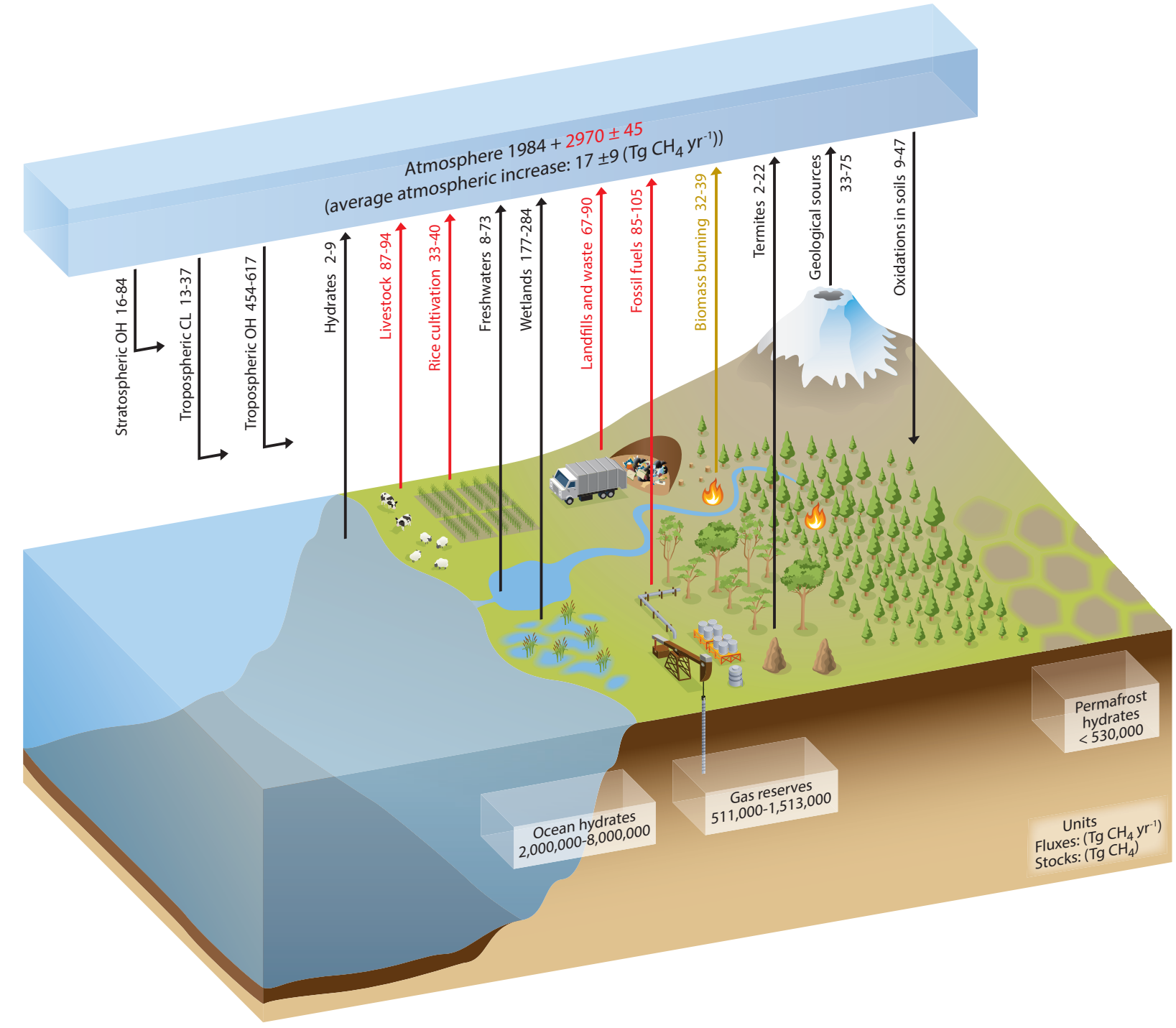

Figure 6.2 | Schematic of the global cycle of $\mathrm{CH}_{4}$. Numbers represent annual fluxes in $\mathrm{Tg}\left(\mathrm{CH}_{4}\right)$ yr-1 estimated for the time period $2000-2009$ and $\mathrm{CH}_{4}$ reservoirs in $\mathrm{Tg}\left(\mathrm{CH}_{4}\right)$ : the atmosphere and three geological reservoirs (hydrates on land and in the ocean floor and gas reserves) (see Section 6.3.3). Black arrows denote 'natural' fluxes, that is, fluxes that are not directly caused by human activities since 1750, red arrows anthropogenic fluxes, and the light brown arrow denotes a combined natural + anthropogenic flux. Note that human activities (e.g., land use) may have modified indirectly the global magnitude of the natural fluxes (Section 6.3.3). Ranges represent minimum and maximum values from cited references as given in Table 6.8 in Section 6.3.3. Gas reserves are from GEA (2006) and are consistent with numbers used by IPCC WG III for future scenarios. Hydrate reservoir sizes are from Archer et al. (2007). The atmospheric inventories have been calculated using a conversion factor of $2.7476 \mathrm{TgCH}_{4}$ per ppb (Prather et al., 2012). The assumed preindustrial annual mean globally averaged $\mathrm{CH}_{4}$ concentration was $722 \pm 25 \mathrm{ppb}$ taking the average of the Antarctic Law Dome ice core observations (MacFarling-Meure et al., 2006) and the measurements from the GRIP ice core in Greenland (Blunier et al., 1995; see also Table 2.1). The atmospheric inventory in the year 2011 is based on an annual globally averaged $\mathrm{CH}_{4}$ concentration of $1803 \pm 4 \mathrm{ppb}$ in the year 2011 (see Table 2.1). It is the sum of the atmospheric increase between 1750 and 2011 (in red) and of the pre-industrial inventory (in black). The average atmospheric increase each year, also called growth rate, is based on a measured concentration increase of $2.2 \mathrm{ppb}_{\mathrm{yr}}{ }^{-1}$ during the time period $2000-2009$ (Dlugokencky et al., 2011). 
carbon storage in some regions. Estimation of this $\mathrm{CO}_{2}$ source to the atmosphere requires knowledge of changes in land area as well as estimates of the carbon stored per area before and after the land use change. In addition, longer term effects, such as the decomposition of soil organic matter after land use change, have to be taken into account (see Section 6.3.2.2). Since 1750, anthropogenic land use changes have resulted into about 50 million $\mathrm{km}^{2}$ being used for cropland and pasture, corresponding to about $38 \%$ of the total ice-free land area (Foley et al., 2007, 2011), in contrast to an estimated cropland and pasture area of 7.5 to 9 million $\mathrm{km}^{2}$ about 1750 (Ramankutty and Foley, 1999; Goldewijk, 2001). The cumulative net $\mathrm{CO}_{2}$ emissions from land use changes between 1750 and 2011 are estimated at approximately $180 \pm 80 \mathrm{PgC}$ (see Section 6.3 and Table 6.1).

Multiple lines of evidence indicate that the observed atmospheric increase in the global $\mathrm{CO}_{2}$ concentration since 1750 (Figure 6.3) is caused by the anthropogenic $\mathrm{CO}_{2}$ emissions (see Section 6.3.2.3). The rising atmospheric $\mathrm{CO}_{2}$ content induces a disequilibrium in the exchange fluxes between the atmosphere and the land and oceans respectively. The rising $\mathrm{CO}_{2}$ concentration implies a rising atmospheric $\mathrm{CO}_{2}$ partial pressure $\left(\mathrm{pCO}_{2}\right)$ that induces a globally averaged net-airto-sea flux and thus an ocean sink for $\mathrm{CO}_{2}$ (see Section 6.3.2.5). On land, the rising atmospheric $\mathrm{CO}_{2}$ concentration fosters photosynthesis via the $\mathrm{CO}_{2}$ fertilisation effect (see Section 6.3.2.6). However, the efficacy of these oceanic and terrestrial sinks does also depend on how the excess carbon is transformed and redistributed within these sink reservoirs. The magnitude of the current sinks is shown in Figure 6.1 (averaged over the years 2000-2009, red arrows), together with the cumulative reservoir content changes over the industrial era (17502011, red numbers) (see Table 6.1, Section 6.3).

\subsubsection{Methane Cycle}

After 1750, atmospheric $\mathrm{CH}_{4}$ levels rose almost exponentially with time, reaching 1650 ppb by the mid-1980s and 1803 ppb by 2011. Between the mid-1980s and the mid-2000s the atmospheric growth of $\mathrm{CH}_{4}$ declined to nearly zero (see Section 6.3.3.1, see also Chapter 2). More recently since 2006, atmospheric $\mathrm{CH}_{4}$ is observed to increase again (Rigby et al., 2008); however, it is unclear if this is a short-term fluctuation or a new regime for the $\mathrm{CH}_{4}$ cycle (Dlugokencky et al., 2009).

There is very high level of confidence that the atmospheric $\mathrm{CH}_{4}$ increase during the Industrial Era is caused by anthropogenic activities. The massive increase in the number of ruminants (Barnosky, 2008), the emissions from fossil fuel extraction and use, the expansion of rice paddy agriculture and the emissions from landfills and waste are the dominant anthropogenic $\mathrm{CH}_{4}$ sources. Total anthropogenic sources contribute at present between 50 and $65 \%$ of the total $\mathrm{CH}_{4}$ sources (see Section 6.3.3). The dominance of $\mathrm{CH}_{4}$ emissions located mostly in the $\mathrm{NH}$ (wetlands and anthropogenic emissions) is evidenced by the observed positive north-south gradient in $\mathrm{CH}_{4}$ concentrations (Figure 6.3). Satellite-based $\mathrm{CH}_{4}$ concentration measurements averaged over the entire atmospheric column also indicate higher concentrations of $\mathrm{CH}_{4}$ above and downwind of densely populated and intensive agriculture areas where anthropogenic emissions occur (Frankenberg et al., 2011).

\subsubsection{Connections Between Carbon and the Nitrogen and Oxygen Cycles}

\subsubsection{Global Nitrogen Cycle Including Nitrous Oxide}

The biogeochemical cycles of nitrogen and carbon are tightly coupled with each other owing to the metabolic needs of organisms for these two elements. Changes in the availability of one element will influence not only biological productivity but also availability and requirements for the other element (Gruber and Galloway, 2008) and in the longer term, the structure and functioning of ecosystems as well.

Before the Industrial Era, the creation of reactive nitrogen $\mathrm{Nr}$ (all nitrogen species other than $\mathrm{N}_{2}$ ) from non-reactive atmospheric $\mathrm{N}_{2}$ occurred primarily through two natural processes: lightning and biological nitrogen fixation (BNF). BNF is a set of reactions that convert $\mathrm{N}_{2}$ to ammonia in a microbially mediated process. This input of $\mathrm{Nr}$ to the land and ocean biosphere was in balance with the loss of $\mathrm{Nr}$ though denitrification, a process that returns $\mathrm{N}_{2}$ back to the atmosphere (Ayres et al., 1994). This equilibrium has been broken since the beginning of the Industrial Era. $\mathrm{Nr}$ is produced by human activities and delivered to ecosystems. During the last decades, the production of $\mathrm{Nr}$ by humans has been much greater than the natural production (Figure 6.4a; Section 6.3.4.3). There are three main anthropogenic sources of $\mathrm{Nr}$ : (1) the Haber-Bosch industrial process, used to make $\mathrm{NH}_{3}$ from $\mathrm{N}_{2}$, for nitrogen fertilisers and as a feedstock for some industries; (2) the cultivation of legumes and other crops, which increases BNF; and (3) the combustion of fossil fuels, which converts atmospheric $\mathrm{N}_{2}$ and fossil fuel nitrogen into nitrogen oxides $\left(\mathrm{NO}_{x}\right)$ emitted to the atmosphere and re-deposited at the surface (Figure 6.4a). In addition, there is a small flux from the mobilization of sequestered $\mathrm{Nr}$ from nitrogen-rich sedimentary rocks (Morford et al., 2011) (not shown in Figure 6.4a).

The amount of anthropogenic $\mathrm{Nr}$ converted back to non-reactive $\mathrm{N}_{2}$ by denitrification is much smaller than the amount of $\mathrm{Nr}$ produced each year, that is, about 30 to $60 \%$ of the total $\mathrm{Nr}$ production, with a large uncertainty (Galloway et al., 2004; Canfield et al., 2010; Bouwman et al., 2013). What is more certain is the amount of $\mathrm{N}_{2} \mathrm{O}$ emitted to the atmosphere. Anthropogenic sources of $\mathrm{N}_{2} \mathrm{O}$ are about the same size as natural terrestrial sources (see Section 6.3.4 and Table 6.9 for the global $\mathrm{N}_{2} \mathrm{O}$ budget). In addition, emissions of $\mathrm{Nr}$ to the atmosphere, as $\mathrm{NH}_{3}$ and $\mathrm{NO}_{x}$, are caused by agriculture and fossil fuel combustion. A portion of the emitted $\mathrm{NH}_{3}$ and $\mathrm{NO}_{\mathrm{x}}$ is deposited over the continents, while the rest gets transported by winds and deposited over the oceans. This atmospheric deposition flux of $\mathrm{Nr}$ over the oceans is comparable to the flux going from soils to rivers and delivered to the coastal ocean (Galloway et al., 2004; Suntharalingam et al., 2012). The increase of $\mathrm{Nr}$ creation during the Industrial Era, the connections among its impacts, including on climate and the connections with the carbon cycle are presented in Box 6.2.

For the global ocean, the best BNF estimate is $160 \mathrm{TgN}^{-1}$, which is roughly the midpoint of the minimum estimate of $140 \mathrm{TgN} \mathrm{yr}^{-1}$ of Deutsch et al. (2007) and the maximum estimate of $177 \mathrm{TgN} \mathrm{yr}^{-1}$ (Groszkopf et al., 2012). The probability that this estimate will need an upward revision in the near future is high because several additional processes are not yet considered (Voss et al., 2013). 

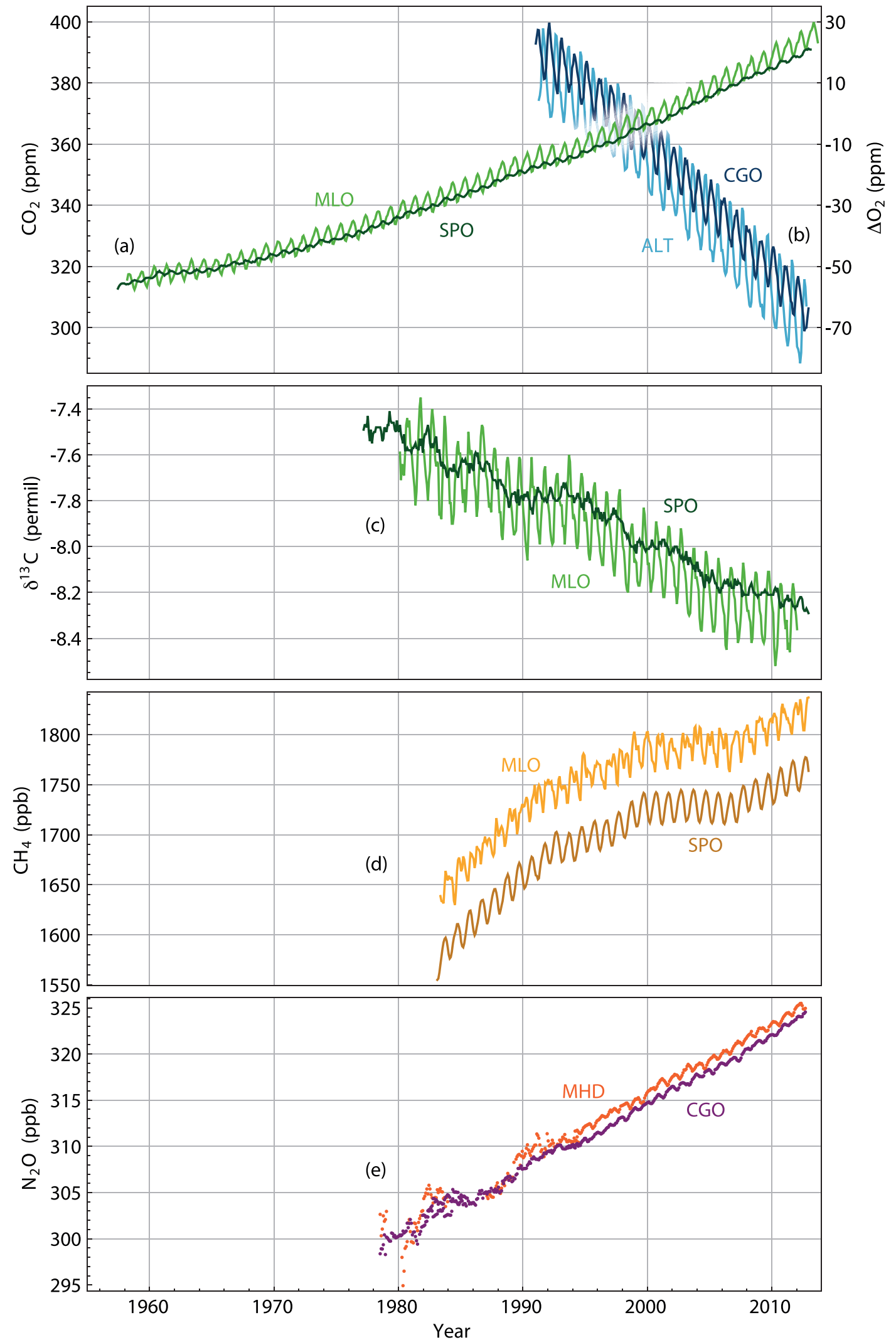

Figure 6.3 Atmospheric concentration of $\mathrm{CO}_{2}$, oxygen, ${ }^{13} \mathrm{C}^{12} \mathrm{C}$ stable isotope ratio in $\mathrm{CO}_{2}, \mathrm{CH}_{4}$ and $\mathrm{N}_{2} \mathrm{O}$ recorded over the last decades at representative stations (a) $\mathrm{CO}_{2}$ from Mauna Loa (MLO) Northern Hemisphere and South Pole Southern Hemisphere (SPO) atmospheric stations (Keeling et al., 2005). (b) $\mathrm{O}_{2}$ from Alert Northern Hemisphere (ALT) and Cape Grim Southern Hemisphere (CGO) stations (http://scrippso2.ucsd.edu/ right axes, expressed relative to a reference standard value). (c) ${ }^{13} \mathrm{C} /{ }^{12} \mathrm{C}$ : Mauna Loa, South Pole (Keeling et al., 2005). (d) $\mathrm{CH}_{4}$ from Mauna Loa and South Pole stations (Dlugokencky et al., 2012). (e) $\mathrm{N}_{2} \mathrm{O}$ from Mace-Head Northern Hemisphere (MHD) and Cape Grim stations (Prinn et al., 2000). 


\section{Box 6.2 | Nitrogen Cycle and Climate-Carbon Cycle Feedbacks}

Human creation of reactive nitrogen by the Haber-Bosch process (see Sections 6.1.3 and 6.3.4), fossil fuel combustion and agricultural biological nitrogen fixation (BNF) dominate $\mathrm{Nr}$ creation relative to biological nitrogen fixation in natural terrestrial ecosystems. This dominance impacts on the radiation balance of the Earth (covered by the IPCC; see, e.g., Chapters 7 and 8), and affects human health and ecosystem health as well (EPA, 2011b; Sutton et al., 2011).

The $\mathrm{Nr}$ creation from 1850 to 2005 is shown in Box 6.2 (Figure 1). After mid-1970s, human production of Nr exceeded natural production. During the 2000s food production (mineral fertilisers, legumes) accounts for three-quarters of $\mathrm{Nr}$ created by humans, with fossil fuel combustion and industrial uses accounting equally for the remainder (Galloway et al., 2008; Canfield et al., 2010; Sutton et al., 2011).

The three most relevant questions regarding the anthropogenic perturbation of the nitrogen cycle with respect to global change are: (1) What are the interactions with the carbon cycle, and the effects on carbon sinks (see Sections 6.3.2.6.5 and 6.4.2.1), (2) What are the effects of increased $\mathrm{Nr}$ on the radiative forcing of nitrate aerosols (Chapter 7, 7.3.2) and tropospheric ozone (Chapters 8), (3) What are the impacts of the excess of $\mathrm{Nr}$ on humans and ecosystems (health, biodiversity, eutrophication, not treated in this report, but see, for example, EPA, 2011 b; Sutton et al., 2011).

Essentially all of the $\mathrm{Nr}$ formed by human activity is spread into the environment, either at the point of creation (i.e., fossil fuel combustion) or after it is used in food production and in industry. Once in the environment, $\mathrm{Nr}$ has a number of negative impacts if not converted back into $\mathrm{N}_{2}$. In addition to its contributions to climate change and stratospheric ozone depletion, $\mathrm{Nr}$ contributes to the formation of smog; increases the haziness of the troposphere; contributes to the acidification of soils and freshwaters; and increases the productivity in forests, grasslands, open and coastal waters and

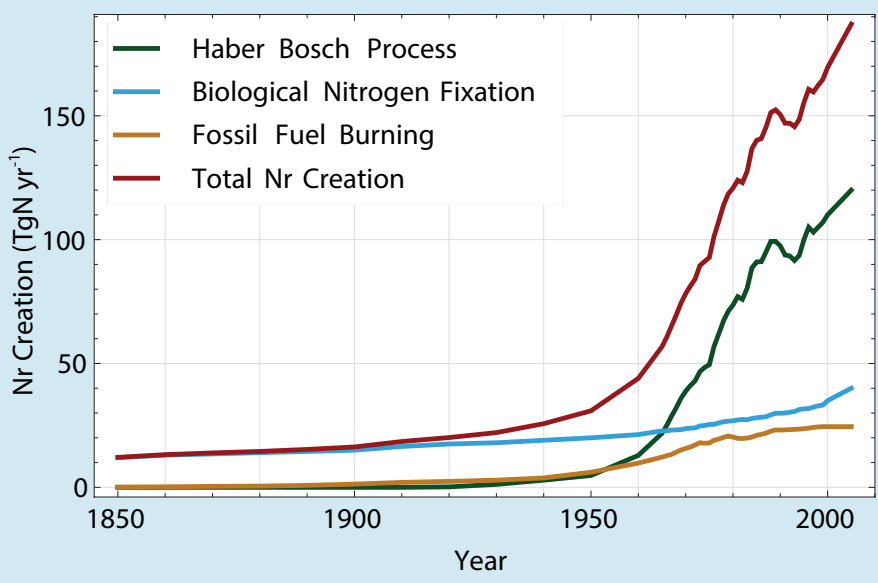

Box 6.2, Figure 1 | Anthropogenic reactive nitrogen ( $\mathrm{Nr}$ ) creation rates (in $\mathrm{TgN} \mathrm{yr}^{-1}$ ) from fossil fuel burning (orange line), cultivation-induced biological nitrogen fixation (blue line), Haber-Bosch process (green line) and total creation (red line). Source: Galloway et al. (2003), Galloway et al. (2008). Note that updates are given in Table 6.9. The only one with significant changes in the more recent literature is cultivationinduced BNF) which Herridge et al. (2008) estimated to be $60 \mathrm{TgN} \mathrm{yr}^{-1}$. The data are only reported since 1850, as no published estimate is available since 1750 . open ocean, which can lead to eutrophication and reduction in biodiversity in terrestrial and aquatic ecosystems. In addition, Nr-induced increases in nitrogen oxides, aerosols, tropospheric ozone, and nitrates in drinking water have negative impacts on human health (Galloway et al., 2008; Davidson et al., 2012). Once the nitrogen atoms become reactive (e.g., $\mathrm{NH}_{3}, \mathrm{NO}_{x}$ ), any given $\mathrm{Nr}$ atom can contribute to all of the impacts noted above in sequence. This is called the nitrogen cascade (Galloway et al., 2003; Box 6.2, Figure 2). The nitrogen cascade is the sequential transfer of the same Nr atom through the atmosphere, terrestrial ecosystems, freshwater ecosystems and marine ecosystems that results in multiple effects in each reservoir. Because of the nitrogen cascade, the creation of any molecule of $\mathrm{Nr}$ from $\mathrm{N}_{2}$, at any location, has the potential to affect climate, either directly or indirectly, as explained in this box This potential exists until the $\mathrm{Nr}$ gets converted back to $\mathrm{N}_{2}$.

The most important processes causing direct links between anthropogenic $\mathrm{Nr}$ and climate change include (Erisman et al., 2011): (1) $\mathrm{N}_{2} \mathrm{O}$ formation during industrial processes (e.g., fertiliser production), combustion, or microbial conversion of substrate containing nitrogen - notably after fertiliser and manure application to soils. $\mathrm{N}_{2} \mathrm{O}$ is a strong greenhouse gas (GHG), (2) emission of anthropogenic $\mathrm{NO}_{x}$ leading to (a) formation of tropospheric $\mathrm{O}_{3}$, (which is the third most important GHG), (b) a decrease of $\mathrm{CH}_{4}$ and (c) the formation of nitrate aerosols. Aerosol formation affects radiative forcing, as nitrogen-containing aerosols have a direct cooling effect in addition to an indirect cooling effect through cloud formation and (3) $\mathrm{NH}_{3}$ emission to the atmosphere which contributes to aerosol formation. The first process has a warming effect. The second has both a warming (as a GHG) and a cooling (through the formation of the $\mathrm{OH}$ radical in the troposphere which reacts with $\mathrm{CH}_{4}$, and through aerosol formation) effect. The net effect of all three $\mathrm{NO}_{\mathrm{x}}$-related contributions is cooling. The third process has a cooling effect.

The most important processes causing an indirect link between anthropogenic $\mathrm{Nr}$ and climate change include: (1) nitrogen-dependent changes in soil organic matter decomposition and hence $\mathrm{CO}_{2}$ emissions, affecting heterotrophic respiration; (2) alteration of the biospheric $\mathrm{CO}_{2}$ sink due to increased supply of $\mathrm{Nr}$. About half of the carbon that is emitted to the atmosphere is 


\section{Box 6.2 (continued)}

taken up by the biosphere; $\mathrm{Nr}$ affects net $\mathrm{CO}_{2}$ uptake from the atmosphere in terrestrial systems, rivers, estuaries and the open ocean in a positive direction (by increasing productivity or reducing the rate of organic matter breakdown) and negative direction (in situations where it accelerates organic matter breakdown). $\mathrm{CO}_{2}$ uptake in the ocean causes ocean acidification, which reduces $\mathrm{CO}_{2}$ uptake; (3) changes in marine primary productivity, generally an increase, in response to $\mathrm{Nr}$ deposition; and (4) $\mathrm{O}_{3}$ formed in the troposphere as a result of $\mathrm{NO}_{x}$ and volatile organic compound emissions reduces plant productivity, and therefore reduces $\mathrm{CO}_{2}$ uptake from the atmosphere. On the global scale the net influence of the direct and indirect contributions of $\mathrm{Nr}$ on the radiative balance was estimated to be $-0.24 \mathrm{~W} \mathrm{~m}^{-2}$ (with an uncertainty range of +0.2 to $-0.5 \mathrm{~W} \mathrm{~m}^{-2}$ ) (Erisman et al., 2011).

$\mathrm{Nr}$ is required for both plants and soil microorganisms to grow, and plant and microbial processes play important roles in the global carbon cycle. The increasing concentration of atmospheric $\mathrm{CO}_{2}$ is observed to increase plant photosynthesis (see Box 6.3) and plant growth, which drives an increase of carbon storage in terrestrial ecosystems. Plant growth is, however, constrained by the availability of $\mathrm{Nr}$ in soils (see Section 6.3.2.6.5). This means that in some nitrogen-poor ecosystems, insufficient $\mathrm{Nr}$ availability will limit carbon sinks, while the deposition of $\mathrm{Nr}$ may instead alleviate this limitation and enable larger carbon sinks (see Section 6.3.2.6.5). Therefore, human production of $\mathrm{Nr}$ has the potential to mitigate $\mathrm{CO}_{2}$ emissions by providing additional nutrients for plant growth in some regions. Microbial growth can also be limited by the availability of $\mathrm{Nr}$, particularly in cold, wet environments, so that human production of $\mathrm{Nr}$ also has the potential to accelerate the decomposition of organic matter, increasing release of $\mathrm{CO}_{2}$. The availability of Nr also changes in response to climate change, generally increasing with warmer temperatures and increased precipitation (see Section 6.4.2.1), but with complex interactions in the case of seasonally inundated environments. This complex network of feedbacks is amenable to study through observation and experimentation (Section 6.3) and Earth System modelling (Section 6.4). Even though we do not yet have a thorough understanding of how nitrogen and carbon cycling will interact with climate change, elevated $\mathrm{CO}_{2}$ and human $\mathrm{Nr}$ production in the future, given scenarios of human activity, current observations and model results all indicate that low nitrogen availability will limit carbon storage on land in the 21st century (see Section 6.4.2.1).

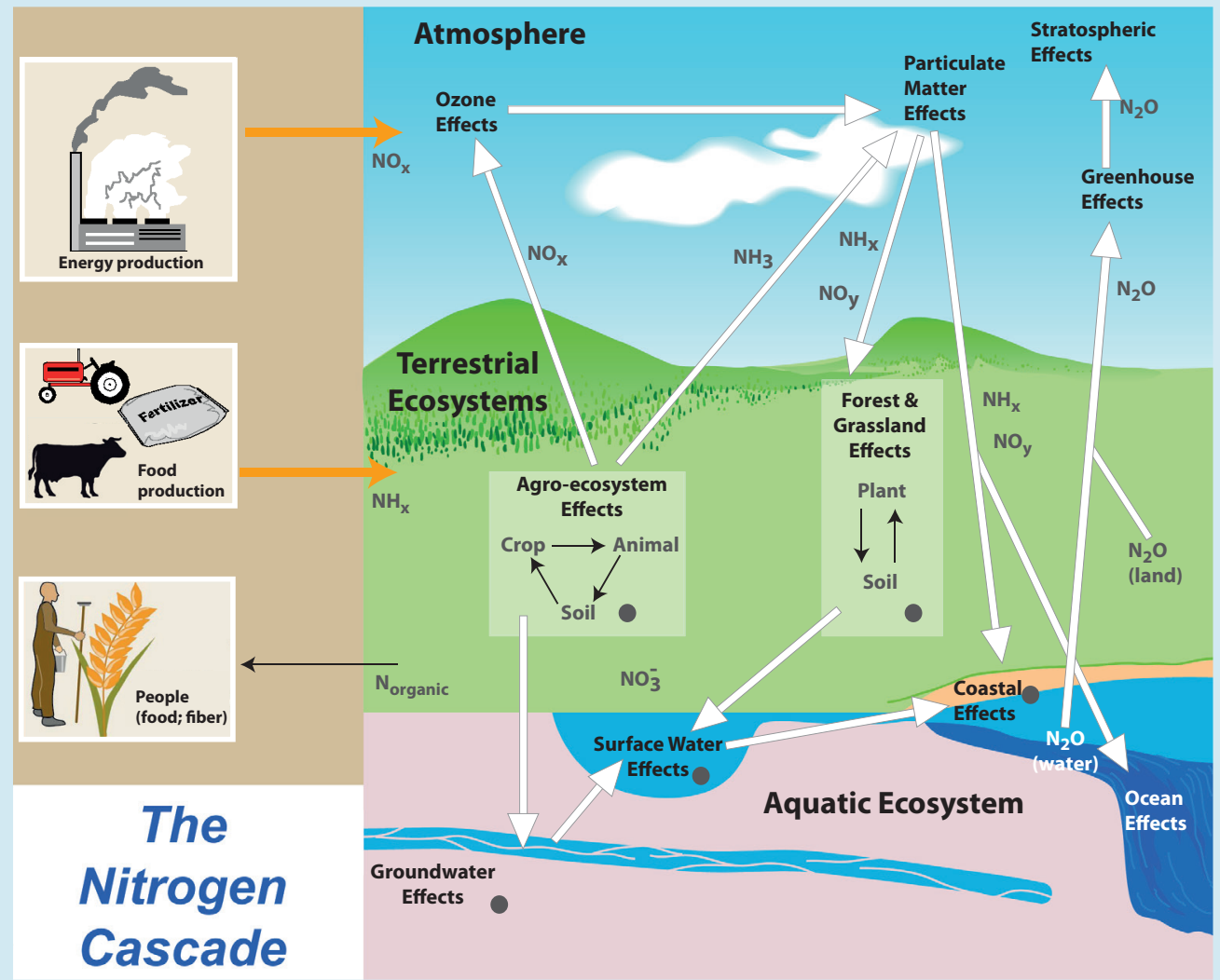

Box 6.2, Figure 2 | Illustration of the nitrogen cascade showing the sequential effects that a single atom of nitrogen in its various molecular forms can have in various reservoirs after it has been converted from nonreactive $\mathrm{N}_{2}$ to a reactive form by energy and food production (orange arrows). Once created the reactive nitrogen has the potential to continue to contribute to impacts until it is converted back to $\mathrm{N}_{2}$. The small black circle indicates that there is the potential for denitrification to occur within that reservoir. $\mathrm{NH}_{3}=$ ammonia; $\mathrm{NH}_{\mathrm{x}}=$ ammonia plus ammonium; $\mathrm{NO}_{3}{ }^{-}=$nitrate; $\mathrm{NO}_{\mathrm{x}}=$ nitrogen oxides; $\mathrm{NO}_{\mathrm{y}}=\mathrm{NO}_{\mathrm{x}}$ and other combinations of nitrogen and oxygen (except $\mathrm{N}_{2} \mathrm{O}$ ); $\mathrm{N}_{2} \mathrm{O}=$ nitrous oxide. (Adapted with permission from the GEO Yearbook 2003, United Nations Environmental Programme (UNEP), 2004 which was based on Galloway et al., 2003.) 


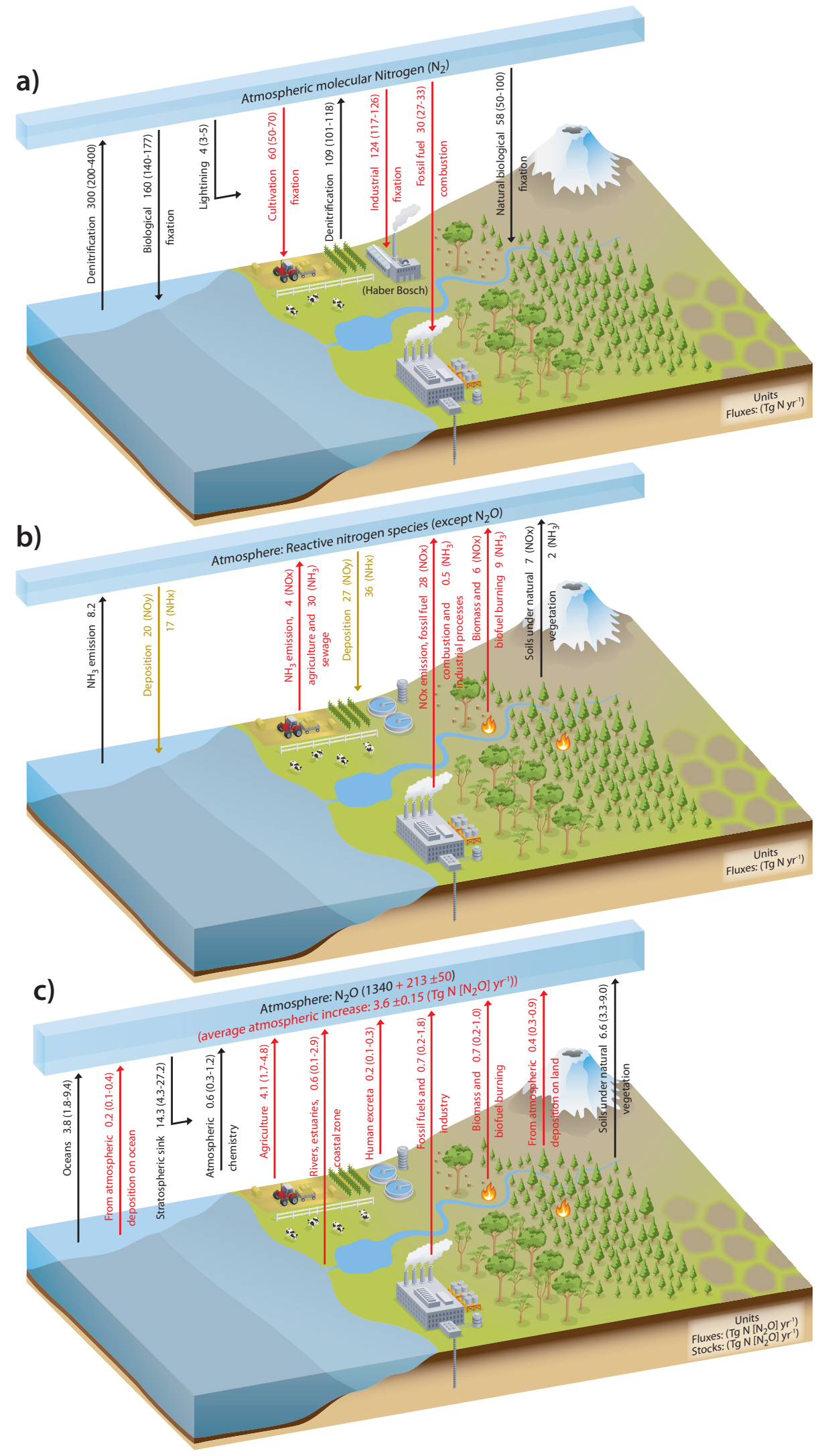

Figure 6.4 | Schematic of the global nitrogen cycle. (a) The natural and anthropogenic processes that create reactive nitrogen and the corresponding rates of denitrification that convert reactive nitrogen back to $\mathrm{N}_{2}$. (b) The flows of the reactive nitrogen species $\mathrm{NO}_{y}$ and $\mathrm{NH}_{x}$. (c) The stratospheric sink of $\mathrm{N}_{2} \mathrm{O}$ is the sum of losses via photolysis and reaction with $\mathrm{O}(1 \mathrm{D})$ (oxygen radical in the 1D excited state; Table 6.9). The global magnitude of this sink is adjusted here in order to be equal to the difference between the total sources and the observed growth rate. This value falls within literature estimates (Volk et al., 1997). The atmospheric inventories have been calculated using a conversion factor of $4.79 \mathrm{TgN}$ $\left(\mathrm{N}_{2} \mathrm{O}\right)$ per ppb (Prather et al., 2012). 
A global denitrification rate is much more difficult to constrain than the BNF considering the changing paradigms of nitrogen cycling in the oxygen minimum zones or the unconstrained losses in permeable sediments on the continental shelves (Gao et al., 2012). The coastal ocean may have losses in the range of 100 to 250 (Voss et al., 2011). For the open and distal ocean Codispoti (2007) estimated an upper limit of denitrification of $400 \mathrm{TgN} \mathrm{yr}^{-1}$. Voss et al. (2013) used a conservative estimate of $100 \mathrm{TgN} \mathrm{yr}^{-1}$ for the coastal ocean, and 200 to $300 \mathrm{TgN} \mathrm{yr}^{-1}$ for the open ocean. Because the upper limit in the global ocean is 400 $\mathrm{TgN} \mathrm{yr}^{-1}, 300 \pm 100 \mathrm{TgN} \mathrm{yr}^{-1}$ is the best estimate for global ocean losses of reactive nitrogen (Table 6.9).

This chapter does not describe the phosphorus and sulphur biogeochemical cycles, but phosphorus limitations on carbon sinks are briefly addressed in Section 6.4.8.2 and future sulphur deposition in Section 6.4.6.2.

\subsubsection{Oxygen}

Atmospheric oxygen is tightly coupled with the global carbon cycle (sometimes called a mirror of the carbon cycle). The burning of fossil fuels removes oxygen from the atmosphere in a tightly defined stoichiometric ratio depending on fuel carbon content. As a consequence of the burning of fossil fuels, atmospheric $\mathrm{O}_{2}$ levels have been observed to decrease steadily over the last 20 years (Keeling and Shertz, 1992; Manning and Keeling, 2006) (Figure 6.3b). Compared to the atmospheric oxygen content of about $21 \%$ this decrease is very small; however, it provides independent evidence that the rise in $\mathrm{CO}_{2}$ must be due to an oxidation process, that is, fossil fuel combustion and/or organic carbon oxidation, and is not caused by, for example, volcanic emissions or by outgassing of dissolved $\mathrm{CO}_{2}$ from a warming ocean. The atmospheric oxygen measurements furthermore also show the north-south concentration $\mathrm{O}_{2}$ difference (higher in the south and mirroring the $\mathrm{CO}_{2}$ north-south concentration difference) as expected from the stronger fossil fuel consumption in the NH (Keeling et al., 1996).

On land, during photosynthesis and respiration, $\mathrm{O}_{2}$ and $\mathrm{CO}_{2}$ are exchanged in nearly a 1:1 ratio. However, with respect to exchanges with the ocean, $\mathrm{O}_{2}$ behaves quite differently from $\mathrm{CO}_{2}$, because compared to the atmosphere only a small amount of $\mathrm{O}_{2}$ is dissolved in the ocean whereas by contrast the oceanic $\mathrm{CO}_{2}$ content is much larger due to the carbonate chemistry. This different behaviour of the two gases with respect to ocean exchange provides a powerful method to assess independently the partitioning of the uptake of anthropogenic $\mathrm{CO}_{2}$ by land and ocean (Manning and Keeling, 2006), Section 6.3.2.3.

\subsection{Variations in Carbon and Other Biogeochemical Cycles Before the Fossil Fuel Era}

The Earth System mechanisms that were responsible for past variations in atmospheric $\mathrm{CO}_{2}, \mathrm{CH}_{4}$, and $\mathrm{N}_{2} \mathrm{O}$ will probably operate in the future as well. Past archives of GHGs and climate therefore provide useful knowledge, including constraints for biogeochemical models applied to the future projections described in Section 6.4. In addition, past archives of GHGs also show with very high confidence that the average rates of increase of $\mathrm{CO}_{2}, \mathrm{CH}_{4}$ and $\mathrm{N}_{2} \mathrm{O}$ are larger during the Industrial Era (see Section 6.3) than during any comparable period of at least the past 22,000 years (Joos and Spahni, 2008).

\subsubsection{Glacial-Interglacial Greenhouse Gas Changes}

\subsubsection{Processes Controlling Glacial Carbon Dioxide}

Ice cores recovered from the Antarctic ice sheet reveal that the concentration of atmospheric $\mathrm{CO}_{2}$ at the Last Glacial Maximum (LGM; see Glossary) at 21 ka was about one third lower than during the subsequent interglacial (Holocene) period started at $11.7 \mathrm{ka}$ (Delmas et al., 1980; Neftel et al., 1982; Monnin et al., 2001). Longer (to 800 ka) records exhibit similar features, with $\mathrm{CO}_{2}$ values of $\sim 180$ to $200 \mathrm{ppm}$ during glacial intervals (Petit et al., 1999). Prior to $420 \mathrm{ka}$, interglacial $\mathrm{CO}_{2}$ values were 240 to $260 \mathrm{ppm}$ rather than 270 to $290 \mathrm{ppm}$ after that date (Lüthi et al., 2008).

A variety of proxy reconstructions as well as models of different complexity from conceptual to complex Earth System Models (ESM; see Glossary) have been used to test hypotheses for the cause of lower LGM atmospheric $\mathrm{CO}_{2}$ concentrations (e.g., Köhler et al., 2005; Sigman et al., 2010). The mechanisms of the carbon cycle during the LGM which lead to low atmospheric $\mathrm{CO}_{2}$ can be broken down by individual drivers (Figure 6.5). It should be recognized, however, that this separation is potentially misleading, as many of the component drivers shown in Figure 6.5 may combine nonlinearly (Bouttes et al., 2011). Only well-established individual drivers are quantified (Figure 6.5), and discussed here.

\subsection{Reduced land carbon}

Despite local evidence of larger carbon storage in permafrost regions during glacial periods (Zimov et al., 2009; Zech et al., 2011), the $\delta^{13} \mathrm{C}$ record of ocean waters as preserved in benthic foraminiferal shells has been used to infer that global terrestrial carbon storage was reduced in glacial times, thus opposite to recorded changes in atmospheric $\mathrm{CO}_{2}$. Data-based estimates of the deficit between LGM and pre-industrial land carbon storage range from a few hundreds to $1000 \mathrm{PgC}$ (e.g., Bird et al., 1996; Ciais et al., 2012). Dynamic vegetation models tend to simulate values at the higher end ( $\sim 800 \mathrm{PgC}$ ) (Kaplan et al., 2002; Otto et al., 2002) and indicate a role for the physiological effects of low $\mathrm{CO}_{2}$ on photosynthesis at the LGM at least as large as that of colder and dryer climate conditions in determining the past extent of forests (Prentice and Harrison, 2009).

\subsection{Lower sea surface temperatures}

Reconstructions of sea surface temperatures (SSTs) during the LGM suggest that the global surface ocean was on average $3^{\circ} \mathrm{C}$ to $5^{\circ} \mathrm{C}$ cooler compared to the Holocene. Because the solubility of $\mathrm{CO}_{2}$ increases at colder temperature (Zeebe and Wolf-Gladrow, 2001), a colder glacial ocean will hold more carbon. However, uncertainty in reconstructing the LGM pattern of ocean temperature, particularly in the tropics (Archer et al., 2000; Waelbroeck et al., 2009), together with problems in transforming this pattern to the resolution of models in light of the nonlinear nature of the $\mathrm{CO}_{2}$-temperature relationship 
(Ridgwell, 2001), creates a large spread in modelled estimates, Most ocean general circulation models (OGCM) projections, however, cluster more tightly and suggest that lower ocean temperatures contribute to lower $\mathrm{CO}_{2}$ values by $25 \mathrm{ppm}$ during the LGM (Figure 6.5).

\subsection{Lower sea level and increased salinity}

During the LGM, sea level was about $\sim 120$ m lower than today, and this change in ocean volume had several well-understood effects on atmospheric $\mathrm{CO}_{2}$ concentrations. Lower sea level impacts the LGM ocean carbon cycle in two main ways. First, the resulting higher LGM ocean surface salinity causes atmospheric $\mathrm{CO}_{2}$ to be higher than during the Holocene. Second, the total dissolved inorganic carbon and alkalinity (a measure of the capacity of an aqueous solution to neutralize acid) become more concentrated in equal proportions, and this process also causes atmospheric $\mathrm{CO}_{2}$ to be higher during the LGM. In total, lower sea level is estimated to contribute to higher $\mathrm{CO}_{2}$ values by 15 ppm during the LGM (Figure 6.5), implying that other processes must explain the lower $\mathrm{CO}_{2}$ values measured in ice cores.

\subsection{Ocean circulation and sea ice}

Reorganization in ocean circulation during glacial periods that promoted the retention of dissolved inorganic carbon in the deep ocean during the LGM has become the focus of most research on the glacial-interglacial $\mathrm{CO}_{2}$ problem. That ocean circulation plays a key role in low glacial period atmospheric $\mathrm{CO}_{2}$ concentration is exemplified by the tight coupling observed between reconstructed deep ocean temperatures and atmospheric $\mathrm{CO}_{2}$ (Shackleton, 2000). Evidence from marine bore hole sites (Adkins et al., 2002) and from marine sediment cores (Jaccard et al., 2005; Skinner et al., 2010) show that the glacial ocean was highly stratified compared to interglacial conditions and may thus have held a larger store of carbon during glacial times. $\delta^{13} \mathrm{CO}_{2}$ ice core records (Lourantou et al., 2010a, 2010b; Schmitt et al., 2012), as well as radiocarbon records from deep-sea corals demonstrate the role of a deep and stratified Southern Ocean in the higher LGM ocean carbon storage. However, conflicting hypotheses exist on the drivers of this increase in the Southern Ocean stratification, for example, northward shift and weakening of Southern Hemisphere (SH) westerly winds (Toggweiler et al., 2006), reduced air-sea buoyancy fluxes (Watson and Garabato, 2006) or massive brine rejections during sea ice formation (Bouttes et al., 2011, 2012). Ocean carbon cycle models have simulated a circulation-induced effect on $\mathrm{LGM} \mathrm{CO}_{2}$ that can explain lower values than during interglacial by 3 ppm (Bopp et al., 2003) to 57 ppm (Toggweiler, 1999).

A long-standing hypothesis is that increased LGM sea ice cover acted as a barrier to air-sea gas exchange and hence reduced the 'leakage' of $\mathrm{CO}_{2}$ during winter months from the ocean to the atmosphere during glacial periods (Broecker and Peng, 1986). However, concurrent changes in ocean circulation and biological productivity complicate the estimation of the impact of increased sea ice extent on LGM atmospheric $\mathrm{CO}_{2}$ (Kurahashi-Nakamura et al., 2007). With the exception of the results of an idealised box model (Stephens and Keeling, 2000), ocean carbon models are relatively consistent in projecting a small effect of higher sea ice extent on maintaining atmospheric $\mathrm{CO}_{2}$ lower during LGM (Archer et al., 2003).

\subsection{Iron fertilisation}

Both marine and terrestrial sediment records indicate higher rates of deposition of dust and hence iron (Fe) supply at the LGM (Mahowald et al., 2006), implying a potential link between Fe fertilisation of marine productivity and lower glacial $\mathrm{CO}_{2}$ (Martin, 1990). However, despite the fact that ocean carbon cycle models generally employ similar reconstructions of glacial dust fluxes (i.e., Mahowald et al., 1999; Mahowald et al., 2006), there is considerable disagreement among them in the associated $\mathrm{CO}_{2}$ change. OGCM that include a description of the Fe cycle tend to cluster at the lower end of simulated $\mathrm{CO}_{2}$ changes between glacial and interglacial (e.g., Archer at al., 2000; Bopp et al., 2003), whereas box models (e.g., Watson et al., 2000) or Earth System Models of Intermediate Complexity (EMICs, e.g., Brovkin et al., 2007) tend to produce $\mathrm{CO}_{2}$ changes which are at the higher end (Parekh et al., 2008). An alternative view comes from inferences drawn from the timing and magnitude of changes in dust and $\mathrm{CO}_{2}$ in ice cores (Röthlisberger et al., 2004), assigning a 20 ppm limit for the lowering of $\mathrm{CO}_{2}$ during the LGM in response to an Southern Ocean Fe fertilisation effect, and a 8 ppm limit for the same effect in the North Pacific.

\subsection{Other glacial carbon dioxide drivers}

A number of further aspects of altered climate and biogeochemistry at the LGM are also likely to have affected atmospheric $\mathrm{CO}_{2}$. Reduced bacterial metabolic rates and remineralization (see Glossary) of organic matter (Matsumoto, 2007; Menviel et al., 2012), increased glacial supply of dissolved silica (required by diatoms to form frustules) (Harrison, 2000), 'silica leakage' (Brzezinski et al., 2002; Matsumoto et al., 2002), changes in net global weathering rates (Berner, 1992; Munhoven, 2002), reduction in coral reef growth and other forms of shallow water $\mathrm{CaCO}_{3}$ accumulation (Berger, 1982), carbonate compensation (Ridgwell and Zeebe, 2005) and changes in the $\mathrm{CaCO}_{3}$ to organic matter 'rain ratio' to the sediments (Archer and Maier-Reimer, 1994) will act to amplify or diminish the effect of many of the aforementioned drivers on glacial $\mathrm{CO}_{2}$.

\subsection{Summary}

All of the major drivers of the glacial-to-interglacial atmospheric $\mathrm{CO}_{2}$ changes (Figure 6.5) are likely to have already been identified. However, Earth System Models have been unable to reproduce the full magnitude of the glacial-to-interglacial $\mathrm{CO}_{2}$ changes. Significant uncertainties exist in glacial boundary conditions and on some of the primary controls on carbon storage in the ocean and in the land. These uncertainties prevent an unambiguous attribution of individual mechanisms as controllers of the low glacial $\mathrm{CO}_{2}$ concentrations. Further assessments of the interplay of different mechanisms prior to deglacial transitions or in glacial inceptions will provide additional insights into the drivers and processes that caused the glacial decrease of $\mathrm{CO}_{2}$. Because several of these identified drivers (e.g., organic matter remineralization, ocean stratification) are sensitive to climate change in general, improved understanding drawn from the glacial-interglacial cycles will help constrain the magnitude of future ocean feedbacks on atmospheric $\mathrm{CO}_{2}$. Other drivers (e.g., iron fertilisation) are involved in geoengineering methods (see Glossary), such that improved under- 
Glacial to Interglacial

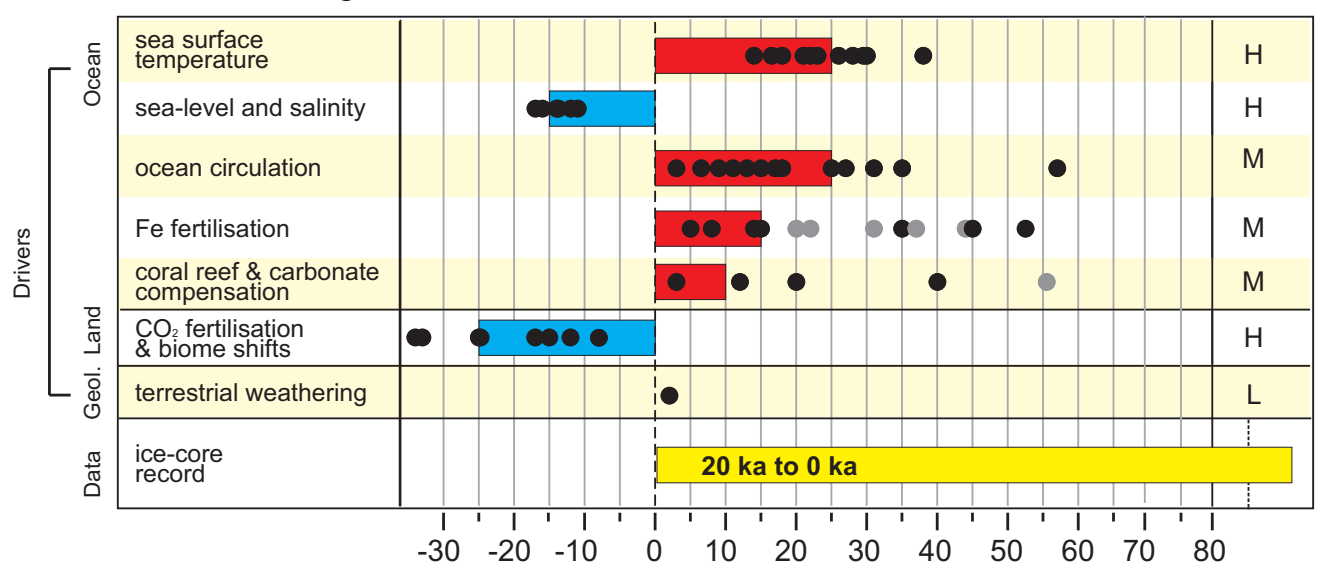

Holocene

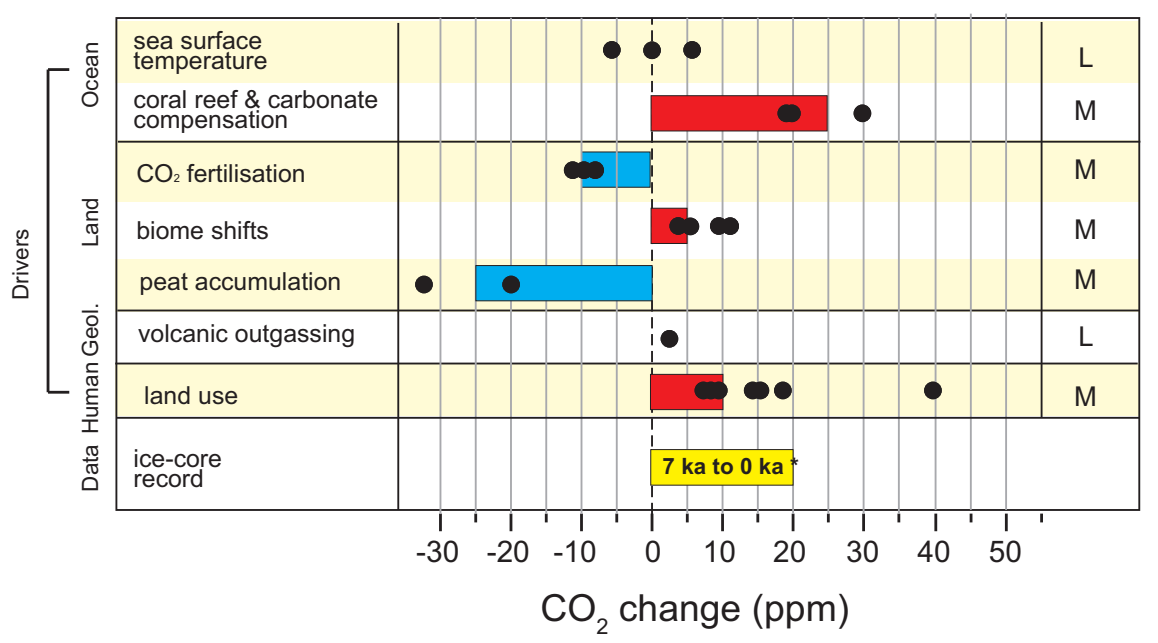

Figure 6.5 Mechanisms contributing to carbon dioxide concentrations changes from Last Glacial Maximum (LGM) to late Holocene (top) and from early/mid Holocene (7 ka) to late Holocene (bottom). Filled black circles represent individual model-based estimates for individual ocean, land, geological or human mechanisms. Solid colour bars represent expert judgment (to the nearest $5 \mathrm{ppm}$ ) rather than a formal statistical average. References for the different model results used for explaining $\mathrm{CO}_{2}$ changes from $\mathrm{LGM}$ to late Holocene are as per (Kohfeld and Ridgwell, 2009) with excluded model projections in grey. References for the different model results used for explaining $\mathrm{CO}_{2}$ changes during the Holocene are: Joos et al. (2004), Brovkin et al. (2002, 2008), Kleinen et al. (2010, 2012), Broecker et al. (1999), Ridgwell et al. (2003), Schurgers et al. (2006), Yu (2011), Ruddiman (2003, 2007), Strassmann et al. (2008), Olofsson and Hickler (2008), Pongratz et al. (2009), Kaplan et al. (2011), Lemmen (2009), Stocker et al. (2011), Roth and Joos (2012). Confidence levels for each mechanism are indicated in the left column - $\mathrm{H}$ for high confidence, $\mathrm{M}$ for medium confidence and $\mathrm{L}$ for low confidence.

standing could also help constrain the potential and applicability of these methods (see Section 6.5.2).

\subsubsection{Processes Controlling Glacial Methane and Nitrous Oxide}

Ice core measurements show that atmospheric $\mathrm{CH}_{4}$ and $\mathrm{N}_{2} \mathrm{O}$ were much lower under glacial conditions compared to interglacial ones. Their reconstructed history encompasses the last 800 ka (Loulergue et al., 2008; Schilt et al., 2010a). Glacial $\mathrm{CH}_{4}$ mixing ratios are in the 350 to $400 \mathrm{ppb}$ range during the eight glacial maxima covered by the ice core record. This is about half the levels observed during interglacial conditions. The $\mathrm{N}_{2} \mathrm{O}$ concentration amounts to $202 \pm 8 \mathrm{ppb}$ at the LGM, compared to the early Holocene levels of about $270 \mathrm{ppb}$ (Flückiger et al., 1999).

$\mathrm{CH}_{4}$ and $\mathrm{N}_{2} \mathrm{O}$ isotopic ratio measurements in ice cores provide important constraints on the mechanisms responsible for their temporal changes. $\mathrm{N}_{2} \mathrm{O}$ isotopes suggest a similar increase in marine and terrestrial $\mathrm{N}_{2} \mathrm{O}$ emissions during the last deglaciation (Sowers et al., 2003). Marine sediment proxies of ocean oxygenation suggest that most of the observed $\mathrm{N}_{2} \mathrm{O}$ deglacial rise was of marine origin (Jaccard and Galbraith, 2012). $\delta \mathrm{D}$ and ${ }^{14} \mathrm{C}$ isotopic composition measurements of $\mathrm{CH}_{4}$ have shown that catastrophic methane hydrate degassing events are unlikely to have caused the last deglaciation $\mathrm{CH}_{4}$ increase (Sowers, 2006; Petrenko et al., 2009; Bock et al., 2010). $\delta^{13} C$ and $\delta D$ measurements of $\mathrm{CH}_{4}$ combined with interpolar atmospheric $\mathrm{CH}_{4}$ gradient changes (Greenland minus Antarctica ice cores) suggest that most of the deglacial $\mathrm{CH}_{4}$ increase was caused by increased emissions from boreal and tropical wetlands and an increase in $\mathrm{CH}_{4}$ atmospheric residence time due to a reduced oxidative capacity of the atmosphere (Fischer et al., 2008). The biomass burning source apparently changed little on the same time scale, whereas this $\mathrm{CH}_{4}$ source experienced large fluctuations over the last millennium (Mischler et al., 2009; Wang et al., 2010b). Recent modelling studies, however, suggest that changes 
in the atmospheric oxidising capacity of the atmosphere at the LGM are probably negligible compared to changes in sources (Levine et al., 2011) and that tropical temperature influencing tropical wetlands and global vegetation were the dominant controls for $\mathrm{CH}_{4}$ atmospheric changes on glacial-interglacial time scales (Konijnendijk et al., 2011).

\subsubsection{Processes Controlling Changes in Carbon Dioxide, Methane, and Nitrous Oxide During Abrupt Glacial Events}

Ice core measurements of $\mathrm{CO}_{2}, \mathrm{CH}_{4}$ and $\mathrm{N}_{2} \mathrm{O}$ show sharp (millennial-scale) changes in the course of glaciations, associated with the so-called Dansgaard/Oeschger (DO) climatic events (see Section 5.7), but their amplitude, shape and timing differ. During these millennial scale climate events, atmospheric $\mathrm{CO}_{2}$ concentrations varied by about $20 \mathrm{ppm}$, in phase with Antarctic, but not with Greenland temperatures. $\mathrm{CO}_{2}$ increased during cold (stadial) periods in Greenland, several thousands years before the time of the rapid warming event in Greenland (Ahn and Brook, 2008). $\mathrm{CH}_{4}$ and $\mathrm{N}_{2} \mathrm{O}$ showed rapid transitions in phase with Greenland temperatures with little or no lag. $\mathrm{CH}_{4}$ changes are in the 50 to 200 ppb range (Flückiger et al., 2004), in phase with Greenland temperature warming at a decadal time scale (Huber et al., 2006). $\mathrm{N}_{2} \mathrm{O}$ changes are large, of same magnitude than glacial-interglacial changes, and for the warmest and longest $\mathrm{DO}$ events $\mathrm{N}_{2} \mathrm{O}$ starts to increase several centuries before Greenland temperature and $\mathrm{CH}_{4}$ (Schilt et al., 2010b).
Conflicting hypotheses exist on the drivers of these millennial-scale changes. Some model simulations suggest that both $\mathrm{CO}_{2}$ and $\mathrm{N}_{2} \mathrm{O}$ fluctuations can be explained by changes in the Atlantic meridional overturning ocean circulation (Schmittner and Galbraith, 2008), $\mathrm{CO}_{2}$ variations being explained mainly by changes in the efficiency of the biological pump which affects deep ocean carbon storage (Bouttes et al., 2011), whereas $\mathrm{N}_{2} \mathrm{O}$ variations could be due to changes in productivity and oxygen concentrations in the subsurface ocean (Schmittner and Galbraith, 2008). Other studies, however, suggest that the millennial-scale $\mathrm{CO}_{2}$ fluctuations can be explained by changes in the land carbon storage (Menviel et al., 2008; Bozbiyik et al., 2011). For $\mathrm{CH}_{4}$ models have difficulties in reproducing changes in wetland emissions compatible with DO atmospheric variations (Hopcroft et al., 2011), and the changes in the atmospheric oxidizing capacity of the atmosphere during DO events seem to be too weak to explain the $\mathrm{CH}_{4}$ changes (Levine et al., 2012).

\subsubsection{Greenhouse Gas Changes over the Holocene}

\subsubsection{Understanding Processes Underlying Holocene Carbon Dioxide Changes}

The evolution of the atmospheric $\mathrm{CO}_{2}, \mathrm{CH}_{4}$, and $\mathrm{N}_{2} \mathrm{O}$ concentrations during the Holocene, the interglacial period which began $11.7 \mathrm{ka}$, is known with high certainty from ice core measurements (Figure 6.6). A decrease in atmospheric $\mathrm{CO}_{2}$ of about $7 \mathrm{ppm}$ is measured in ice cores

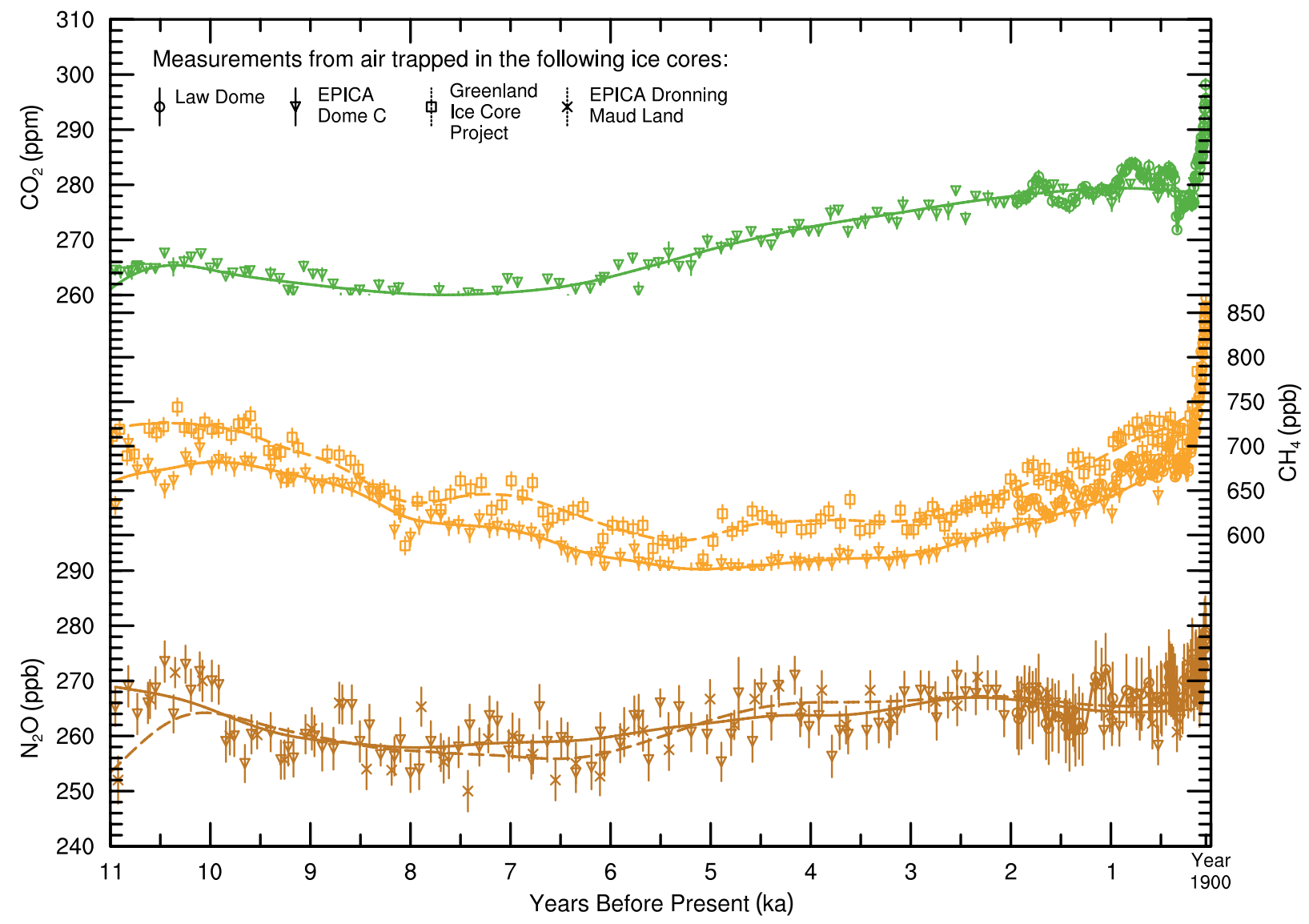

Figure 6.6 Variations of $\mathrm{CO}_{2}, \mathrm{CH}_{4}$, and $\mathrm{N}_{2} \mathrm{O}$ concentrations during the Holocene. The data are for Antarctic ice cores: European Programme for Ice Coring in Antarctica EPICA Dome C (Flückiger et al., 2002; Monnin et al., 2004), triangles; EPICA Dronning Maud Land (Schilt et al., 2010b), crosses; Law Dome (MacFarling-Meure et al., 2006), circles; and for Greenland Ice Core Project (GRIP) (Blunier et al., 1995), squares. Lines correspond to spline fits. 
between 11 and $7 \mathrm{ka}$, followed by a 20 ppm $\mathrm{CO}_{2}$ increase until the onset of the Industrial Era in 1750 (Indermühle et al., 1999; Monnin et al., 2004; Elsig et al., 2009). These variations in atmospheric $\mathrm{CO}_{2}$ over the past $11 \mathrm{kyr}$ preceding industrialisation are more than five times smaller than the $\mathrm{CO}_{2}$ increase observed during the Industrial Era (see Section 6.3.2.3). Despite the small magnitude of $\mathrm{CO}_{2}$ variations prior to the Industrial Era, these changes are nevertheless useful for understanding the role of natural forcing in carbon and other biogeochemical cycles during interglacial climate conditions.

Since the IPCC AR4, the mechanisms underlying the observed $20 \mathrm{ppm}$ $\mathrm{CO}_{2}$ increase between $7 \mathrm{ka}$ and the Industrial Era have been a matter of intensive debate. During three interglacial periods prior to the Holocene, $\mathrm{CO}_{2}$ did not increase, and this led to a hypothesis that pre-industrial anthropogenic $\mathrm{CO}_{2}$ emissions could be associated with early land use change and forest clearing (Ruddiman, 2003, 2007). However, ice core $\mathrm{CO}_{2}$ data (Siegenthaler et al., 2005b) indicate that during Marine Isotope Stage 11 (see Section 5.2.2), an interglacial period that lasted from 400 to $420 \mathrm{ka}, \mathrm{CO}_{2}$ increased similarly to the Holocene period. Drivers of atmospheric $\mathrm{CO}_{2}$ changes during the Holocene can be divided into oceanic and terrestrial processes (Figure 6.5) and their roles are examined below.

\subsection{Oceanic processes}

The change in oceanic carbonate chemistry could explain the slow atmospheric $\mathrm{CO}_{2}$ increase during the Holocene since $7 \mathrm{ka}$. Proposed mechanisms include: (1) a shift of oceanic carbonate sedimentation from deep sea to the shallow waters due to sea level rise onto continental shelves causing accumulation of $\mathrm{CaCO}_{3}$ on shelves including coral reef growth, a process that releases $\mathrm{CO}_{2}$ to the atmosphere (Ridgwell et al., 2003; Kleinen et al., 2010), (2) a 'carbonate compensation' in response to the release of carbon from the deep ocean during deglaciation and to the buildup of terrestrial biosphere in the early Holocene (Broecker et al., 1999; Joos et al., 2004; Elsig et al., 2009; Menviel and Joos, 2012). Proxies for carbonate ion concentration in the deep sea (Yu et al., 2010) and a decrease in modern $\mathrm{CaCO}_{3}$ preservation in equatorial Pacific sediments (Anderson et al., 2008) support the hypothesis that the ocean was a source of $\mathrm{CO}_{2}$ to the atmosphere during the Holocene. Changes in SSTs over the last $7 \mathrm{kyr}$ (Kim et al., 2004) could have contributed to slightly lower (Brovkin et al., 2008) or higher (Menviel and Joos, 2012) atmospheric $\mathrm{CO}_{2}$ concentration but, very likely, SST-driven $\mathrm{CO}_{2}$ change represents only a minor contribution to the observed $\mathrm{CO}_{2}$ increase during the Holocene after 7 ka (Figure 6.5).

\subsection{Terrestrial processes}

The $\delta^{13} \mathrm{C}$ of atmospheric $\mathrm{CO}_{2}$ trapped in ice cores can be used to infer changes in terrestrial biospheric carbon pools. Calculations based on inferred $\delta^{13} \mathrm{C}$ of atmospheric $\mathrm{CO}_{2}$ during the Holocene suggest an increase in terrestrial carbon storage of about $300 \mathrm{PgC}$ between 11 and $5 \mathrm{ka}$ and small overall terrestrial changes thereafter (Elsig et al., 2009). Modelling studies suggest that $\mathrm{CO}_{2}$ fertilisation (Box 6.3) in response to increasing atmospheric $\mathrm{CO}_{2}$ concentration after $7 \mathrm{ka}$ contributed to a substantially increased terrestrial carbon storage (>100 PgC) on Holocene time scales (Kaplan et al., 2002; Joos et al., 2004; Kleinen et al., 2010). Orbitally forced climate variability, includ- ing the intensification and decline of the Afro-Asian monsoon and the mid-Holocene warming of the high latitudes of the $\mathrm{NH}$ are estimated in models to have caused changes in vegetation distribution and hence of terrestrial carbon storage. These climate-induced carbon storage changes are estimated using models to have been smaller than the increase due to $\mathrm{CO}_{2}$ fertilisation (Brovkin et al., 2002; Schurgers et al., 2006). The Holocene accumulation of carbon in peatlands has been reconstructed globally, suggesting a land carbon additional storage of several hundred petagrams of carbon between the early Holocene and the Industrial Era, although uncertainties remain on this estimate (Tarnocai et al., 2009; Yu, 2011; Kleinen et al., 2012). Volcanic $\mathrm{CO}_{2}$ emissions to the atmosphere between 12 and 7 ka were estimated to be two to six times higher than during the last millennium, of about 0.1

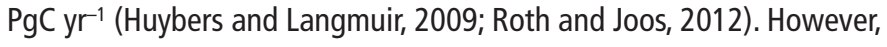
a peak in the inferred volcanic emissions coincides with the period of decreasing atmospheric $\mathrm{CO}_{2}$ and the confidence in changes of volcanic $\mathrm{CO}_{2}$ emissions is low.

Global syntheses of the observational, paleoecological and archaeological records for Holocene land use change are not currently available (Gaillard et al., 2010). Available reconstructions of anthropogenic land use and land cover change (LULCC) prior to the last millennium currently extrapolate using models and assumptions from single regions to changes in all regions of the world (Goldewijk et al., 2011; Kaplan et al., 2011). Because of regional differences in land use systems and uncertainty in historical population estimates, the confidence in spatially explicit LULCC reconstructions is low.

Some recent studies focused on reconstructing LULCC and making very simple assumptions regarding the effect of land use on carbon (Olofsson and Hickler, 2008; Lemmen, 2009). Other studies relied on more sophisticated terrestrial biosphere models to simulate carbon storage and loss in response to pre-industrial LULCC during the late Holocene (Strassmann et al., 2008; Pongratz et al., 2009; Stocker et al., 2011). The conclusion of the aforementioned studies was that cumulative Holocene carbon emissions as a result of pre-industrial LULCC were not large enough ( 50 to $150 \mathrm{PgC}$ during the Holocene before 1850) to have had an influence larger than an increase of $\sim 10 \mathrm{ppm}$ on late Holocene observed $\mathrm{CO}_{2}$ concentration increase (Figure 6.5). However, a modelling study by Kaplan et al. (2011) suggested that more than 350 $\mathrm{PgC}$ could have been released as a result of LULCC between $8 \mathrm{ka}$ and 1850 as a result of a much stronger loss of soil carbon in response to land use change, than in other studies.

In addition to clearing of forests, large-scale biomass burning activity, inferred from synthesized charcoal records and bog sediments has been hypothesized to correlate with the observed Late Holocene atmospheric $\mathrm{CO}_{2}$ (Carcaillet et al., 2002). A global extensive synthesis of charcoal records for the last $21 \mathrm{kyr}$ (Power et al., 2008) and updates of those shows that fire activity followed climate variability on global (Marlon et al., 2008; Daniau et al., 2012) and regional scale (Archibald et al., 2009; Mooney et al., 2011; Marlon et al., 2012; Power et al., 2013). There is no evidence, however, for a distinct change in fire activity linked to human activity alone as hypothesized from a regional charcoal record synthesis for the tropical Americas (Nevle and Bird, 2008; Nevle et al., 2011). Fire being a newly studied component, no estimate for its role is given in Figure 6.5. 


\subsubsection{Holocene Methane and Nitrous Oxide Drivers}

The atmospheric $\mathrm{CH}_{4}$ levels decreased from the early Holocene to about $6 \mathrm{ka}$, were lowest at around $5 \mathrm{ka}$, and increased between $5 \mathrm{ka}$ and year 1750 by about $100 \mathrm{ppb}$ (Figure 6.6). Major Holocene agricultural developments, in particular rice paddy cultivation and widespread domestication of ruminants, have been proposed as an explanation for the Late Holocene $\mathrm{CH}_{4}$ rise (Ruddiman, 2007). The most recent syntheses of archaeological data point to an increasing anthropogenic $\mathrm{CH}_{4}$ source from domesticated ruminants after $5 \mathrm{ka}$ and from rice cultivation after 4 ka (Ruddiman, 2007; Fuller et al., 2011). The modelling support for either natural or anthropogenic explanations of the Late Holocene increase in the atmospheric $\mathrm{CH}_{4}$ concentration is equivocal. A study by Kaplan et al. (2006) suggested that a part of the Late Holocene $\mathrm{CH}_{4}$ rise could be explained by anthropogenic sources. Natural wetland $\mathrm{CH}_{4}$ models driven by simulated climate changes are able (Singarayer et al., 2011) or unable (Konijnendijk et al., 2011) to simulate Late Holocene increase in the $\mathrm{CH}_{4}$ concentration, reflecting a large spread in present-day $\mathrm{CH}_{4}$ emissions simulated by this type of models (Melton et al., 2013; see Section 6.3.3.2). Consequently, about as likely as not, the atmospheric $\mathrm{CH}_{4}$ increase after 5000 years ago can be attributed to early human activities. The mechanisms causing the $\mathrm{N}_{2} \mathrm{O}$ concentration changes during the Holocene are not firmly identified (Flückiger et al., 2002).

\subsubsection{Greenhouse Gas Changes over the Last Millennium}

\subsubsection{A Decrease of Carbon Dioxide around Year 1600 and Possible Explanations for this Event}

High resolution ice cores records reveal that atmospheric $\mathrm{CO}_{2}$ during the last millennium varied with a drop in atmospheric $\mathrm{CO}_{2}$ concentration by 7 to $10 \mathrm{ppm}$ around year 1600 , followed by a $\mathrm{CO}_{2}$ increase during the 17th century (Trudinger et al., 2002; Siegenthaler et al., 2005a; MacFarling-Meure et al., 2006; Ahn et al., 2012). This is shown in Figure 6.7. The $\mathrm{CO}_{2}$ decrease during the 17 th century was used to evaluate the response of atmospheric $\mathrm{CO}_{2}$ concentration to a century-scale shift in global temperature (Scheffer et al., 2006; Cox and Jones, 2008; Frank et al., 2010) which was found to be dependent on the choice of global temperature reconstructions used in the model.

One of the possible explanations for the drop in atmospheric $\mathrm{CO}_{2}$ around year 1600 is enhanced land and/or ocean carbon uptake in response to the cooling caused by reduced solar irradiance during the Maunder Minimum (Section 5.3.5.3). However, simulations using Earth System Models of Intermediate Complexity (EMICS)(Gerber et al., 2003; Brovkin et al., 2004) and by complex Earth System Models (ESMs) (Jungclaus et al., 2010) suggest that solar irradiance forcing alone is not sufficient

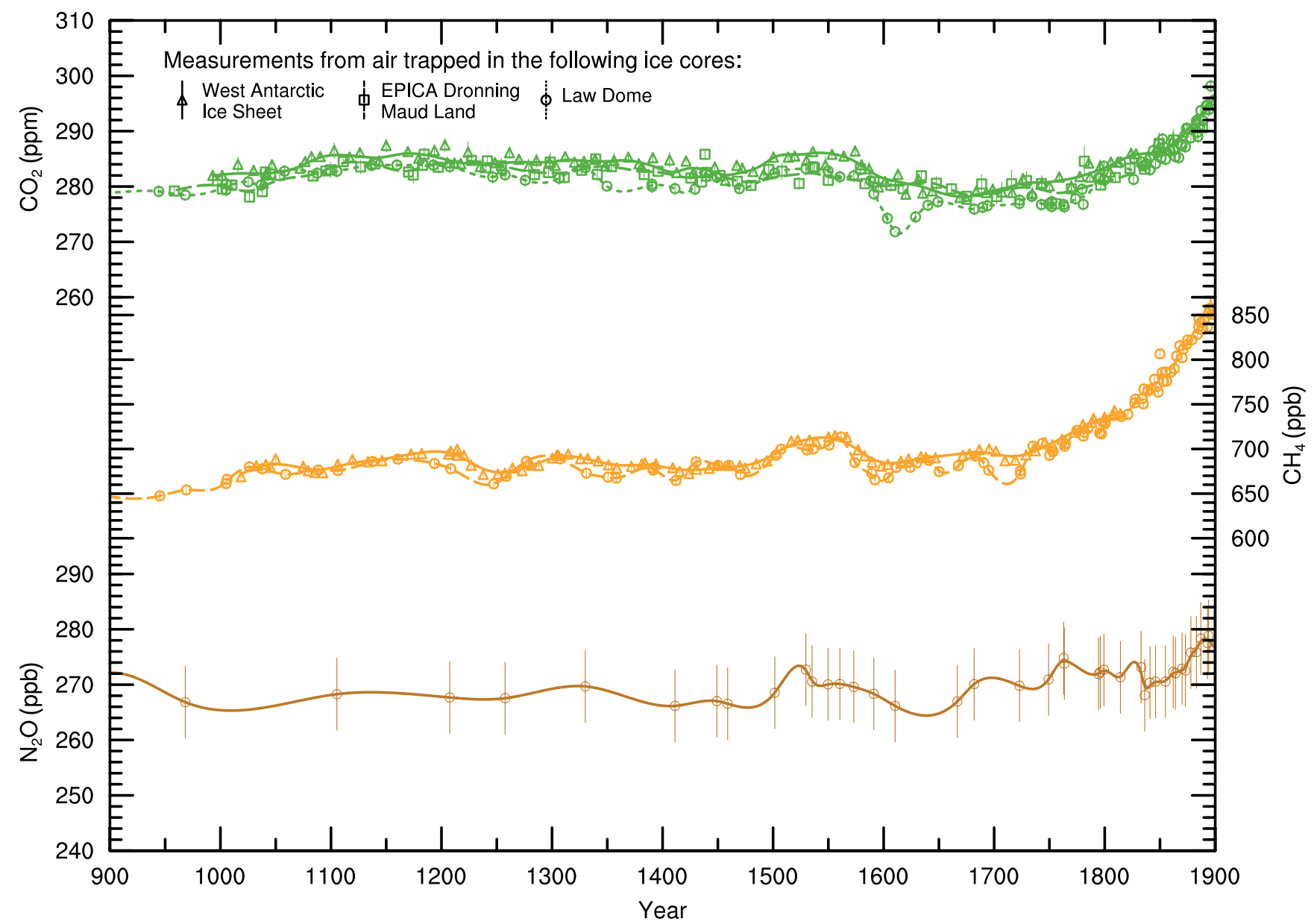

Figure 6.7 | Variations of $\mathrm{CO}_{2}, \mathrm{CH}_{4}$, and $\mathrm{N}_{2} \mathrm{O}$ during 900-1900 from ice cores. The data are for Antarctic ice cores: Law Dome (Etheridge et al., 1996; MacFarling-Meure et al., 2006), circles; West Antarctic Ice Sheet (Mitchell et al., 2011; Ahn et al., 2012), triangles; Dronning Maud Land (Siegenthaler et al., 2005a), squares. Lines are spline fits to individual measurements. 
to explain the magnitude of the $\mathrm{CO}_{2}$ decrease. The drop in atmospheric $\mathrm{CO}_{2}$ around year 1600 could also be caused by a cooling from increased volcanic eruptions (Jones and Cox, 2001; Brovkin et al., 2010; Frölicher et al., 2011). A third hypothesis calls for a link between $\mathrm{CO}_{2}$ and epidemics and wars associated with forest regrowth over abandoned lands and increased carbon storage, especially in Central America. Here, results are model and scenario dependent. Simulations by Pongratz et al. (2011a) do not reproduce a decrease in $\mathrm{CO}_{2}$, while simulations by Kaplan et al. (2011) suggest a considerable increase in land carbon storage around year 1600. The temporal resolution of Central American charcoal and pollen records is insufficient to support or falsify these model results (e.g., Nevle and Bird, 2008; Marlon et al., 2008).

Ensemble simulations over the last 1200 years have been conducted using an ESM (Jungclaus et al., 2010) and EMICs (Eby et al., 2013) including a fully interactive carbon cycle. The sensitivity of atmospheric $\mathrm{CO}_{2}$ concentration to $\mathrm{NH}$ temperature changes in ESM was modeled to be of 2.7 to $4.4 \mathrm{ppm}^{\circ} \mathrm{C}^{-1}$, while EMICs show on average a higher sensitivity of atmospheric $\mathrm{CO}_{2}$ to global temperature changes of $8.6 \mathrm{ppm}$ ${ }^{\circ} \mathrm{C}^{-1}$. These sensitivities fall within the range of 1.7 to $21.4 \mathrm{ppm}{ }^{\circ} \mathrm{C}^{-1}$ of a recent reconstruction based on tree-ring $\mathrm{NH}$ temperature reconstructions (Frank et al., 2010).

\subsubsection{Mechanisms Controlling Methane and Nitrous Oxide during the Last Millennium}

Recent high-resolution ice core records confirm a $\mathrm{CH}_{4}$ decrease in the late 16th century by about $40 \mathrm{ppb}$ (MacFarling-Meure et al., 2006; Mitchell et al., 2011), as shown in Figure 6.7. Correlations between this drop in atmospheric $\mathrm{CH}_{4}$ and the lower temperatures reconstructed during the 15th and 16th centuries suggest that climate change may have reduced $\mathrm{CH}_{4}$ emissions by wetlands during this period. In addition to changes in the wetland $\mathrm{CH}_{4}$ source, changes in biomass burning have been invoked to explain the last millennium $\mathrm{CH}_{4}$ record (Ferretti et al., 2005; Mischler et al., 2009), ice core CO and CO isotopes (Wang et al., 2010b) and global charcoal depositions (Marlon et al., 2008). Changes in anthropogenic $\mathrm{CH}_{4}$ emissions during times of war and plague hypothetically contributed to variability in atmospheric $\mathrm{CH}_{4}$ concentration (Mitchell et al., 2011). Ice core $\delta^{13} \mathrm{CH}_{4}$ measurements suggested pronounced variability in both natural and anthropogenic $\mathrm{CH}_{4}$ sources over the 1000-1800 period (Sapart et al., 2012). No studies are known about mechanisms of $\mathrm{N}_{2} \mathrm{O}$ changes for the last millennium.

\subsection{Evolution of Biogeochemical Cycles Since the Industrial Revolution}

\subsubsection{Carbon Dioxide Emissions and Their Fate Since 1750}

Prior to the Industrial Era, that began in 1750, the concentration of atmospheric $\mathrm{CO}_{2}$ fluctuated roughly between $180 \mathrm{ppm}$ and $290 \mathrm{ppm}$ for at least 2.1 Myr (see Section 5.2.2 and Hönisch et al., 2009; Lüthi et al., 2008; Petit et al., 1999). Between 1750 and 2011, the combustion of fossil fuels (coal, gas, oil and gas flaring) and the production of cement have released $375 \pm 30 \mathrm{PgC}\left(1 \mathrm{PgC}=10^{15} \mathrm{gC}\right)$ to the atmosphere (Table 6. 1; Boden et al., 2011). Land use change activities, mainly deforestation, has released an additional $180 \pm 80 \mathrm{PgC}$ (Table 6.1). This carbon released by human activities is called anthropogenic carbon.

Of the $555 \pm 85$ PgC of anthropogenic carbon emitted to the atmosphere from fossil fuel and cement and land use change, less than half have accumulated in the atmosphere $(240 \pm 10 \mathrm{PgC}$ (Table 6.1). The remaining anthropogenic carbon has been absorbed by the ocean and

Table 6.1 | Global anthropogenic $\mathrm{CO}_{2}$ budget, accumulated since the Industrial Revolution (onset in 1750) and averaged over the 1980s, 1990s, 2000s, as well as the last 10 years until 2011. By convention, a negative ocean or land to atmosphere $\mathrm{CO}_{2}$ flux is equivalent to a gain of carbon by these reservoirs. The table does not include natural exchanges (e.g., rivers, weathering) between reservoirs. The uncertainty range of $90 \%$ confidence interval presented here differs from how uncertainties were reported in AR4 (68\%).

\begin{tabular}{|c|c|c|c|c|c|}
\hline & $\begin{array}{c}\text { 1750-2011 } \\
\text { Cumulative } \\
\text { PgC }\end{array}$ & $\begin{array}{c}1980-1989 \\
\mathrm{PgC} \mathrm{yr}^{-1}\end{array}$ & $\begin{array}{c}1990-1999 \\
\mathrm{PgC} \mathrm{yr}^{-1}\end{array}$ & $\begin{array}{c}2000-2009 \\
\mathrm{PgC} \mathrm{yr}^{-1}\end{array}$ & $\begin{array}{c}2002-2011 \\
\mathrm{PgC} \mathrm{yr}\end{array}$ \\
\hline Atmospheric increase $\mathrm{a}^{\mathrm{a}}$ & $240 \pm 10^{f}$ & $3.4 \pm 0.2$ & $3.1 \pm 0.2$ & $4.0 \pm 0.2$ & $4.3 \pm 0.2$ \\
\hline Ocean-to-atmosphere flux & $-155 \pm 30^{f}$ & $-2.0 \pm 0.7$ & $-2.2 \pm 0.7$ & $-2.3 \pm 0.7$ & $-2.4 \pm 0.7$ \\
\hline $\begin{array}{l}\text { Land-to-atmosphere flux } \\
\text { Partitioned as follows }\end{array}$ & $30 \pm 45^{f}$ & $-0.1 \pm 0.8$ & $-1.1 \pm 0.9$ & $-1.5 \pm 0.9$ & $-1.6 \pm 1.0$ \\
\hline Residual land sinke & $-160 \pm 90^{f}$ & $-1.5 \pm 1.1$ & $-2.6 \pm 1.2$ & $-2.6 \pm 1.2$ & $-2.5 \pm 1.3$ \\
\hline
\end{tabular}

Notes:

a Data from Charles D. Keeling, (http://scrippsco2.ucsd.edu/data/data.html), Thomas Conway and Pieter Tans, National Oceanic and Atmospheric Administration-Earth System Research Laboratory (NOAA-ESRL, www.esrl.noaa.gov/gmd/ccgg/trends/) using a conversion factor of 2.120 PgC per ppm (Prather et al., 2012). Prior to the atmospheric record in 1960, ice core data is used (Neftel et al., 1982; Friedli et al., 1986; Etheridge et al., 1996).

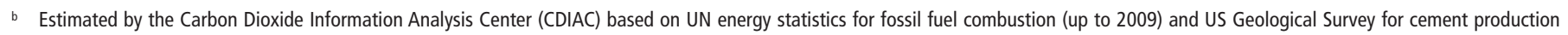
(Boden et al., 2011), and updated to 2011 using BP energy statistics.

Based on observations for 1990-1999, with the trends based on existing global estimates (see Section 6.3.2.5 and Table 6.4).

d Based on the "bookkeeping" land use change flux accounting model of Houghton et al. (2012) until 2010, and assuming constant LUC emissions for 2011, consistent with satellite-based fire emissions (Le Quéré et al., 2013; see Section 6.3.2.2 and Table 6.2).

e Calculated as the sum of the Land-to-atmosphere flux minus Net land use change flux, assuming the errors on each term are independent and added quadratically.

The 1750-2011 estimate and its uncertainty is rounded to the nearest $5 \mathrm{PgC}$.

$g$ Estimated from the cumulative net land use change emissions of Houghton et al. (2012) during 1850-2011 and the average of four publications (Pongratz at al., 2009; van Minnen et al., 2009; Shevliakova et al., 2009; Zaehle et al., 2011) during 1750-1850. 
in terrestrial ecosystems: the carbon 'sinks' (Figure 6.8). The ocean stored $155 \pm 30 \mathrm{PgC}$ of anthropogenic carbon since 1750 (see Section 6.3.2.5.3 and Box 6.1). Terrestrial ecosystems that have not been affected by land use change since 1750, have accumulated $160 \pm 90$ $\mathrm{PgC}$ of anthropogenic carbon since 1750 (Table 6.1), thus not fully compensating the net $\mathrm{CO}_{2}$ losses from terrestrial ecosystems to the atmosphere from land use change during the same period estimated of $180 \pm 80 \mathrm{PgC}$ (Table 6.1). The net balance of all terrestrial ecosys- tems, those affected by land use change and the others, is thus close to neutral since 1750, with an average loss of $30 \pm 45$ (see Figure 6.1). This increased storage in terrestrial ecosystems not affected by land use change is likely to be caused by enhanced photosynthesis at higher $\mathrm{CO}_{2}$ levels and nitrogen deposition, and changes in climate favouring carbon sinks such as longer growing seasons in mid-to-high latitudes. Forest area expansion and increased biomass density of forests that result from changes in land use change are also carbon sinks, and they
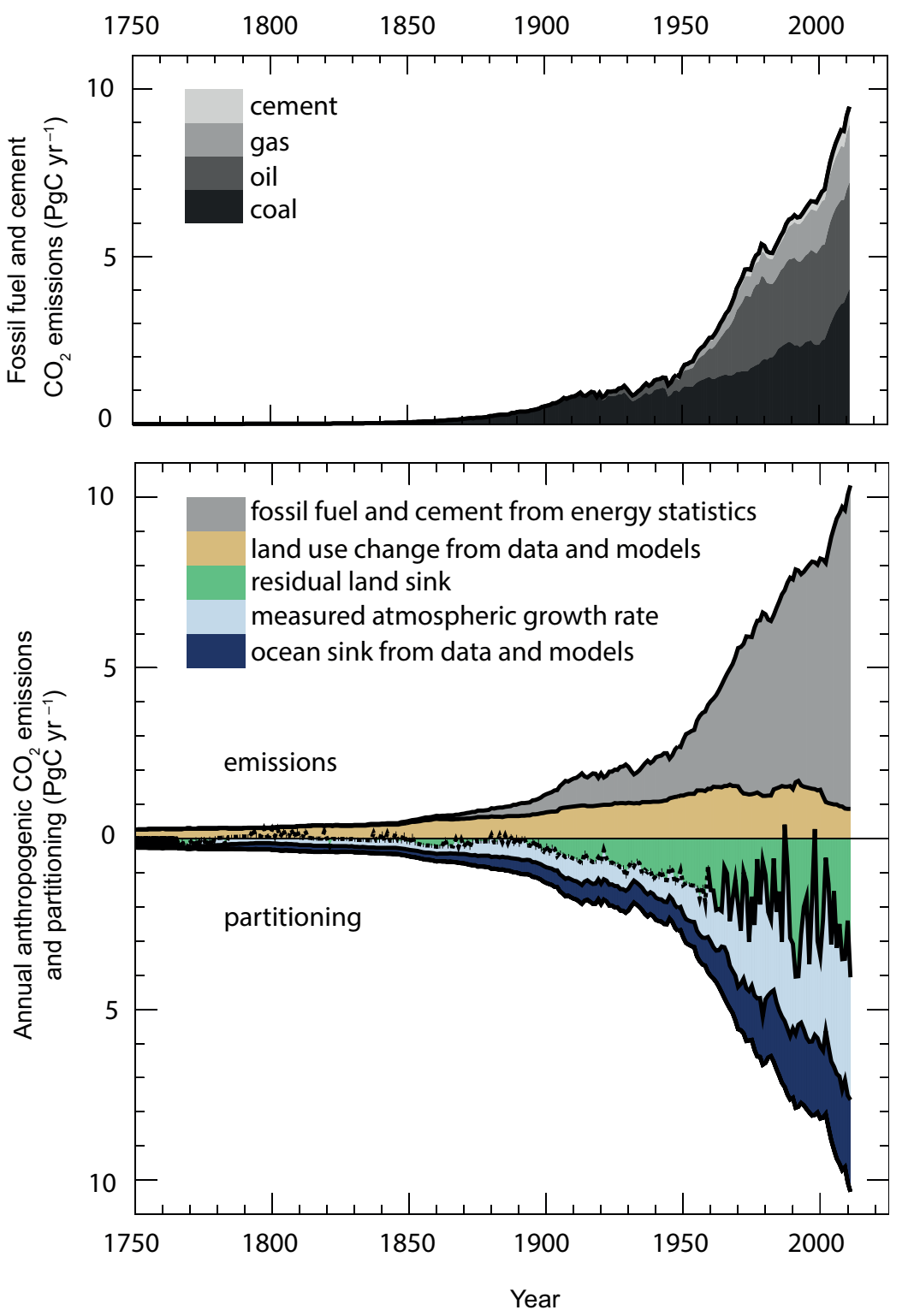

Figure 6.8 Annual anthropogenic $\mathrm{CO}_{2}$ emissions and their partitioning among the atmosphere, land and ocean ( $\mathrm{PgC} \mathrm{yr}^{-1}$ ) from 1750 to 2011. (Top) Fossil fuel and cement $\mathrm{CO}_{2}$ emissions by category, estimated by the Carbon Dioxide Information Analysis Center (CDIAC) based on UN energy statistics for fossil fuel combustion and US Geological Survey for cement production (Boden et al., 2011). (Bottom) Fossil fuel and cement $\mathrm{CO}_{2}$ emissions as above. $\mathrm{CO}_{2}$ emissions from net land use change, mainly deforestation, are based on land cover change data and estimated for 1750-1850 from the average of four models (Pongratz et al., 2009; Shevliakova et al., 2009; van Minnen et al., 2009; Zaehle et al., 2011) before 1850 and from Houghton et al. (2012) after 1850 (see Table 6.2). The atmospheric $\mathrm{CO}_{2}$ growth rate (term in light blue 'atmosphere from measurements' in the figure) prior to 1959 is based on a spline fit to ice core observations (Neftel et al., 1982; Friedli et al., 1986; Etheridge et al., 1996) and a synthesis of atmospheric measurements from 1959 (Ballantyne et al., 2012). The fit to ice core observations does not capture the large interannual variability in atmospheric $\mathrm{CO}_{2}$ and is represented with a dashed line. The ocean $\mathrm{CO}_{2}$ sink prior to 1959 (term in dark blue 'ocean from indirect observations and models' in the figure) is from Khatiwala et al. (2009) and from a combination of models and observations from 1959 from (Le Quére et al., 2013). The residual land sink (term in green in the figure) is computed from the residual of the other terms, and represents the sink of anthropogenic $\mathrm{CO}_{2}$ in natural land ecosystems. The emissions and their partitioning only include the fluxes that have changed since 1750 , and not the natural $\mathrm{CO}_{2}$ fluxes (e.g., atmospheric $\mathrm{CO}_{2}$ uptake from weathering, outgassing of $\mathrm{CO}_{2}$ from lakes and rivers, and outgassing of $\mathrm{CO}_{2}$ by the ocean from carbon delivered by rivers; see Figure 6.1) between the atmosphere, land and ocean reservoirs that existed before that time and still exist today. The uncertainties in the various terms are discussed in the text and reported in Table 6.1 for decadal mean values. 
are accounted in Table 6.1 as part of the net flux from land use change. The increased terrestrial carbon storage in ecosystems not affected by land use change is called the Residual land sink in Table 6.1 because it is inferred from mass balance as the difference between fossil and net land use change emissions and measured atmospheric and oceanic storage increase.

\subsubsection{Global Carbon Dioxide Budget}

Since the IPCC AR4 (Denman et al., 2007), a number of new advancements in data availability and data-model synthesis have allowed the establishment of a more constrained anthropogenic $\mathrm{CO}_{2}$ budget and better attribution of its flux components. The advancements are: (1) revised data on the rates of land use change conversion from country statistics (FAO, 2010) now providing an arguably more robust estimate of the land use change flux (Houghton et al., 2012; Section 6.3.2.2); (2) a new global compilation of forest inventory data that provides an independent estimate of the amount of carbon that has been gained by forests over the past two decades, albeit with very scarce measurements for tropical forest (Pan et al., 2011); (3) over 2 million new observations of the partial pressure of $\mathrm{CO}_{2}\left(\mathrm{pCO}_{2}\right)$ at the ocean surface have been taken and added to the global databases (Takahashi et al., 2009; Pfeil et al., 2013) and used to quantify ocean $\mathrm{CO}_{2}$ sink variability and trends (Section 6.3.2.5) and to evaluate and constrain models (Schuster et al., 2013; Wanninkhof et al., 2013); and (4) the use of multiple constraints with atmospheric inversions and combined atmosphere-ocean
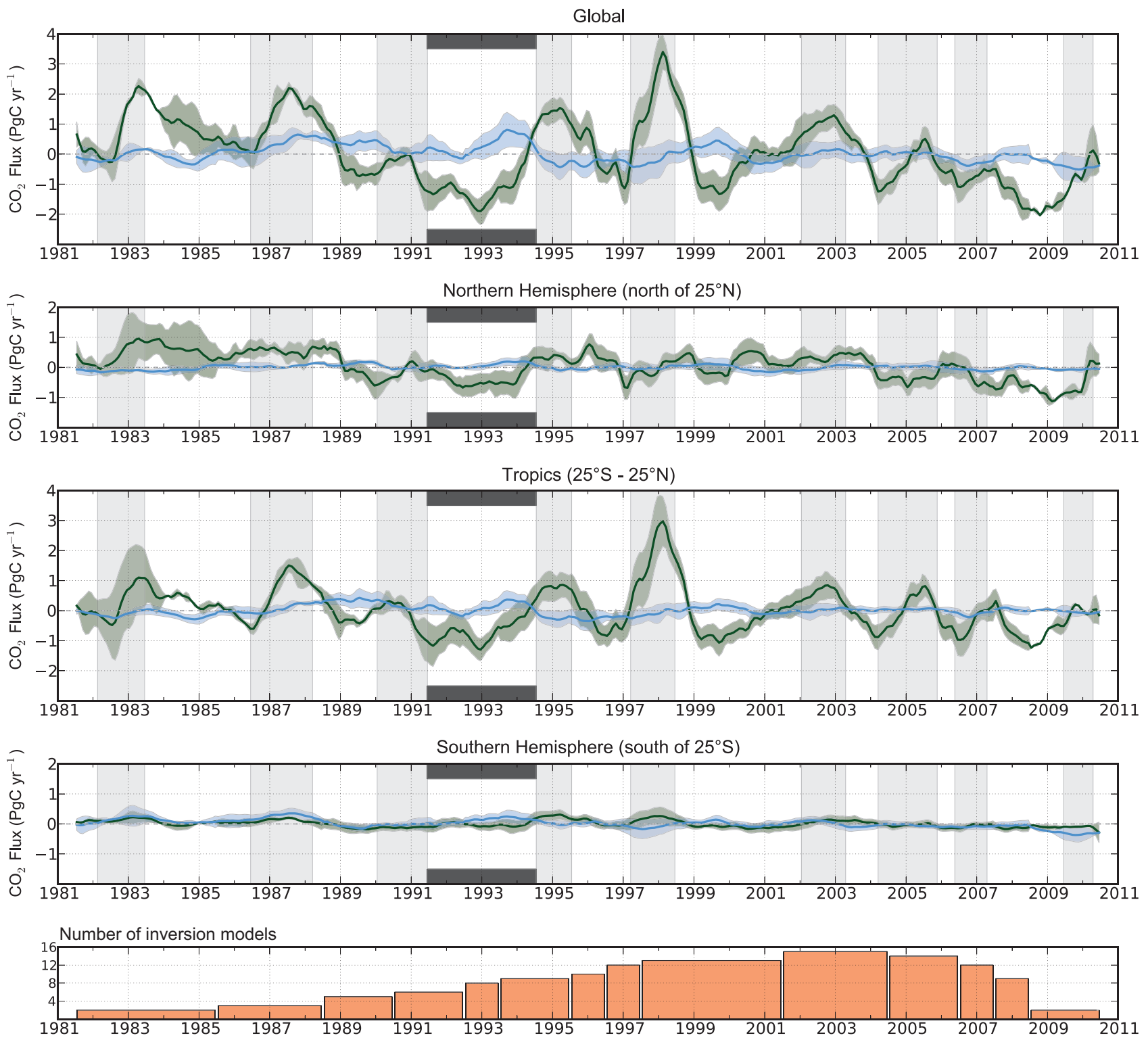

Figure 6.9 | Interannual surface $\mathrm{CO}_{2}$ flux anomalies from inversions of the TRANSCOM project for the period 1981-2010 (Peylin et al., 2013). The ensemble of inversion results contains up to 17 atmospheric inversion models. The orange bars in the bottom panel indicate the number of available inversion models for each time period. The ensemble mean is bounded by the 1- $\sigma$ inter-model spread in ocean-atmosphere (blue) and land-atmosphere (green) $\mathrm{CO}_{2}$ fluxes $\left(\mathrm{PgC}\right.$ yr ${ }^{-1}$ ) grouped into large latitude bands, and the global. For each flux and each region, the $\mathrm{CO}_{2}$ flux anomalies were obtained by subtracting the long-term mean flux from each inversion and removing the seasonal signal. Grey shaded regions indicate El Niño episodes, and the black bars indicate the cooling period following the Mt. Pinatubo eruption, during which the growth rate of $\mathrm{CO}_{2}$ remained low. A positive flux means a larger than normal source of $\mathrm{CO}_{2}$ to the atmosphere (or a smaller $\mathrm{CO}_{2}$ sink). 
inversions (so called top down approaches; Jacobson et al., 2007) and the up-scaling of reservoir-based observations using models (so called bottom up approaches) provides new coarse scale consistency checks on $\mathrm{CO}_{2}$ flux estimates for land and ocean regions (McGuire et al., 2009; Piao et al., 2009b; Schulze et al., 2009; Ciais et al., 2010; Schuster et al., 2013). The causes of the year-to-year variability observed in the annual atmospheric $\mathrm{CO}_{2}$ accumulation shown in Figure 6.8 are estimated with a medium to high confidence to be mainly driven by terrestrial processes occurring in tropical latitudes as inferred from atmospheric $\mathrm{CO}_{2}$ inversions and supported by ocean data and models (Bousquet et al., 2000; Raupach et al., 2008; Sarmiento et al., 2010) (Figures 6.9 and 6.13; Section 6.3.2.5) and land models (Figure 6.16; Section 6.3.2.6).

\subsubsection{Carbon Dioxide Emissions from Fossil Fuel Combustion and Cement Production}

Global $\mathrm{CO}_{2}$ emissions from the combustion of fossil fuels used for this chapter are determined from national energy consumption statistics and converted to emissions by fuel type (Marland and Rotty, 1984). Estimated uncertainty for the annual global emissions are on the order of $\pm 8 \%$ (converted from $\pm 10 \%$ uncertainty for $95 \%$ confidence intervals in Andres et al. (2012) to the $90 \%$ confidence intervals used here). The uncertainty has been increasing in recent decades because a larger fraction of the global emissions originate from emerging economies where energy statistics and emission factors per fuel type are more uncertain (Gregg et al., 2008). $\mathrm{CO}_{2}$ emissions from cement production were $4 \%$ of the total emissions during 2000-2009, compared to $3 \%$ in the 1990s (Boden et al., 2011). Additional emissions from gas flaring represent $<1 \%$ of the global emissions.

Global $\mathrm{CO}_{2}$ emissions from fossil fuel combustion and cement production were $7.8 \pm 0.6 \mathrm{PgC} \mathrm{yr}^{-1}$ on average during 2000-2009, $6.4 \pm 0.5$ $\mathrm{PgC} \mathrm{yr}^{-1}$ during 1990-1999 and 5.5 $\pm 0.4 \mathrm{PgC} \mathrm{yr}^{-1}$ during 1980-1989 (Table 6.1; Figure 6.8). Global fossil fuel $\mathrm{CO}_{2}$ emissions increased by $3.2 \% \mathrm{yr}^{-1}$ on average during the decade 2000-2009 compared to $1.0 \% \mathrm{yr}^{-1}$ in the 1990 s and $1.9 \% \mathrm{yr}^{-1}$ in the 1980 s. Francey et al. (2013) recently suggested a cumulative underestimation of $8.8 \mathrm{PgC}$ emissions during the period 1993-2004, which would reduce the contrast in emissions growth rates between the two decades. The global financial crisis in 2008-2009 induced only a short-lived drop in global emissions in $2009(-0.3 \%)$, with the return to high annual growth rates of $5.1 \%$ and $3.0 \%$ in 2010 and 2011, respectively, and fossil fuel and cement $\mathrm{CO}_{2}$ emissions of $9.2 \pm 0.8 \mathrm{PgC}$ in 2010 and $9.5 \pm 0.8 \mathrm{PgC}$ in 2011(Peters et al., 2013).

\subsubsection{Net Land Use Change Carbon Dioxide Flux}

$\mathrm{CO}_{2}$ is emitted to the atmosphere by land use and land use change activities, in particular deforestation, and taken up from the atmosphere by other land uses such as afforestation (the deliberate creation of new forests) and vegetation regrowth on abandoned lands. A critical distinction in estimating land use change is the existence of gross and net fluxes. Gross fluxes are the individual fluxes from multiple processes involved in land use change that can be either emissions to or removals from the atmosphere occurring at different time scales. For example, gross emissions include instantaneous emissions from deforestation fires and long-term emissions from the decomposition of organic carbon; and they also include the long-term $\mathrm{CO}_{2}$ uptake by forest regrowth and soil carbon storage on abandoned agricultural lands, afforestation and storage changes of wood products (Houghton et al., 2012; Mason Earles et al., 2012). The net flux of land use change is the balance among all source and sink processes involved in a given timeframe. The net flux of land use change is globally a net source to the atmosphere (Table 6.1; Figure 6.8).

Approaches to estimate global net $\mathrm{CO}_{2}$ fluxes from land use fall into three categories: (1) the 'bookkeeping' method that tracks carbon in living vegetation, dead plant material, wood products and soils with cultivation, harvesting and reforestation using country-level reports on changes in forest area and biome-averaged biomass values (Houghton, 2003); (2) process-based terrestrial ecosystem models that simulate on a grid-basis the carbon stocks (biomass, soils) and exchange fluxes between vegetation, soil and atmosphere (see references in Table 6.2) and (3) detailed regional (primarily tropical forests) analyses based on satellite data that estimate changes in forest area or biomass (DeFries et al., 2002; Achard et al., 2004; Baccini et al., 2012; Harris et al., 2012). Satellite-derived estimates of $\mathrm{CO}_{2}$ emissions to the atmosphere from so-called deforestation fires (van der Werf et al., 2010) provide additional constraints on the spatial attribution and variability of land use change gross emissions. Most global estimates do not include emissions from peat burning or decomposition after a land use change, which are estimated to be $0.12 \mathrm{PgC} \mathrm{yr}^{-1}$ over 1997-2006 for peat fires (van der Werf et al., 2008) and between 0.10 and $0.23 \mathrm{PgC} \mathrm{yr}^{-1}$ from the decomposition of drained peat (Hooijer et al., 2010). The processes and time scales captured by these methods to estimate net land use change $\mathrm{CO}_{2}$ emissions are diverse, creating difficulties with comparison of different estimates (Houghton et al., 2012; Table 6.2). The bookkeeping method of Houghton et al. (2012) was used for Table 6.1 because it is closest to observations and includes the most extensive set of management practices (Table 6.2). Methods that do not include long-term 'legacy' fluxes from soils caused by deforestation (Table 6.2) underestimate net land use change $\mathrm{CO}_{2}$ emissions by 13 to $62 \%$ depending on the starting year and decade (Ramankutty et al., 2006), and methods that do not include the fate of carbon wood harvest and shifting cultivation underestimate $\mathrm{CO}_{2}$ emissions by 25 to $35 \%$ (Houghton et al., 2012).

Global net $\mathrm{CO}_{2}$ emissions from land use change are estimated at 1.4, 1.5 and $1.1 \mathrm{PgC} \mathrm{yr}^{-1}$ for the $1980 \mathrm{~s}, 1990 \mathrm{~s}$ and 2000 s, respectively, by the bookkeeping method of Houghton et al. (2012) (Table 6.2; Figure 6.10). This estimate is consistent with global emissions simulated by process-based terrestrial ecosystem models using mainly three land cover change data products as input for time-varying maps of land use change (Table 6.2). The bookkeeping method estimate is also generally consistent although higher than the satellite-based methods (tropics only). Part of the discrepancy can be accounted for by emissions from extratropical regions ( 0.1 PgC $\mathrm{yr}^{-1}$; Table 6.3) and by legacy fluxes for land cover change prior to $1980 \mathrm{~s}\left(\sim 0.2 \mathrm{PgC} \mathrm{yr}^{-1}\right)$ that are not covered by satellite-based methods used in Table 6.2, and by the fact that the bookkeeping method accounts for degradation and shifting agriculture $\mathrm{CO}_{2}$ losses not detected in the satellite-based method reported in Table

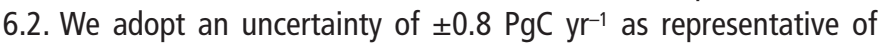
$90 \%$ uncertainty intervals. This is identical to the uncertainty of \pm 0.5 $\mathrm{PgC} \mathrm{yr}^{-1}$ representing $\pm 1-\sigma$ interval (68\% if Gaussian distributed error) 
from Houghton et al. (2012). This uncertainty of $\pm 0.8 \mathrm{PgC} \mathrm{yr}^{-1}$ on net land use change $\mathrm{CO}_{2}$ fluxes is smaller than the one that was reported in AR4 of 0.5 to $2.7 \mathrm{PgC} \mathrm{yr}^{-1}$ for the $1990 \mathrm{~s}$ ( $68 \%$ confidence interval). In this chapter, uncertainty is estimated based on expert judgment of the available evidence, including improved accuracy of land cover change incorporating satellite data, the larger number of independent methods to quantify emissions and the consistency of the reported results (Table 6.2; Figure 6.10).
Different estimates of net land use change $\mathrm{CO}_{2}$ emissions are shown in Figure 6.10. The lower net land use change $\mathrm{CO}_{2}$ emissions reported in the 2000s compared to the $1990 \mathrm{~s}$, by $0.5 \mathrm{PgC} \mathrm{yr}^{-1}$ in the bookkeeping method based on FAO (2010), and by 0.3 to $0.5 \mathrm{PgC} \mathrm{yr}^{-1}$ from five process-based ecosystem models based on the HistorY Database of the global Environment (HYDE) land cover change data updated to 2009 (Goldewijk et al., 2011), are within the error bar of the data and methods. The bookkeeping method suggests that most of the LUC emissions

Table 6.2 | Estimates of net land to atmosphere $\mathrm{CO}_{2}$ flux from land use change covering recent decades $\left(\mathrm{PgC}\right.$ yr-1). Positive values indicate $\mathrm{CO}_{2}$ losses to the atmosphere. Various forms of land management are also included in the different estimates, including wood harvest (W), shifting cultivation (C) and harvesting (H) of crops and peat burning and peat drainage (P). All methods include the vegetation degradation after land clearance. Additional processes included are initial biomass loss during the year of deforestation (I), decomposition of slash and soil carbon during the year of initial loss $(\mathrm{D})$, regrowth $(\mathrm{R})$, change in storage in wood products pools $(\mathrm{S})$, the effect of increasing $\mathrm{CO}_{2},(\mathrm{C})$, the effect of observed climate variability between decades (M) and 'legacy' long-term decomposition flux carried over from land use change transitions prior to start of time period used for reporting in the table (L). In the absence of data on $\mathrm{L}$ in the assessed estimates, the studies have either assumed instantaneous loss of all biomass and soil carbon (I, a committed future flux) or did not consider the legacy flux L. Satellite-based methods have examined Land Use Change (LUC) emissions in the tropical regions only. Numbers in parentheses are ranges in uncertainty provided in some studies.

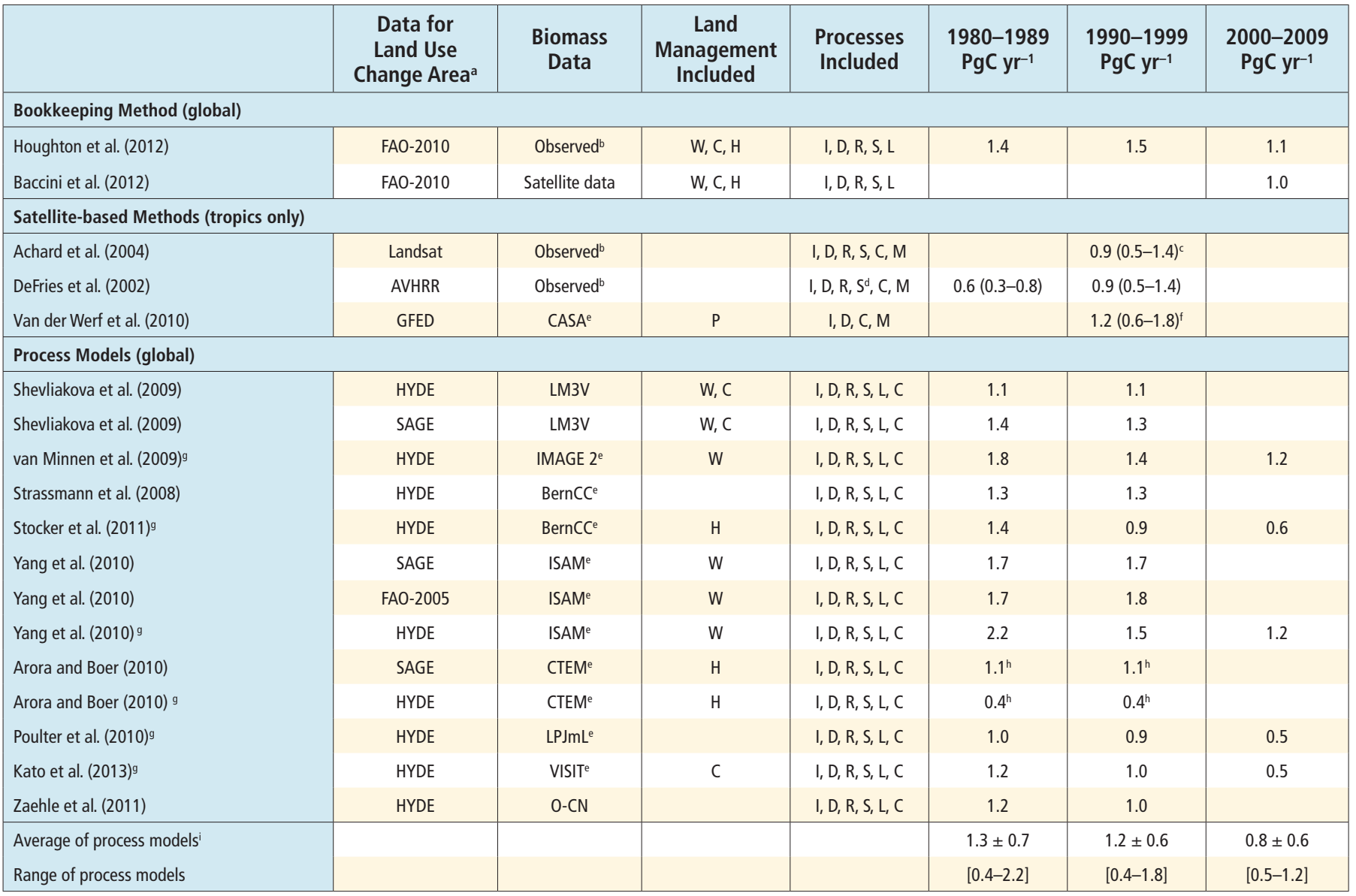

Notes:

References for the databases used: FAO (2010) as applied in Houghton et al. (2012); FAO (2005) as applied in Houghton (2003), updated; GFED (van der Werf et al., 2009); HYDE (Goldewijk et al., 2011), SAGE (Ramankutty and Foley, 1999). Landsat and AVHRR are satellite-based data and GFED is derived from satellite products as described in the references.

b Based on average estimates by biomes compiled from literature data (see details in corresponding references).

1990-1997 only.

d Legacy fluxes for land cover change prior to 1980 are not included and are estimated to add about $0.2 \mathrm{PgC} \mathrm{yr}^{-1}$ to the $1980 \mathrm{~s}$ and 0.1 PgC yr ${ }^{-1}$ to the $1990 \mathrm{~s}$ estimates, based on Ramankutty et al. (2006).

e The vegetation and soil biomass is computed using a vegetation model described in the reference.

f 1997-2006 average based on estimates of carbon emissions from deforestation and degradation fires, including peat fires and oxidation. Estimates were doubled to account for emissions other than fire including respiration of leftover plant materials and soil carbon following deforestation following (Olivier et al., 2005).

$g$ Method as described in the reference but updated to 2010 using the land cover change data listed in column 2.

h The large variability produced by the calculation method is removed for comparison with other studies by averaging the flux over the two decades.

Average of estimates from all process models and $90 \%$ confidence uncertainty interval; note that the spread of the different estimates does not follow a Gaussian distribution. AVHRR = Advanced Very High Resolution Radiometer; FAO = Food and Agriculture Organization (UN); GFED = Global Fire Emissions Database; HYDE = HistorY Database of the global Environment; SAGE = Center for Sustainability and the Global Environment. 


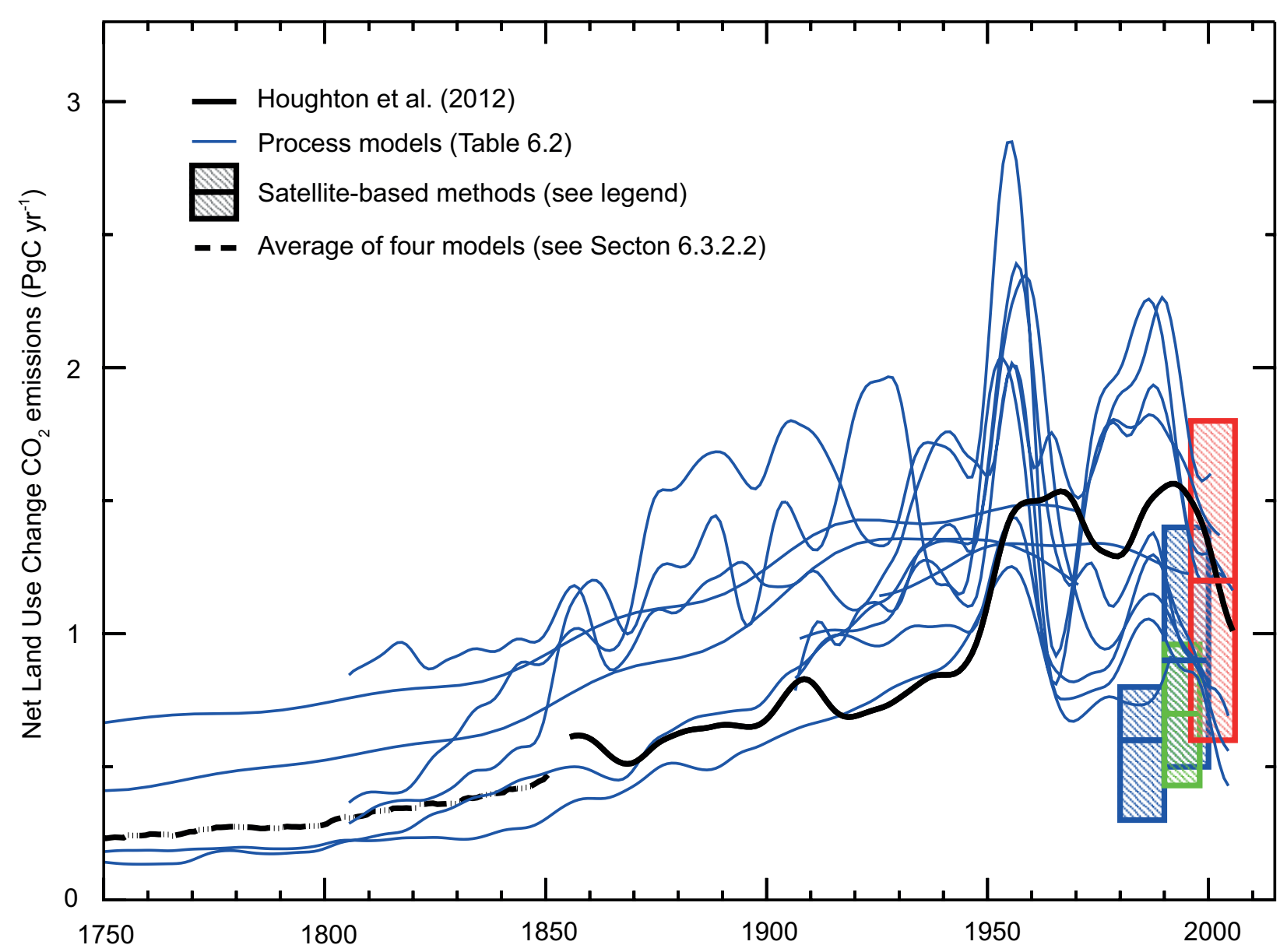

Figure 6.10 Net land use change $\mathrm{CO}_{2}$ emissions $\left(\mathrm{PgC} \mathrm{yr}{ }^{-1}\right)$. All methods are based on land cover change data (see Table 6.2) and are smoothed with a 10-year filter to remove interannual variability. The bookkeeping estimate of Houghton et al. (2012) (thick black over 1850-2011) and the average of four process models (dash black) over 1750-1850 (see 6.3.2.2) are used in Table 6.1. The process model results for net land use change $\mathrm{CO}_{2}$ emissions from Table 6.2 are shown in blue. Satellite-based methods are available for the tropics only, from (red) van der Werf et al. (2010), (blue) DeFries et al. (2002), and (green) Achard et al. (2004). Note that the definitions of land use change fluxes vary between models (Table 6.2). The grey shading shows a constant uncertainty of $\pm 0.8 \mathrm{PgC} \mathrm{yr}^{-1}$ around the mean estimate used in Table 6.3 .

originate from Central and South America, Africa and Tropical Asia since the 1980s (Table 6.3). The process models based on the HYDE database allocate about $30 \%$ of the global land use change emissions to East Asia, but this is difficult to reconcile with the large afforestation programmes reported in this region. Inconsistencies in the available land cover change reconstructions and in the modelling results prevent a firm assessment of recent trends and their partitioning among regions (see regional data in Table 6.3).

In this chapter, we do not assess individual gross fluxes that sum up to make the net land use change $\mathrm{CO}_{2}$ emission, because there are too few independent studies. Gross emissions from tropical deforestation and degradation were $3.0 \pm 0.5 \mathrm{PgC} \mathrm{yr}^{-1}$ for the $1990 \mathrm{~s}$ and $2.8 \pm 0.5$ $\mathrm{PgC} \mathrm{yr}{ }^{-1}$ for the 2000s using forest inventory data, FAO (2010) and the bookeeping method (Pan et al., 2011). These gross emissions are about double the net emissions because of the presence of a large regrowth that compensates for about half of the gross emissions. A recent analysis estimated a lower gross deforestation of 0.6 to $1.2 \mathrm{PgC}^{-1}{ }^{-1}$ (Harris et al., 2012). That study primarily estimated permanent deforestation and excluded additional gross emissions from degraded forests, shifting agriculture and some carbon pools. In fact, gross emissions from permanent deforestation are in agreement between the bookkeeping method of Houghton et al. (2012) and the satellite data analysis of Harris et al. (2012).

Over the 1750-2011 period, cumulative net $\mathrm{CO}_{2}$ emissions from land use change of $180 \pm 80 \mathrm{PgC}$ are estimated (Table 6.1): The uncertainty is based on the spread of the available estimates (Figure 6.10). The cumulative net $\mathrm{CO}_{2}$ emissions from land use change have been dominated by deforestation and other land use change in the mid-northern latitudes prior to 1980s, and in the tropics since the 1980s, largely from deforestation in tropical America and Asia with smaller contributions from tropical Africa. Deforestation from 800 to 1750 has been estimated at $27 \mathrm{PgC}$ using a process-based ecosystem model (Pongratz et al., 2009).

\subsubsection{Atmospheric Carbon Dioxide Concentration Growth Rate}

Since the beginning of the Industrial Era (1750), the concentration of $\mathrm{CO}_{2}$ in the atmosphere has increased by $40 \%$, from $278 \pm 5 \mathrm{ppm}$ to $390.5 \pm 0.1 \mathrm{ppm}$ in 2011 (Figure 6.11; updated from Ballantyne et al. (2012), corresponding to an increase in $\mathrm{CO}_{2}$ of $240 \pm 10 \mathrm{PgC}$ in the 
atmosphere. Atmospheric $\mathrm{CO}_{2}$ grew at a rate of $3.4 \pm 0.2 \mathrm{PgC} \mathrm{yr}^{-1}$ in the 1980s, $3.1 \pm 0.2 \mathrm{PgC} \mathrm{yr}^{-1}$ in the 1990s and $4.0 \pm 0.2 \mathrm{PgC} \mathrm{yr}^{-1}$ in the 2000s (Conway and Tans, 2011) (Table 6.1). The increase of atmospheric $\mathrm{CO}_{2}$ between 1750 and 1957, prior to direct measurements in the atmosphere, is established from measurements of $\mathrm{CO}_{2}$ trapped in air bubbles in ice cores (e.g., Etheridge et al., 1996). After 1957, the increase of atmospheric $\mathrm{CO}_{2}$ is established from highly precise con- tinuous atmospheric $\mathrm{CO}_{2}$ concentration measurements at background stations (e.g., Keeling et al., 1976).

The ice core record of atmospheric $\mathrm{CO}_{2}$ during the past century exhibits interesting variations, which can be related to climate induced-changes in the carbon cycle. Most conspicuous is the interval from about 1940 to 1955 , during which atmospheric $\mathrm{CO}_{2}$ concentration stabilised

Table 6.3 | Estimates of net land to atmosphere flux from land use change (PgC yr-1; except where noted) for decadal periods from 1980s to 2000s by region. Positive values indicate net $\mathrm{CO}_{2}$ losses from land ecosystems affected by land use change to the atmosphere. Uncertainties are reported as $90 \%$ confidence interval (unlike $68 \%$ in AR4). Numbers in parentheses are ranges in uncertainty provided in some studies. Tropical Asia includes the Middle East, India and surrounding countries, Indonesia and Papua New Guinea. East Asia includes China, Japan, Mongolia and Korea.

\begin{tabular}{|c|c|c|c|c|c|c|c|c|}
\hline & $\begin{array}{c}\text { Land Cover } \\
\text { Data }\end{array}$ & $\begin{array}{c}\text { Central and } \\
\text { South Americas }\end{array}$ & Africa & $\begin{array}{l}\text { Tropical } \\
\text { Asia }\end{array}$ & $\begin{array}{l}\text { North } \\
\text { America }\end{array}$ & Eurasia & East Asia & Oceania \\
\hline \multicolumn{9}{|l|}{$2000 \mathrm{~s}$} \\
\hline van der Werf et al. $(2010)^{a, b}$ & GFED & 0.33 & 0.15 & 0.35 & & & & \\
\hline DeFries and Rosenzweig (2010)c & MODIS & 0.46 & 0.08 & 0.36 & & & & \\
\hline Houghton et al. (2012) & FAO-2010 & 0.48 & $0.31^{e}$ & 0.25 & 0.01 & $-0.07^{d}$ & $0.01^{e}$ & \\
\hline van Minnen et al. (2009)a & HYDE & 0.45 & 0.21 & 0.20 & 0.09 & 0.08 & 0.10 & 0.03 \\
\hline Stocker et al. (2011) a & HYDE & 0.19 & 0.18 & 0.21 & 0.019 & -0.067 & 0.12 & 0.011 \\
\hline Yang et al. (2010)a & HYDE & 0.14 & 0.03 & 0.25 & 0.25 & 0.39 & 0.12 & 0.02 \\
\hline Poulter et al. (2010)a & HYDE & 0.09 & 0.13 & 0.14 & 0.01 & 0.03 & 0.05 & 0.00 \\
\hline Kato et al. (2013) & HYDE & 0.36 & -0.09 & 0.23 & -0.05 & -0.04 & 0.10 & 0.00 \\
\hline Average & & $0.31 \pm 0.25$ & $0.13 \pm 0.20$ & $0.25 \pm 0.12$ & $0.05 \pm 0.17$ & $0.12 \pm 0.31$ & $0.08 \pm 0.07$ & $0.01 \pm 0.02$ \\
\hline \multicolumn{9}{|l|}{$1990 \mathrm{~s}$} \\
\hline DeFries et al. (2002) & AVHRR & $\begin{array}{c}0.5 \\
(0.2-0.7)\end{array}$ & $\begin{array}{c}0.1 \\
(0.1-0.2)\end{array}$ & $\begin{array}{c}0.4 \\
(0.2-0.6)\end{array}$ & & & & \\
\hline Achard et al. (2004) & Landsat & $\begin{array}{c}0.3 \\
(0.3-0.4)\end{array}$ & $\begin{array}{c}0.2 \\
(0.1-0.2)\end{array}$ & $\begin{array}{c}0.4 \\
(0.3-0.5)\end{array}$ & & & & \\
\hline Houghton et al. (2012) & FAO-2010 & 0.67 & $0.32^{\mathrm{e}}$ & 0.45 & 0.05 & $-0.04^{\mathrm{d}}$ & $0.05^{\mathrm{e}}$ & \\
\hline van Minnen et al. (2009) a & HYDE & 0.48 & 0.22 & 0.34 & 0.07 & 0.08 & 0.20 & 0.07 \\
\hline Stocker et al. (2011) & HYDE & 0.30 & 0.14 & 0.19 & -0.072 & 0.11 & 0.27 & 0.002 \\
\hline Yang et al. (2010) & HYDE & 0.20 & 0.04 & 0.31 & 0.27 & 0.47 & 0.19 & 0.00 \\
\hline Poulter et al. (2010) & HYDE & 0.26 & 0.13 & 0.12 & 0.07 & 0.16 & 0.11 & 0.01 \\
\hline Kato et al. (2013) ${ }^{\mathrm{a}}$ & HYDE & 0.53 & 0.07 & 0.25 & -0.04 & -0.01 & 0.16 & 0.02 \\
\hline Average & & $0.41 \pm 0.27$ & $0.15 \pm 0.15$ & $0.31 \pm 0.19$ & $0.08 \pm 0.19$ & $0.16 \pm 0.30$ & $0.16 \pm 0.13$ & $0.02 \pm 0.05$ \\
\hline \multicolumn{9}{|l|}{$1980 \mathrm{~s}$} \\
\hline DeFries et al. (2002) & AVHRR & $\begin{array}{c}0.4 \\
(0.2-0.5)\end{array}$ & $\begin{array}{c}0.1 \\
(0.08-0.14)\end{array}$ & $\begin{array}{c}0.2 \\
(01-0.3)\end{array}$ & & & & \\
\hline Houghton et al. (2012) & FAO-2010 & 0.79 & $0.22^{e}$ & 0.32 & 0.04 & $0.00^{d}$ & $0.07^{e}$ & \\
\hline van Minnen et al. (2009)a & HYDE & 0.70 & 0.18 & 0.43 & 0.07 & 0.06 & 0.37 & 0.04 \\
\hline Stocker et al. (2011) & HYDE & 0.44 & 0.16 & 0.25 & 0.085 & 0.11 & 0.40 & 0.009 \\
\hline Yang et al. (2010)a & HYDE & 0.26 & 0.01 & 0.34 & 0.30 & 0.71 & 0.59 & 0.00 \\
\hline Poulter et al. (2010)a & HYDE & 0.37 & 0.11 & 0.19 & 0.02 & 0.03 & 0.29 & 0.01 \\
\hline Kato et al. (2013) & HYDE & 0.61 & 0.07 & 0.25 & -0.04 & -0.02 & 0.35 & 0.01 \\
\hline Average & & $0.51 \pm 0.32$ & $0.12 \pm 0.12$ & $0.28 \pm 0.14$ & $0.08 \pm 0.19$ & $0.15 \pm 0.46$ & $0.35 \pm 0.28$ & $0.01 \pm 0.03$ \\
\hline
\end{tabular}

Notes:

a Method as described in the reference but updated to 2010 using the HYDE land cover change data.

b 1997-2006 average based on estimates of $\mathrm{CO}_{2}$ emissions from deforestation and degradation fires, including peat carbon emissions. Estimates were doubled to account for emissions other than fire including respiration of leftover plant materials and soil carbon following deforestation following (Olivier et al., 2005). Estimates include peat fires and peat soil oxidation. If peat fires are excluded, estimate in tropical Asia is 0.23 and Pan-tropical total is 0.71 .

c $\mathrm{CO}_{2}$ estimates were summed for dry and humid tropical forests, converted to $\mathrm{C}$ and normalized to annual values. Estimates are based on satellite-derived deforestation area (Hansen et al., 2010), and assume 0.6 fraction of biomass emitted with deforestation. Estimates do not include carbon uptake by regrowth or legacy fluxes from historical deforestation. Estimates cover emissions from 2000 to 2005.

d Includes China only.

e East Asia and Oceania are averaged in one region. The flux is split in two equally for computing the average; North Africa and the Middle East are combined with Eurasia. AVHRR = Advanced Very High Resolution Radiometer; FAO = Food and Agriculture Organization (UN); GFED = Global Fire Emissions Database; HYDE = HistorY Database of the global Environment; MODIS = Moderate Resolution Imaging Spectrometer. 
(Trudinger et al., 2002), and the $\mathrm{CH}_{4}$ and $\mathrm{N}_{2} \mathrm{O}$ growth slowed down (MacFarling-Meure et al., 2006), possibly caused by slightly decreasing temperatures over land in the NH (Rafelski et al., 2009).

There is substantial evidence, for example, from ${ }^{13} \mathrm{C}$ carbon isotopes in atmospheric $\mathrm{CO}_{2}$ (Keeling et al., 2005) that source/sink processes on land generate most of the interannual variability in the atmospheric $\mathrm{CO}_{2}$ growth rate (Figure 6.12). The strong positive anomalies of the $\mathrm{CO}_{2}$ growth rate in El Niño years (e.g., 1986-1987 and 1997-1998) originated in tropical latitudes (see Sections 6.3.6.3 and 6.3.2.5.4), while the anomalies in 2003 and 2005 originated in northern mid-latitudes, perhaps reflecting the European heat wave in 2003 (Ciais et al., 2005). Volcanic forcing also contributes to multi-annual variability in carbon storage on land and in the ocean (Jones and Cox, 2001; Gerber et al., 2003; Brovkin et al., 2010; Frölicher et al., 2011).

With a very high confidence, the increase in $\mathrm{CO}_{2}$ emissions from fossil fuel burning and those arising from land use change are the dominant

cause of the observed increase in atmospheric $\mathrm{CO}_{2}$ concentration. Several lines of evidence support this conclusion:

- The observed decrease in atmospheric $\mathrm{O}_{2}$ content over past two decades and the lower $\mathrm{O}_{2}$ content in the northern compared to the $\mathrm{SH}$ are consistent with the burning of fossil fuels (see Figure 6.3 and Section 6.1.3.2; Keeling et al., 1996; Manning and Keeling, 2006).

- $\mathrm{CO}_{2}$ from fossil fuels and from the land biosphere has a lower ${ }^{13} \mathrm{C} /{ }^{12} \mathrm{C}$ stable isotope ratio than the $\mathrm{CO}_{2}$ in the atmosphere. This induces a decreasing temporal trend in the atmospheric ${ }^{13} \mathrm{C} /{ }^{12} \mathrm{C}$ ratio of atmospheric $\mathrm{CO}_{2}$ concentration as well as, on annual average, slightly lower ${ }^{13} \mathrm{C} /{ }^{12} \mathrm{C}$ values in the $\mathrm{NH}$ (Figure 6.3). These signals are measured in the atmosphere.

- Because fossil fuel $\mathrm{CO}_{2}$ is devoid of radiocarbon $\left({ }^{14} \mathrm{C}\right)$, reconstructions of the ${ }^{14} \mathrm{C} / \mathrm{C}$ isotopic ratio of atmospheric $\mathrm{CO}_{2}$ from tree rings
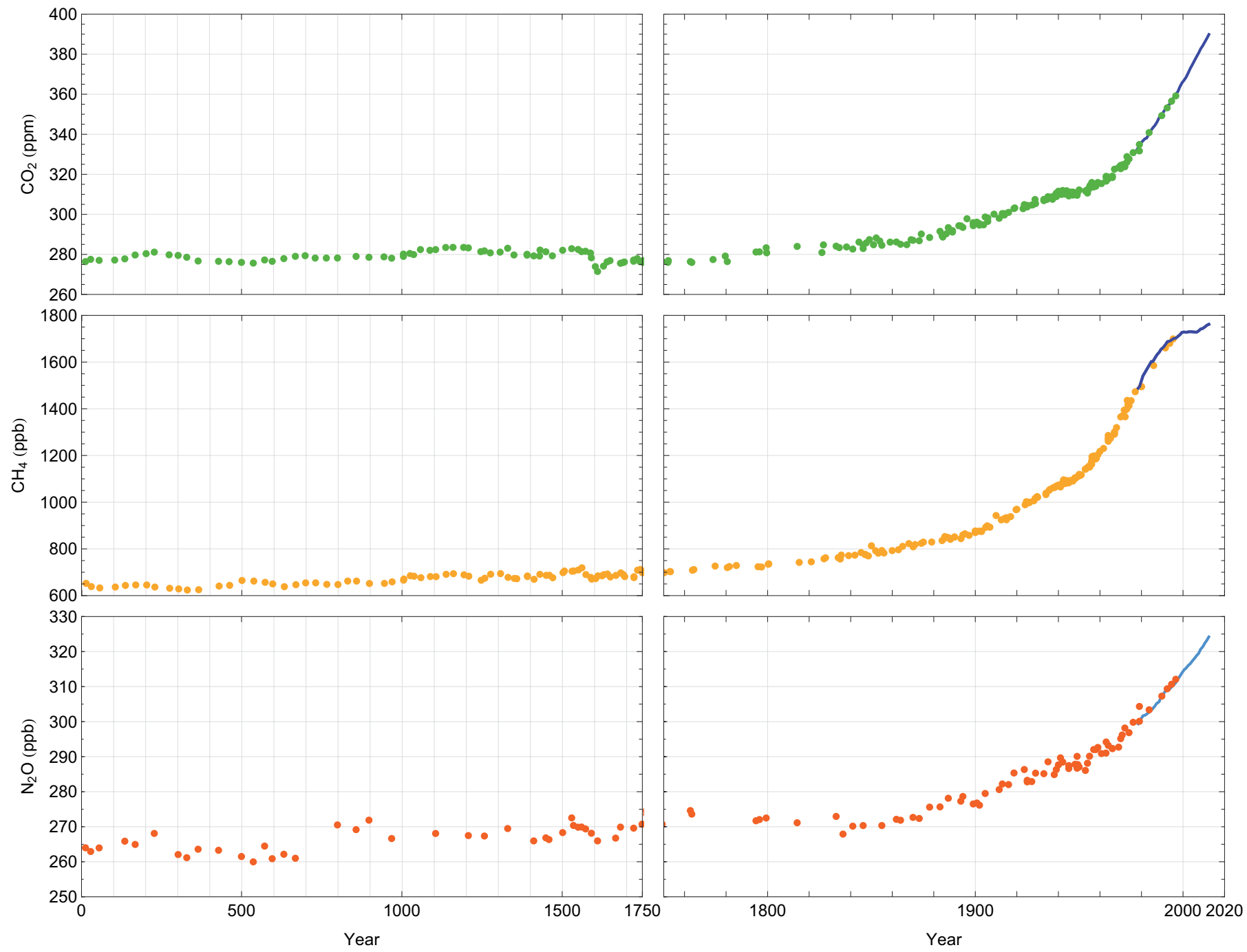

Figure 6.11 Atmospheric $\mathrm{CO}_{2}, \mathrm{CH}_{4}$, and $\mathrm{N}_{2} \mathrm{O}$ concentrations history over the industrial era (right) and from year 0 to the year 1750 (left), determined from air enclosed in ice cores and firn air (colour symbols) and from direct atmospheric measurements (blue lines, measurements from the Cape Grim observatory) (MacFarling-Meure et al., 2006). 
show a declining trend, as expected from the addition of fossil $\mathrm{CO}_{2}$ (Stuiver and Quay, 1981; Levin et al., 2010). Yet nuclear weapon tests in the 1950s and 1960s have been offsetting that declining trend signal by adding ${ }^{14} \mathrm{C}$ to the atmosphere. Since this nuclear weapon induced ${ }^{14} \mathrm{C}$ pulse in the atmosphere has been fading, the ${ }^{14} \mathrm{C} / \mathrm{C}$ isotopic ratio of atmospheric $\mathrm{CO}_{2}$ is observed to resume its declining trend (Naegler and Levin, 2009; Graven et al., 2012).

- Most of the fossil fuel $\mathrm{CO}_{2}$ emissions take place in the industrialised countries north of the equator. Consistent with this, on annual average, atmospheric $\mathrm{CO}_{2}$ measurement stations in the $\mathrm{NH}$ record increasingly higher $\mathrm{CO}_{2}$ concentrations than stations in the $\mathrm{SH}$, as witnessed by the observations from Mauna Loa, Hawaii, and the South Pole (see Figure 6.3). The annually averaged concentration difference between the two stations has increased in proportion of the estimated increasing difference in fossil fuel combustion emissions between the hemispheres (Figure 6.13; Keeling et al., 1989; Tans et al., 1989; Fan et al., 1999).

- The rate of $\mathrm{CO}_{2}$ emissions from fossil fuel burning and land use change was almost exponential, and the rate of $\mathrm{CO}_{2}$ increase in the atmosphere was also almost exponential and about half that of the emissions, consistent with a large body of evidence about changes of carbon inventory in each reservoir of the carbon cycle presented in this chapter.
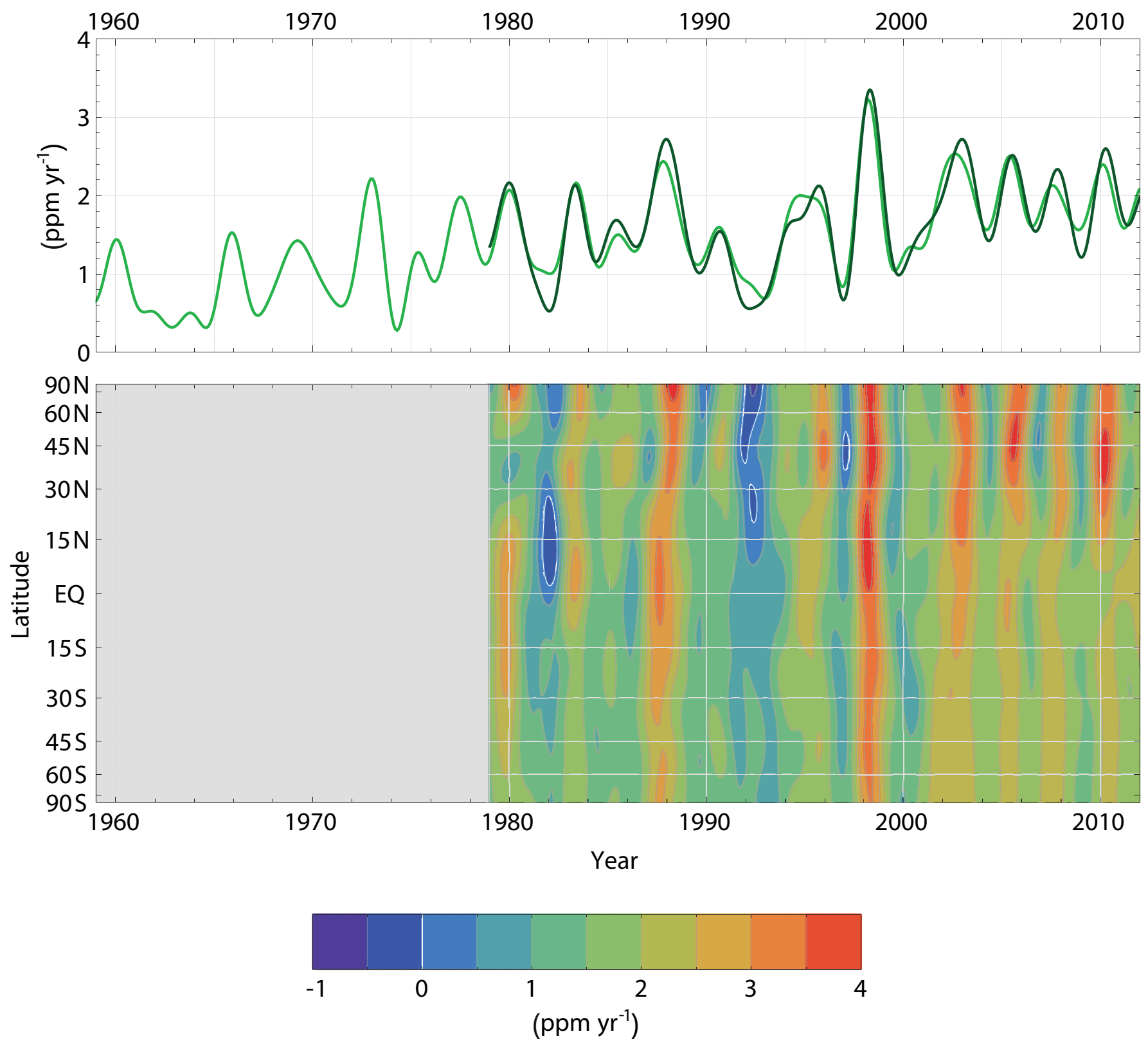

Figure 6.12 | (Top) Global average atmospheric $\mathrm{CO}_{2}$ growth rate, computed from the observations of the Scripps Institution of Oceanography (SIO) network (light green line: Keeling et al. 2005, updated) and from the marine boundary layer air reference measurements of the National Oceanic and Atmospheric Administration -Global Monitoring Division (NOAA-GMD) network (dark green line: Conway et al., 1994; Dlugokencky and Tans, 2013b). (Bottom) Atmospheric growth rate of $\mathrm{CO}_{2}$ as a function of latitude determined from the National Oceanic and Atmospheric Administration-Earth System Research Laboratory (NOAA-ESRL) network, representative of stations located in the marine boundary layer at each given latitude (Masarie and Tans, 1995; Dlugokencky and Tans, 2013b). Sufficient observations are available only since 1979. 


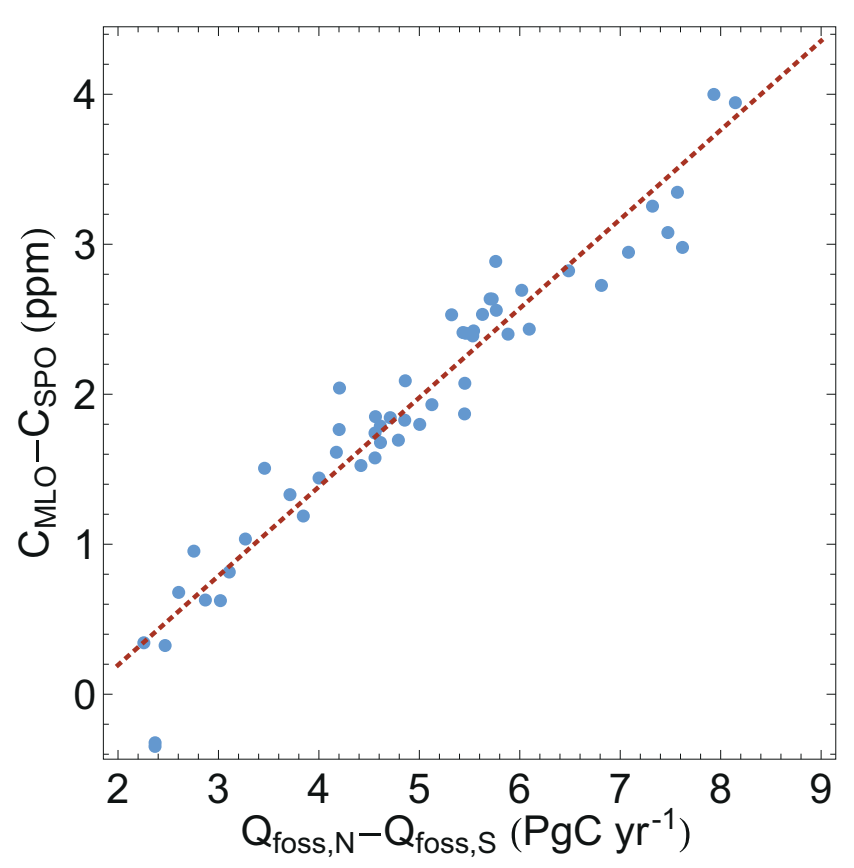

Figure 6.13 | Blue points: Annually averaged $\mathrm{CO}_{2}$ concentration difference between the station Mauna Loa in the Northern Hemisphere and the station South Pole in the Southern Hemisphere (vertical axis; Keeling et al., 2005, updated) versus the difference in fossil fuel combustion $\mathrm{CO}_{2}$ emissions between the hemispheres (Boden et al., 2011). Dark red dashed line: regression line fitted to the data points.

\subsubsection{Carbon Dioxide Airborne Fraction}

Until recently, the uncertainty in $\mathrm{CO}_{2}$ emissions from land use change emissions was large and poorly quantified which led to the use of an airborne fraction (see Glossary) based on $\mathrm{CO}_{2}$ emissions from fossil fuel only (e.g., Figure 7.4 in AR4 and Figure 6.26 of this chapter). However, reduced uncertainty of emissions from land use change and larger agreement in its trends over time (Section 6.3.2.2) allow making use of an airborne fraction that includes all anthropogenic emissions. The airborne fraction will increase if emissions are too fast for the uptake of $\mathrm{CO}_{2}$ by the carbon sinks (Bacastow and Keeling, 1979; Gloor et al., 2010; Raupach, 2013). It is thus controlled by changes in emissions rates, and by changes in carbon sinks driven by rising $\mathrm{CO}_{2}$, changes in climate and all other biogeochemical changes.

A positive trend in airborne fraction of $\sim 0.3 \% \mathrm{yr}^{-1}$ relative to the mean of $0.44 \pm 0.06$ (or about 0.05 increase over 50 years) was found by all recent studies (Raupach et al., 2008, and related papers; Knorr, 2009; Gloor et al., 2010) using the airborne fraction of total anthropogenic $\mathrm{CO}_{2}$ emissions over the approximately 1960-2010 period (for which the most accurate atmospheric $\mathrm{CO}_{2}$ data are available). However, there is no consensus on the significance of the trend because of differences in the treatment of uncertainty and noise (Raupach et al., 2008; Knorr, 2009). There is also no consensus on the cause of the trend (Canadell et al., 2007b; Raupach et al., 2008; Gloor et al., 2010). Land and ocean carbon cycle model results attributing the trends of fluxes to underlying processes suggest that the effect of climate change and variability on ocean and land sinks have had a significant influence (Le Quéré et al., 2009), including the decadal influence of volcanic eruptions (Frölicher et al., 2013).

\subsubsection{Ocean Carbon Dioxide Sink}

\subsection{Global ocean sink and decadal change}

The estimated mean anthropogenic ocean $\mathrm{CO}_{2}$ sink assessed in AR4 was $2.2 \pm 0.7 \mathrm{PgC} \mathrm{yr}^{-1}$ for the 1990s based on observations (McNeil et al., 2003; Manning and Keeling, 2006; Mikaloff-Fletcher et al., 2006), and is supported by several contemporary estimates (see Chapter 3). Note that the uncertainty of $\pm 0.7 \mathrm{PgC} \mathrm{yr}^{-1}$ reported here $(90 \%$ confidence interval) is the same as the $\pm 0.4 \mathrm{PgC} \mathrm{yr}^{-1}$ uncertainty reported in AR4 (68\% confidence intervals). The uptake of anthropogenic $\mathrm{CO}_{2}$ by the ocean is primarily a response to increasing $\mathrm{CO}_{2}$ in the atmos-
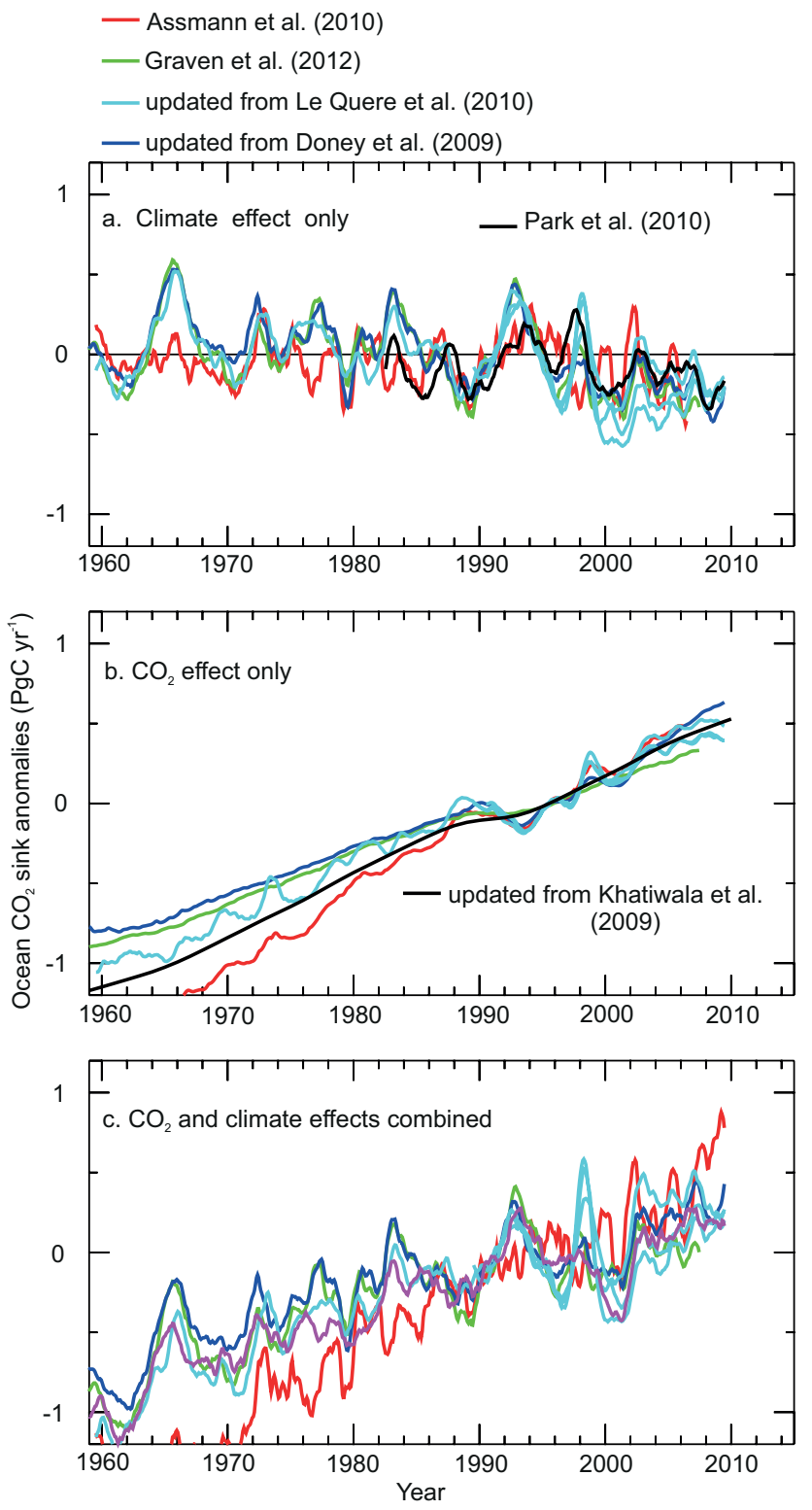

Figure 6.14 | Anomalies in the ocean $\mathrm{CO}_{2}$ ocean-to-atmosphere flux in response to (a) changes in climate, (b) increasing atmospheric $\mathrm{CO}_{2}$ and (c) the combined effects of increasing $\mathrm{CO}_{2}$ and changes in climate $\left(\mathrm{PgC} \mathrm{yr}{ }^{-1}\right)$. All estimates are shown as anomalies with respect to the 1990-2000 averages. Estimates are updates from ocean models (in colours) and from indirect methods based on observations (Khatiwala et al., 2009; Park et al., 2010). A negative ocean-to-atmosphere flux represents a sink of $\mathrm{CO}_{2}$, as in Table 6.1 . 
Table 6.4 Decadal changes in the ocean $\mathrm{CO}_{2}$ sink from models and from data-based methods (a positive change between two decades means an increasing sink with time). It is reminded that the total $\mathrm{CO}_{2}$ sink for the 1990 s is estimated at $2.2 \pm 0.7 \mathrm{PgC} \mathrm{yr}^{-1}$ based on observations.

\begin{tabular}{|c|c|c|c|}
\hline & Method & $\begin{array}{c}\text { 1990s Minus 1980s } \\
\text { PgC yr-1 }\end{array}$ & $\begin{array}{c}\text { 2000s Minus } 1990 \mathrm{~s} \\
\mathrm{PgC} \mathrm{yr}{ }^{-1}\end{array}$ \\
\hline \multicolumn{4}{|l|}{$\mathrm{CO}_{2}$ effects only } \\
\hline Khatiwala et al. (2009) & Data-based ${ }^{c}$ & 0.24 & 0.20 \\
\hline Mikaloff-Fletcher et al. (2006)a & Data-based ${ }^{d}$ & 0.40 & 0.44 \\
\hline Assmann et al. (2010) (to 2007 only) & Model & 0.28 & 0.35 \\
\hline Graven et al. (2012) & Model & 0.15 & 0.25 \\
\hline Le Quéré et al. (2010) NCEP & Model & 0.16 & 0.32 \\
\hline Le Quéré et al. (2010) ECMWF & Model & - & 0.39 \\
\hline Le Quéré et al. (2010) JPL & Model & - & 0.32 \\
\hline Average $^{b}$ & & $0.23 \pm 0.15$ & $0.33 \pm 0.13$ \\
\hline \multicolumn{4}{|l|}{ Climate effects only } \\
\hline Doney et al. (2009) & Model & -0.02 & -0.21 \\
\hline Le Quéré et al. (2010) NCEP & Model & 0.02 & -0.27 \\
\hline Le Quéré et al. (2010) ECMWF & Model & - & -0.14 \\
\hline Le Quéré et al. (2010) JPL & Model & - & -0.36 \\
\hline Average $^{b}$ & & $0.02 \pm 0.05$ & $-0.19 \pm 0.18$ \\
\hline $\mathrm{CO}_{2}$ and climate effects combined & & $0.25 \pm 0.16$ & $0.14 \pm 0.22$ \\
\hline
\end{tabular}

Notes:

a As published by Sarmiento et al. (2010).

b Average of all estimates $\pm 90 \%$ confidence interval. The average includes results by Le Quéré et al. (2010)-NCEP only because the other Le Quéré et al. model versions do not differ sufficiently to be considered separately.

Based on observed patterns of atmospheric minus oceanic $\mathrm{pCO}_{2}$, assuming the difference increases with time following the increasing atmospheric $\mathrm{CO}_{2}$.

d Ocean inversion, assuming constant oceanic transport through time.

e Based on observed fit between the variability in temperature and $\mathrm{pCO}_{2}$, and observed variability in temperature.

ECMWF = European Centre for Medium-Range Weather Forecasts; JPL = Jet Propulsion Laboratory; NCEP = National Centers for Environmental Prediction.

phere and is limited mainly by the rate at which anthropogenic $\mathrm{CO}_{2}$ is transported from the surface waters into the deep ocean (Sarmiento et al., 1992; Graven et al., 2012). This anthropogenic ocean $\mathrm{CO}_{2}$ sink occurs on top of a very active natural oceanic carbon cycle. Recent climate trends, such as ocean warming, changes in ocean circulation and changes in marine ecosystems and biogeochemical cycles, can have affected both the anthropogenic ocean $\mathrm{CO}_{2}$ sink as well as the natural air-sea $\mathrm{CO}_{2}$ fluxes. We report a decadal mean uptake of 2.0 $\pm 0.7 \mathrm{PgC} \mathrm{yr}^{-1}$ for the $1980 \mathrm{~s}$ and of $2.3 \pm 0.7 \mathrm{PgC} \mathrm{yr}^{-1}$ for the $2000 \mathrm{~s}$ (Table 6.4). The methods used are: (1) an empirical Green's function approach fitted to observations of transient ocean tracers (Khatiwala et al., 2009), (2) a model-based Green's function approach fitted to anthropogenic carbon reconstructions (Mikaloff-Fletcher et al., 2006), (3) estimates based on empirical relationships between observed ocean surface $\mathrm{pCO}_{2}$ and temperature and salinity (Park et al., 2010) and (4) process-based global ocean biogeochemical models forced by observed meteorological fields (Doney et al., 2009; Assmann et al., 2010; Le Quéré et al., 2010; Graven et al., 2012). All these different methods suggest that in the absence of recent climate change and climate variability, the ocean anthropogenic $\mathrm{CO}_{2}$ sink should have increased by $0.23 \pm 0.15 \mathrm{PgC} \mathrm{yr}^{-1}$ between the $1980 \mathrm{~s}$ and the $1990 \mathrm{~s}$, and by $0.33 \pm 0.13 \mathrm{PgC} \mathrm{yr}^{-1}$ between the 1990s and the 2000s (Figure
6.14). The decadal estimates in the ocean $\mathrm{CO}_{2}$ sink reported in Table 6.4 as ' $\mathrm{CO}_{2}$ effects only' are entirely explained by the faster rate of increase of atmospheric $\mathrm{CO}_{2}$ in the later decade. On the other hand, 'climate effects only' in Table 6.4 are assessed to have no noticeable effect on the sink difference between the 1980s and the $1990 \mathrm{~s}(0.02 \pm 0.05 \mathrm{PgC}$ $\left.\mathrm{yr}^{-1}\right)$, but are estimated to have reduced the ocean anthropogenic $\mathrm{CO}_{2}$ sink by $0.19 \pm 0.18 \mathrm{PgC} \mathrm{yr}^{-1}$ between the 1990s and the 2000s (Table 6.4).

\subsection{Regional changes in ocean dissolved inorganic carbon}

Observational-based estimates for the global ocean inventory of anthropogenic carbon are obtained from shipboard repeated hydrographic cross sections (Sabine et al., 2004; Waugh et al., 2006; Khatiwala et al., 2009). These estimates agree well among each other, with an average value of $155 \pm 30 \mathrm{PgC}$ of increased dissolved inorganic carbon for the period 1750-2011 (see Chapter 3). The uptake of anthropogenic carbon into the ocean is observed to be larger in the high latitudes than in the tropics and subtropics over the entire Industrial Era, because of the more vigorous ocean convection in the high latitudes (Khatiwala et al., 2009). A number of ocean cross sections have been repeated over the last decade, and the observed changes 
Table 6.5 | Regional rates of change in inorganic carbon storage from shipboard repeated hydrographic cross sections.

\begin{tabular}{|c|c|c|c|}
\hline Section & Time & $\begin{array}{l}\text { Storage Rate } \\
\left(\mathrm{mol} \mathrm{C} \mathrm{m}^{-2} \mathrm{yr}^{-1}\right)\end{array}$ & Data Source \\
\hline Global average (used in Table 6.1) & 2007-2008 & $0.5 \pm 0.2$ & Khatiwala et al. (2009) \\
\hline \multicolumn{4}{|l|}{ Pacific Ocean } \\
\hline Section along $30^{\circ} \mathrm{S}$ & $1992-2003$ & $1.0 \pm 0.4$ & Murata et al. (2007) \\
\hline $\mathrm{N}$ of $50^{\circ} \mathrm{S}, 120^{\circ} \mathrm{W}$ to $180^{\circ} \mathrm{W}$ & 1974-1996 & $0.9 \pm 0.3$ & Peng et al. (2003) \\
\hline $154^{\circ} \mathrm{W}, 20^{\circ} \mathrm{N}$ to $50^{\circ} \mathrm{S}$ & $1991-2006$ & $0.6 \pm 0.1$ & Sabine et al. (2008) \\
\hline $149^{\circ} \mathrm{W}, 4^{\circ} \mathrm{S}$ to $10^{\circ} \mathrm{N}$ & 1993-2005 & $0.3 \pm 0.1$ & Murata et al. (2009) \\
\hline $149^{\circ} \mathrm{W}, 24^{\circ} \mathrm{N}$ to $30^{\circ} \mathrm{N}$ & 1993-2005 & $0.6 \pm 0.2$ & Murata et al. (2009) \\
\hline Northeast Pacific & 1973-1991 & $1.3 \pm 0.5$ & Peng et al. (2003) \\
\hline$\sim 160^{\circ} \mathrm{E}, \sim 45^{\circ} \mathrm{N}$ & $1997-2008$ & $0.4 \pm 0.1$ & Wakita et al. (2010) \\
\hline North of $20^{\circ} \mathrm{N}$ & $1994-2004 / 2005$ & $0.4 \pm 0.2$ & Sabine et al. (2008) \\
\hline $10^{\circ} \mathrm{S}$ to $5^{\circ} \mathrm{N}$ & 1978-1995 & 0.7 & Peng et al. (1998) \\
\hline Section along $20^{\circ} \mathrm{S}$ & $1995-2003 / 2004$ & $1.0 \pm 0.1$ & Murata et al. (2010) \\
\hline \multicolumn{4}{|l|}{ Atlantic Ocean } \\
\hline Section along $30^{\circ} \mathrm{S}$ & 1992/1993-2003 & $0.6 \pm 0.1$ & Murata et al. (2010) \\
\hline$\sim 30^{\circ} \mathrm{W}, 56^{\circ} \mathrm{S}$ to $15^{\circ} \mathrm{S}$ & 1989-2005 & 0.8 & Wanninkhof et al. (2010) \\
\hline $20^{\circ} \mathrm{W}, 64^{\circ} \mathrm{N}$ to $15^{\circ} \mathrm{N}$ & $1993-2003$ & 0.6 & Wanninkhof et al. (2010) \\
\hline$\sim 25^{\circ} \mathrm{W}, 15^{\circ} \mathrm{N}$ to $15^{\circ} \mathrm{S}$ & 1993-2003 & 0.2 & Wanninkhof et al. (2010) \\
\hline $40^{\circ} \mathrm{N}$ to $65^{\circ} \mathrm{N}$ & 1981-1997/1999 & $2.2 \pm 0.7$ & Friis et al. (2005) \\
\hline $20^{\circ} \mathrm{N}$ to $40^{\circ} \mathrm{N}$ & $1981-2004$ & $1.2 \pm 0.3$ & Tanhua et al. (2007) \\
\hline
\end{tabular}

in carbon storage (Table 6.5) suggest that some locations have rates of carbon accumulation that are higher and others that are lower than the global average estimated by Khatiwala et al. (2009). Model results suggest that there may be an effect of climate change and variability in the storage of total inorganic carbon in the ocean (Table 6.4), but that this effect is small $(\sim 2 \mathrm{PgC}$ over the past 50 years; Figure 6.14$)$ compared to the cumulative uptake of anthropogenic carbon during the same period.

\subsection{Interannual variability in air-sea $\mathrm{CO}_{2}$ fluxes}

The interannual variability in the global ocean $\mathrm{CO}_{2}$ sink is estimated

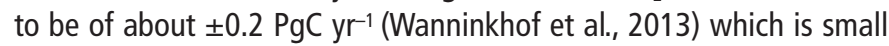
compared to the interannual variability of the terrestrial $\mathrm{CO}_{2}$ sink (see Sections 6.3.2.3 and 6.3.2.6.3; Figure 6.12). In general, the ocean takes up more $\mathrm{CO}_{2}$ during El Niño episodes (Park et al., 2010) because of the temporary suppression of the source of $\mathrm{CO}_{2}$ to the atmosphere over the eastern Pacific upwelling. Interannual variability of $\sim 0.3 \mathrm{PgC}^{-1}$ has been reported for the North Atlantic ocean region alone (Watson et al., 2009) but there is no agreement among estimates regarding the exact magnitude of driving factors of air-sea $\mathrm{CO}_{2}$ flux variability in this region (Schuster et al., 2013). Interannual variability of 0.1 to $0.2 \mathrm{PgC} \mathrm{yr}^{-1}$ was also estimated by models and one atmospheric inversion in the Southern Ocean (Le Quéré et al., 2007), possibly driven by the Southern Annular Mode of climate variability (Lenton and Matear, 2007; Lovenduski et al., 2007; Lourantou and Metzl, 2011).

\subsection{Regional ocean carbon dioxide partial pressure trends}

Observations of the partial pressure of $\mathrm{CO}_{2}$ at the ocean surface $\left(\mathrm{pCO}_{2}\right)$ show that ocean $\mathrm{pCO}_{2}$ has been increasing generally at about the same rate as $\mathrm{CO}_{2}$ in the atmosphere when averaged over large ocean regions during the past two to three decades (Yoshikawa-Inoue and Ishii, 2005; Takahashi et al., 2009; McKinley et al., 2011). However, analyses of regional observations highlight substantial regional and temporal variations around the mean trend.

In the North Atlantic, repeated observations show ocean $\mathrm{pCO}_{2}$ increasing regionally either at the same rate or faster than atmospheric $\mathrm{CO}_{2}$ between about 1990 and 2006 (Schuster et al., 2009), thus indicating a constant or decreasing sink for $\mathrm{CO}_{2}$ in that region, in contrast to the increasing sink expected from the response of the ocean to increasing 
atmospheric $\mathrm{CO}_{2}$ alone. The anomalous North Atlantic trends appear to be related to sea surface warming and its effect on solubility (Corbière et al., 2007) and/or changes in ocean circulation (Schuster and Watson, 2007; Schuster et al., 2009) and deep convection (Metzl et al., 2010). Recent changes have been associated with decadal variability in the North Atlantic Oscillation (NAO) and the Atlantic Multidecadal Variability (AMV) (Thomas et al., 2007; Ullman et al., 2009; McKinley et al., 2011; Tjiputra et al., 2012). A systematic analysis of trends estimated in this region show no agreement regarding the drivers of change (Schuster et al., 2013).

In the Southern Ocean, an approximately constant sink was inferred from atmospheric (Le Quéré et al., 2007) and oceanic (Metzl, 2009; Takahashi et al., 2009) $\mathrm{CO}_{2}$ observations but the uncertainties are large (Law et al., 2008). Most ocean biogeochemistry models reproduce the constant sink and attribute it as a response to an increase in Southern Ocean winds driving increased upwards transport of carbon-rich deep waters (Lenton and Matear, 2007; Verdy et al., 2007; Lovenduski et al., 2008; Le Quéré et al., 2010). The increase in winds has been attributed to the depletion of stratospheric ozone (Thompson and Solomon, 2002) with a contribution from GHGs (Fyfe and Saenko, 2006).

Large decadal variability has been observed in the Equatorial Pacific (Ishii et al., 2009) associated with changes in the phasing of the Pacific Decadal Oscillation (see Glossary) and its impact on gas transfer velocity (Feely et al., 2006; Valsala et al., 2012). By contrast, ocean $\mathrm{pCO}_{2}$ appears to have increased at a slower rate than atmospheric $\mathrm{CO}_{2}$ (thus a growing ocean $\mathrm{CO}_{2}$ sink in that region) in the northern North Pacific Ocean (Takahashi et al., 2006). There is less evidence available to attribute the observed changes in other regions to changes in underlying processes or climate change and variability.

\subsection{Processes driving variability and trends in air-sea carbon dioxide fluxes}

Three type of processes are estimated to have an important effect on the air-sea $\mathrm{CO}_{2}$ fluxes on century time scales: (1) the dissolution of $\mathrm{CO}_{2}$ at the ocean surface and its chemical equilibrium with other forms of carbon in the ocean (mainly carbonate and bicarbonate), (2) the transport of carbon between the surface and the intermediate and deep ocean and (3) changes in the cycling of carbon through marine ecosystem processes (the ocean biological pump; see Section 6.1.1.1). The surface dissolution and equilibration of $\mathrm{CO}_{2}$ with the atmosphere is well understood and quantified. It varies with the surface ocean conditions, in particular with temperature (solubility effect) and alkalinity. The capacity of the ocean to take up additional $\mathrm{CO}_{2}$ for a given alkalinity decreases at higher temperature $(4.23 \%$ per degree warming; Takahashi et al., 1993) and at elevated $\mathrm{CO}_{2}$ concentrations (about $15 \%$ per 100 ppm, computed from the so called Revelle factor; Revelle and Suess, 1957).

Recent changes in nutrient supply in the ocean are also thought to have changed the export of organic carbon from biological processes below the surface layer, and thus the ocean $\mathrm{CO}_{2}$ sink (Duce et al., 2008). Anthropogenic reactive nitrogen $\mathrm{Nr}$ (see Box 6.2) entering the ocean via atmospheric deposition or rivers acts as a fertiliser and may enhance carbon export to depth and hence the $\mathrm{CO}_{2}$ sink. This $\mathrm{Nr}$ contribution has been estimated to be between 0.1 and $0.4 \mathrm{PgC} \mathrm{yr}^{-1}$ around the year 2000 using models (Duce et al., 2008; Reay et al. 2008; Krishnamurthy et al., 2009; Suntharalingam et al., 2012). Similarly, increases in iron deposition over the ocean from dust generated by human activity is estimated to have enhanced the ocean cumulative $\mathrm{CO}_{2}$ uptake by $8 \mathrm{PgC}$ during the 20th century (or about $0.05 \mathrm{PgC} \mathrm{yr}^{-1}$ in the past decades) (Mahowald et al., 2010). Although changes in ocean circulation and in global biogeochemical drivers have the potential to alter the ocean carbon fluxes through changes in marine ecosystems, modelling studies show only small variability in ocean biological pump which has not significantly impacted the response of the ocean carbon cycle over the recent period (Bennington et al., 2009).

Model studies suggest that the response of the air-sea $\mathrm{CO}_{2}$ fluxes to climate change and variability in recent decades has decreased the rate at which anthropogenic $\mathrm{CO}_{2}$ is absorbed by the ocean (Sarmiento et al. (2010); Figure 6.14 and Table 6.4). This result is robust to the model or climate forcing used (Figure 6.13), but no formal attribution to anthropogenic climate change has been made. There is insufficient data coverage to separate the impact of climate change on the global ocean $\mathrm{CO}_{2}$ sink directly from observations, though the regional trends described in Section 6.3.2.5.4 suggest that surface ocean $\mathrm{pCO}_{2}$ responds to changes in ocean properties in a significant and measurable way.

\subsection{Model evaluation of global and regional ocean carbon balance}

Ocean process-based carbon cycle models are capable of reproducing the mean air-sea fluxes of $\mathrm{CO}_{2}$ derived from $\mathrm{pCO}_{2}$ observations (Takahashi et al., 2009), including their general patterns and amplitude (Sarmiento et al., 2000), the anthropogenic uptake of $\mathrm{CO}_{2}$ (Orr et al., 2001; Wanninkhof et al., 2013) and the regional distribution of air-sea fluxes (Gruber et al., 2009). The spread between different model results for air-sea $\mathrm{CO}_{2}$ fluxes is the largest in the Southern Ocean (Matsumoto et al., 2004), where intense convection occurs. Tracer observations (Schmittner et al., 2009) and water mass analysis (ludicone et al., 2011) have been used to reduce the model uncertainty associated with this process and improve the simulation of carbon fluxes. The models reproduce the observed seasonal cycle of $\mathrm{pCO}_{2}$ in the sub-tropics but generally do poorly in sub-polar regions where the balance of processes is more difficult to simulate well (McKinley et al., 2006; Schuster et al., 2013). Less information is available to evaluate specifically the representation of biological fluxes in the models, outside of their realistic representation of surface ocean chlorophyll distributions. Ocean process-based carbon cycle models used in AR5 reproduce the relatively small interannual variability inferred from observations (Figure 6.12; Wanninkhof et al., 2013). See also Section 9.4.5.

Sensitivity of modelled air-sea fluxes to $\mathrm{CO}_{2}$. Data-based studies estimated a cumulative carbon uptake of $\sim 155 \pm 30$ PgC across studies for the 1750-2011 time period (Sabine et al., 2004; Waugh et al., 2006; Khatiwala et al., 2009), a mean anthropogenic $\mathrm{CO}_{2}$ sink of 2.2 $\pm 0.7 \mathrm{PgC} \mathrm{yr}^{-1}$ for the 1990s, and decadal trends of $0.13 \mathrm{PgC} \mathrm{yr}^{-1}$ per decade during the two decades 1990-2009 (Wanninkhof et al., 2013; from atmospheric inversions), respectively. Models that have estimated these quantities give a total ocean uptake of $170 \pm 25 \mathrm{PgC}$ for 
1750-2011 (from the model ensemble of Orr et al., (2005) until 1994, plus an additional $40 \mathrm{PgC}$ from estimates in Table 6.4 for 1995-2011), a mean anthropogenic $\mathrm{CO}_{2}$ sink of $2.1 \pm 0.6 \mathrm{PgC} \mathrm{yr}^{-1}$ for 1990-1999 (Le Quéré et al., 2013) and a decadal trend of $0.14 \mathrm{PgC} \mathrm{yr}^{-1}$ per decade for 1990-2009 (Wanninkhof et al., 2013). Therefore, although the ocean models do not reproduce all the details of the regional structure and changes in air-sea $\mathrm{CO}_{2}$ fluxes, their globally integrated ocean $\mathrm{CO}_{2}$ sink and decadal rate of change of this sink is in good agreement with the available observations.

Sensitivity of modelled air-sea fluxes to climate. The relationship between air-sea $\mathrm{CO}_{2}$ flux and climate is strongly dependent on the oceanic region and on the time scale. Ocean carbon cycle models of the type used in AR5 estimate a reduction in cumulative ocean $\mathrm{CO}_{2}$ uptake of 1.6 to $5.4 \mathrm{PgC}$ over the period 1959-2008 (1.5 to 5.4\%) in response to climate change and variability compared to simulations with no changes in climate (Figure 6.14), partly due to changes in the equatorial Pacific and to changes in the Southern Ocean. The only observation-based estimate available to evaluate the climate response of the global air-sea $\mathrm{CO}_{2}$ flux is from Park et al. (2010), which is at the low end of the model estimate for the past two decades (Table 6.4). However, this estimate does not include the nonlinear effects of changes in ocean circulation and warming on the global air-sea $\mathrm{CO}_{2}$ flux, which could amplify the response of the ocean $\mathrm{CO}_{2}$ sink to climate by 20 to 30\% (Le Quéré et al., 2010; Zickfeld et al., 2011).

Processes missing in ocean models. The most important processes missing in ocean carbon cycle models used in the AR5 are those representing explicitly small-scale physical circulation (e.g., eddies, brine formation), which are parameterised in models. These processes have an important influence on the vertical transport of water, heat, salt and carbon (Loose and Schlosser, 2011; Sallée et al., 2012). In particular, changes in vertical transport in the Southern Ocean are thought to explain part of the changes in atmospheric $\mathrm{CO}_{2}$ between glacial and interglacial conditions, a signal that is not entirely reproduced by models (Section 6.2) suggesting that the sensitivity of ocean models could be underestimated.

Processes related to marine ecosystems in global ocean models are also limited to the simulation of lower trophic levels, with crude parameterizations for sinking processes, bacterial and other loss processes at the surface and in the ocean interior and their temperature dependence (Kwon et al., 2009). Projected changes in carbon fluxes from the response of marine ecosystems to changes in temperature (Beaugrand et al., 2010), ocean acidification (Riebesell et al., 2009) (see Glossary) and pressure from fisheries (Pershing et al., 2010) are all considered potentially important, though not yet quantified. Several processes have been specifically identified that could lead to changes in the ocean $\mathrm{CO}_{2}$ sink, in particular the temperature effects on marine ecosystem processes (Riebesell et al., 2009; Taucher and Oschlies, 2011) and the variable nutrient ratios induced by ocean acidification or ecosystem changes (Tagliabue et al., 2011). Coastal ocean processes are also poorly represented in global and may influence the ocean $\mathrm{CO}_{2}$ sink. Nevertheless, the fit of ocean model results to the integrated $\mathrm{CO}_{2}$ sink and decadal trends discussed above suggest that, up to now, the missing processes have not had a dominant effect on ocean $\mathrm{CO}_{2}$ beyond the limits of the uncertainty of the data.

\subsubsection{Land Carbon Dioxide Sink}

\subsection{Global residual land sink and atmosphere-to-land} carbon dioxide flux

The residual land $\mathrm{CO}_{2}$ sink, that is, the uptake of $\mathrm{CO}_{2}$ in ecosystems excluding the effects of land use change, is $1.5 \pm 1.1,2.6 \pm 1.2$ and 2.6 $\pm 1.2 \mathrm{PgC} \mathrm{yr}^{-1}$ for the 1980s, 1990s and 2000s, respectively (Table 6.1). After including the net land use change emissions, the atmosphereto-land flux of $\mathrm{CO}_{2}$ (Table 6.1) corresponds to a net sink of $\mathrm{CO}_{2}$ by all terrestrial ecosystems. This sink has intensified globally from a neutral $\mathrm{CO}_{2}$ flux of $0.1 \pm 0.8 \mathrm{PgC} \mathrm{yr}^{-1}$ in the 1980 s to a net $\mathrm{CO}_{2}$ sink of $1.1 \pm$ $0.9 \mathrm{PgC} \mathrm{yr}^{-1}$ and $1.5 \pm 0.9 \mathrm{PgC} \mathrm{yr}^{-1}$ during the 1990s and 2000s, respectively (Table 6.1; Sarmiento et al., 2010). This growing land sink is also supported by an atmospheric inversion (Gurney and Eckels, 2011) and by process-based models (Le Quéré et al., 2009).

\subsection{Regional atmosphere-to-land carbon dioxide fluxes}

The results from atmospheric $\mathrm{CO}_{2}$ inversions, terrestrial ecosystem models and forest inventories consistently show that there is a large net $\mathrm{CO}_{2}$ sink in the northern extratropics, albeit the very limited availability of observations in the tropics (Jacobson et al., 2007; Gurney and Eckels, 2011; Pan et al., 2011). Inversion estimates of atmosphere-land $\mathrm{CO}_{2}$ fluxes show net atmosphere-to-land $\mathrm{CO}_{2}$ flux estimates ranging

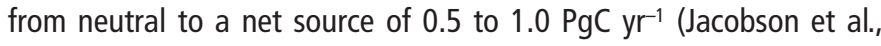
2007; Gurney and Eckels, 2011) (Figure 6.15). However, Stephens et al. (2007) selected from an ensemble of inversion models those that were consistent with independent aircraft cross-validation data, and constrained an atmosphere-to-land $\mathrm{CO}_{2}$ flux of $0.1 \pm 0.8 \mathrm{PgC}^{-1}$ during the period 1992-1996, and a $\mathrm{NH}$ net $\mathrm{CO}_{2}$ sink of $1.5 \pm 0.6 \mathrm{PgC} \mathrm{yr}^{-1}$. These results shows that after subtracting emissions from land use change, tropical land ecosystems might also be large $\mathrm{CO}_{2}$ sinks.

Based on repeated forest biomass inventory data, estimated soil carbon changes, and $\mathrm{CO}_{2}$ emissions from land use change from the bookkeeping method of Houghton et al. (2012), Pan et al. (2011) estimated a global forest carbon accumulation of $0.5 \pm 0.1 \mathrm{PgCyr}^{-1}$ in boreal forests, and of $0.8 \pm 0.1 \mathrm{PgC} \mathrm{yr}^{-1}$ in temperate forests for the period 2000-2007. Tropical forests were found to be near neutral with net emissions from land use change being compensated by sinks in established tropical forests (forests not affected by land use change), therefore consistent with the Stephens et al. (2007) inversion estimate of tropical atmosphere-land $\mathrm{CO}_{2}$ fluxes.

Since AR4, a number of studies have compared and attempted to reconcile regional atmosphere-to-land $\mathrm{CO}_{2}$ flux estimates from multiple approaches and so providing further spatial resolution of the regional contributions of carbon sources and sinks (Table 6.6). A synthesis of regional contributions estimated a $1.7 \mathrm{PgC} \mathrm{yr}^{-1}$ sink in the $\mathrm{NH}$ regions above $20^{\circ} \mathrm{N}$ with consistent estimates from terrestrial models and inventories (uncertainty: $\pm 0.3 \mathrm{PgC} \mathrm{yr}^{-1}$ ) and atmospheric $\mathrm{CO}_{2}$ inversions (uncertainty: $\pm 0.7 \mathrm{PgC} \mathrm{yr}^{-1}$ ) (Ciais et al., 2010). 

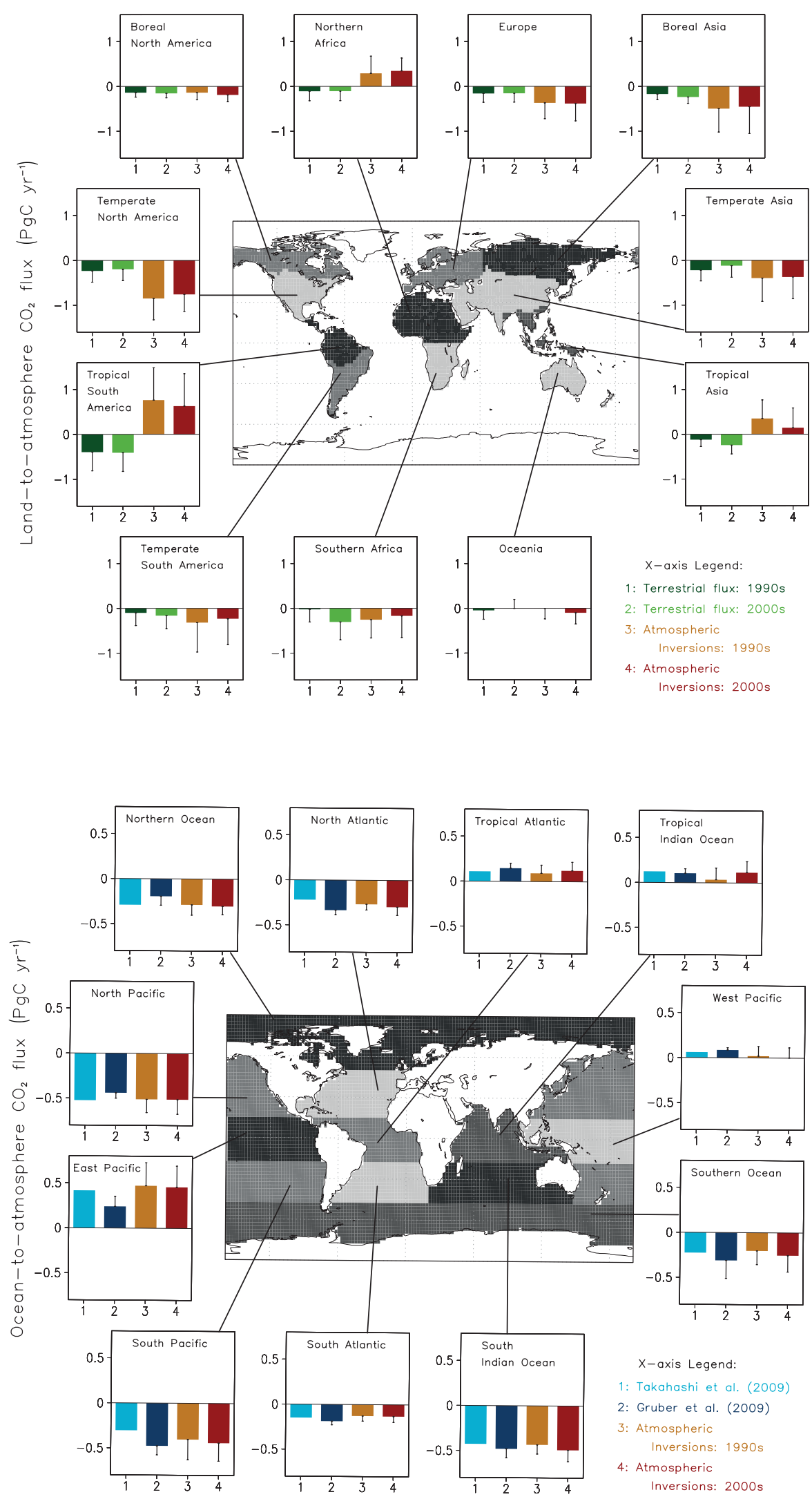

Figure 6.15 (Top) Bar plots showing decadal average $\mathrm{CO}_{2}$ fluxes for 11 land regions (1) as estimated by 10 different atmospheric $\mathrm{CO}_{2}$ inversions for the $1990 \mathrm{~s}$ (yellow) and 2000s (red) (Peylin et al., 2013; data source: http://transcom.Isce.ipsl.fr/), and (2) as simulated by 10 dynamic vegetation models (DGVMs) for the 1990s (green) and 2000s (light green) (Piao et al., 2013; data source: http://www-Iscedods.cea.fr/invsat/RECCAP/). The divisions of land regions are shown in the map. (Bottom) Bar plots showing decadal average $\mathrm{CO}_{2}$ fluxes for 11 ocean regions (1) as estimated by 10 different atmospheric $\mathrm{CO}_{2}$ inversions for the 1990 s (yellow) and 2000s (red) (data source: http://transcom.Isce.ipsl.fr/), (2) inversion of contemporary interior ocean carbon measurements using 10 ocean transport models (dark blue) (Gruber et al., 2009) and (3) surface ocean pCO ${ }_{2}$ measurements based air-sea exchange climatology (Takahashi et al., 2009). The divisions of 11 ocean regions are shown in the map. 
Table 6.6 | Regional $\mathrm{CO}_{2}$ budgets using top-down estimates (atmospheric inversions) and bottom-up estimates (inventory data, biogeochemical modelling, eddy-covariance), excluding fossil fuel emissions. A positive sign indicates a flux from the atmosphere to the land (i.e., a land sink).

\begin{tabular}{|c|c|c|c|c|}
\hline Region & $\mathrm{CO}_{2}$ Sink $\left(\mathrm{PgC} \mathrm{yr}^{-1}\right)$ & Uncertainty ${ }^{a}$ & Period & Reference \\
\hline Artic Tundra & 0.1 & $\pm 0.3^{\mathrm{b}}$ & $2000-2006$ & McGuire et al. (2012) \\
\hline Australia & 0.04 & \pm 0.03 & 1990-2009 & Haverd et al. (2013) \\
\hline Europe & 0.9 & \pm 0.2 & $2001-2005$ & Luyssaert et al. (2012) \\
\hline North America & 0.6 & \pm 0.02 & $2000-2005$ & King et al. (2012) \\
\hline South America & -0.3 & \pm 0.3 & 2000-2005 & Gloor et al. (2012) \\
\hline
\end{tabular}

Notes:

a One standard deviation from mean unless indicated otherwise.

b Based on range provided.

6.3.2.6.3 Interannual variability in atmosphere-to-land carbon dioxide fluxes

The interannual variability of the residual land sink shown in Figures 6.12 and 6.16 accounts for most of the interannual variability of the atmospheric $\mathrm{CO}_{2}$ growth rate (see Section 6.3.2.3). Atmospheric $\mathrm{CO}_{2}$ inversion results suggest that tropical land ecosystems dominate the global $\mathrm{CO}_{2}$ variability, with positive anomalies during El Niño episodes (Bousquet et al., 2000; Rödenbeck et al., 2003; Baker et al., 2006), which is consistent with the results of one inversion of atmospheric ${ }^{13} \mathrm{C}$ and $\mathrm{CO}_{2}$ measurements (Rayner et al., 2008). A combined El Niño-Southern Oscillation (ENSO)-Volcanic index time series explains $75 \%$ of the observed variability (Raupach et al., 2008). A positive phase of ENSO (El Niño, see Glossary) is generally associated with enhanced land $\mathrm{CO}_{2}$ source, and a negative phase (La Niña) with enhanced land $\mathrm{CO}_{2}$ sink (Jones and Cox, 2001; Peylin et al., 2005). Observations from eddy covariance networks suggest that interannual carbon flux variability in the tropics and temperate regions is dominated by precipitation, while boreal ecosystem fluxes are more sensitive to temperature and shortwave radiation variation (Jung et al., 2011), in agreement with the results from process-based terrestrial ecosystem models (Piao et al., 2009a). Terrestrial biogeochemical models suggest that interannual net biome productivity (NBP) variability is dominated by GPP (see Glossary) rather than terrestrial ecosystem respiration (Piao et al., 2009b; Jung et al., 2011).

\subsection{Carbon fluxes from inland water}

Global analyses estimate that inland waters receive about 1.7 to 2.7 $\mathrm{PgC} \mathrm{yr}^{-1}$ emitted by soils to rivers headstreams, of which, 0.2 to 0.6 $\mathrm{PgC} \mathrm{yr}^{-1}$ is buried in aquatic sediments, 0.8 to $1.2 \mathrm{PgC} \mathrm{yr}^{-1}$ returns to the atmosphere as $\mathrm{CO}_{2}$, and $0.9 \mathrm{PgC} \mathrm{yr}^{-1}$ is delivered to the ocean (Cole et al., 2007; Battin et al., 2009; Aufdenkampe et al., 2011). Estimates of the transport of carbon from land ecosystems to the coastal ocean by rivers are $\sim 0.2 \mathrm{PgC} \mathrm{yr}^{-1}$ for Dissolved Organic Carbon (DOC), 0.3 $\mathrm{PgC} \mathrm{yr}^{-1}$ for Dissolved Inorganic Carbon (DIC), and 0.1 to $0.4 \mathrm{PgC} \mathrm{yr}^{-1}$ for Particulate Organic Carbon (POC) (Seitzinger et al., 2005; Syvitski et al., 2005; Mayorga et al., 2010). For the DIC fluxes, only about twothirds of it originates from atmospheric $\mathrm{CO}_{2}$ and the rest of the carbon is supplied by weathered carbonate rocks (Suchet and Probst, 1995; Gaillardet et al., 1999; Oh and Raymond, 2006; Hartmann et al., 2009).
Regional DIC concentrations in rivers has increased during the Industrial Era (Oh and Raymond, 2006; Hamilton et al., 2007; Perrin et al., 2008). Agricultural practices coupled with climate change can lead to large increases in regional scale DIC export in watersheds with a large agricultural footprint (Raymond et al., 2008). Furthermore, regional urbanization also elevates DIC fluxes in rivers (Baker et al., 2008; Barnes and Raymond, 2009), which suggests that anthropogenic activities have contributed a significant portion of the annual global river DIC flux to the ocean.

Land clearing and management are thought to produce an acceleration of POC transport, much of which is trapped in alluvial and colluvial deposition zones, lakes, reservoirs and wetlands (Stallard, 1998; Smith et al., 2001b; Syvitski et al., 2005). Numerous studies have demonstrated an increase in the concentration of DOC in rivers in the northeastern United States and northern/central Europe over the past two to four decades (Worrall et al., 2003; Evans et al., 2005; Findlay, 2005; Monteith et al., 2007; Lepistö et al., 2008). Owing to the important role of wetlands in DOC production, the mobilization of DOC due to human-induced changes in wetlands probably represents an important cause of changes in global river DOC fluxes to date (Seitzinger et al., 2005), although a global estimate of this alteration is not available. A robust partitioning between natural and anthropogenic carbon fluxes in freshwater systems is not yet possible, nor a quantification of the ultimate fate of carbon delivered by rivers to the coastal and open oceans.

\subsection{Processes driving terrestrial atmosphere-to-land} carbon dioxide fluxes

Assessment of experimental data, observations and model results suggests that the main processes responsible for the residual land sink include the $\mathrm{CO}_{2}$ fertilisation effect on photosynthesis (see Box 6.3), nitrogen fertilisation by increased deposition (Norby, 1998; Thornton et al., 2007; Bonan and Levis, 2010; Zaehle and Dalmonech, 2011) and climate effects (Nemani et al., 2003; Gloor et al., 2009). It is likely that reactive nitrogen deposition over land currently increases natural $\mathrm{CO}_{2}$ in particular in forests, but the magnitude of this effect varies between regions (Norby, 1998; Thornton et al., 2007; Bonan and Levis, 2010; Zaehle and Dalmonech, 2011). Processes responsible for the net atmosphere-to-land $\mathrm{CO}_{2}$ sink on terrestrial ecosystems include, in addition, forest regrowth and afforestation (Myneni et al., 2001; 


\section{Box 6.3 | The Carbon Dioxide Fertilisation Effect}

Elevated atmospheric $\mathrm{CO}_{2}$ concentrations lead to higher leaf photosynthesis and reduced canopy transpiration, which in turn lead to increased plant water use efficiency and reduced fluxes of surface latent heat. The increase in leaf photosynthesis with rising $\mathrm{CO}_{2}$, the so-called $\mathrm{CO}_{2}$ fertilisation effect, plays a dominant role in terrestrial biogeochemical models to explain the global land carbon sink (Sitch et al., 2008), yet it is one of most unconstrained process in those models.

Field experiments provide a direct evidence of increased photosynthesis rates and water use efficiency (plant carbon gains per unit of water loss from transpiration) in plants growing under elevated $\mathrm{CO}_{2}$. These physiological changes translate into a broad range of higher plant carbon accumulation in more than two-thirds of the experiments and with increased net primary productivity (NPP) of about 20 to $25 \%$ at double $\mathrm{CO}_{2}$ from pre-industrial concentrations (Ainsworth and Long, 2004; Luo et al., 2004, 2006; Nowak et al., 2004; Norby et al., 2005; Canadell et al., 2007a; Denman et al., 2007; Ainsworth et al., 2012; Wang et al., 2012a). Since the AR4, new evidence is available from long-term Free-air $\mathrm{CO}_{2}$ Enrichment (FACE) experiments in temperate ecosystems showing the capacity of ecosystems exposed to elevated $\mathrm{CO}_{2}$ to sustain higher rates of carbon accumulation over multiple years (Liberloo et al., 2009; McCarthy et al., 2010; Aranjuelo et al., 2011; Dawes et al., 2011; Lee et al., 2011; Zak et al., 2011). However, FACE experiments also show the diminishing or lack of $\mathrm{CO}_{2}$ fertilisation effect in some ecosystems and for some plant species (Dukes et al., 2005; Adair et al., 2009; Bader et al., 2009; Norby et al., 2010; Newingham et al., 2013). This lack of response occurs despite increased water use efficiency, also confirmed with tree ring evidence (Gedalof and Berg, 2010; Peñuelas et al., 2011).

Nutrient limitation is hypothesized as primary cause for reduced or lack of $\mathrm{CO}_{2}$ fertilisation effect observed on NPP in some experiments (Luo et al., 2004; Dukes et al., 2005; Finzi et al., 2007; Norby et al., 2010). Nitrogen and phosphorus are very likely to play the most important role in this limitation of the $\mathrm{CO}_{2}$ fertilisation effect on NPP, with nitrogen limitation prevalent in temperate and boreal ecosystems, and phosphorus limitation in the tropics (Luo et al., 2004; Vitousek et al., 2010; Wang et al., 2010a; Goll et al., 2012). Micronutrients interact in diverse ways with other nutrients in constraining NPP such as molybdenum and phosphorus in the tropics (Wurzburger et al., 2012). Thus, with high confidence, the $\mathrm{CO}_{2}$ fertilisation effect will lead to enhanced NPP, but significant uncertainties remain on the magnitude of this effect, given the lack of experiments outside of temperate climates.

Pacala et al., 2001; Houghton, 2010; Bellassen et al., 2011; Williams et al., 2012a), changes in forest management and reduced harvest rates (Nabuurs et al., 2008).

Process attribution of the global land $\mathrm{CO}_{2}$ sink is difficult due to limited availability of global data sets and biogeochemical models that include all major processes. However, regional studies shed light on key drivers and their interactions. The European and North American carbon sinks are explained by the combination of forest regrowth in abandoned lands and decreased forest harvest along with the fertilisation effects of rising $\mathrm{CO}_{2}$ and nitrogen deposition (Pacala et al., 2001; Ciais et al., 2008; Sutton et al., 2008; Schulze et al., 2010; Bellassen et al., 2011; Williams et al., 2012a). In the tropics, there is evidence from forest inventories that increasing forest growth rates are not explained by the natural recovery from disturbances, suggesting that increasing atmospheric $\mathrm{CO}_{2}$ and climate change play a role in the observed sink in established forests (Lewis et al., 2009; Pan et al., 2011). There is also recent evidence of tropical nitrogen deposition becoming more notable although its effects on the net carbon balance have not been assessed (Hietz et al., 2011).

The land carbon cycle is very sensitive to climate changes (e.g., precipitation, temperature, diffuse vs. direct radiation), and thus the changes in the physical climate from increasing GHGs as well as in the diffuse fraction of sunlight are likely to be causing significant changes in the carbon cycle (Jones et al., 2001; Friedlingstein et al., 2006; Mercado et al., 2009). Changes in the climate are also associated with disturbances such as fires, insect damage, storms, droughts and heat waves which are already significant processes of interannual variability and possibly trends of regional land carbon fluxes (Page et al., 2002; Ciais et al., 2005; Chambers et al., 2007; Kurz et al., 2008b; Clark et al., 2010; van der Werf et al., 2010; Lewis et al., 2011) (see Section 6.3.2.2).

Warming (and possibly the $\mathrm{CO}_{2}$ fertilisation effect) has also been correlated with global trends in satellite greenness observations, which resulted in an estimated 6\% increase of global NPP, or the accumulation of 3.4 PgC on land over the period 1982-1999 (Nemani et al., 2003). This enhanced NPP was attributed to the relaxation of climatic constraints to plant growth, particularly in high latitudes. Concomitant to the increased of NPP with warming, global soil respiration also increased between 1989 and 2008 (Bond-Lamberty and Thomson, 2010), reducing the magnitude of the net land sink. A recent study suggests a declining NPP trend over 2000-2009 (Zhao and Running, 2010) although the model used to reconstruct NPP trends from satellite observation has not been widely accepted (Medlyn, 2011; Samanta et al., 2011).

\subsection{Model evaluation of global and regional terrestrial carbon balance}

Evaluation of global process-based land carbon models was performed against ground and satellite observations including (1) measured $\mathrm{CO}_{2}$ 
fluxes and carbon storage change at particular sites around the world, in particular sites from the Fluxnet global network (Baldocchi et al., 2001; Jung et al., 2007; Stöckli et al., 2008; Schwalm et al., 2010; Tan et al., 2010), (2) observed spatio-temporal change in leaf area index (LAI) (Lucht et al., 2002; Piao et al., 2006) and (3) interannual and seasonal change in atmospheric $\mathrm{CO}_{2}$ (Randerson et al., 2009; Cadule et al., 2010).

Figure 6.16 compares the global land $\mathrm{CO}_{2}$ sink driven by climate change and rising $\mathrm{CO}_{2}$ as simulated by different process based carbon cycle models (without land use change), with the residual land sink computed as the sum of fossil fuel and cement emissions and land use change emissions minus the sum of $\mathrm{CO}_{2}$ growth rate and ocean sink (Le Quéré et al., 2009; Friedlingstein et al., 2010). Although these two quantities are not the same, the multi-model mean reproduces well the trend and interannual variability of the residual land sink which is dominated by climate variability and climate trends and $\mathrm{CO}_{2}$, respectively, both represented in models (Table 6.7). Limited availability of in situ measurements, particularly in the tropics, limits the progress towards reducing uncertainty on model parameterizations.

Regional and local measurements can be used to evaluate and improve global models. Regionally, forest inventory data show that the forest carbon sink density over Europe is of $-89 \pm 19 \mathrm{gC} \mathrm{m}^{-2} \mathrm{yr}^{-1}$, which is compatible with model estimates with afforestation $\left(-63 \mathrm{gC} \mathrm{m}^{-2}\right.$ $\mathrm{yr}^{-1}$; Luyssaert et al., 2010), while modelled NPP was $43 \%$ larger than the inventory estimate. In North America, the ability of 22 terrestrial carbon cycle models to simulate the seasonal cycle of land-atmosphere $\mathrm{CO}_{2}$ exchange from 44 eddy covariance flux towers was poor with a difference between observations and simulations of 10 times the observational uncertainty (Schwalm et al., 2010). Model shortcomings included spring phenology, soil thaw, snow pack melting and lag responses to extreme climate events (Keenan et al., 2012). In China, the magnitude of the carbon sink estimated by five terrestrial ecosystem models $\left(-0.22\right.$ to $\left.-0.13 \mathrm{PgC} \mathrm{yr}^{-1}\right)$ was comparable to the observation-based estimate $\left(-0.18 \pm 0.73 \mathrm{PgC} \mathrm{yr}^{-1}\right.$; Piao et al., 2009a), but modelled interannual variation was weakly correlated to observed regional land-atmosphere $\mathrm{CO}_{2}$ fluxes (Piao et al., 2011).

Sensitivity of the terrestrial carbon cycle to rising atmospheric carbon dioxide. An inter-comparison of 10 process-based models showed increased NPP by $3 \%$ to $10 \%$ over the last three decades, during which $\mathrm{CO}_{2}$ increased by $\sim 50 \mathrm{ppm}$ (Piao et al., 2013). These results are consistent within the broad range of responses from experimental studies (see Box 6.3). However, Hickler et al. (2008) suggested that currently available FACE results (largely from temperate regions) are not applicable to vegetation globally because there may be large spatial heterogeneity in vegetation responses to $\mathrm{CO}_{2}$ fertilisation.

Table 6.7 | Estimates of the land $\mathrm{CO}_{2}$ sink from process-based terrestrial ecosystem models driven by rising $\mathrm{CO}_{2}$ and by changes in climate. The land sink simulated by these models is close to but not identical to the terrestrial $\mathrm{CO}_{2}$ sink from Table 6.1 because the models calculate the effect of $\mathrm{CO}_{2}$ and climate over managed land, and many do not include nitrogen limitation and disturbances.

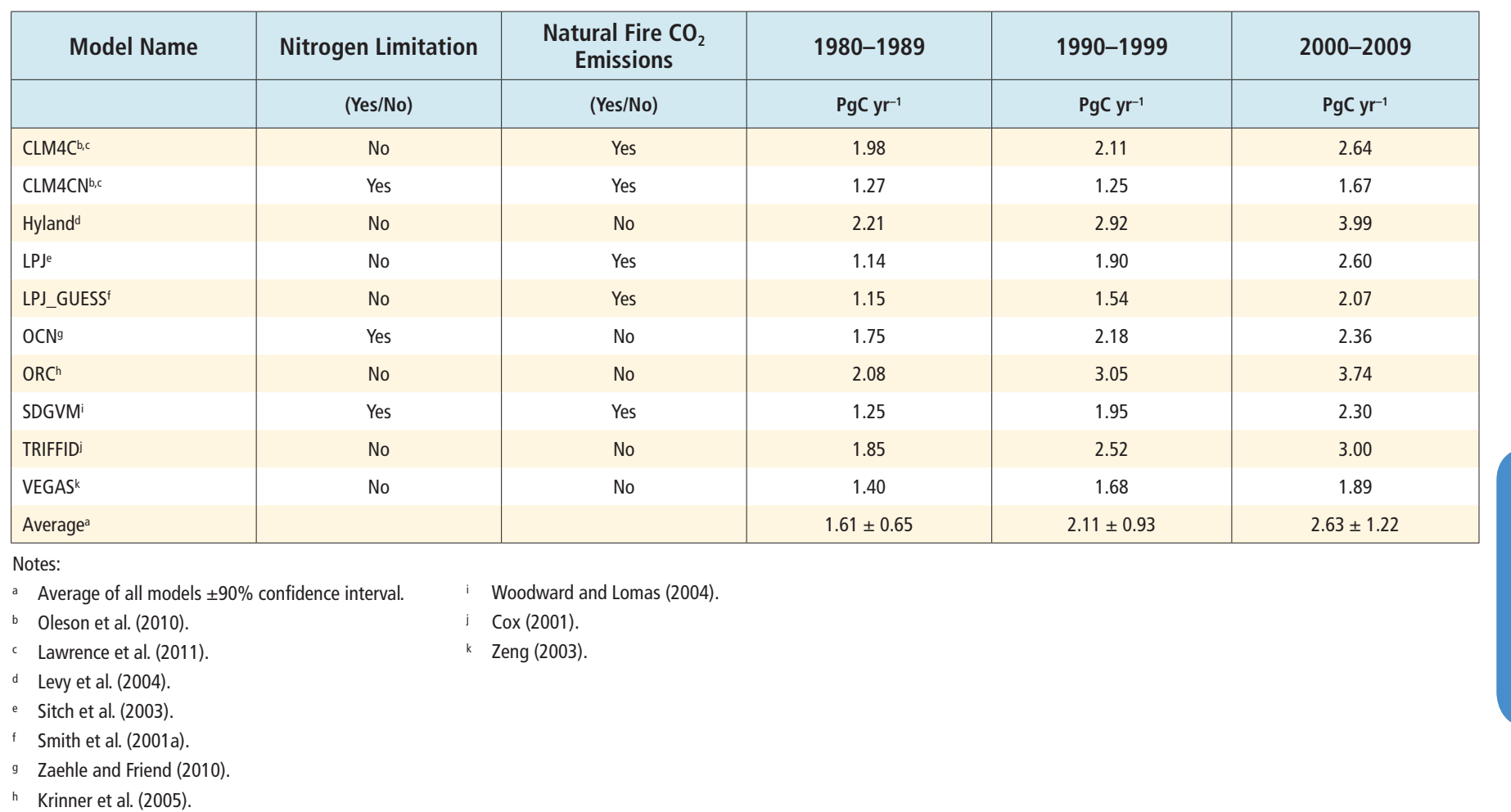

All of these models run are forced by rising $\mathrm{CO}_{2}$ concentration and time-varying historical reconstructed weather and climate fields using the same protocol from the TRENDY project (Piao et al. 2013). (http://www.globalcarbonproject.org/global/pdf/DynamicVegetationModels.pdf).

CLM4C = Community Land Model for Carbon; CLM4CN = Community Land Model for Carbon-Nitrogen; GUESS = General Ecosystem Simulator; LPJ = Lund-Potsdam-Jena Dynamic Global Vegetation Model; OCN = Cycling of Carbon and Nitrogen on land, derived from ORCHIDEE model; ORC = ORCHIDEE, ORganizing Carbon and Hydrology in Dynamic EcosystEms model; SDGVM = Sheffield Dynamic Global Vegetation Model; TRIFFID = Top-down Representation of Interactive Foliage and Flora Including Dynamics; VEGAS = VEgetation-Global-Atmosphere-Soil terrestrial carbon cycle model. 


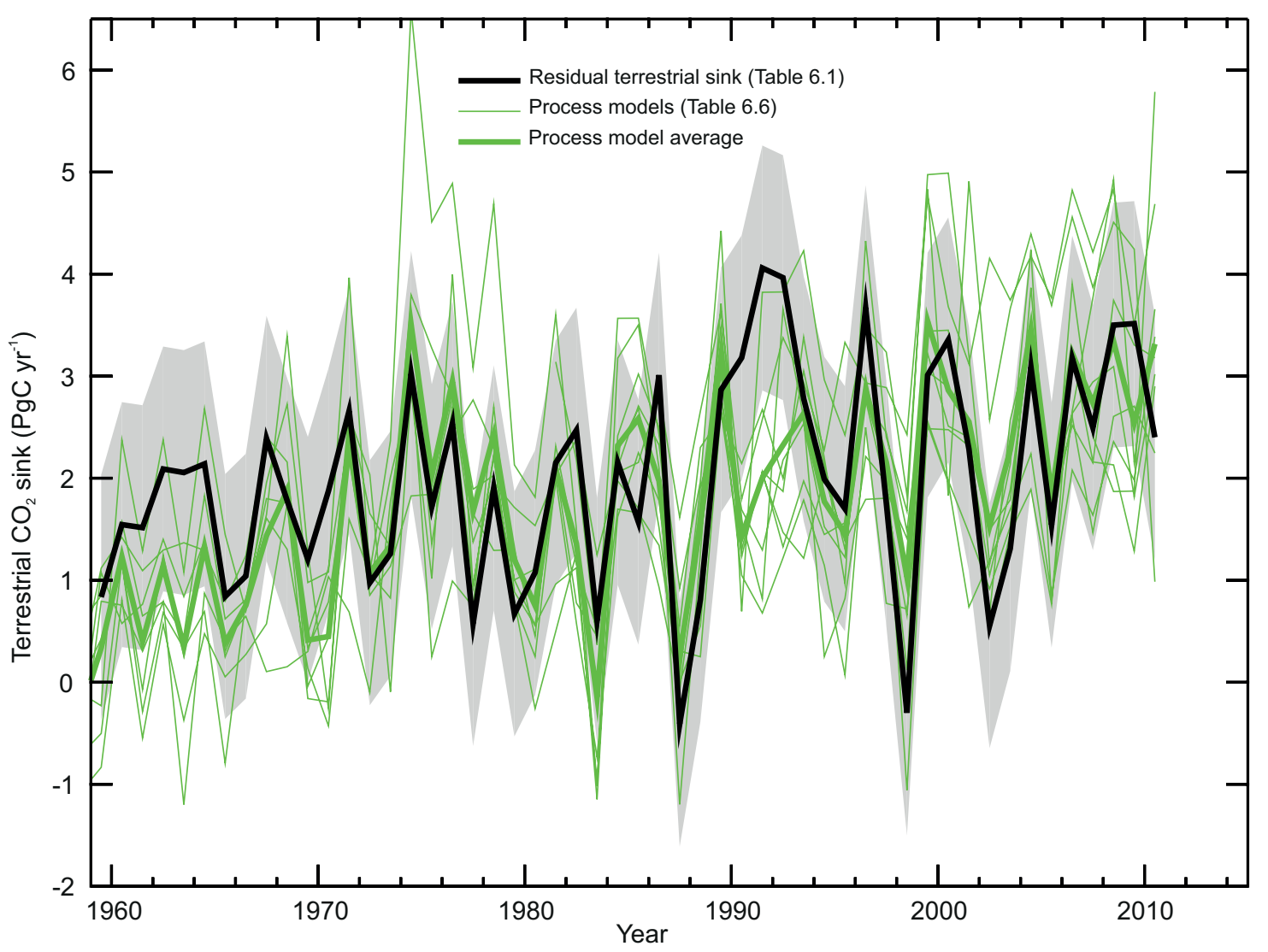

Figure 6.16 The black line and gray shading represent the estimated value of the residual land sink (PgC yr-1) and its uncertainty from Table 6.1, which is calculated from the difference between emissions from fossil fuel and land use change plus emissions from net land use change, minus the atmospheric growth rate and the ocean sink. The atmosphereto-land flux simulated by process land ecosystem models from Table 6.7 are shown in thin green, and their average in thick green. A positive atmosphere-to-land flux represents a sink of $\mathrm{CO}_{2}$. The definition of the atmosphere-to-land flux simulated by these models is close to but not identical to the residual land sink from Table 6.1 (see Table 6.7).

Sensitivity of terrestrial carbon cycle to climate trends and variability. Warming exerts a direct control on the net land-atmosphere $\mathrm{CO}_{2}$ exchange because both photosynthesis and respiration are sensitive to changes in temperature. From estimates of interannual variations in the residual land sink, $1^{\circ} \mathrm{C}$ of positive global temperature anomaly leads to a decrease of $4 \mathrm{PgC} \mathrm{yr}^{-1}$ of the global land $\mathrm{CO}_{2}$ sink (Figure 6.17). This observed interannual response is close to the response of the models listed in Table $6.7\left(-3.5 \pm 1.5 \mathrm{PgC} \mathrm{yr}^{-10} \mathrm{C}^{-1}\right.$ in Piao et al., 2013), albeit individual models show a range going from -0.5 to -6.2 $\mathrm{PgC} \mathrm{yr}{ }^{-1} \mathrm{C}^{-1}$. The sensitivity of atmospheric $\mathrm{CO}_{2}$ concentration to century scale temperature change was estimated at about 3.6 to $45.6 \mathrm{PgC}$ ${ }^{\circ} \mathrm{C}^{-1}$ (or 1.7 to $21.4 \mathrm{ppm} \mathrm{CO}{ }_{2}^{\circ} \mathrm{C}^{-1}$ ) using the ice core observed $\mathrm{CO}_{2}$ drop during the Little Ice Age (see Section 6.2; Frank et al., 2010).

Terrestrial carbon cycle models used in AR5 generally underestimate GPP in the water limited regions, implying that these models do not correctly simulate soil moisture conditions, or that they are too sensitive to changes in soil moisture (Jung et al., 2007). Most models (Table 6.7) estimated that the interannual precipitation sensitivity of the global land $\mathrm{CO}_{2}$ sink to be higher than that of the observed residual land sink $\left(-0.01 \mathrm{PgC} \mathrm{yr}^{-1} \mathrm{~mm}^{-1}\right.$; Figure 6.17).

Processes missing in terrestrial carbon cycle models. First, many models do not explicitly take into account the various forms of disturbances or ecosystem dynamics: migration, fire, logging, harvesting, insect outbreaks and the resulting variation in forest age structure which is known to affect the net carbon exchange (Kurz et al., 2008c; Bellassen et al., 2010; Higgins and Harte, 2012). Second, many key processes relevant to decomposition of carbon are missing in models (Todd-Brown et al., 2012), and particularly for permafrost carbon and for carbon in boreal and tropical wetlands and peatlands, despite the large amount of carbon stored in these ecosystems and their vulnerability to warming and land use change (Tarnocai et al., 2009; Hooijer et al., 2010; Page et al., 2011). However, progress has been made (Wania et al., 2009; Koven et al., 2011; Schaefer et al., 2011). Third, nutrient dynamics are taken into account only by few models despite the fact it is well established that nutrient constrains NPP and nitrogen deposition enhances NPP (Elser et al., 2007; Magnani et al., 2007; LeBauer and Treseder, 2008); see Section 6.3.2.6.5. Very few models have phosphorus dynamics (Zhang et al., 2011; Goll et al., 2012). Fourth, the negative effects of elevated tropospheric ozone on NPP have not been taken into account by most current carbon cycle models (Sitch et al., 2007). Fifth, transfer of radiation, water and heat in the vegetation-soil-atmosphere continuum are treated very simply in the global ecosystem models. Finally, processes that transport carbon at the surface (e.g., water and tillage erosion; Quinton et al., 2010) and human managements including fertilisation and irrigation (Gervois et al., 2008) are poorly or not represented at all. Broadly, models are still at their early stages in dealing with land use, land use change and forestry. 


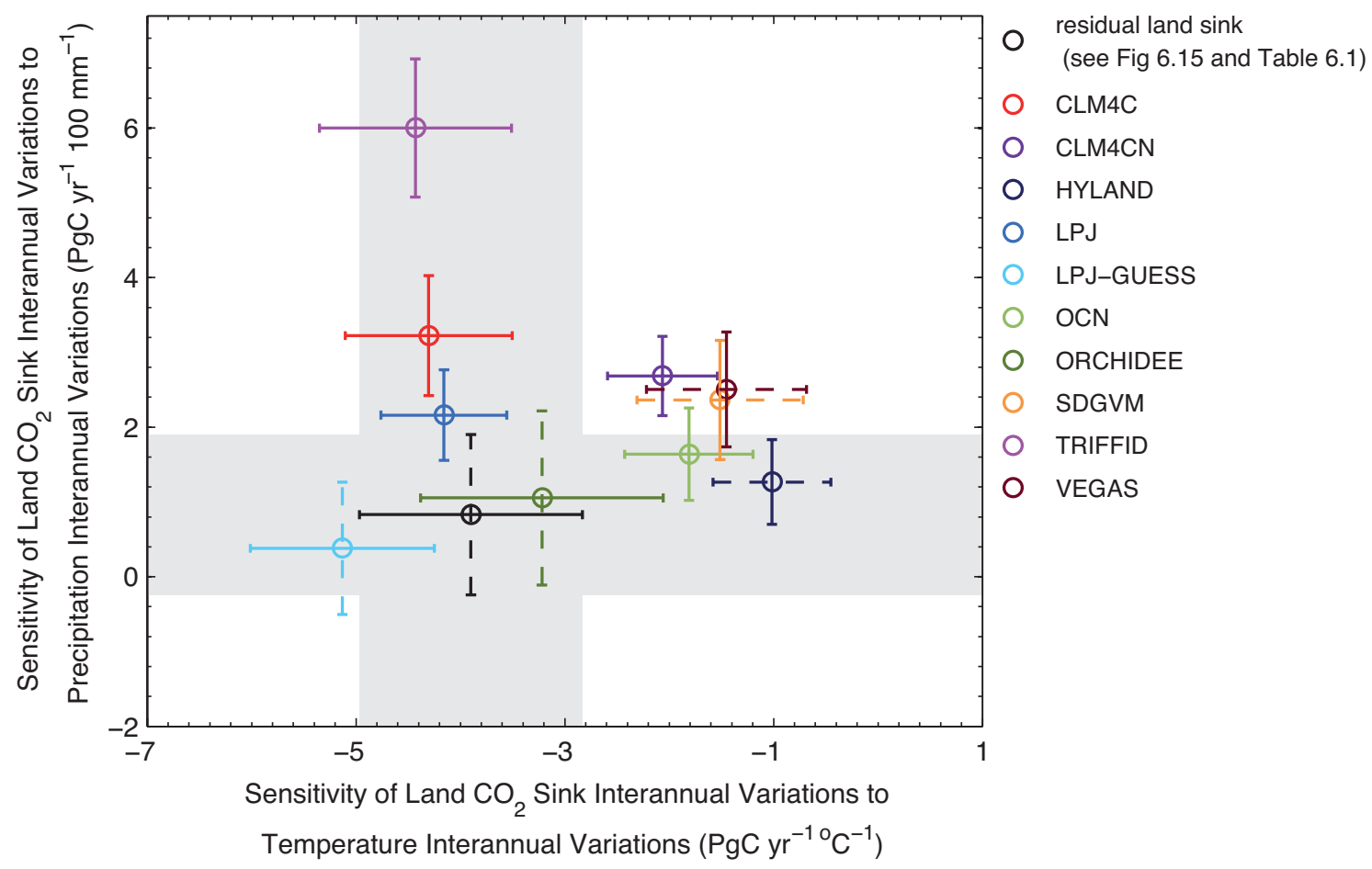

Figure 6.17 The response of interannual land $\mathrm{CO}_{2}$ flux anomaly to per $1{ }^{\circ} \mathrm{C}$ interannual temperature anomaly and per 100 mm interannual precipitation anomaly during 1980-2009. Black circles show climate sensitivity of land $\mathrm{CO}_{2}$ sink estimated from the residual land sink (see Figure 6.15 and Table 6.1), which is the sum of fossil fuel and cement emissions and land use change emissions minus the sum of observed atmospheric $\mathrm{CO}_{2}$ growth rate and modeled ocean sink sink (Le Quéré et al., 2009; Friedlingstein and Prentice, 2010). Coloured circles show land $\mathrm{CO}_{2}$ sink estimated by 10 process-based terrestrial carbon cycle models (CLM4C (Community Land Model for Carbon), CLM4CN (Community Land Model for Carbon-Nitrogen), HYLAND (HYbrid LAND terrestrial ecosystem model), LPJ (Lund-Potsdam-Jena Dynamic Global Vegetation Model), LPJ-GUESS (LPJ-General Ecosystem Simulator, OCN (Cycling of Carbon and Nitrogen on land, derived from ORCHIDEE model), ORCHIDEE (ORganizing Carbon and Hydrology in Dynamic EcosystEms model), SDGVM (Sheffield Dynamic Global Vegetation Model), TRIFFID (Top-down Representation of Interactive Foliage and Flora Including Dynamics) and VEGAS (terrestrial vegetation and carbon model)). Error bars show standard error of the sensitivity estimates. Dashed error bars indicate the estimated sensitivity by the regression approach is statistically insignificant $(P>$ 0.05). Grey area denoted the area bounded by the estimated climate sensitivity of the residual land sink \pm the standard error of the estimated climate sensitivity of the residual land sink. The sensitivity of land $\mathrm{CO}_{2}$ sink interannual variations to interannual variations of temperature (or precipitation) is estimated as the regression coefficient of temperature (or precipitation) in a multiple regression of detrended anomaly of land $\mathrm{CO}_{2}$ sink against detrended anomaly of annual mean temperature and annual precipitation.

\subsubsection{Global Methane Budget}

AR5 is the first IPCC assessment report providing a consistent synthesis of the $\mathrm{CH}_{4}$ budget per decade using multiple atmospheric $\mathrm{CH}_{4}$ inversion models (top-down) and process-based models and inventories (bottom-up). Table 6.8 shows the budgets for the decades of 1980s, 1990s and 2000s. Uncertainties on emissions and sinks are listed using minimum and maximum of each published estimate for each decade. Bottom-up approaches are used to attribute decadal budgets to individual processes emitting $\mathrm{CH}_{4}$ (see Section 6.1.1.2 for a general overview). Top-down inversions provide an atmospheric-based constraint mostly for the total $\mathrm{CH}_{4}$ source per region, and the use of additional observations (e.g., isotopes) allows inferring emissions per source type. Estimates of $\mathrm{CH}_{4}$ sinks in the troposphere by reaction with tropospheric $\mathrm{OH}$, in soils and in the stratosphere are also presented. Despite significant progress since the AR4, large uncertainties remain in the present knowledge of the budget and its evolution over time.

\subsubsection{Atmospheric Changes}

Since the beginning of the Industrial Era, the atmospheric $\mathrm{CH}_{4}$ concentration increased by a factor of 2.5 (from 722 ppb to 1803 ppb in 2011).
$\mathrm{CH}_{4}$ is currently measured by a network of more than 100 surface sites (Blake et al., 1982; Cunnold et al., 2002; Langenfelds et al., 2002; Dlugokencky et al., 2011), aircraft profiles (Brenninkmeijer et al., 2007), satellite (Wecht et al., 2012; Worden et al., 2012) and before 1979 from analyses of firn air and ice cores (see Sections 5.2.2 and Section 6.2, and Figure 6.11). The growth of $\mathrm{CH}_{4}$ in the atmosphere is largely in response to increasing anthropogenic emissions. The vertically averaged atmospheric $\mathrm{CH}_{4}$ concentration field can be mapped by remote sensing from the surface using Fourier Transform Infrared Spectroscopy (FTIR) instruments (Total Carbon Column Observing Network, TCCON, http://www.tccon.caltech.edu/) and from space by several satellite instruments: Atmospheric Infrared Sounder (AIRS, since 2002; http:// airs.jpl.nasa.gov), Tropospheric Emission Spectrometer (TES, since 2004; http://tes.jpl.nasa.gov), Infrared Atmospheric Sounder Interferometer (IASI, since 2006; Crévoisier et al., 2009), Scanning Imaging Spectrometer for Atmospheric Cartography (SCIAMACHY, 2003-2012; Frankenberg et al., 2008), and Greenhouse Gases Observing Satellite-Thermal And Near infrared Sensor for carbon Observation Fourier-Transform Spectrometer (GOSAT-TANSO-FTS, since 2009; Morino et al., 2011). As an example, SCIAMACHY shows the column $\mathrm{CH}_{4}$ gradient between the two hemispheres as well as increased concentrations over Southeast Asia, due to emissions from agriculture, wetlands, waste and 
energy production (Frankenberg et al., 2008). In situ observations provide very precise measurements $(\sim 0.2 \%)$ but unevenly located at the surface of the globe. Satellite data offer a global coverage at the cost of a lower precision on individual measurements $(\sim 2 \%)$ and possible biases (Bergamaschi et al., 2009).

The growth rate of $\mathrm{CH}_{4}$ has declined since the mid-1980s, and a near zero growth rate (quasi-stable concentrations) was observed during 1999-2006, suggesting an approach to steady state where the sum of emissions are in balance with the sum of sinks (Dlugokencky et al., 2003; Khalil et al., 2007; Patra et al., 2011; Figure 6.18). The reasons for this growth rate decline after the mid-1980s are still debated, and results from various studies provide possible scenarios: (1) a reduction of anthropogenic emitting activities such as coal mining, gas industry and/or animal husbandry, especially in the countries of the former Soviet Union (Dlugokencky et al., 2003; Chen and Prinn, 2006; Savolainen et al., 2009; Simpson et al., 2012); (2) a compensation between increasing anthropogenic emissions and decreasing wetland emissions (Bousquet et al., 2006; Chen and Prinn, 2006); (3) significant (Rigby et al., 2008) to small (Montzka et al., 2011) changes in OH concentrations and/or based on two different ${ }^{13} \mathrm{CH}_{4}$ data sets; (4) reduced emissions from rice paddies attributed to changes in agricultural practices (Kai et al., 2011); or (5) stable microbial and fossil fuel emissions from 1990 to 2005 (Levin et al., 2012).

Since 2007, atmospheric $\mathrm{CH}_{4}$ has been observed to increase again (Rigby et al., 2008; Dlugokencky et al., 2009) with positive anomalies of emissions of $21 \mathrm{Tg}\left(\mathrm{CH}_{4}\right) \mathrm{yr}^{-1}$ and $18 \mathrm{Tg}\left(\mathrm{CH}_{4}\right) \mathrm{yr}^{-1}$ estimated by inversions during 2007 and 2008, respectively (Bousquet et al., 2011) as compared to the 1999-2006 period. The increase of emissions in 2007-2008 was dominated by tropical regions (Bousquet et al., 2011), with a major contribution from tropical wetlands and some contribution from high-latitude wetlands during the 2007 anomaly (Dlugokencky et al., 2009; Bousquet et al., 2011). This increase is suggested by the growth rate over latitude in Figure 6.18 (Dlugokencky et al., 2009). The recent increase of $\mathrm{CH}_{4}$ concentration since 2007 is also consistent
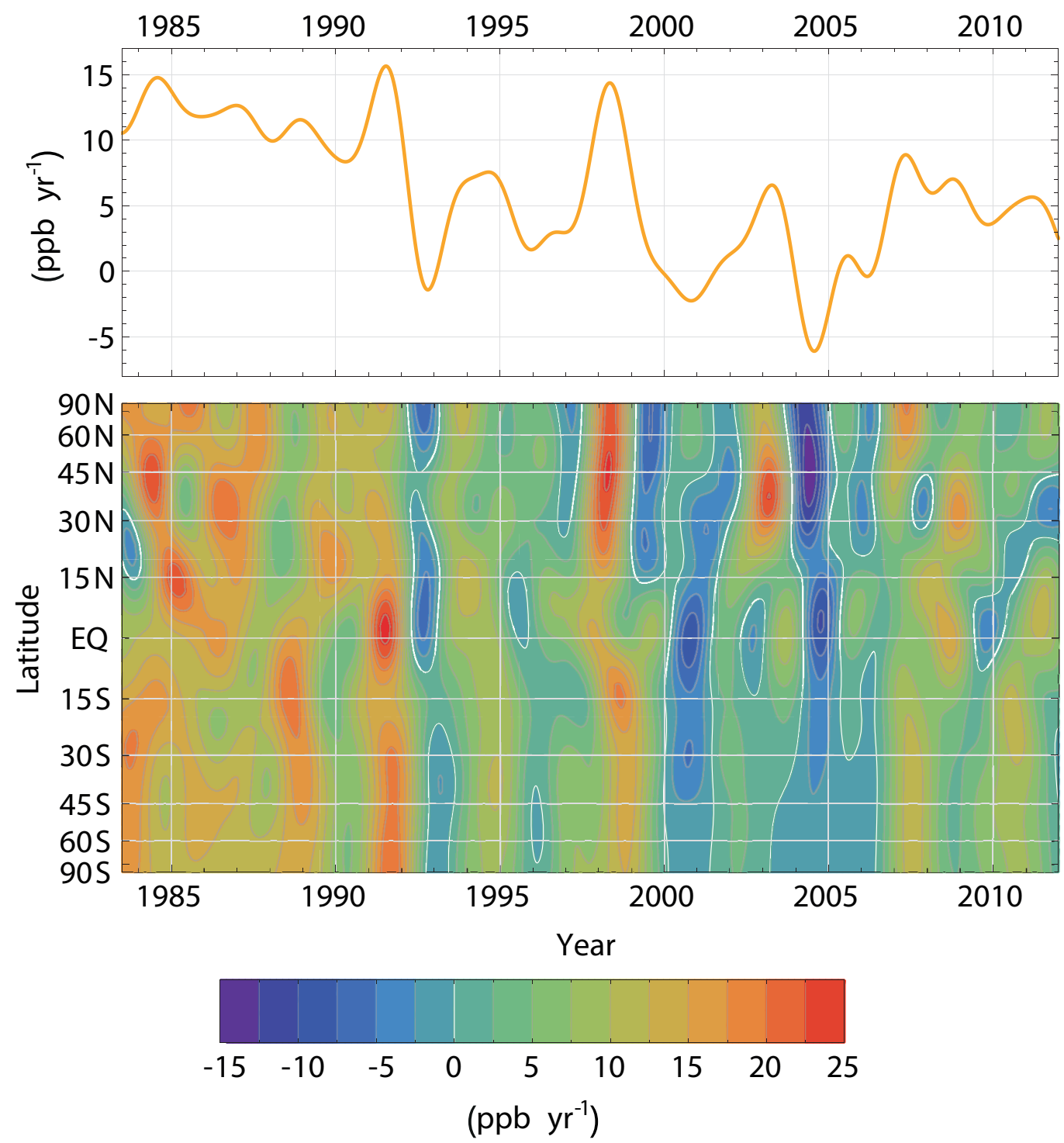

Figure 6.18 (Top) Globally averaged growth rate of atmospheric $\mathrm{CH}_{4}$ in ppb yr-1 determined from the National Oceanic and Atmospheric Administration-Earth System Research Laboratory (NOAA-ESRL) network, representative for the marine boundary layer. (Bottom) Atmospheric growth rate of $\mathrm{CH}_{4}$ as a function of latitude (Masarie and Tans, 1995; Dlugokencky and Tans, 2013b). 
Table 6.8 Global $\mathrm{CH}_{4}$ budget for the past three decades (in $\mathrm{Tg}\left(\mathrm{CH}_{4}\right) \mathrm{yr}{ }^{-1}$ ) and present day (2011) ${ }^{38}$. The bottom-up estimates for the decade of 2000-2009 are used in the Executive Summary and in Figure 6.2. T-D stands for Top-Down inversions and B-U for Bottom-Up approaches. Only studies covering at least 5 years of each decade have been used. Reported values correspond to the mean of the cited references and therefore not always equal (max-min)/2; likewise, ranges [in brackets] represent minimum and maximum values of the cited references. The sum of sources and sinks from B-U approaches does not automatically balance the atmospheric changes. For B-U studies, individual source types are also presented. For T-D inversions, the 1980s decade starts in 1984. As some atmospheric inversions did not reference their global sink, balance with the atmosphere and the sum of the sources has been assumed. One biomass burning estimate (Schultz et al., 2007) excludes biofuels (a). Stratospheric loss for B-U is the sum of the loss by OH radicals, a $10 \mathrm{Tg} \mathrm{yr}^{-1}$ loss due to 01D radicals (Neef et al., 2010) and a 20 to $35 \%$ contribution due to $\mathrm{Cl}$ radicals ${ }^{24}$ (Allan et al., 2007). Present day budgets ${ }^{39}$ adopt a global mean lifetime of $9.14 \mathrm{yr}( \pm 10 \%)$.

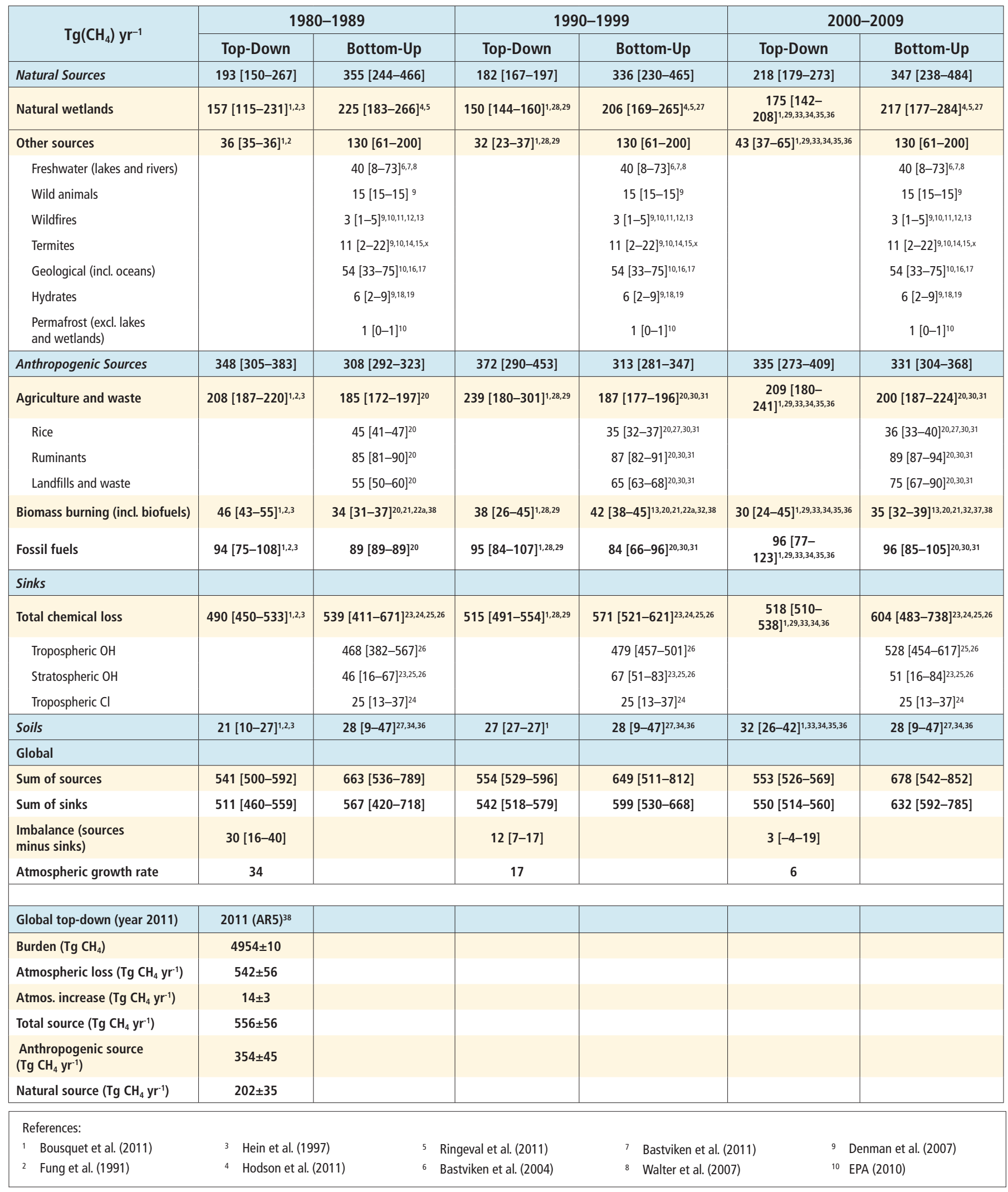




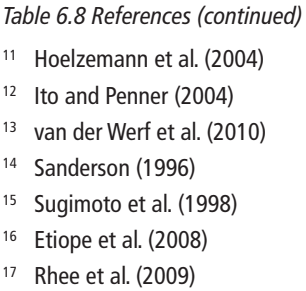

18 Dickens (2003)

19 Shakhova et al. (2010)

20 EDGAR4-database (2009)

21 Mieville et al. (2010)

22 Schultz et al. (2007)

(excluding biofuels)

23 Neef et al. (2010)

\author{
24 Allan et al. (2007) \\ 25 Williams et al. (2012b) \\ 26 Voulgarakis et al. (2013) \\ 27 Spahni et al. (2011) \\ 28 Chen and Prinn (2006) \\ 29 Pison et al. (2009) \\ 30 Dentener et al. (2005)
}

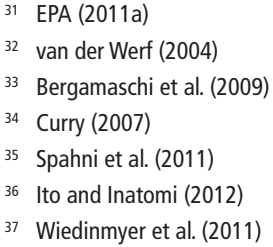

with anthropogenic emission inventories, which show more (EDGAR v4.2) or less (EPA, 2011a) rapidly increasing anthropogenic $\mathrm{CH}_{4}$ emissions in the period 2000-2008. This is related to increased energy production in growing Asian economies (EDGAR, edgar.jrc.ec.europa. eu; EPA, http://www.epa.gov/nonco2/econ-inv/international.html). The atmospheric increase has continued after 2009, at a rate of 4 to $5 \mathrm{ppb}$ $\mathrm{yr}^{-1}$ (Sussmann et al., 2012).

\subsubsection{Methane Emissions}

IThe $\mathrm{CH}_{4}$ growth rate results from the balance between emissions and sinks. Methane emissions around the globe are biogenic, thermogenic or pyrogenic in origin (Neef et al., 2010), and they can be the direct result of either human activities and/or natural processes (see Section 6.1.1.2 and Table 6.8). Biogenic sources are due to degradation of organic matter in anaerobic conditions (natural wetlands, ruminants, waste, landfills, rice paddies, fresh waters, termites). Thermogenic sources come from the slow transformation of organic matter into fossil fuels on geological time scales (natural gas, coal, oil). Pyrogenic sources are due to incomplete combustion of organic matter (biomass and biofuel burning). Some sources can eventually combine a biogenic and a thermogenic origin (e.g., natural geological sources such as oceanic seeps, mud volcanoes or hydrates). Each of these three types of emissions is characterized by ranges in its isotopic composition $\mathrm{in}^{13} \mathrm{C}$ $\mathrm{CH}_{4}$ : typically -55 to $-70 \%$ for biogenic, -25 to $-45 \%$ for thermogenic, and -13 to $-25 \%$ for pyrogenic. These isotopic distinctions provide a basis for attempting to separate the relative contribution of different methane sources using the top-down approach (Bousquet et al., 2006; Neef et al., 2010; Monteil et al., 2011).

During the decade of the 2000s, natural sources of $\mathrm{CH}_{4}$ account for 35 to $50 \%$ of the decadal mean global emissions (Table 6.8). The single most dominant $\mathrm{CH}_{4}$ source of the global flux and interannual variability is $\mathrm{CH}_{4}$ emissions from wetlands (177 to $284 \mathrm{Tg}\left(\mathrm{CH}_{4}\right) \mathrm{yr}{ }^{-1}$ ). With high confidence, climate driven changes of emissions from wetlands are the main drivers of the global inter-annual variability of $\mathrm{CH}_{4}$ emissions. The term 'wetlands' denotes here a variety of ecosystems emitting $\mathrm{CH}_{4}$ in the tropics and the high latitudes: wet soils, swamps, bogs and peatlands. These emissions are highly sensitive to climate change and variability, as shown, for instance, from the high $\mathrm{CH}_{4}$ growth rate in 2007-2008 that coincides with positive precipitation and temperature anomalies (Dlugokencky et al., 2009). Several process-based models of methane emissions from wetlands have been developed and improved since AR4 (Hodson et al., 2011; Ringeval et al., 2011; Spahni et al., 2011; Melton et al., 2013), yet the confidence in modeled wetland $\mathrm{CH}_{4}$ emissions remains low, particularly because of limited observational data sets available for model calibration and evaluation. Spatial distribution and temporal variability of wetlands also remains highly unconstrained in spite the existence of some remote sensing products (Papa et al., 2010). It has been observed that wetland $\mathrm{CH}_{4}$ emissions increase in response to elevated atmospheric $\mathrm{CO}_{2}$ concentrations (van Groenigen et al., 2011). van Groenigen et al. attribute such an increase in $\mathrm{CH}_{4}$ emissions from natural wetlands to increasing soil moisture due to the reduced plant demand for water under higher $\mathrm{CO}_{2}$. However, the sign and magnitude of the $\mathrm{CH}_{4}$ emission response to changes in temperature and precipitation vary among models but show, on average, a decrease of wetland area and $\mathrm{CH}_{4}$ flux with increasing temperature, especially in the tropics, and a modest $(\sim 4 \%)$ increase of wetland area and $\mathrm{CH}_{4}$ flux with increasing precipitation (Melton et al., 2013).

In AR4, natural geological sources were estimated between 4 and 19 $\mathrm{Tg}\left(\mathrm{CH}_{4}\right) \mathrm{yr}^{-1}$. Since then, Etiope et al. (2008) provided improved emission estimates from terrestrial (13 to $\left.29 \mathrm{Tg}\left(\mathrm{CH}_{4}\right) \mathrm{yr}^{-1}\right)$ and marine $(\sim 20$ $\mathrm{Tg}\left(\mathrm{CH}_{4}\right) \mathrm{yr}^{-1}$ ) seepages, mud volcanoes $\left(6\right.$ to $\left.9 \mathrm{Tg}\left(\mathrm{CH}_{4}\right) \mathrm{yr}^{-1}\right)$, hydrates (5 to $10 \mathrm{Tg}\left(\mathrm{CH}_{4}\right) \mathrm{yr}^{-1}$ ) and geothermal and volcanic areas (3 to $6 \mathrm{Tg}\left(\mathrm{CH}_{4}\right)$ $\left.\mathrm{yr}^{-1}\right)$, which represent altogether between 42 and $64 \mathrm{Tg}\left(\mathrm{CH}_{4}\right) \mathrm{yr}^{-1}$ (see Table 6.8 for full range of estimates). This contribution from natural, geological and partly fossil $\mathrm{CH}_{4}$ is larger than in AR4 and consistent with a ${ }^{14} \mathrm{CH}_{4}$ reanalysis showing natural and anthropogenic fossil contributions to the global $\mathrm{CH}_{4}$ budget to be around 30\% (medium confidence) (Lassey et al., 2007) and not around $20 \%$ as previously estimated (e.g., AR4). However, such a large percentage was not confirmed by an analysis of the global atmospheric record of ethane (Simpson et al., 2012) which is co-emitted with geological $\mathrm{CH}_{4}$.

Of the natural sources of $\mathrm{CH}_{4}$, emissions from thawing permafrost and $\mathrm{CH}_{4}$ hydrates in the northern circumpolar region will become potentially important in the 21 st century because they could increase dramatically due to the rapid climate warming of the Arctic and the large carbon pools stored there (Tarnocai et al., 2009; Walter Anthony et al., 2012) (see Section 6.4.3.4). Hydrates are, however, estimated to represent only a very small emission, between 2 and $9 \mathrm{Tg}\left(\mathrm{CH}_{4}\right) \mathrm{yr}^{-1}$ under the current time period (Table 6.8). Supersaturation of dissolved $\mathrm{CH}_{4}$ at the bottom and surface waters in the East Siberian Arctic Shelf indicate some $\mathrm{CH}_{4}$ activity across the region, with a net sea-air flux of 10.5 $\mathrm{Tg}\left(\mathrm{CH}_{4}\right) \mathrm{yr}^{-1}$ which is similar in magnitude to the flux for the entire ocean (Shakhova et al., 2010) but it is not possible to say whether this source has always been present or is a consequence of recent Arctic changes. The ebullition of $\mathrm{CH}_{4}$ from decomposing, thawing lake sediments in north Siberia with an estimated flux of $\sim 4 \mathrm{Tg}\left(\mathrm{CH}_{4}\right) \mathrm{yr}^{-1}$ is another demonstration of the activity of this region and of its potential importance in the future (Walter et al., 2006; van Huissteden et al., 2011). The sum of all natural emission estimates other than wetlands is still very uncertain based on bottom-up studies [see Table 6.8, range of 238 to $484 \mathrm{Tg}\left(\mathrm{CH}_{4)} \mathrm{yr}^{-1}\right.$ for 2000-2009]. 
Pyrogenic sources of $\mathrm{CH}_{4}$ (biomass burning in Table 6.8) are assessed to have a small contribution in the global flux for the 2000s (32 to $\left.39 \mathrm{Tg}\left(\mathrm{CH}_{4}\right) \mathrm{yr}^{-1}\right)$. Biomass burning of tropical and boreal forests (17 to $\left.21 \mathrm{Tg}\left(\mathrm{CH}_{4}\right) \mathrm{yr}^{-1}\right)$ play a much smaller role than wetlands in interannual variability of emissions, except during intensive fire periods (Langenfelds et al., 2002; Simpson et al., 2006). Only during the 1997-1998 record strong El Niño, burning of forests and peatland that took place in Indonesia and Malaysia, released $\sim 12 \mathrm{Tg}\left(\mathrm{CH}_{4}\right)$ and contributed to the observed growth rate anomaly (Langenfelds et al., 2002; van der Werf et al., 2004). Other smaller fire $\mathrm{CH}_{4}$ emissions positive anomalies were suggested over the northern mid-latitudes in 2002-2003, in particular over Eastern Siberia in 2003 (van der Werf et al., 2010) and Russia in 2010. Traditional biofuel burning is estimated to be a source of 14 to 17 $\mathrm{Tg}\left(\mathrm{CH}_{4}\right) \mathrm{yr}^{-1}$ (Andreae and Merlet, 2001; Yevich and Logan, 2003).

Keppler at al. (2006) reported that plants under aerobic conditions were able to emit $\mathrm{CH}_{4}$, and thus potentially could constitute a large additional emission, which had not been previously considered in the global $\mathrm{CH}_{4}$ budget. Later studies do not support plant emissions as a widespread mechanism (Dueck et al., 2007; Wang et al., 2008; Nisbet et al., 2009) or show small to negligible emissions in the context of the global $\mathrm{CH}_{4}$ budget (Vigano et al., 2008; Nisbet et al., 2009; Bloom et al., 2010). Alternative mechanisms have been suggested to explain an apparent aerobic $\mathrm{CH}_{4}$ production, which involve (1) adsorption and desorption (Kirschbaum and Walcroft, 2008; Nisbet et al., 2009), (2) degradation of organic matter under strong ultraviolet (UV) light (Dueck et al., 2007; Nisbet et al., 2009) and (3) methane in the groundwater emitted through internal air spaces in tree bodies (Terazawa et al., 2007). Overall, a significant emission of $\mathrm{CH}_{4}$ by plants under aerobic conditions is very unlikely, and this source is not reported in Table 6.8.

Anthropogenic $\mathrm{CH}_{4}$ sources are estimated to range between $50 \%$ and $65 \%$ of the global emissions for the 2000 s (Table 6.8). They include rice paddies agriculture, ruminant animals, sewage and waste, landfills, and fossil fuel extraction, storage, transformation, transportation and use (coal mining, gas and oil industries). Anthropogenic sources are dominant over natural sources in top-down inversions ( 65\%) but they are of the same magnitude in bottom-up models and inventories (Table 6.8). Rice paddies emit between 33 to $40 \mathrm{Tg}\left(\mathrm{CH}_{4}\right) \mathrm{yr}{ }^{-1}$ and $90 \%$ of these emissions come from tropical Asia, with more than $50 \%$ from China and India (Yan et al., 2009). Ruminant livestock, such as cattle, sheep, goats, etc. produce $\mathrm{CH}_{4}$ by food fermentation in their anoxic rumens with a total estimate of between 87 and $94 \mathrm{Tg}\left(\mathrm{CH}_{4}\right) \mathrm{yr}{ }^{-1}$. Major regional contributions of this flux come from India, China, Brazil and the USA (EPA, 2006; Olivier and Janssens-Maenhout, 2012), EDGAR v4.2. India, with the world's largest livestock population emitted 11.8 $\mathrm{Tg}\left(\mathrm{CH}_{4}\right) \mathrm{yr}^{-1}$ in 2003 , including emission from enteric fermentation (10.7 $\left.\mathrm{Tg}\left(\mathrm{CH}_{4}\right) \mathrm{yr}^{-1}\right)$ and manure management $\left(1.1 \mathrm{Tg}\left(\mathrm{CH}_{4}\right) \mathrm{yr}{ }^{-1}\right.$; Chhabra et al., 2013). Methanogenesis in landfills, livestock manure and waste waters produces between 67 and $90 \mathrm{Tg}\left(\mathrm{CH}_{4}\right)$ yr-1 due to anoxic conditions and a high availability of acetate, $\mathrm{CO}_{2}$ and $\mathrm{H}_{2}$. Loss of natural gas $\left(\sim 90 \% \mathrm{CH}_{4}\right)$ is the largest contributor to fossil fuel related fugitive emissions, estimated between 85 and $105 \mathrm{Tg}\left(\mathrm{CH}_{4}\right) \mathrm{yr}^{-1}$ in the USA (EPA, 2006; Olivier and Janssens-Maenhout, 2012), EDGAR v4.2.

\subsubsection{Sinks of Atmospheric Methane}

The main sink of atmospheric $\mathrm{CH}_{4}$ is its oxidation by $\mathrm{OH}$ radicals, a chemical reaction that takes place mostly in the troposphere and stratosphere (Table 6.8). $\mathrm{OH}$ removes each year an amount of $\mathrm{CH}_{4}$ equivalent to $90 \%$ of all surface emissions (Table 6.8 ), that is, $9 \%$ of the total burden of $\mathrm{CH}_{4}$ in the atmosphere, which defines a partial atmospheric lifetime with respect to $\mathrm{OH}$ of 7 to 11 years for an atmospheric burden of $4800 \mathrm{Tg}\left(\mathrm{CH}_{4}\right)$ (4700 to $4900 \mathrm{TgCH}_{4}$ as computed by Atmospheric Chemistry and Climate Model Intercomparison Project (ACCMIP) atmospheric chemistry models in Voulgarakis et al. (2013), thus slightly different from Figure 6.2; see Section 8.2.3.3 for ACCMIP models). A recent estimate of the $\mathrm{CH}_{4}$ lifetime is $9.1 \pm 0.9$ years (Prather et al., 2012). A small sink of atmospheric $\mathrm{CH}_{4}$ is suspected, but still debated, in the marine boundary layer due to a chemical reaction with chlorine (Allan et al., 2007). Another small sink is the reaction of $\mathrm{CH}_{4}$ with $\mathrm{Cl}$ radicals and O(1D) in the stratosphere (Shallcross et al., 2007; Neef et al., 2010). Finally, oxidation in upland soils (with oxygen) by methanotrophic bacterias removes about 9 to $47 \mathrm{Tg}\left(\mathrm{CH}_{4}\right) \mathrm{yr}^{-1}$ (Curry, 2007; Dutaur and Verchot, 2007; Spahni et al., 2011; Ito and Inatomi, 2012).

There have been a number of published estimates of global $\mathrm{OH}$ concentrations and variations over the past decade (Prinn et al., 2001; Dentener et al., 2003; Bousquet et al., 2005; Prinn et al., 2005; Rigby et al., 2008; Montzka et al., 2011). The very short lifetime of $\mathrm{OH}$ makes it almost impossible to measure directly global $\mathrm{OH}$ concentrations in the atmosphere. Chemistry transport models (CTMs), chemistry climate models (CCMs) or proxy methods have to be used to obtain a global mean value and time variations. For the 2000s, CTMs and CCMs (Young et al., 2013) estimate a global chemical loss of methane due to $\mathrm{OH}$ of $604 \mathrm{Tg}\left(\mathrm{CH}_{4}\right) \mathrm{yr}^{-1}$ (509 to $\left.764 \mathrm{Tg}\left(\mathrm{CH}_{4}\right) \mathrm{yr}^{-1}\right)$. This loss is larger, albeit compatible considering the large uncertainties, with a recent extensive analysis by Prather et al. (2012) inferring a global chemical loss of $554 \pm 56 \mathrm{Tg}\left(\mathrm{CH}_{4}\right) \mathrm{yr}^{-1}$. Top-down inversions using methyl-chloroform (MCF) measurements to infer $\mathrm{OH}$ provide a smaller chemical loss of $518 \mathrm{Tg}\left(\mathrm{CH}_{4}\right) \mathrm{yr}^{-1}$ with a more narrow range of 510 to $538 \mathrm{Tg}\left(\mathrm{CH}_{4}\right) \mathrm{yr}^{-1}$ in the 2000s. However, inversion estimates probably do not account for all sources of uncertainties (Prather et al., 2012).

CCMs and CTMs simulate small interannual variations of $\mathrm{OH}$ radicals, typically of 1 to $3 \%$ (standard deviation over a decade) due to a high buffering of this radical by atmospheric photochemical reactions (Voulgarakis et al., 2013; Young et al., 2013). Atmospheric inversions show much larger variations for the 1980 s and the 1990 s ( 5 to $10 \%$ ), because of their oversensitivity to uncertainties on MCF emissions, when measurements of this tracer are used to reconstruct $\mathrm{OH}$ (Montzka et al., 2011), although reduced variations are inferred after 1998 by Prinn et al. (2005). For the 2000s, the reduction of MCF in the atmosphere, due to the Montreal protocol (1987) and its further amendments, allows a consistent estimate of small $\mathrm{OH}$ variations between atmospheric inversions $(< \pm 5 \%)$ and CCMs/CTMs $(< \pm 3 \%)$. However, the very low atmospheric values reached by MCF (few ppt in 2010) impose the need to find another tracer to reconstruct global $\mathrm{OH}$ in the upcoming years. Finally, evidence for the role of changes in $\mathrm{OH}$ concentrations in explaining the increase in atmospheric methane since 2007 is variable, ranging from a significant contribution (Rigby et al., 2008) to only a small role (Bousquet et al., 2011). 


\subsubsection{Global Methane Budget for the 2000s}

Based on the inversion of atmospheric measurements of $\mathrm{CH}_{4}$ from surface stations, global $\mathrm{CH}_{4}$ emissions for the 2000s are of $553 \mathrm{Tg}\left(\mathrm{CH}_{4}\right)$ $\mathrm{yr}^{-1}$, with a range of 526 to $569 \mathrm{Tg}\left(\mathrm{CH}_{4}\right) \mathrm{yr}^{-1}$ (Table 6.8). The total loss of atmospheric methane is of $550 \mathrm{Tg}\left(\mathrm{CH}_{4}\right) \mathrm{yr}^{-1}$ with a range of 514 to 560 $\mathrm{Tg}\left(\mathrm{CH}_{4}\right) \mathrm{yr}^{-1}$, determining a small imbalance of about $3 \mathrm{Tg}\left(\mathrm{CH}_{4}\right) \mathrm{yr}^{-1}$, in line with the small growth rate of $6 \mathrm{Tg}\left(\mathrm{CH}_{4}\right) \mathrm{yr}^{-1}$ observed for the 2000 s.

Based on bottom-up models and inventories, a larger global $\mathrm{CH}_{4}$ emissions of $678 \mathrm{Tg}\left(\mathrm{CH}_{4}\right) \mathrm{yr}^{-1}$ are found, mostly because of the still debated upward re-evaluation of geological (Etiope et al., 2008) and freshwater (Walter et al., 2007; Bastviken et al., 2011) emission sources. An averaged total loss of $632 \mathrm{Tg}\left(\mathrm{CH}_{4}\right) \mathrm{yr}^{-1}$ is found, by an ensemble of Atmospheric Chemistry models (Lamarque et al., 2013) leading to an imbalance of about $\left.45 \mathrm{Tg}_{(\mathrm{CH}}\right) \mathrm{yr}^{-1}$ during the $2000 \mathrm{~s}$, as compared to the observed mean growth rate of $6 \mathrm{Tg}\left(\mathrm{CH}_{4}\right) \mathrm{yr}^{-1}($ Table 6.8; Dlugokencky et al., 2011). There is no constraint that applies to the sum of emissions in the bottom-up approach, unlike for top-down inversions when these have constrained $\mathrm{OH}$ fields (e.g., from MCF). Therefore, top-down inversions can help constrain global $\mathrm{CH}_{4}$ emissions in the global budget, although they do not resolve the same level of detail in the mix of sources than the bottom-up approaches, and thus provide more limited information about processes (Table 6.8).

\subsubsection{Global Nitrogen Budgets and Global Nitrous Oxide Budget in the 1990s}

The atmospheric abundance of $\mathrm{N}_{2} \mathrm{O}$ has been increasing mainly as a result of agricultural intensification to meet the food demand for a growing human population. Use of synthetic fertiliser (primarily from the Haber-Bosch process) and manure applications increase the production of $\mathrm{N}_{2} \mathrm{O}$ in soils and sediments, via nitrification and denitrification pathways, leading to increased $\mathrm{N}_{2} \mathrm{O}$ emissions to the atmosphere. Increased emissions occur not only in agricultural fields, but also in aquatic systems after nitrogen leaching and runoff, and in natural soils and ocean surface waters as a result of atmospheric deposition of nitrogen originating from agriculture, fossil fuel combustion and industrial activities. Food production is likely responsible for $80 \%$ of the increase in atmospheric $\mathrm{N}_{2} \mathrm{O}$ (Kroeze et al., 1999; Davidson, 2009; Williams and Crutzen, 2010; Syakila and Kroeze, 2011; Zaehle et al., 2011; Park et al., 2012), via the addition of nitrogen fertilisers. Global emissions of $\mathrm{N}_{2} \mathrm{O}$ are difficult to estimate owing to heterogeneity in space and time. Table 6.9 presents global emissions based on upscaling of local flux measurements at the surface. Modelling of the atmospheric lifetime of $\mathrm{N}_{2} \mathrm{O}$ and atmospheric inversions constrain global and regional $\mathrm{N}_{2} \mathrm{O}$ budgets (Hirsch et al., 2006; Huang et al., 2008; Rhee et al., 2009; Prather et al., 2012), although there is uncertainty in these estimates because of uncertainty in the dominant loss term of $\mathrm{N}_{2} \mathrm{O}$, that is, the destruction of $\mathrm{N}_{2} \mathrm{O}$ by photolysis and reaction with $\mathrm{O}(1 \mathrm{D})$ in the stratosphere. The long atmospheric lifetime of $\mathrm{N}_{2} \mathrm{O}$ (118 to 131 years, Volk et al., 1997; Hsu and Prather, 2010; Fleming et al., 2011; see Chapter 8) implies that it will take more than a century before atmospheric abundances stabilise after the stabilization of global emissions. This is of concern not only because of its contribution to the radiative forcing (see Glossary), but also because of the relative importance of $\mathrm{N}_{2} \mathrm{O}$ and other GHGs in affecting the ozone layer (Ravishankara et al., 2009; Fleming et al., 2011).
Since AR4 (Table 6.9 for the 1990s), a number of studies allow us to update some of the $\mathrm{N}_{2} \mathrm{O}$ emission estimates. First and most importantly, the IPCC Guidelines were revised in 2006 (De Klein et al., 2007) and in particular emission factors for estimating agricultural $\mathrm{N}_{2} \mathrm{O}$ emissions. Applying these 2006 emission factors to global agricultural statistics results in higher direct emissions from agriculture (from fertilised soils and animal production) than in AR4, but into indirect emissions (associated with leaching and runoff of $\mathrm{Nr}$ resulting in $\mathrm{N}_{2} \mathrm{O}$ emissions from groundwater, riparian zones and surface waters) that are considerably lower than reported in AR4 (Table 6.9). It should be noted that emissions of $\mathrm{N}_{2} \mathrm{O}$ show large uncertainties when default emission factors are applied at the global scale (Crutzen et al., 2008; Davidson, 2009; Smith et al., 2012). Second, estimates of the anthropogenic source of $\mathrm{N}_{2} \mathrm{O}$ from the open ocean have been made for the first time. These emissions result from atmospheric deposition of anthropogenic $\mathrm{Nr}$ (nitrogen oxides and ammonia/ammonium) (Duce et al., 2008; Suntharalingam et al., 2012). This anthropogenic ocean $\mathrm{N}_{2} \mathrm{O}$ source was implicitly included as part of the natural ocean $\mathrm{N}_{2} \mathrm{O}$ source in $\mathrm{AR} 4$, but is now given as a separate anthropogenic source of 0.2 (0.1 to 0.4$)$

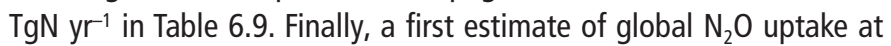
the surface is now available (Syakila et al., 2010; Syakila and Kroeze, 2011), based on reviews of measurements of $\mathrm{N}_{2} \mathrm{O}$ uptake in soils and sediments (Chapuis-Lardy et al., 2007; Kroeze et al., 2007). The uncertainty in this sink of $\mathrm{N}_{2} \mathrm{O}$ is large. On the global scale, this surface sink is negligible, but at the local scale it may not be irrelevant.

\subsubsection{Atmosphere Nitrous Oxide Burden and Growth Rate}

The concentration of $\mathrm{N}_{2} \mathrm{O}$ is currently $20 \%$ higher than pre-industrial levels (Figure 6.11; MacFarling-Meure et al., 2006). Figure 6.19 shows the annual growth rate of atmospheric $\mathrm{N}_{2} \mathrm{O}$ estimated from direct measurements (National Oceanic and Atmospheric Administration Global Monitoring Division (NOAA-GMD) network of surface stations). On decadal time scales, the concentration of $\mathrm{N}_{2} \mathrm{O}$ has been increasing at a rate of $0.73 \pm 0.03 \mathrm{ppb} \mathrm{yr}^{-1}$. The interannual variability in mid- to high-latitude $\mathrm{N}_{2} \mathrm{O}$ abundance in both the $\mathrm{NH}$ and $\mathrm{SH}$ was found to correlate with the strength of the stratospheric Brewer-Dobson circulation (Nevison et al., 2011). Variability in stratosphere to troposphere air mass exchange, coupled with the stratospheric $\mathrm{N}_{2} \mathrm{O}$ sink is likely to be responsible for a fraction of the interannual variability in tropospheric $\mathrm{N}_{2} \mathrm{O}$, but the understanding of this process is poor (Huang et al., 2008). This removal process signal is obscured in the SH by the timing of oceanic thermal and biological ventilation signals (Nevison et al., 2011) and terrestrial sources (Ishijima et al., 2009). These two factors may thus also be important determinants of seasonal and interannual variability of $\mathrm{N}_{2} \mathrm{O}$ in the atmosphere. Quantitative understanding of terrestrial $\mathrm{N}_{2} \mathrm{O}$ emissions variability is poor, although emissions are known to be sensitive to soil water content (Ishijima et al., 2009). A first process model-based estimate suggests that the mainly climate-driven variability in the terrestrial source may account for only $0.07 \mathrm{ppb} \mathrm{yr}^{-1}$ variability in atmospheric $\mathrm{N}_{2} \mathrm{O}$ growth rate, which would be difficult to detect in the observed growth rate (Zaehle et al., 2011).

Most $\mathrm{N}_{2} \mathrm{O}$ is produced by biological (microbial) processes such as nitrification and denitrification in terrestrial and aquatic systems, including rivers, estuaries, coastal seas and the open ocean (Table 6.9; Freing et al., 2012). In general, more $\mathrm{N}_{2} \mathrm{O}$ is formed when more reactive nitrogen 
is available. The production of $\mathrm{N}_{2} \mathrm{O}$ shows large spatial and temporal variability. Emission estimates for tropical regions and for aquatic systems are relatively uncertain. Inverse modelling studies show that the errors in emissions are large, especially in (sub)-tropical regions (e.g., Hirsch et al., 2006; Huang et al., 2008). Emissions from rivers, estuaries and continental shelves have been the subject of debate for many years (Seitzinger and Kroeze, 1998; De Klein et al., 2007). Recent studies confirm that rivers can be important sources of $\mathrm{N}_{2} \mathrm{O}$, which could be a reason to reconsider recent estimates of aquatic $\mathrm{N}_{2} \mathrm{O}$ emissions (Beaulieu et al., 2011; Rosamond et al., 2012).
Table 6.9 does not include the formation of atmospheric $\mathrm{N}_{2} \mathrm{O}$ from abiotic decomposition of ammonium nitrate in the presence of light, appropriate relative humidity and a surface. This process recently has been proposed as a potentially important source of $\mathrm{N}_{2} \mathrm{O}$ (Rubasinghege et al., 2011); however, a global estimate does not yet exist. Table 6.9 indicates that the global $\mathrm{N}_{2} \mathrm{O}$ emissions in the mid-1990s amount to 17.5 (8.1 to 30.7) $\left.\mathrm{TgN}_{(\mathrm{N}} \mathrm{O}\right) \mathrm{yr}^{-1}$. The uncertainty range is consistent with that of atmospheric inversions studies (14.1 to 17.8) by Huang et al. (2008). The estimates of anthropogenic $\mathrm{N}_{2} \mathrm{O}$ emissions of Table 6.9 are in line with the top-down estimates by Prather et al. (2012) of 6.5 $\pm 1.3 \mathrm{TgN}\left(\mathrm{N}_{2} \mathrm{O}\right) \mathrm{yr}^{-1}$, and somewhat higher than their estimates for

Table 6.9 Section 1 gives the global nitrogen budget $\left(\operatorname{TgN~yr}^{-1}\right)$ : (a) creation of reactive nitrogen, (b) emissions of $\mathrm{NO}_{x,} \mathrm{NH}_{3}$ in 2000 s to atmosphere, (c) deposition of nitrogen to continents and oceans, (d) discharge of total nitrogen to coastal ocean and (e) conversion of $\mathrm{Nr}_{\text {to }} \mathrm{N}_{2}$ by denitrification. Section 2 gives the $\mathrm{N}_{2} \mathrm{O}$ budget for the year 2006, and for the 1990 s compared to AR4. Unit: $\operatorname{Tg}\left(\mathrm{N}_{2} \mathrm{O}-\mathrm{N}\right) \mathrm{yr}^{-1}$.

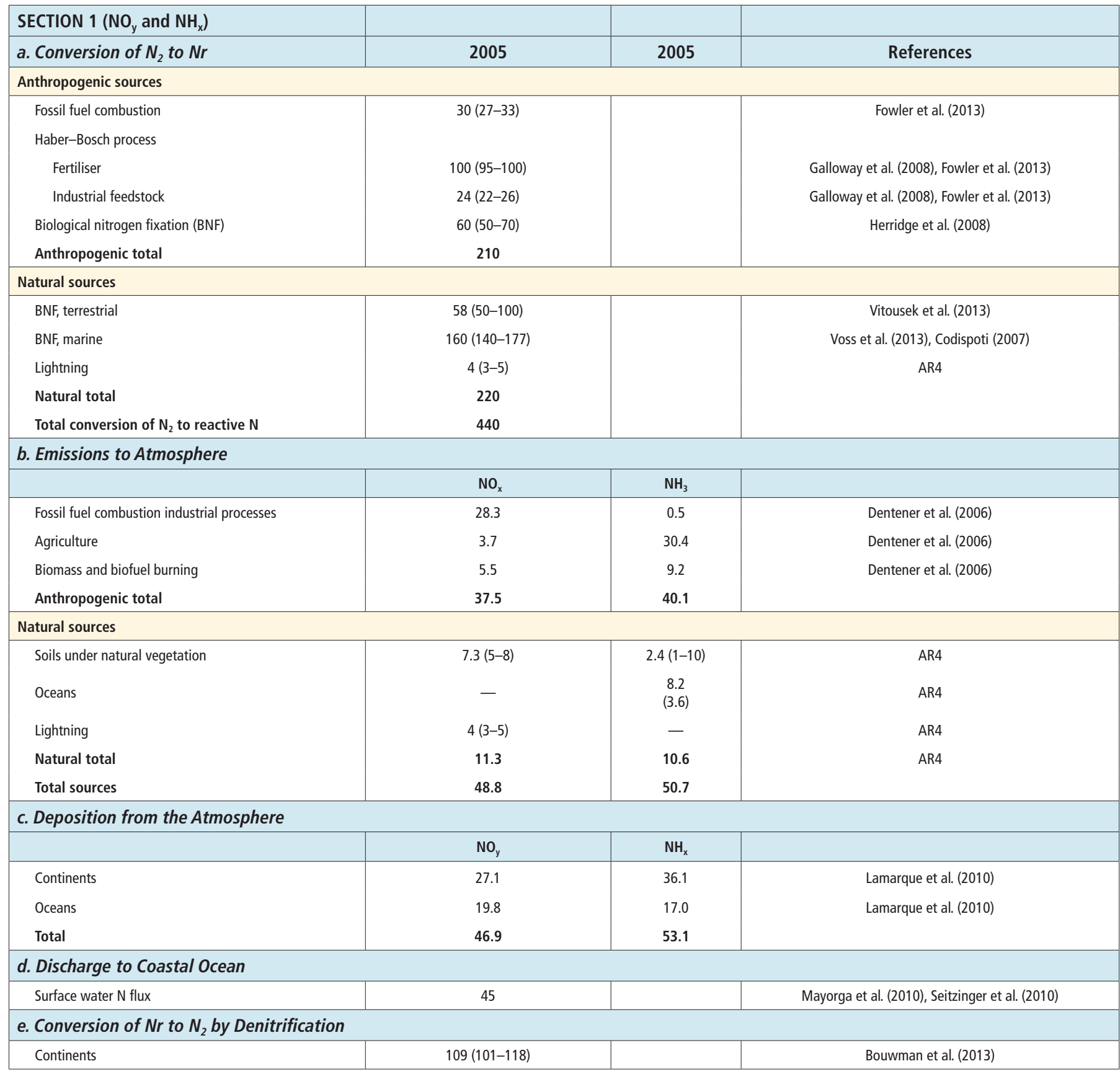

(continued on next page) 
Table 6.9 (continued)

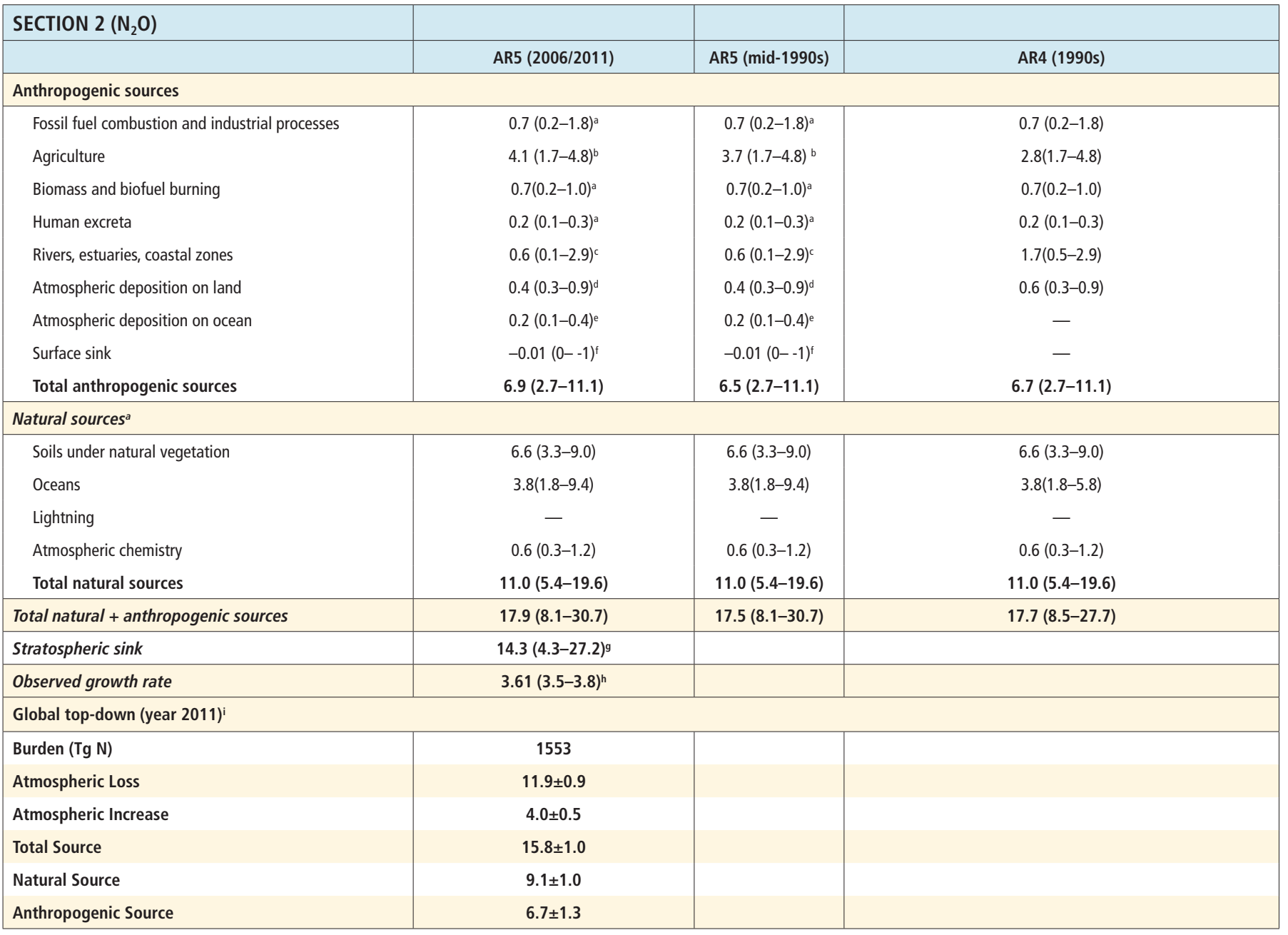

Notes:

a All units for $\mathrm{N}_{2} \mathrm{O}$ fluxes are in $\mathrm{TgN}\left(\mathrm{N}_{2} \mathrm{O}\right) \mathrm{yr}^{-1}$ as in AR4 (not based on 2006 IPCC Guidelines). Lower end of range in the natural ocean from Rhee et al. (2009); higher end of the range from Bianchi et al. (2012) and Olivier and Janssens-Maenhout (2012); natural soils in line with Stocker et al. (2013).

b Direct soil emissions and emissions from animal production; calculated following 2006 IPCC Guidelines (Syakila and Kroeze, 2011); range from AR4 (Olivier and Janssens-Maenhout, 2012).

c Following 2006 IPCC Guidelines (Kroeze et al., 2010; Syakila and Kroeze, 2011). Higher end of range from AR4; lower end of range from 1996 IPCC Guidelines (Mosier et al., 1998). Note that a recent study indicates that emissions from rivers may be underestimated in the IPCC assessments (Beaulieu et al., 2011).

d Following 2006 IPCC Guidelines (Syakila and Kroeze, 2011).

e Suntharalingam et al. (2012).

Syakila et al. (2010).

g The stratospheric sink regroups losses via photolysis and reaction with O(1D) that account for $90 \%$ and $10 \%$ of the sink, respectively (Minschwaner et al., 1993). The global magnitude of the stratospheric sink was adjusted in order to be equal to the difference between the total sources and the observed growth rate. This value falls within literature estimates (Volk et al., 1997).

h Data from Sections 6.1 and 6.3 (see Figure 6.4c). The range on the observed growth rate in this table is given by the $90 \%$ confidence interval of Figure $6.4 \mathrm{c}$.

Based on Prather et al. (2012), updated to 2011 (Table 2.1) and used in Chapter 11 projections; uncertainties evaluated as $68 \%$ confidence intervals, $\mathrm{N}_{2} \mathrm{O}$ budget reduced based on recently published longer lifetimes of $131 \pm 10$ yrs, see Annex II.2.3 and II.4.3.

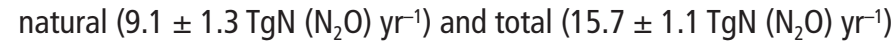
emissions. Anthropogenic emissions have steadily increased over the last two decades and were 6.9 (2.7 to 11.1$) \mathrm{TgN}\left(\mathrm{N}_{2} \mathrm{O}\right) \mathrm{yr}^{-1}$ in 2006, or $6 \%$ higher than the value in mid-1990s (Davidson, 2009; Zaehle et al., 2011) (see also Figure 6.4c). Overall, anthropogenic $\mathrm{N}_{2} \mathrm{O}$ emissions are now a factor of 8 greater than their estimated level in 1900. These trends are consistent with observed increases in atmospheric $\mathrm{N}_{2} \mathrm{O}$ (Syakila et al., 2010). Human activities strongly influence the source of $\mathrm{N}_{2} \mathrm{O}$, as nitrogen fertiliser used in agriculture is now the main source of nitrogen for nitrification and denitrification (Opdyke et al., 2009). Nitrogen stable isotope ratios confirm that fertilised soils are primar- ily responsible for the historic increase in $\mathrm{N}_{2} \mathrm{O}$ (Röckmann and Levin, 2005; Sutka et al., 2006; Park et al., 2012).

\subsubsection{Sensitivity of Nitrous Oxide Fluxes to Climate and Elevated Carbon Dioxide}

Previous studies suggested a considerable positive feedback between $\mathrm{N}_{2} \mathrm{O}$ and climate (Khalil and Rasmussen, 1989) supported by observed glacial-interglacial increases of $\sim 70 \mathrm{ppb}$ in atmospheric $\mathrm{N}_{2} \mathrm{O}$ (Flückiger et al., 1999). Climate change influences marine and terrestrial $\mathrm{N}_{2} \mathrm{O}$ sources, but their individual contribution and even the sign of their 
response to long-term climate variations are difficult to estimate (see Section 6.2). Simulations by terrestrial biosphere models suggest a moderate increase of global $\mathrm{N}_{2} \mathrm{O}$ emissions with recent climate changes, related mainly to changes in land temperature (Zaehle and Dalmonech, 2011; Xu-Ri et al., 2012), thus suggesting a possible positive feedback to the climate system. Nonetheless, the recent change in atmospheric $\mathrm{N}_{2} \mathrm{O}$ is largely dominated to anthropogenic reactive nitrogen (Nr) and industrial emissions (Holland et al., 2005; Davidson, 2009; Zaehle and Dalmonech, 2011). Stocker et al. (2013) have found, using a global coupled model of climate and biogeochemical cycles, that future climate change will amplify terrestrial $\mathrm{N}_{2} \mathrm{O}$ emissions resulting from anthropogenic $\mathrm{Nr}$ additions, consistent with empirical understanding (Butterbach-Bahl and Dannenmann, 2011). This result suggests that the use of constant emission factors might underestimate future $\mathrm{N}_{2} \mathrm{O}$ emission trajectories. Significant uncertainty remains in the $\mathrm{N}_{2} \mathrm{O}$-climate feedback from land ecosystems, given the poorly known response of emission processes to the changes in seasonal and frequency distribution of precipitation, and also because agricultural emissions themselves may also be sensitive to climate.

$\mathrm{N}_{2} \mathrm{O}$ production will be affected by climate change through the effects on the microbial nitrification and denitrification processes (Barnard et al., 2005; Singh et al., 2010; Butterbach-Bahl and Dannenmann, 2011). Warming experiments tend to show enhanced $\mathrm{N}_{2} \mathrm{O}$ emission (Lohila et al., 2010; Brown et al., 2011; Chantarel et al., 2011; Larsen et al., 2011). Elevated $\mathrm{CO}_{2}$ predominantly increases $\mathrm{N}_{2} \mathrm{O}$ emissions(van Groenigen et al., 2011); however, reductions have also been observed (Billings et al., 2002; Mosier et al., 2002), induced by changes in soil moisture, plant productivity and nitrogen uptake, as well as activity and composition of soil microbial and fungal communities (Barnard et al., 2005; Singh et al., 2010). The effect of interacting climate and atmospheric $\mathrm{CO}_{2}$ change modulates and potentially dampens the individual responses to each driver (Brown et al., 2011). A terrestrial biosphere model that integrates the interacting effects of temperature, moisture and $\mathrm{CO}_{2}$
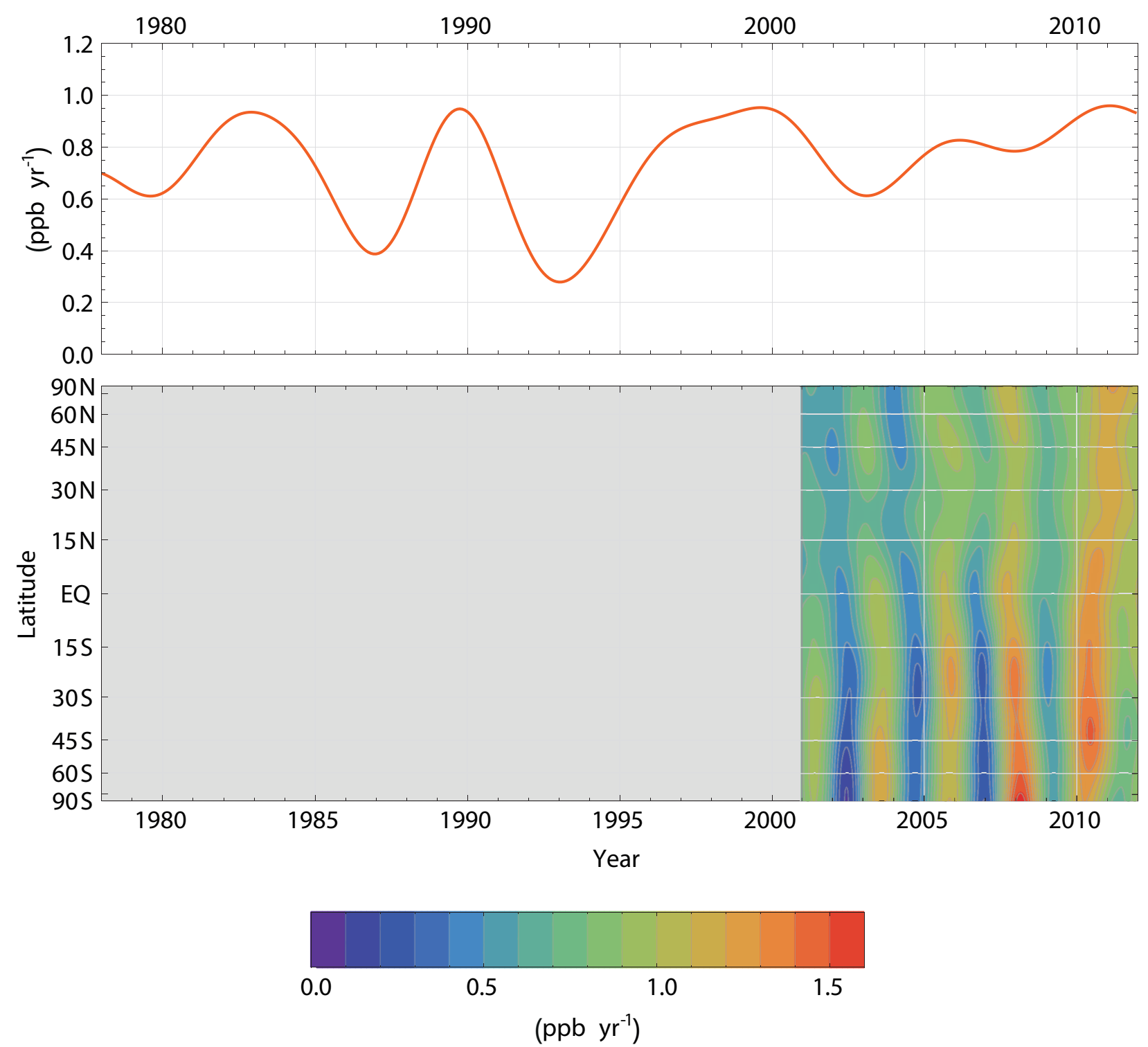

Figure 6.19 (Top) Globally averaged growth rate of atmospheric $\mathrm{N}_{2} \mathrm{O}$ in ppb $\mathrm{yr}^{-1}$ representative for the marine boundary layer. (Bottom) Atmospheric growth rate of $\mathrm{N}_{2} \mathrm{O}$ as a function of latitude. Sufficient observations are available only since the year 2002. Observations from the National Oceanic and Atmospheric Administration-Earth System Research Laboratory (NOAA-ESRL) network (Masarie and Tans, 1995; Dlugokencky and Tans, 2013b). 
changes is capable of qualitatively reproducing the observed sensitivities to these factors and their combinations (Xu-Ri et al., 2012). Thawing permafrost soils under particular hydrological settings may liberate reactive nitrogen and turn into significant sources of $\mathrm{N}_{2} \mathrm{O}$; however, the global significance of this source is not established (Elberling et al., 2010).

\subsubsection{Global Nitrogen Budget}

For base year 2010, anthropogenic activities created 210 (190 to 230) $\mathrm{TgN}$ of reactive nitrogen $\mathrm{Nr}$ from $\mathrm{N}_{2}$. This human-caused creation of reactive nitrogen in 2010 is at least 2 times larger than the rate of natural terrestrial creation of $\sim 58 \mathrm{TgN}$ (50 to $100 \mathrm{TgN} \mathrm{yr}^{-1}$ ) (Table 6.9, Section 1a). Note that the estimate of natural terrestrial biological fixation (58 $\mathrm{TgN} \mathrm{yr}^{-1}$ ) is lower than former estimates (100 TgN yr-1, Galloway et al., 2004), but the ranges overlap, 50 to $100 \mathrm{TgN} \mathrm{yr}^{-1}$, vs. 90 to 120 $\mathrm{TgN} \mathrm{yr}^{-1}$, respectively). Of this created reactive nitrogen, $\mathrm{NO}_{x}$ and $\mathrm{NH}_{3}$ emissions from anthropogenic sources are about fourfold greater than natural emissions (Table 6.9, Section 1b). A greater portion of the $\mathrm{NH}_{3}$ emissions is deposited to the continents rather than to the oceans, relative to the deposition of $\mathrm{NO}_{y}$, due to the longer atmospheric residence time of the latter. These deposition estimates are lower limits, as they do not include organic nitrogen species. New model and measurement information (Kanakidou et al., 2012) suggests that incomplete inclusion of emissions and atmospheric chemistry of reduced and oxidized organic nitrogen components in current models may lead to systematic underestimates of total global reactive nitrogen deposition by up to $35 \%$ (Table 6.9, Section 1c). Discharge of reactive nitrogen to the coastal oceans is $\sim 45 \mathrm{TgN} \mathrm{yr}^{-1}$ (Table 6.9, Section 1d). Denitrification converts $\mathrm{Nr}$ back to atmospheric $\mathrm{N}_{2}$. The current estimate for the production of atmospheric $\mathrm{N}_{2}$ is $110 \mathrm{TgN} \mathrm{yr}^{-1}$ (Bouwman et al., 2013). Thus of the $\sim 280 \mathrm{TgN} \mathrm{yr}^{-1}$ of $\mathrm{Nr}$ from anthropogenic and natural sources, $\sim 40 \%$ gets converted to $\mathrm{N}_{2}$ each year. The remaining $60 \%$ is stored in terrestrial ecosystems, transported by rivers and by atmospheric transport and deposition to the ocean, or emitted as $\mathrm{N}_{2} \mathrm{O}$ (a small fraction of total $\mathrm{Nr}$ only despite the important forcing of increasing $\mathrm{N}_{2} \mathrm{O}$ emissions for climate change). For the oceans, denitrification producing atmospheric $\mathrm{N}_{2}$ is 200 to $400 \mathrm{TgN} \mathrm{yr}^{-1}$, which is larger than the current uptake of atmospheric $\mathrm{N}_{2}$ by ocean biological fixation of 140 to $177 \mathrm{TgN} \mathrm{yr}^{-1}$ (Table 6.9 Section 1e; Figure 6.4a).

\subsection{Projections of Future Carbon and Other Biogeochemical Cycles}

\subsubsection{Introduction}

In this section, we assess coupled model projections of changes in the evolution of $\mathrm{CO}_{2}, \mathrm{CH}_{4}$ and $\mathrm{N}_{2} \mathrm{O}$ fluxes, and hence the role of carbon and other biogeochemical cycles in future climate under socioeconomic emission scenarios (see Box 6.4). AR4 reported how climate change can affect the natural carbon cycle in a way that could feed back onto climate itself. A comparison of 11 coupled climate-carbon cycle models of different complexity (Coupled Carbon Cycle Climate-Model Intercomparison Project (C4MIP); Friedlingstein et al., 2006) showed that all 11 models simulated a positive feedback. There is substantial quantitative uncertainty in future $\mathrm{CO}_{2}$ and temperature, both across coupled carbon-climate models (Friedlingstein et al., 2006; Plattner et al., 2008) and within each model parametrizations (Falloon et al., 2011; Booth et al., 2012; Higgins and Harte, 2012). This uncertainty on the coupling between carbon cycle and climate is of comparable magnitude to the uncertainty caused by physical climate processes discussed in Chapter 12 of this Report (Denman et al., 2007; Gregory et al., 2009; Huntingford et al., 2009).

Other biogeochemical cycles and feedbacks play an important role in the future of the climate system, although the carbon cycle represents the strongest of these. Natural $\mathrm{CH}_{4}$ emissions from wetland and fires are sensitive to climate change (Sections 6.2, 6.4.7 and 6.3.3.2). The fertilising effects of nitrogen deposition and rising $\mathrm{CO}_{2}$ also affect $\mathrm{CH}_{4}$ emissions by wetlands through increased plant productivity (Stocker et al., 2013). Changes in the nitrogen cycle, in addition to interactions with $\mathrm{CO}_{2}$ sources and sinks, are very likely to affect the emissions of $\mathrm{N}_{2} \mathrm{O}$ both on land and from the ocean (Sections 6.3.4.2 and 6.4.6) and potentially on the rate of $\mathrm{CH}_{4}$ oxidation (Gärdenäs et al., 2011). A recent review highlighted the complexity of terrestrial biogeochemical feedbacks on climate change (Arneth et al., 2010) and used the methodology of Gregory et al. (2009) to express their magnitude in common units of $\mathrm{W} \mathrm{m} \mathrm{m}^{-2}{ }^{\circ} \mathrm{C}^{-1}$ (Figure 6.20). A similar degree of complexity exists in the ocean and in interactions between land, atmosphere and ocean cycles. Many of these processes are not yet represented in coupled climate-biogeochemistry models. Leuzinger et al. (2011) observed a trend from manipulation experiments for higher-order interactions between feedbacks to reduce the magnitude of response. Confidence in the magnitude, and sometimes even the sign, of many of these feedbacks between climate and carbon and other biogeochemical cycles is low.

The response of land and ocean carbon storage to changes in climate, atmospheric $\mathrm{CO}_{2}$ and other anthropogenic activities (e.g., land use change; Table 6.2) varies strongly on different time scales. This chapter has assessed carbon cycle changes across many time scales from millennial (see Section 6.2) to interannual and seasonal (see Section 6.3), and these are summarized in Table 6.10. A common result is that an increase in atmospheric $\mathrm{CO}_{2}$ will always lead to an increase in land and ocean carbon storage, all other things being held constant. Cox et al. (2013) find an empirical relationship between short-term interannual variability and long-term land tropical carbon cycle sensitivity that may offer an observational constraint on the climate-carbon cycle response over the next century. Generally, however, changes in climate on different time scales do not lead to a consistent sign and magnitude of the response in carbon storage change owing to the many different mechanisms that operate. Thus, changes in carbon cycling on one time scale cannot be extrapolated to make projections on different time scales, but can provide valuable information on the processes at work and can be used to evaluate and improve models.

\subsubsection{Carbon Cycle Feedbacks in Climate Modelling Intercomparison Project Phase 5 Models}

\subsubsection{Global Analysis}

The carbon cycle response to future climate and $\mathrm{CO}_{2}$ changes can be viewed as two strong and opposing feedbacks (Gregory et al., 2009). 
The climate-carbon response $(\gamma)$ determines changes in carbon storage due to changes in climate, and the concentration-carbon response ( $\beta$ ) determines changes in storage due to elevated $\mathrm{CO}_{2}$. Climate-carbon cycle feedback responses have been analyzed for eight CMIP5 ESMs that performed idealised simulations involving atmospheric $\mathrm{CO}_{2}$ increasing at a prescribed rate of $1 \% \mathrm{yr}^{-1}$ (Arora et al., 2013; Box 6.4). There is high confidence that increased atmospheric $\mathrm{CO}_{2}$ will lead to increased land and ocean carbon uptake but by an uncertain amount. Models agree on the sign of land and ocean response to rising $\mathrm{CO}_{2}$ but show only medium and low agreement for the magnitude of ocean and land carbon uptake respectively (Figure 6.21). Future climate change will decrease land and ocean carbon uptake compared to the case with constant climate (medium confidence). Models agree on the sign, globally, of land and ocean response to climate change but show low agreement on the magnitude of this response, especially for the land.
Land and ocean carbon uptake may differ in sign between different regions and between models (Section 6.4.2.3). Inclusion of nitrogen cycle processes in two of the land carbon cycle model components out of these eight reduces the magnitude of the sensitivity to both $\mathrm{CO}_{2}$ and climate (Section 6.4.6.3) and increases the spread across the CMIP5 ensemble. The CMIP5 spread in ocean sensitivity to $\mathrm{CO}_{2}$ and climate appears reduced compared with C4MIP.

The role of the idealised experiment presented here is to study model processes and understand what causes the differences between models. Arora et al. (2013) assessed the global carbon budget from these idealised simulations and found that the $\mathrm{CO}_{2}$ contribution to changes in land and ocean carbon storage sensitivity is typically four to five times larger than the sensitivity to climate across the CMIP5 ESMs. The land carbon-climate response $(\gamma)$ is larger than the ocean carbon-climate

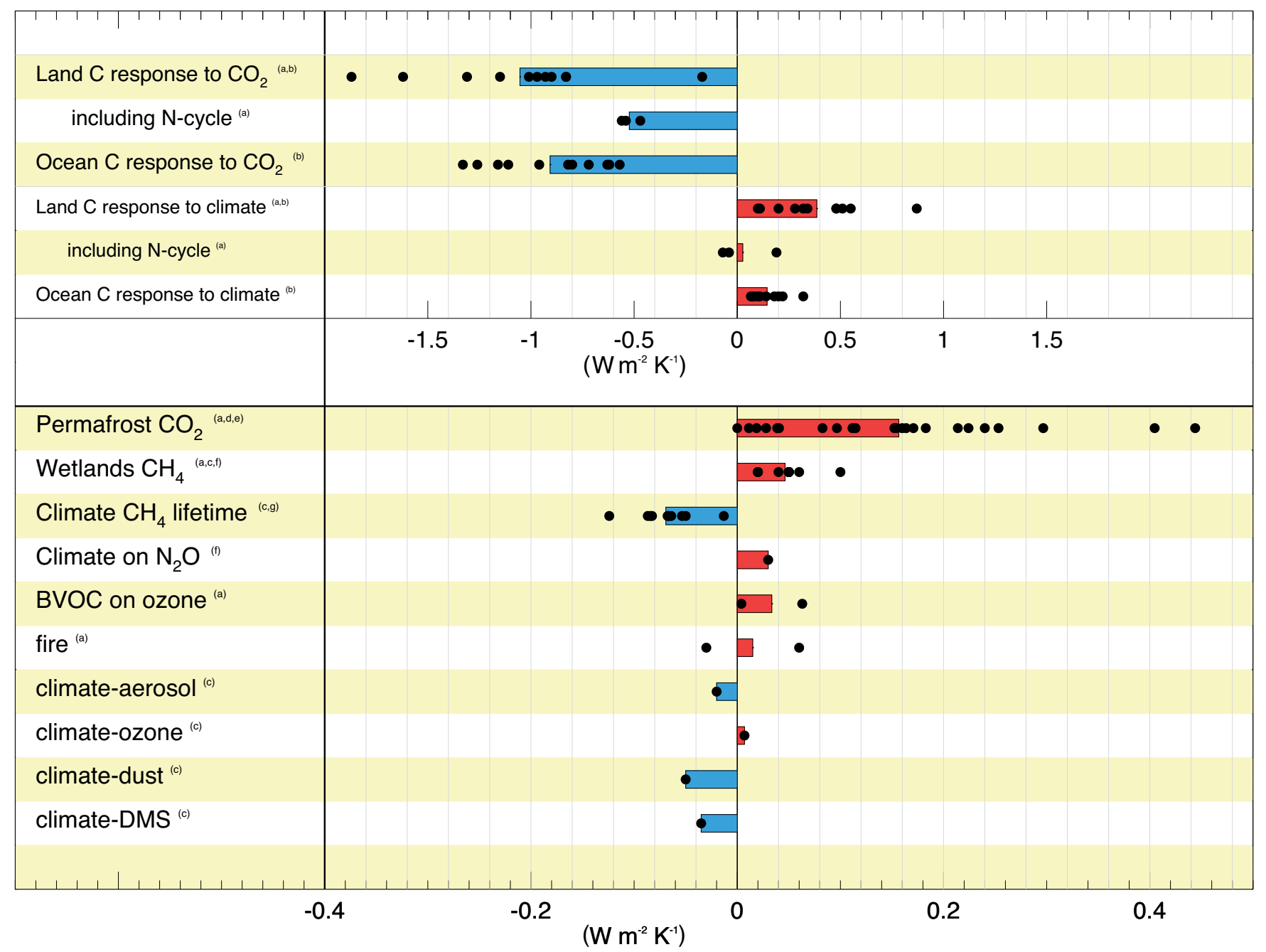

Figure 6.20 | A synthesis of the magnitude of biogeochemical feedbacks on climate. Gregory et al. (2009) proposed a framework for expressing non-climate feedbacks in common units $\left(\mathrm{W} \mathrm{m}^{-2}{ }^{\circ} \mathrm{C}^{-1}\right)$ with physical feedbacks, and Arneth et al. (2010) extended this beyond carbon cycle feedbacks to other terrestrial biogeochemical feedbacks. The figure shows the results compiled by Arneth et al. (2010), with ocean carbon feedbacks from the C4MIP coupled climate-carbon models used for AR4 also added. Some further biogeochemical feedbacks are also shown but this list is not exhaustive. Black dots represent single estimates, and coloured bars denote the simple mean of the dots with no weighting or assessment being made to likelihood of any single estimate. There is low confidence in the magnitude of the feedbacks in the lower portion of the figure, especially for those with few, or only one, dot. The role of nitrogen limitation on terrestrial carbon sinks is also shown - this is not a separate feedback, but rather a modulation to the climate-carbon and concentration-carbon feedbacks. These feedback metrics are also to be state or scenario dependent and so cannot always be compared like-for-like (see Section 6.4.2.2). Results have been compiled from (a) Arneth et al. (2010), (b) Friedlingstein et al. (2006), (c) Hadley Centre Global Environmental Model 2-Earth System (HadGEM2-ES, Collins et al., 2011) simulations, (d) Burke et al. (2013), (e) von Deimling et al. (2012), (f) Stocker et al. (2013), (g) Stevenson et al. (2006). Note the different $x$-axis scale for the lower portion of the figure. 


\section{Box 6.4 | Climate-Carbon Cycle Models and Experimental Design}

\section{What are coupled climate-carbon cycle models and why do we need them?}

Atmosphere-Ocean General Circulation Models (AOGCMs; see Glossary) have long been used for making climate projections, and have formed the core of previous IPCC climate projection chapters (e.g., Meehl et al. (2007); see also Chapters 1, 9 and 12). For the 5th Coupled Model Intercomparison Project (CMIP5), many models now have an interactive carbon cycle. What exactly does this mean, how do they work and how does their use differ from previous climate models? AOGCMs typically represent the physical behaviour of the atmosphere and oceans but atmospheric composition, such as the amount of $\mathrm{CO}_{2}$ in the atmosphere, is prescribed as an input to the model. This approach neglects the fact that changes in climate might affect the natural biogeochemical cycles, which control atmospheric composition, and so there is a need to represent these processes in climate projections.

At the core of coupled climate-carbon cycle models is the physical climate model, but additional components of land and ocean biogeochemistry respond to the changes in the climate conditions to influence in return the atmospheric $\mathrm{CO}_{2}$ concentration. Input to themodels comes in the form of anthropogenic $\mathrm{CO}_{2}$ emissions, which can increase the $\mathrm{CO}_{2}$ and then the natural carbon cycle exchanges $\mathrm{CO}_{2}$ between the atmosphere and land and ocean components. These 'climate-carbon cycle models' ('Earth System Models', ESMs; see Glossary) provide a predictive link between fossil fuel $\mathrm{CO}_{2}$ emissions and future $\mathrm{CO}_{2}$ concentrations and climate and are an important part of the CMIP5 experimental design (Hibbard et al., 2007; Taylor et al., 2012).

Apart from Earth System GCMs, so-called Earth System Models of Intermediate Complexity (EMICs) are often used to perform similar experiments (Claussen et al., 2002; Plattner et al., 2008). EMICs have reduced resolution or complexity but run much more quickly and can be used for longer experiments or large ensembles.

\section{How are these models used?}

The capability of ESMs to simulate carbon cycle processes and feedbacks, and in some models other biogeochemical cycles, allows for a greater range of quantities to be simulated such as changes in natural carbon stores, fluxes or ecosystem functioning. There may also be applications where it is desirable for a user to predefine the pathway of atmospheric $\mathrm{CO}_{2}$ and prescribe it as a forcing to the ESMs. Thus, numerical simulations with ESM models can be either 'concentration driven' or 'emissions driven'.

Concentration-driven simulations follow the 'traditional' approach of prescribing the time-evolution of atmospheric $\mathrm{CO}_{2}$ as an input to the model. This is shown schematically in Box 6.4 Figure 1 (left-hand side). Atmospheric $\mathrm{CO}_{2}$ concentration is prescribed as input to the model from a given scenario and follows a predefined pathway regardless of changes in the climate or natural carbon cycle processes. The processes between the horizontal dashed lines in the figure represent the model components which are calculated during the concentration-driven simulation. Externally prescribed changes in atmospheric $\mathrm{CO}_{2}$ concentration, which drive climate change, affect land and ocean carbon storage. By construction, changes in land and ocean storage, however, do not feed back on the atmospheric $\mathrm{CO}_{2}$ concentration or on climate. The changes in natural carbon fluxes and stores are output by the model.

So-called 'compatible fossil fuel emissions', $E$, can be diagnosed afterwards from mass conservation by calculating the residual between the prescribed $\mathrm{CO}_{2}$ pathway and the natural fluxes:

$$
\left.E=\frac{d \mathrm{CO}_{2}}{d t}{ }_{\text {prescribed }}+\text { (land_carbon_uptake }+ \text { ocean_carbon_uptake }\right)
$$

Land use change emissions cannot be diagnosed separately from a single simulation (see Section 6.4.3.2).

Emissions-driven simulations allow the full range of interactions in the models to operate and determine the evolution of atmospheric $\mathrm{CO}_{2}$ and climate as an internal part of the simulation itself (Box 6.4, Figure 1, right-hand side). In this case emissions of $\mathrm{CO}_{2}$ are the externally prescribed input to the model and the subsequent changes in atmospheric $\mathrm{CO}_{2}$ concentration are simulated by it.

In emissions-driven experiments, the global atmospheric $\mathrm{CO}_{2}$ growth rate is calculated within the model as a result of the net balance between the anthropogenic emissions, $E$, and natural fluxes:

$$
\frac{d \mathrm{CO}_{2}}{d t} \text { simulated }=E-\text { (land_carbon_uptake + ocean_carbon_uptake) }
$$

The effect of climate change on the natural carbon cycle will manifest itself either through changes in atmospheric $\mathrm{CO}_{2}$ in the emissions-driven experiments or in the compatible emissions in the concentration-driven experiments. 


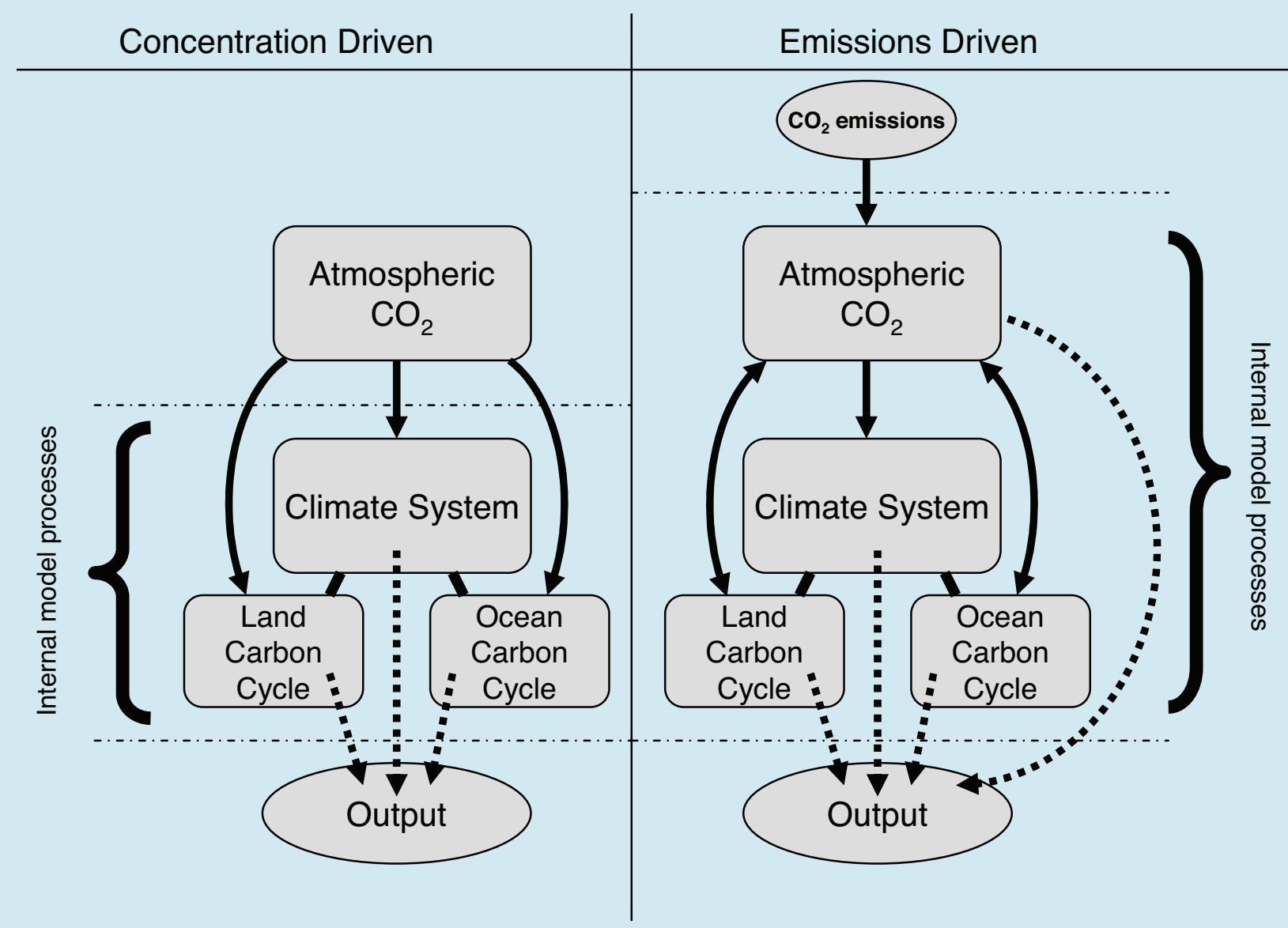

Box 6.4, Figure 1 | Schematic representation of carbon cycle numerical experimental design. Concentration-driven (left) and emissions-driven (right) simulation experiments make use of the same Earth System Models (ESMs), but configured differently. Concentration-driven simulations prescribe atmospheric $\mathrm{CO}_{2}$ as a predefined input to the climate and carbon cycle model components, but their output does not affect the $\mathrm{CO}_{2}$. Compatible emissions can be calculated from the output of the concentration-driven simulations. Emissions-driven simulations prescribe $\mathrm{CO}_{2}$ emissions as the input and atmospheric $\mathrm{CO}_{2}$ is an internally calculated element of the ESM.

Concentration-driven simulation experiments have the advantage that they can also be performed by GCMs without an interactivecarbon cycle and have been used extensively in previous assessments (e.g., Prentice et al., 2001). For this reason, most of the Representative Concentration Pathway (RCP) simulations (see Chapter 1) presented later in this chapter with carbon cycle models and in Chapter 12 with models that do not all have an interactive carbon cycle are performed this way. Emissions-driven simulations have the advantage of representing the full range of interactions in the coupled climate-carbon cycle models. The RCP8.5 pathway was repeated by many ESM models as an emissions-driven simulation (Chapter 12).

\section{Feedback Analysis}

The ESMs are made up of many 'components', corresponding to different processes or aspects of the system. To understand their behaviour, techniques have been applied to assess different aspects of the models' sensitivities (Friedlingstein et al., 2003, 2006; Arora et al., 2013). The two dominant emerging interactions are the sensitivity of the carbon cycle to changes in $\mathrm{CO}_{2}$ and its sensitivity to changes in climate. These can be measured using two metrics: 'beta' ( $\beta$ ) measures the strength of changes in carbon fluxes by land or ocean in response to changes in atmospheric $\mathrm{CO}_{2} ;{ }^{\prime}$ gamma' $(\gamma)$ measures the strength of changes in carbon fluxes by land or ocean in response to changes in climate. These metrics can be calculated as cumulative changes in carbon storage (as in Friedlingstein et al., 2006) or instantaneous rates of change (Arora et al., 2013).

It is not possible to calculate these sensitivities in a single simulation, so it is necessary to perform 'decoupled' simulations in which some processes in the models are artificially disabled in order to be able to evaluate the changes in other processes. See Table 1 in Box 6.4. 


\section{Box 6.4 (continued)}

A large positive value of $\beta$ denotes that a model responds to increasing $\mathrm{CO}_{2}$ by simulating large increases in natural carbon sinks. Negative values of $\gamma$ denote that a model response to climate warming is to reduce $\mathrm{CO}_{2}$ uptake from the atmosphere, while a positive value means warming acts to increase $\mathrm{CO}_{2}$ uptake. $\beta$ and $\gamma$ values are not specified in a model, but are properties that emerge from the suite of complex processes represented in the model. The values of the $\beta$ and $\gamma$ metrics diagnosed from simulations can vary from place to place within the same model (see Section 6.4.2.3), although it is the average over the whole globe that determines the global extent of the climate-carbon cycle feedback.

Such an idealised analysis framework should be seen as a technique for assessing relative sensitivities of models and understanding their differences, rather than as absolute measures of invariant system properties. By design, these experiments exclude land use change.

The complex ESMs have new components and new processes beyond conventional AO GCMs and thus require additional evaluation to assess their ability to make climate projections. Evaluation of the carbon cycle model components of ESMs is presented in Section 6.3.2.5.6 for ocean carbon models and Section 6.3.2.6.6 for land carbon models. Evaluation of the fully coupled ESMs is presented in Chapter 9.

Box 6.4, Table 1 | Configurations of simulations designed for feedback analysis by allowing some carbon-climate interactions to operate but holding others constant. The curves denote whether increasing or constant $\mathrm{CO}_{2}$ values are input to the radiation and carbon cycle model components. In a fully coupled simulation, the carbon cycle components of the models experience both changes in atmospheric $\mathrm{CO}_{2}$ (see Box 6.3 on fertilisation) and changes in climate. In 'biogeochemically' coupled experiments, the atmospheric radiation experiences constant $\mathrm{CO}_{2}$ (i.e., the radiative forcing of increased $\mathrm{CO}_{2}$ is not activated in the simulation) whereas the carbon cycle model components experience increasing $\mathrm{CO}_{2}$. This experiment quantifies the strength of the effect of rising $\mathrm{CO}_{2}$ concentration alone on the carbon cycle $(\beta)$. In a radiatively coupled experiment, the climate model's radiation scheme experiences an increase in the radiative forcing of $\mathrm{CO}_{2}$ (and hence produces a change in climate) but $\mathrm{CO}_{2}$ concentration is kept fixed to pre-industrial value as input to the carbon cycle model components. This simulation quantifies the effect of climate change alone on the carbon cycle $(\gamma)$.

\begin{tabular}{|c|c|c|c|}
\hline & $\begin{array}{l}\mathrm{CO}_{2} \text { input to } \\
\text { radiation scheme }\end{array}$ & $\begin{array}{l}\mathrm{CO}_{2} \text { input to carbon- } \\
\text { cycle scheme }\end{array}$ & Reason \\
\hline Fully coupled & & & Simulates the fully coupled system \\
\hline $\begin{array}{l}\text { 'Biogeochemically' } \\
\text { coupled } \\
\text { 'esmFixClim' }\end{array}$ & & & $\begin{array}{l}\text { Isolates the carbon-cycle response to } \mathrm{CO}_{2} \\
(\beta) \text { for land and oceans }\end{array}$ \\
\hline $\begin{array}{l}\text { Radiatively coupled } \\
\text { 'esmFdbk' }\end{array}$ & & & $\begin{array}{l}\text { Isolates carbon-cycle response to climate } \\
\text { change }(\gamma) \text { for land and for oceans }\end{array}$ \\
\hline
\end{tabular}


response in all models. Although land and ocean contribute equally to the total carbon-concentration response ( $\beta$ ), the model spread in the land response is greater than for the ocean.

\subsubsection{Scenario Dependence of Feedbacks}

The values of carbon-cycle feedback metrics can vary markedly for different scenarios and as such cannot be used to compare model simulations over different time periods, nor to inter-compare model simulations with different scenarios (Arora et al., 2013). Gregory et al. (2009) demonstrated how sensitive the feedback metrics are to the rate of change of $\mathrm{CO}_{2}$ for two models: faster rates of $\mathrm{CO}_{2}$ increase lead to reduced $\beta$ values as the carbon uptake (especially in the ocean) lags further behind the forcing. $\gamma$ is much less sensitive to the scenario, as both global temperature and carbon uptake lag the forcing.

\subsubsection{Regional Feedback Analysis}

The linear feedback analysis with the $\beta$ and $\gamma$ metrics of Friedlingstein et al. (2006) has been applied at the regional scale to future carbon uptake by Roy et al. (2011) and Yoshikawa et al. (2008). Figure 6.22 shows this analysis extended to land and ocean points for the CMIP5 models under the $1 \% \mathrm{yr}^{-1} \mathrm{CO}_{2}$ simulations.

\subsection{Regional ocean response}

Increased $\mathrm{CO}_{2}$ is projected by the CMIP5 models to increase oceanic $\mathrm{CO}_{2}$ sinks almost everywhere (positive $\beta$ ) (high confidence) with the exception of some very limited areas (Figure 6.22). The spatial distribution of the $\mathrm{CO}_{2}$ ocean response, $\beta_{0}$, is consistent between the models and with the Roy et al. (2011) analysis. On average, the regions with

Table 6.10 | Comparison of the sign and magnitude of changes in carbon storage (PgC) by land and ocean over different time scales. These changes are shown as approximate numbers to allow a comparison across time scales. For more details see the indicated chapter section. An indication, where known, of what causes these changes (climate, $\mathrm{CO}_{2}$, land use change) is also given with an indication of the sign: ' + ' means that an increase in $\mathrm{CO}_{2}$ or global-mean temperature is associated with an increase in carbon storage (positive $\beta$ or $\gamma$; see Section 6.4.2), and a '-' means an increase in $\mathrm{CO}_{2}$ or global-mean temperature is associated with a decrease in carbon storage (negative $\beta$ or $\gamma$ ). The processes that operate to drive these changes can vary markedly, for example, from seasonal phenology of vegetation to long-term changes in ice sheet cover or ocean circulation impacting carbon reservoirs. Some of these processes are 'reversible' in the context that they can increase and decrease cyclically, whereas some are 'irreversible' in the context that changes in one sense might be much longer than in the opposite direction.

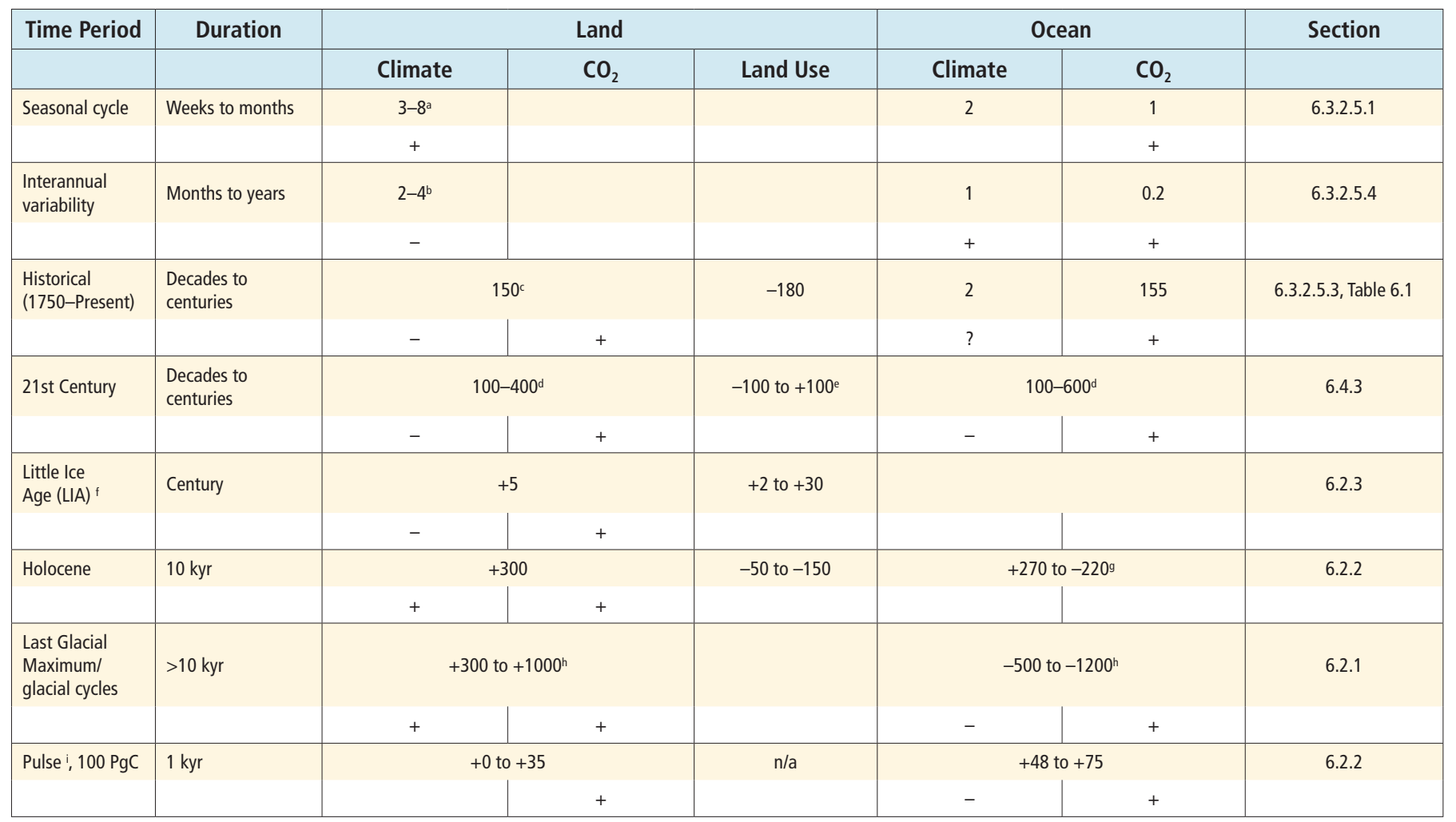

Notes:

a Dominated by northern mid to high latitudes.

b Dominated by the tropics.

c 'Residual land sink', Table 6.1.

d Varies widely according to scenario. Climate effect estimated separately for RCP4.5 as -157 PgC (combined land and ocean), but not for other scenarios.

e Future scenarios may increase or decrease area of anthropogenic land use.

f Little Ice Age, 1500-1750.

g Shown here are two competing drivers of Holocene ocean carbon changes: carbonate accumulation on shelves (coral growth) and carbonate compensation to pre-Holocene changes. These are discussed in Section 6.2.2

h Defined as positive if increasing from LGM to present, negative if decreasing.

Idealised simulations with models to assess the response of the global carbon cycle to a sudden release of $100 \mathrm{PgC}$. 


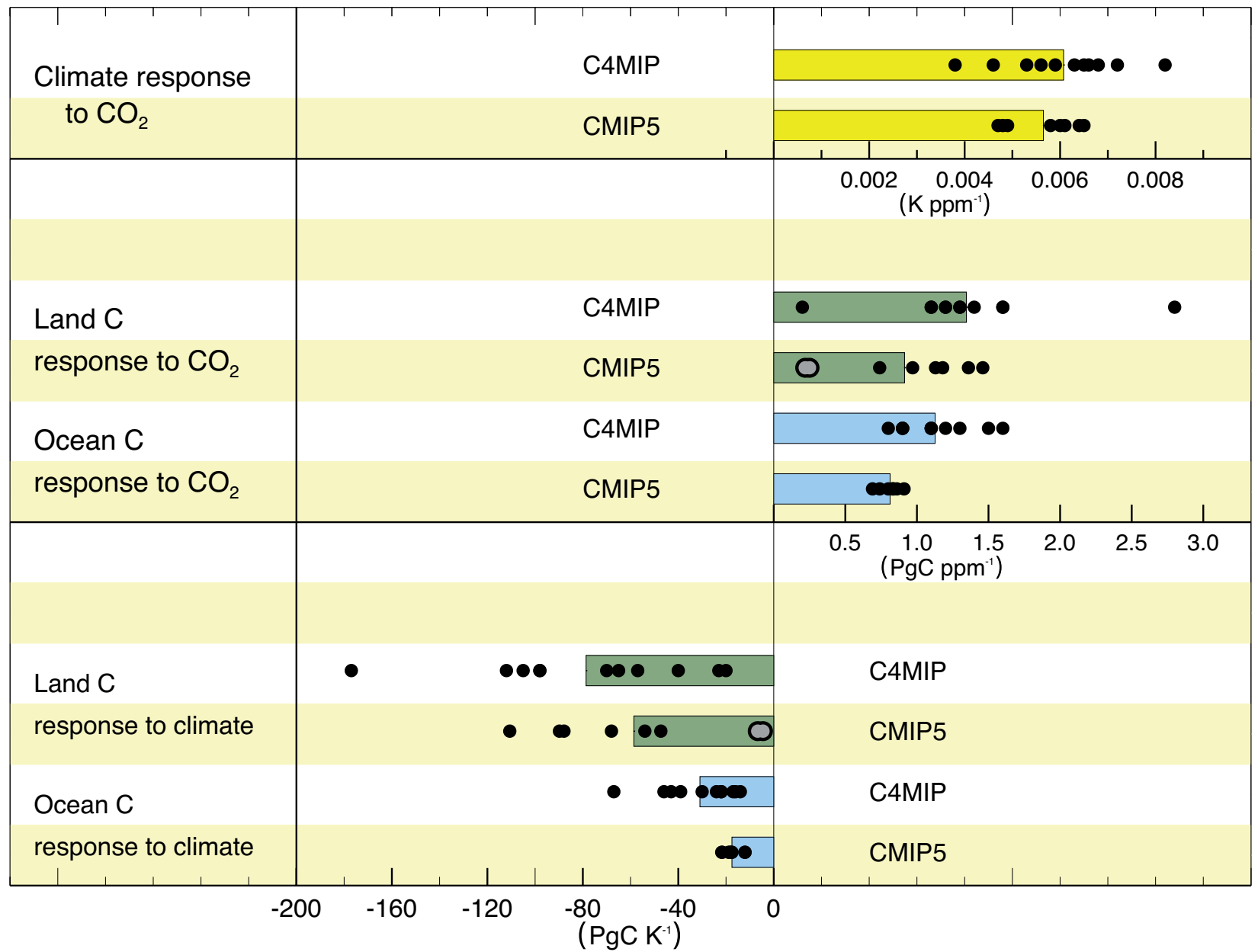

Figure 6.21 | Comparison of carbon cycle feedback metrics between the C4MIP ensemble of seven GCMs and four EMICs under the Special Report on Emission Scenario-A2 (SRES-A2) (Friedlingstein et al., 2006) and the eight CMIP5 models (Arora et al., 2013) under the 140 -year $1 \% \mathrm{CO}_{2}$ increase per year scenario. Black dots represent a single model simulation and coloured bars the mean of the multi-model results; grey dots are used for models with a coupled terrestrial nitrogen cycle. The comparison with C4MIP is for context, but these metrics are known to be variable across different scenarios and rates of change (see Section 6.4.2.2). Some of the CMIP5 models are derived from models that contributed to C4MIP and some are new to this analysis. Table 6.11 lists the main attributes of each CMIP5 model used in this analysis. The SRES A2 scenario is closer in rate of change to a $0.5 \% \mathrm{yr}^{-1}$ scenario and as such it should be expected that the CMIP5 $\gamma$ terms are comparable, but the $\beta$ terms are likely to be around $20 \%$ smaller for CMIP5 than for C4MIP due to lags in the ability of the land and ocean to respond to higher rates of $\mathrm{CO}_{2}$ increase (Gregory et al., 2009). This dependence on scenario (Section 6.4.2.2) reduces confidence in any quantitative statements of how CMIP5 carbon cycle feedbacks differ from C4MIP. CMIP5 models used: Max Planck Institute-Earth System Model-Low Resolution (MPI-ESM-LR), Beijing Climate Center-Climate System Model 1 (BCC-CSM1), Hadley Centre Global Environmental Model 2-Earth System (HadGEM2-ES), Institute Pierre Simon Laplace-Coupled Model 5A-Low Resolution (IPSL-CM5A-LR), Canadian Earth System Model 2 (CanESM2), Norwegian Earth System Model- intermediate resolution with carbon cycle (NorESMME), Community Earth System Model 1-Biogeochemical (CESM1-BGC), Model for Interdisciplinary Research On Climate-Earth System Model (MIROC-ESM).

the strongest increase of oceanic $\mathrm{CO}_{2}$ sinks in response to higher atmospheric $\mathrm{CO}_{2}$ are the North Atlantic and the Southern Oceans. The magnitude and distribution of $\beta_{0}$ in the ocean closely resemble the distribution of historical anthropogenic $\mathrm{CO}_{2}$ flux from inversion studies and forward modelling studies (Gruber et al., 2009), with the dominant anthropogenic $\mathrm{CO}_{2}$ uptake in the Southern Ocean (Section 6.3.2.5).

Climate warming is projected by the CMIP5 models to reduce oceanic carbon uptake in most oceanic regions (negative $\gamma$ ) (medium confidence) consistent with the Roy et al. (2011) analysis (Figure 6.22). This sensitivity of ocean $\mathrm{CO}_{2}$ sinks to climate, $\gamma_{0}$, is mostly negative (i.e., a reduced regional ocean $\mathrm{CO}_{2}$ sink in response to climate change) but with regions of positive values in the Arctic, the Antarctic and in the equatorial Pacific (i.e., climate change increases ocean $\mathrm{CO}_{2}$ sink in these regions). The North Atlantic Ocean and the mid-latitude Southern
Ocean have the largest negative $\gamma_{0}$ values. Reduced $\mathrm{CO}_{2}$ uptake in response to climate change in the sub-polar Southern Ocean and the tropical regions has been attributed to warming induced decreased $\mathrm{CO}_{2}$ solubility, reduced $\mathrm{CO}_{2}$ uptake in the mid latitudes to decreased $\mathrm{CO}_{2}$ solubility and decreased water mass formation which reduces the absorption of anthropogenic $\mathrm{CO}_{2}$ in intermediate and deep waters (Roy et al., 2011). Increased uptake in the Arctic Ocean and the polar Southern Ocean is partly associated with a reduction in the fractional sea ice coverage (Roy et al., 2011).

\subsection{Regional land response}

Increased $\mathrm{CO}_{2}$ is projected by the CMIP5 models to increase land $\mathrm{CO}_{2}$ sinks everywhere (positive $\beta$ ) (medium confidence). This response, $\beta_{L}$, has the largest values over tropical land, in humid rather than arid 


\begin{tabular}{|c|c|c|c|c|c|c|c|c|c|c|c|c|}
\hline 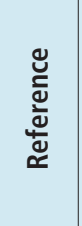 & & 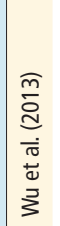 & 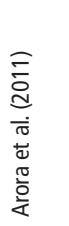 & 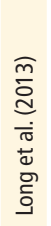 & 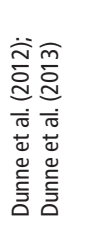 & 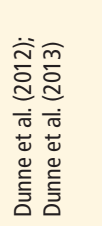 & 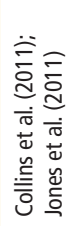 & & 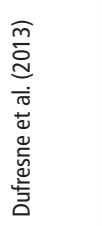 & 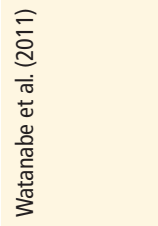 & 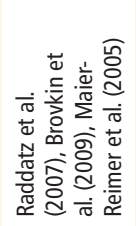 & 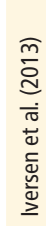 \\
\hline \multirow{3}{*}{ 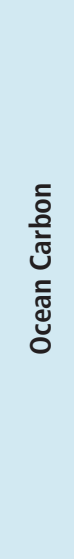 } & 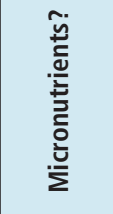 & $\frac{\pi}{2}$ & $z$ & $>$ & $>$ & $>$ & $>$ & & $>$ & $z$ & $>$ & $z$ \\
\hline & 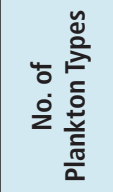 & $\stackrel{\pi}{\Omega}$ & - & $\sigma$ & 0 & 0 & $m$ & & $\sim$ & 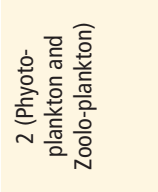 & $\sim$ & $\sim$ \\
\hline & 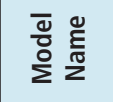 & $\sum_{\bar{z}}^{\tilde{z}}$ & $\sum_{\bigcup}^{\circlearrowright}$ & 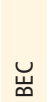 & $\begin{array}{l}\text { Ñ } \\
\text { à }\end{array}$ & $\begin{array}{l}\text { Nิ } \\
\text { à }\end{array}$ & 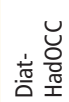 & & $\begin{array}{l}\text { 岕 } \\
\frac{n}{\alpha}\end{array}$ & 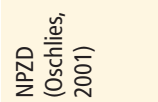 & 艺 & 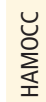 \\
\hline \multirow{6}{*}{ 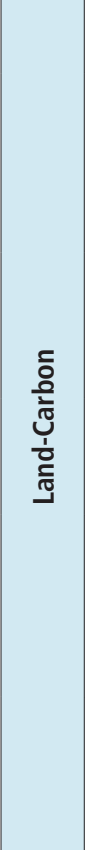 } & $\stackrel{0}{\stackrel{2}{*}}$ & $z$ & $z$ & $>$ & $>$ & $>$ & $z$ & & $>$ & $z$ & $>$ & $>$ \\
\hline & 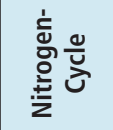 & $z$ & $z$ & $>$ & $z$ & $z$ & $z$ & & $z$ & $z$ & $z$ & $>$ \\
\hline & 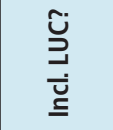 & & $>$ & $>$ & $>$ & $>$ & $>$ & & $>$ & $>$ & $>$ & $>$ \\
\hline & 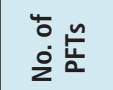 & $\stackrel{n}{-}$ & $a$ & $\stackrel{n}{\sim}$ & in & in & in & & $\stackrel{m}{\sim}$ & $\underline{m}$ & 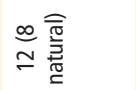 & 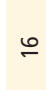 \\
\hline & 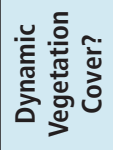 & $z$ & $z$ & $z$ & $>$ & $>$ & $>$ & & $z$ & $>$ & $>$ & $z$ \\
\hline & 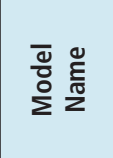 & 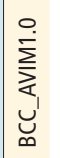 & $\underset{⿱ 山 己}{\sum_{U}}$ & $\sum_{U}^{J}$ & $\sum^{m}$ & $\sum^{m}$ & $\stackrel{\breve{~}}{\varrho}$ & & $\begin{array}{l}\text { 岀 } \\
\text { 顽 } \\
\text { ㅇ }\end{array}$ & 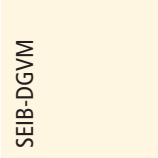 & 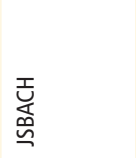 & $\sum_{U}^{J}$ \\
\hline 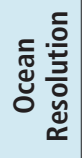 & & $\begin{array}{c}q \\
g \\
0 \\
\vdots \\
1 \\
0 \\
0\end{array}$ & 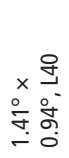 & $\stackrel{-}{-}$ & 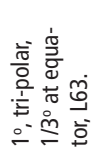 & 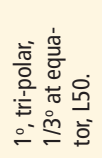 & 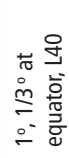 & & 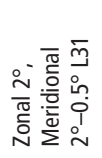 & 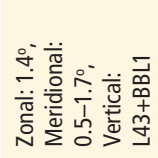 & 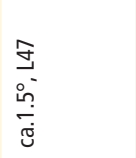 & $\stackrel{n}{\mathfrak{P}^{-}}$ \\
\hline 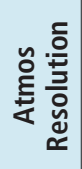 & & 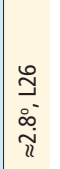 & $\begin{array}{l}\stackrel{\mathscr{n}}{m} \\
\stackrel{\rho}{\varrho}\end{array}$ & 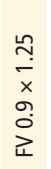 & 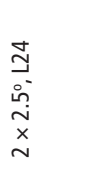 & 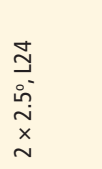 & 낭 & & 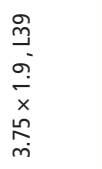 & $\begin{array}{l}\stackrel{\bigcirc}{ \pm} \\
\stackrel{\Xi}{ \pm}\end{array}$ & 롱 & 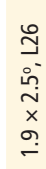 \\
\hline 을 일 & & પ্ৰ & 气્ّ & 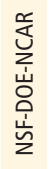 & $\begin{array}{l}\overrightarrow{0} \\
\text { 岕 } \\
\text { 这 } \\
\text { 을 }\end{array}$ & $\begin{array}{l}\overrightarrow{1} \\
\text { U. } \\
0 \\
0 \\
0 \\
2\end{array}$ & 농 & $\sum_{\vdots}$ & $\overrightarrow{\underline{\underline{\varrho}}}$ & 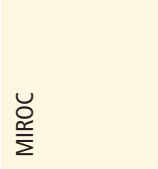 & 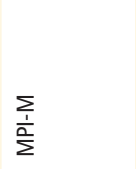 & U্ \\
\hline $\begin{array}{l}\overline{0} \\
\frac{0}{0}\end{array}$ & & 它 & 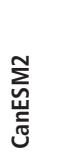 & 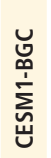 & 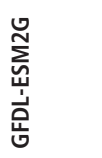 & 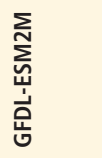 & 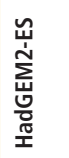 & $\sum_{\underline{\Sigma}}^{J}$ & 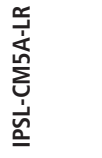 & 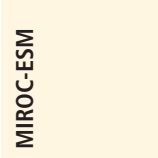 & 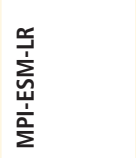 & 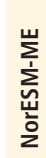 \\
\hline
\end{tabular}




\section{a. Regional carbon-concentration feedback}
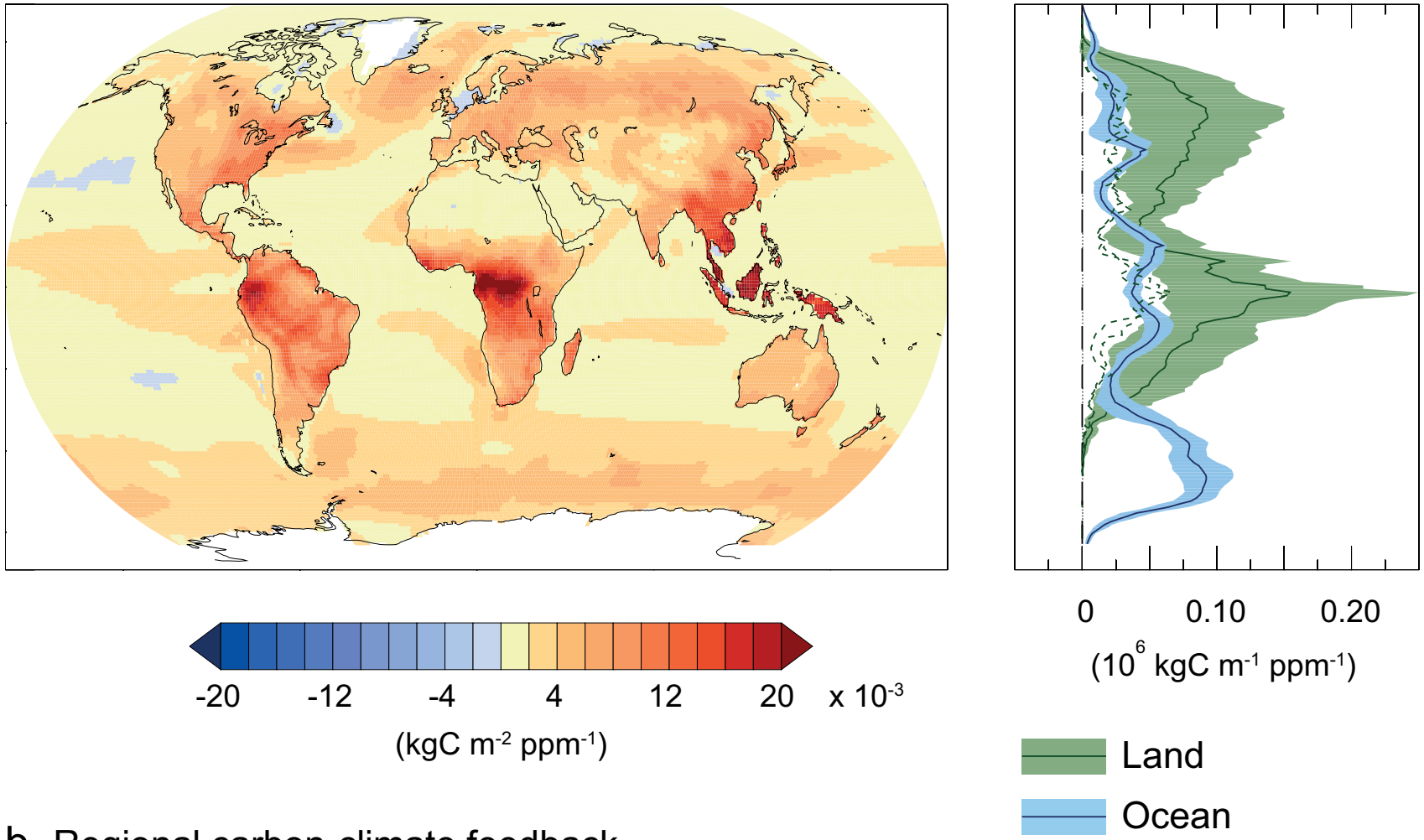

\section{b. Regional carbon-climate feedback}
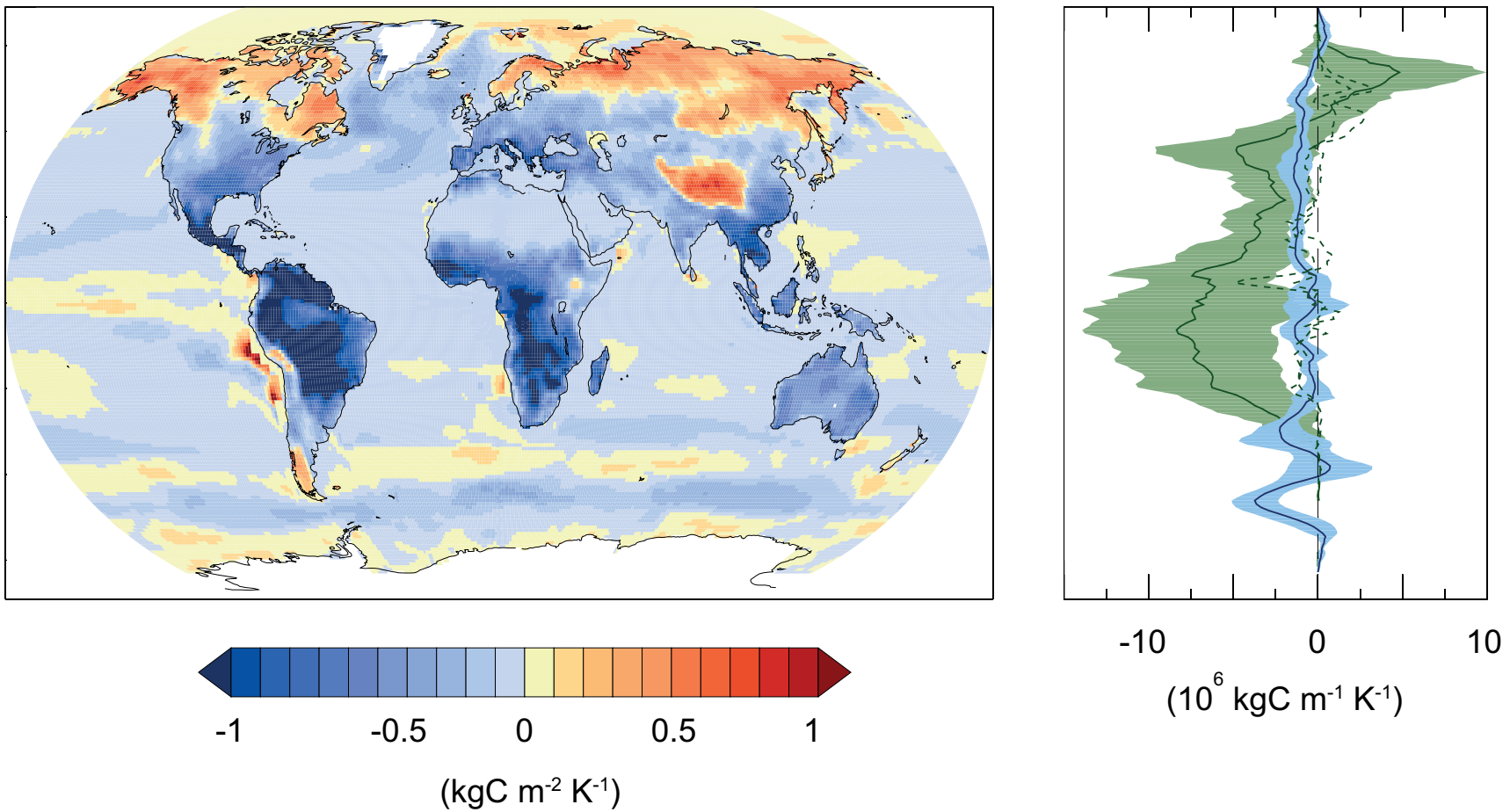

Figure 6.22 The spatial distributions of multi-model-mean land and ocean $\beta$ and $\gamma$ for seven $\mathrm{CMIP5}$ models using the concentration-driven idealised $1 \% \mathrm{yr}^{-1} \mathrm{CO}_{2}$ simulations. For land and ocean, $\beta$ and $\gamma$ are defined from changes in terrestrial carbon storage and changes in air-sea integrated fluxes respectively, from $1 \times \mathrm{CO}_{2}$ to $4 \times \mathrm{CO}_{2}$, relative to global (not local) $\mathrm{CO}_{2}$ and temperature change. In the zonal mean plots, the solid lines show the multi-model mean and shaded areas denote \pm 1 standard deviation. Models used: Beijing Climate Center-Climate System Model 1 (BCC-CSM1), Canadian Earth System Model 2 (CanESM2), Community Earth System Model 1-Biogeochemical (CESM1-BGC), Hadley Centre Global Environmental Model 2-Earth System (HadGEM2-ES), Institute Pierre Simon Laplace- Coupled Model 5A-Low Resolution (IPSL-CM5A-LR), Max Planck InstituteEarth System Model-Low Resolution (MPI-ESM-LR), Norwegian Earth System Model 1 (Emissions capable) (NorESM1-ME). The dashed lines show the models that include a land carbon component with an explicit representation of nitrogen cycle processes (CESM1-BGC, NorESM1-ME). 
regions, associated with enhanced carbon uptake in forested areas of already high biomass. In the zonal totals, there is a secondary peak of high $\beta_{\mathrm{L}}$ values over NH temperate and boreal ecosystems, partly due to a greater land area there but also coincident with large areas of forest. Models agree on the sign of response but have low agreement on the magnitude.

The climate effect alone is projected by the CMIP5 models to reduce land $\mathrm{CO}_{2}$ sinks in tropics and mid latitudes (negative $\gamma$ ) (medium confidence). CMIP5 models show medium agreement that warming may increase land carbon uptake in high latitudes but none of these models include representation of permafrost carbon pools which are projected to decrease in warmer conditions (Section 6.4.3.3); therefore confidence is low regarding the sign and magnitude of future high-latitude land carbon response to climate change. Matthews et al. (2005) showed that vegetation productivity is the major cause of C4MIP model spread, but this manifests itself as changes in soil organic matter (Jones and Falloon, 2009).

\subsubsection{Implications of the Future Projections for the Carbon Cycle and Compatible Emissions}

\subsubsection{The RCP Future Carbon Dioxide Concentration and Emissions Scenarios}

The CMIP5 simulations include four future scenarios referred to as Representative Concentration Pathways (RCPs; see Glossary) (Moss et al., 2010): RCP2.6, RCP4.5, RCP6.0, RCP8.5 (see Chapter 1). These future scenarios include $\mathrm{CO}_{2}$ concentration and emissions, and have been generated by four Integrated Assessment Models (IAMs) and are labelled according to the approximate global radiative forcing level at 2100. These scenarios are described in more detail in Chapter 1 (Box 1.1) and Section 12.3 and also documented in Annex II.

van Vuuren et al. (2011) showed that the basic climate and carbon cycle responses of IAMs is generally consistent with the spread of climate and carbon cycle responses from ESMs. For the physical and biogeochemical components of the RCP scenarios 4.5, 6.0 and 8.5, the underlying IAMs are closely related. Only the Integrated Model to Assess the Global Environment (IMAGE) IAM, which created RCP2.6, differs markedly by using a more sophisticated carbon cycle sub-model for land and ocean. The Model for the Assessment of Greenhouse-gas Induced Climate Change 6 (MAGICC6) simple climate model was subsequently used to generate the $\mathrm{CO}_{2}$ pathway for all four RCP scenarios using the $\mathrm{CO}_{2}$ emissions output by the four IAMs (Meinshausen et al., 2011).

\subsubsection{Land Use Changes in Future Scenarios}

ESMs and IAMs use a diversity of approaches for representing land use changes, including different land use classifications, parameter settings, and geographical scales. To implement land use change in a consistent manner across ESMs, a 'harmonized' set of annual gridded land use change during the period 1500-2100 was developed for input to the CMIP5 ESMs (Hurtt et al., 2011).
Not all the CMIP5 ESMs used the full range of information available from the land use change scenarios, such as wood harvest projections or sub-grid scale shifting cultivation. Sensitivity studies indicated that these processes, along with the start date of the simulation, all strongly affect estimated carbon fluxes (Hurtt et al., 2011; Sentman et al., 2011).

Land use has been in the past and will be in the future a significant driver of forest land cover change and terrestrial carbon storage. Land use trajectories in the RCPs show very distinct trends and cover a wide range of projections. These land use trajectories are very sensitive to assumptions made by each individual IAM regarding the amount of land needed for food production (Figure 6.23). The area of cropland and pasture increases in RCP8.5 with the Model for Energy Supply Strategy Alternatives and their General Environmental Impact (MESSAGE) IAM model, mostly driven by an increasing global population, but cropland area also increases in the RCP2.6 with the IMAGE IAM model, as a result of bio-energy production and increased food demand as well. RCP6 with the AIM model shows an expansion of cropland but a decline in pasture land. RCP4.5 with the Global Change Assessment Model (GCAM) IAM is the only scenario to show a decrease in global cropland. Several studies (Wise et al., 2009; Thomson et al., 2010; Tilman et al., 2011) highlight the large sensitivity of future land use requirements to assumptions such as increases in crop yield, changes in diet, or how agricultural technology and intensification is applied.

Within the IAMs, land use change is translated into land use $\mathrm{CO}_{2}$ emissions as shown in Figure 6.23(b). Cumulative emissions for the 21st century (Figure 6.23c) vary markedly across RCPs, with increasing cropland and pastureland areas in RCP2.6 and RCP8.5 giving rise to the highest emissions from land use change, RCP4.5 to intermediate emissions and RCP6.0 to close to zero net emissions. All scenarios suggest that 21 st century land use emissions will be less than half of those from 1850 to the present day as rate of change of land conversion stabilises in future.

The adoption of widely differing approaches among ESMs for the treatment and diagnosis of land use and land cover change (LULCC) processes in terrestrial carbon cycle models leads to substantial betweenmodel variation in the simulated impact on land carbon stocks. It is not yet possible to fully quantify LULCC fluxes from the CMIP5 model simulations. The harmonization process applied to LULCC data sets for CMIP5 has been an important step toward consistency among IAMs; however, among ESMs, and between IAMs and ESMs, assignment of meaningful uncertainty ranges to present-day and future LULCC fluxes and states remains a critical knowledge gap with implications for compatible emissions to achieve $\mathrm{CO}_{2}$ pathways (Section 6.4.3.3; Jones et al., 2013).

\subsubsection{Projections of Future Carbon Cycle Response by Earth System Models Under the Representative Concentration Pathway Scenarios}

Simulated changes in land and ocean carbon uptake and storage under the four RCP scenarios are presented here using results from CMIP5 ESMs concentration-driven simulations (see Box 6.4). The implications of these changes on atmospheric $\mathrm{CO}_{2}$ and climate as simulated by CMIP5 emissions-driven simulations are presented in Chapter 12. 

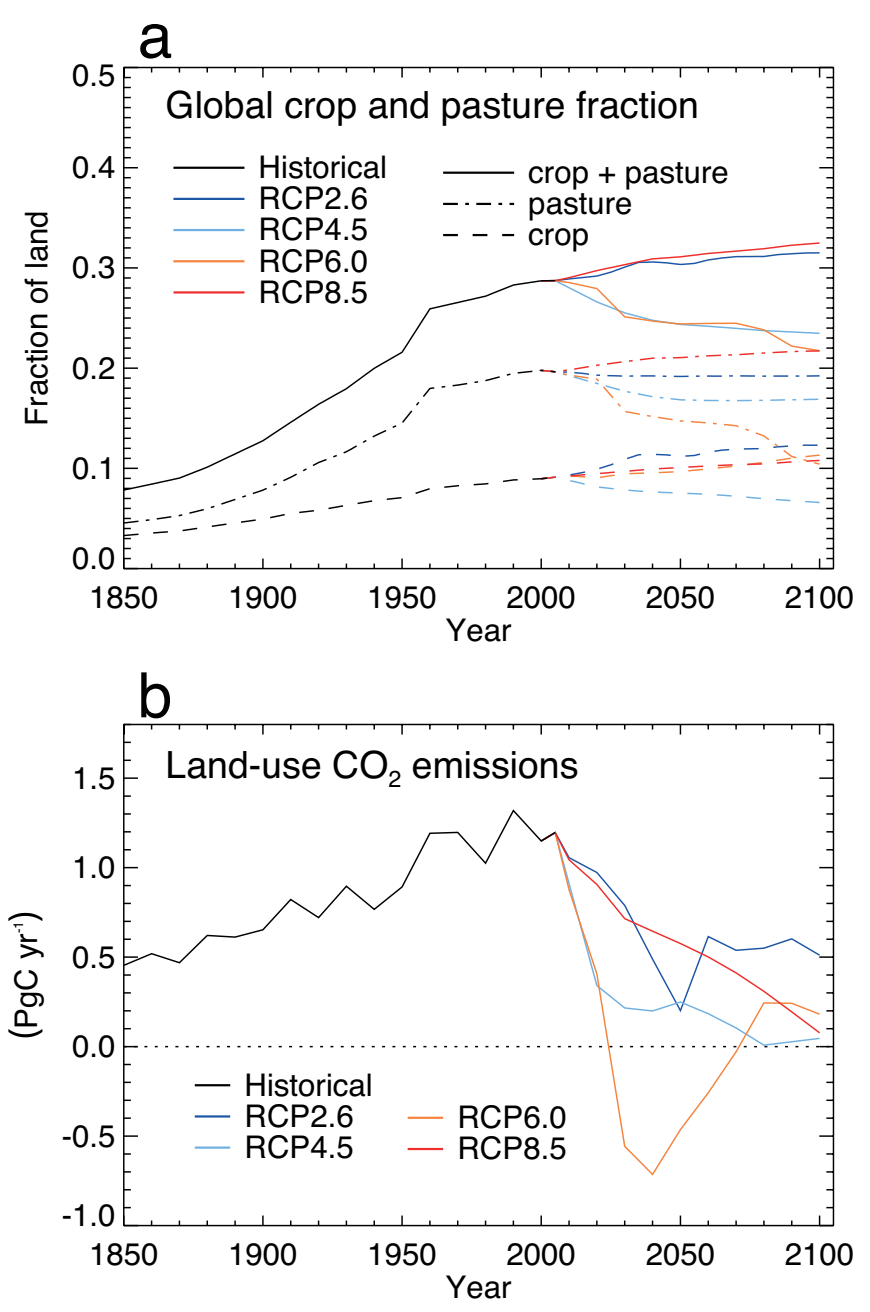

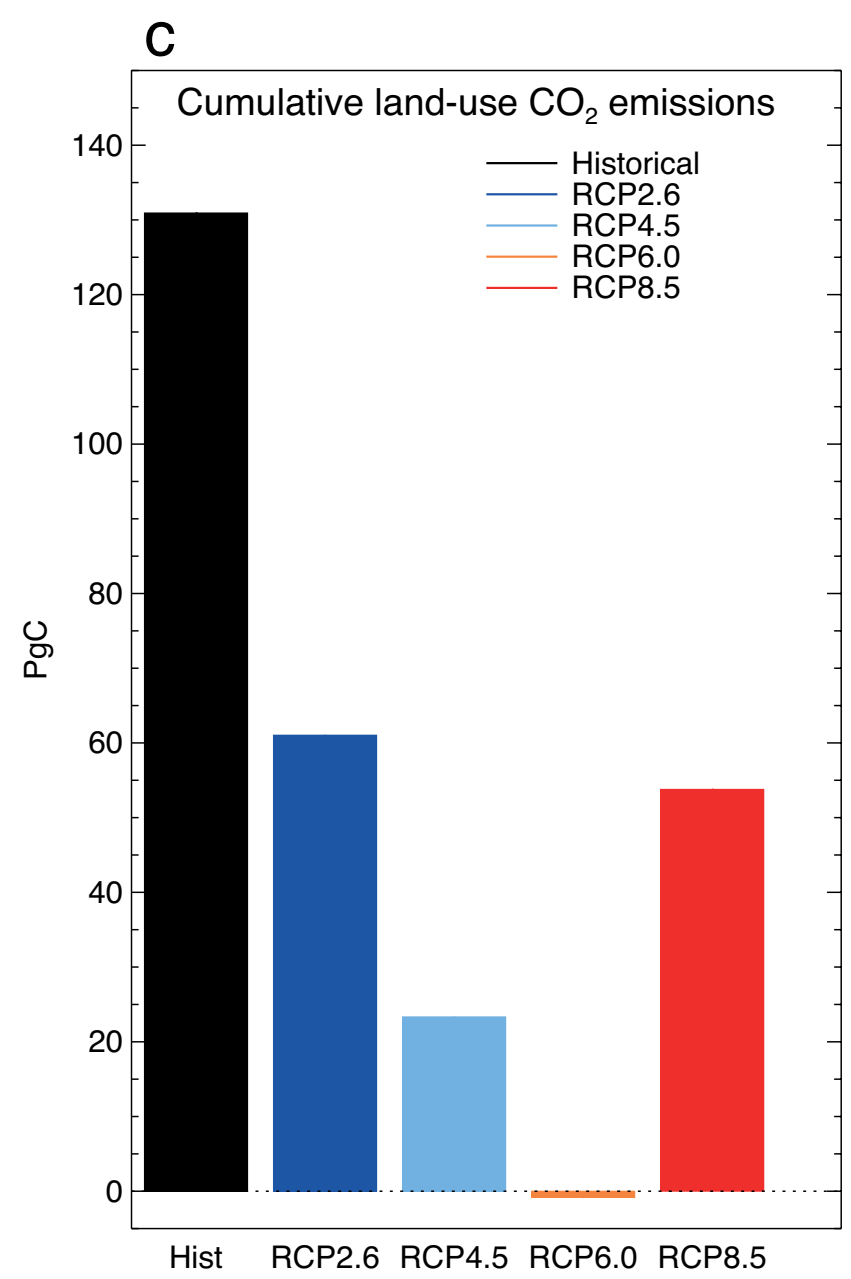

Figure 6.23 Land use trends and $\mathrm{CO}_{2}$ emissions according to the four different integrated assessment models (IAMs) used to define the RCP scenarios. Global changes in croplands and pasture from the historical record and the RCP scenarios (top left), and associated annual land use emissions of $\mathrm{CO}_{2}$ (bottom left). Bars (right panel) show cumulative land use emissions for the historical period (defined here as 1850-2005) and the four RCP scenarios from 2006 to 2100.

The results of the concentration-driven CMIP5 ESMs simulations show medium agreement on the magnitude of cumulative ocean carbon uptake from 1850 to 2005 (Figure 6.24a): average $127 \pm 28 \mathrm{PgC}(1$ standard deviation). The models show low agreement on the sign and magnitude of changes in land carbon storage (Figure 6.24a): average $2 \pm 74 \mathrm{PgC}$ (1 standard deviation). These central estimates are very close to observational estimates of $125 \pm 25 \mathrm{PgC}$ for the ocean and $-5 \pm 40 \mathrm{PgC}$ for the net cumulative land-atmosphere flux respectively (see Table 6.12), but show a large spread across models. With very high confidence, for all four RCP scenarios, all models project continued ocean uptake throughout the 21st century, with higher uptake corresponding to higher concentration pathways. For RCP4.5, all the models also project an increase in land carbon uptake, but for RCP2.6, RCP6.0 and RCP8.5 a minority of models (4 out of 11 for RCP2.6, 1 out of 8 for RCP6.0 and 4 out of 15 for RCP8.5; Jones et al., 2013) project a decrease in land carbon storage at 2100 relative to 2005 . Model spread in land carbon projections is much greater than model spread in ocean carbon projections, at least in part due to different treatment of land use change. Decade mean land and ocean fluxes are documented in Annex II, Table All.3.1a, b. Important processes missing from many or all CMIP5 land carbon cycles include the role of nutrient cycles, permafrost, fire and ecosystem acclimation to changing climate. For this reason we assign low confidence to quantitative projections of future land uptake.

The concentration-driven ESM simulations can be used to quantify the compatible fossil fuel emissions required to follow the four RCP $\mathrm{CO}_{2}$ pathways (Jones et al., 2013; see Box 6.4, Figure 6.25, Table 6.12, Annex II, Table All.2.1a). There is significant spread between ESMs, but general consistency between ESMs and compatible emissions estimated by IAMs to define each RCP scenario. However, for RCP8.5 on average, the CMIP5 models project lower compatible emissions than the MESSAGE IAM. The IMAGE IAM predicts that global negative emissions are required to achieve the RCP2.6 decline in radiative forcing from $3 \mathrm{~W} \mathrm{~m}^{-2}$ to $2.6 \mathrm{~W} \mathrm{~m}^{-2}$ by 2100 . All models agree that strong emissions reductions are required to achieve this after about 2020 (Jones et al., 2013). An average emission reduction of 50\% (range 14 to $96 \%$ ) is required by 2050 relative to 1990 levels. There is disagreement between those ESMs that performed this simulation over the necessity for global emissions in the RCP2.6 to become negative by 
a

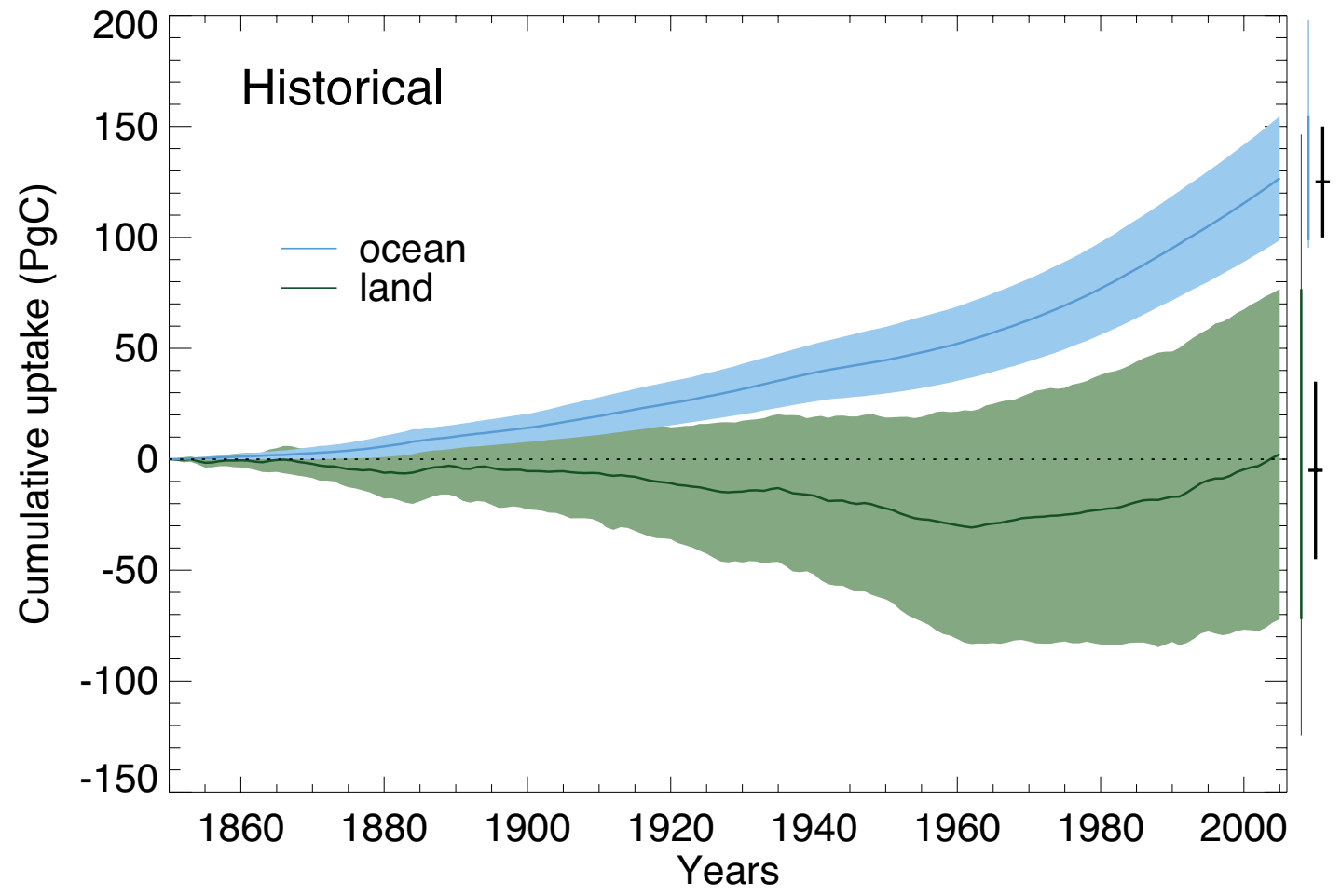

b
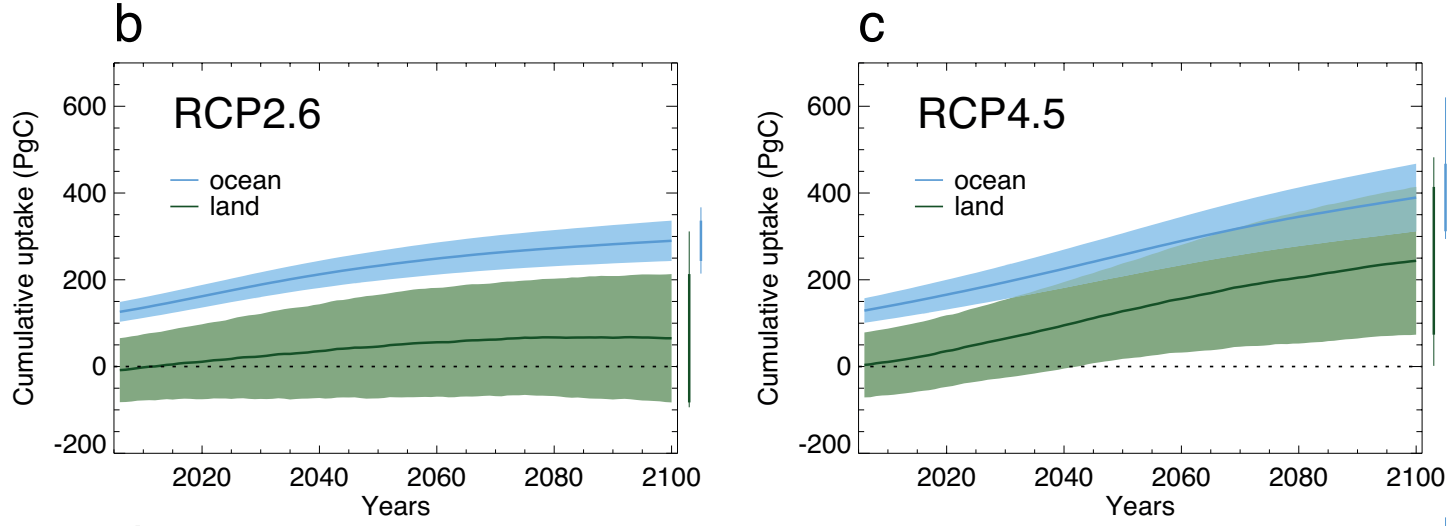

d
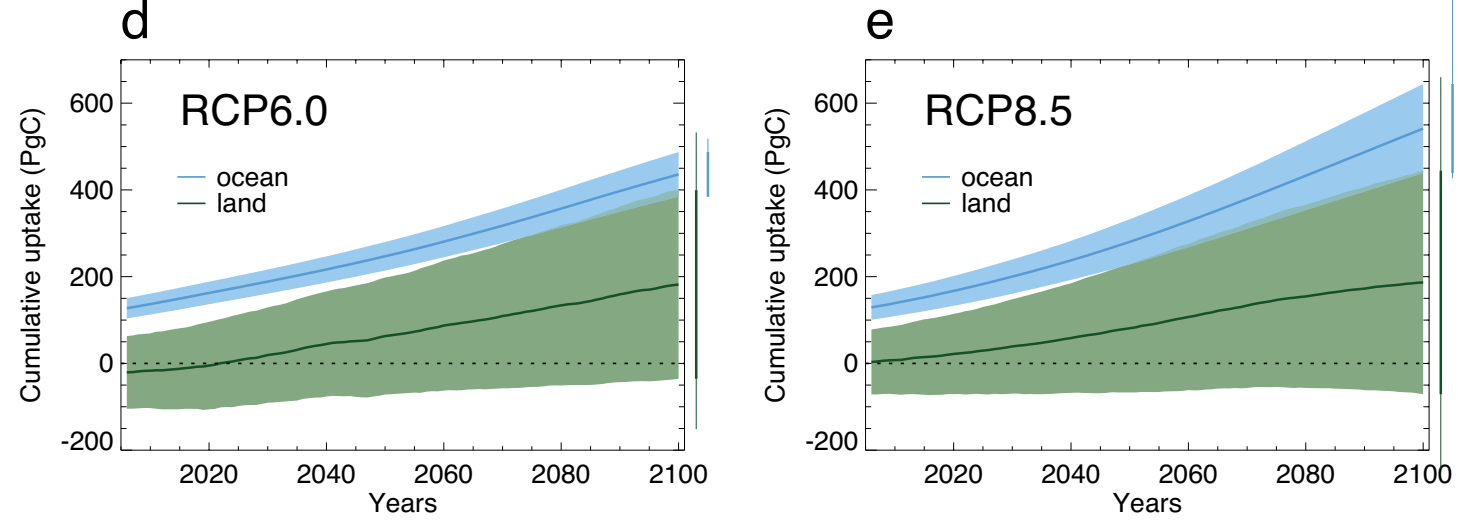

Figure 6.24 | Cumulative land and ocean carbon uptake simulated for the historical period 1850-2005 (top) and for the four RCP scenarios up to 2100 (b-e). Mean (thick line) and 1 standard deviation (shaded). Vertical bars on the right show the full model range as well as standard deviation. Black bars show observationally derived estimates for 2005. Models used: Canadian Earth System Model 2 (CanESM2), Geophysical Fluid Dynamics Laboratory-Earth System Model 2G (GFDL-ESM2G), Geophysical Fluid Dynamics Laboratory-Earth System Model 2M (GFDL-ESM2M), Hadley Centre Global Environmental Model 2-Carbon Cycle (HadGEM2-CC), Hadley Centre Global Environmental Model 2-Earth System (HadGEM2-ES), Institute Pierre Simon Laplace-Coupled Model 5A-Low Resolution (IPSL-CM5A-LR), Institute Pierre Simon Laplace-Coupled Model 5A-Medium Resolution (IPSL-CM5A-MR), Institute Pierre Simon Laplace-Coupled Model 5B-Low Resolution (IPSL-CM5B-LR), Model for Interdisciplinary Research On Climate-Earth System Model (MIROC-ESM-CHEM), Model for Interdisciplinary Research On Climate-Earth System Model (MIROC-ESM), Max Planck Institute-Earth System Model-Low Resolution (MPI-ESM-LR), Norwegian Earth System Model 1 (Emissions capable) (NorESM1-ME), Institute for Numerical Mathematics Coupled Model 4 (INMCM4), Community Earth System Model 1-Biogeochemical (CESM1-BGC), Beijing Climate Center-Climate System Model 1.1 (BCC-CSM1.1). Not every model performed every scenario simulation. 
Table 6.12 | The range of compatible fossil fuel emissions (PgC) simulated by the CMIP5 models for the historical period and the four RCP scenarios, expressed as cumulative fossil fuel emission. To be consistent with Table 6.1 budgets are calculated up to 2011 for historical and 2012-2100 for future scenarios, and values are rounded to the nearest $5 \mathrm{PgC}$.

\begin{tabular}{|c|c|c|c|c|c|c|c|c|c|}
\hline & \multicolumn{3}{|c|}{$\begin{array}{c}\text { Compatible Fossil Fuel } \\
\text { Emissions Diagnosed from } \\
\text { Concentration-Driven CMIP5 Simulations }\end{array}$} & \multicolumn{3}{|c|}{ Land Carbon Changes } & \multicolumn{3}{|c|}{ Ocean Carbon Changes } \\
\hline & $\begin{array}{l}\text { Historical / } \\
\text { RCP Scenario }\end{array}$ & $\begin{array}{l}\text { CMIP5 ESM } \\
\text { Mean }\end{array}$ & $\begin{array}{l}\text { CMIP5 ESM } \\
\text { Range }\end{array}$ & $\begin{array}{l}\text { Historical / } \\
\text { RCP Scenario }\end{array}$ & $\begin{array}{c}\text { CMIP5 ESM } \\
\text { Mean }\end{array}$ & $\begin{array}{l}\text { CMIP5 ESM } \\
\text { Range }\end{array}$ & $\begin{array}{l}\text { Historical / } \\
\text { RCP Scenario }\end{array}$ & $\begin{array}{c}\text { CMIP5 ESM } \\
\text { Mean }\end{array}$ & $\begin{array}{l}\text { CMIP5 ESM } \\
\text { Range }\end{array}$ \\
\hline $1850-2011$ & $375^{a}$ & 350 & $235-455$ & $5 \pm 40^{b}$ & 10 & -125 to 160 & $140 \pm 25^{b}$ & 140 & $110-220$ \\
\hline RCP2.6 & 275 & 270 & $140-410$ & c & 65 & -50 to 195 & c & 150 & 105-185 \\
\hline RCP4.5 & 735 & 780 & 595-1005 & & 230 & 55 to 450 & & 250 & $185-400$ \\
\hline RCP6.0 & 1165 & 1060 & $840-1250$ & & 200 & -80 to 370 & & 295 & $265-335$ \\
\hline RCP8.5 & 1855 & 1685 & 1415-1910 & & 180 & -165 to 500 & & 400 & $320-635$ \\
\hline
\end{tabular}

Notes:

a Historical estimates of fossil fuel are as prescribed to all CMIP5 ESMs in the emissions-driven simulations (Andres et al., 2011).

b Estimate of historical net land and ocean carbon uptake from Table 6.1 but over the shorter 1850-2011 time period.

IAM breakdown of future carbon changes by land and ocean are not available.

the end of the 21st century to achieve this, with six ESMs simulating negative compatible emissions and four ESM models simulating positive emissions from 2080 to 2100 . The RCP2.6 scenario achieves this negative emission rate through use of large-scale bio-energy with carbon-capture and storage (BECCS). It is as likely as not that sustained globally negative emissions will be required to achieve the reductions in atmospheric $\mathrm{CO}_{2}$ in the RCP2.6 scenario. This would be classed as a carbon dioxide removal (CDR) form of geoengineering under the definition used in this IPCC report, and is discussed further in Section 6.5.2. The ESMs themselves make no assumptions about how the compatible emissions could or would be achieved, but merely compute the global total emission that is required to follow the $\mathrm{CO}_{2}$ concentration pathway, accounting for the carbon cycle response to climate and $\mathrm{CO}_{2}$, and for land use change $\mathrm{CO}_{2}$ emissions.

The dominant cause of future changes in the airborne fraction of fossil fuel emissions (see Section 6.3.2.4) is the emissions scenario and not carbon cycle feedbacks (Jones et al., 2013; Figure 6.26). Models show high agreement that 21 st century cumulative airborne fraction will increase under rapidly increasing $\mathrm{CO}_{2}$ in RCP8.5 and decreases under the peak-and-decline RCP2.6 scenarios. The airborne fraction declines slightly under RCP4.5 and remains of similar magnitude in the RCP6.0 scenario. Between-model spread in changes in the land-fraction is greater than between-scenario spread. Models show high agreement that the ocean fraction will increase under RCP2.6 and remain of similar magnitude in the other RCP scenarios.

Several studies (Jones et al., 2006; Matthews, 2006; Plattner et al., 2008; Miyama and Kawamiya, 2009) have shown that climate-carbon cycle feedbacks affect the compatible fossil fuel $\mathrm{CO}_{2}$ emissions that are consistent with a given $\mathrm{CO}_{2}$ concentration pathway. Using decoupled RCP4.5 simulations (see Box 6.4) five CMIP5 ESMs agree that the climate impact on carbon uptake by both land and oceans will reduce the compatible fossil fuel $\mathrm{CO}_{2}$ emissions for that scenario by between $6 \%$ and $29 \%$ between 2006 and 2100 respectively (Figure 6.27), equating to an average of $157 \pm 76 \mathrm{PgC}$ ( 1 standard deviation) less carbon that can be emitted from fossil fuel use if climate feedback (see Glossary) is included. Compatible emissions would be reduced by a greater degree under higher $\mathrm{CO}_{2}$ scenarios that exhibit a greater degree of climate change (Jones et al., 2006).

\subsubsection{Permafrost Carbon}

Current estimates of permafrost soil carbon stocks are $\sim 1700 \mathrm{PgC}$ (Tarnocai et al., 2009), the single largest component of the terrestrial carbon pool. Terrestrial carbon models project a land $\mathrm{CO}_{2}$ sink with warming at high northern latitudes; however none of the models participating in C4MIP or CMIP5 included explicit representation of permafrost soil carbon decomposition in response to future warming. Including permafrost carbon processes into an ESM may change the sign of the high northern latitude carbon cycle response to warming from a sink to a source (Koven et al., 2011). Overall, there is high confidence that reductions in permafrost extent due to warming will cause thawing of some currently frozen carbon. However, there is low confidence on the magnitude of carbon losses through $\mathrm{CO}_{2}$ and $\mathrm{CH}_{4}$ emissions to the atmosphere. The magnitude of $\mathrm{CO}_{2}$ and $\mathrm{CH}_{4}$ emissions to the atmosphere is assessed to range from 50 to $250 \mathrm{PgC}$ between 2000 and 2100 for RCP8.5. The magnitude of the source of $\mathrm{CO}_{2}$ to the atmosphere from decomposition of permafrost carbon in response to warming varies widely according to different techniques and scenarios. Process models provide different estimates of the cumulative loss of permafrost carbon: 7 to 17 PgC (Zhuang et al., 2006) (not considered in the range given above because it corresponds only to contemporary tundra soil carbon), 55 to $69 \mathrm{Pg}$ (Koven et al., 2011), 126 to $254 \mathrm{PgC}$ (Schaefer et al., 2011) and 68 to 508 PgC (MacDougall et al., 2012) (not considered in the range given above because this estimate is not obtained from a concentration driven, but for emission driven RCP scenario and it is the only study of that type so far). Combining observed vertical soil carbon profiles with modeled thaw rates provides an estimate that the total quantity of newly thawed soil carbon by 2100 will be 246 PgC for RCP4.5 and 436 PgC for RCP8.5 (Harden et al., 2012), although not all of this amount will be released to the atmosphere on that time scale. Uncertainty estimates suggest the cumulative amount of thawed permafrost carbon could range from 33 to $114 \mathrm{PgC}(68 \%$ range) under RCP8.5 warming (Schneider von Deimling et al., 2012), or 50 to $270 \mathrm{PgC}$ (5th to 95th percentile range) (Burke et al., 2013). 

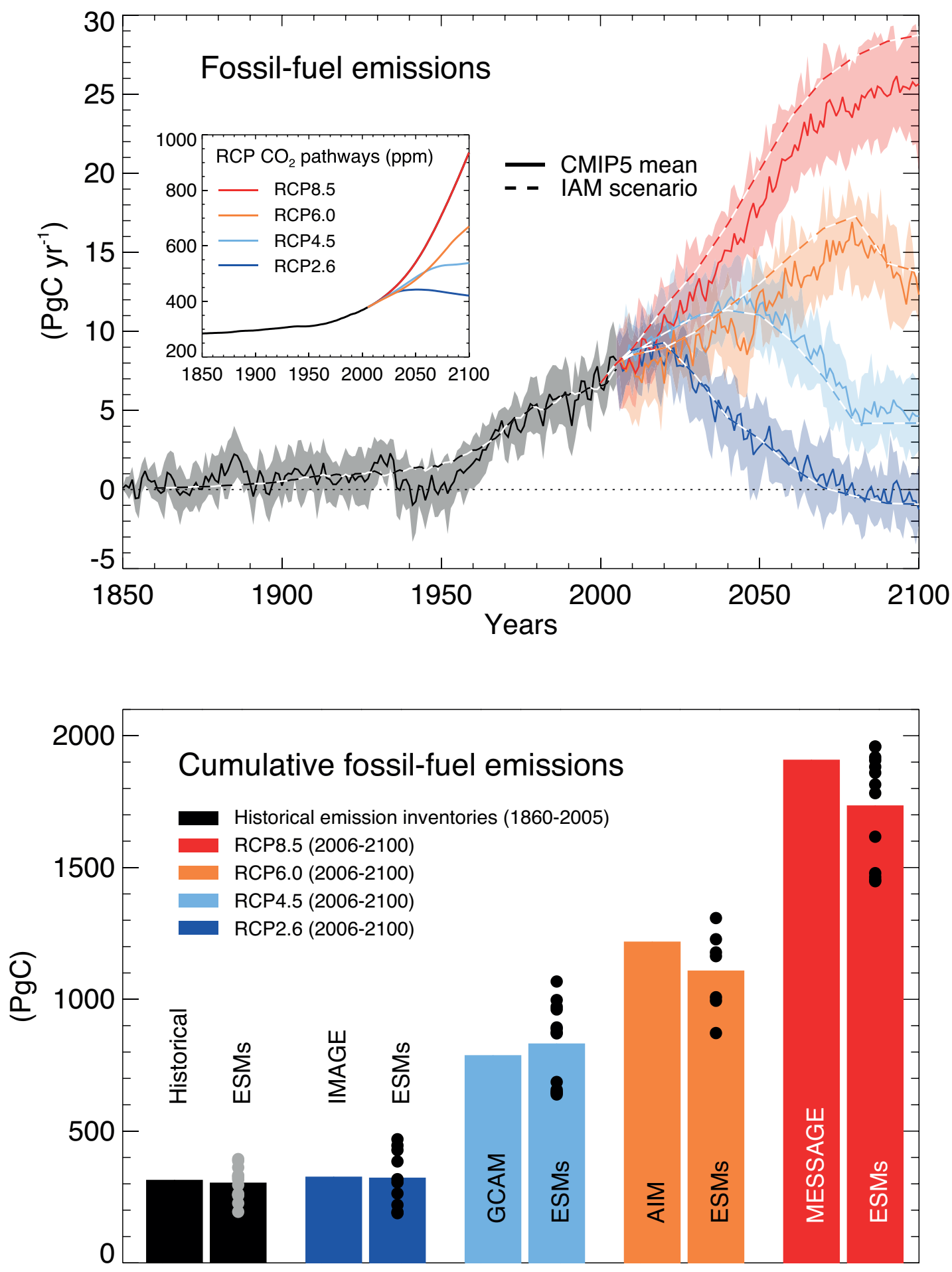

Figure 6.25 | Compatible fossil fuel emissions simulated by the CMIP5 ESMs for the four RCP scenarios. Top: time series of compatible emission rate (PgC yr $\left.{ }^{-1}\right)$. Dashed lines represent the historical estimates and emissions calculated by the Integrated Assessment Models (IAMs) used to define the RCP scenarios, solid lines and plumes show results from CMIP5 ESMs (model mean, with 1 standard deviation shaded). Bottom: cumulative emissions for the historical period (1860-2005) and 21st century (defined in CMIP5 as 2006-2100) for historical estimates and RCP scenarios. Dots denote individual ESM results, bars show the multi-model mean. In the CMIP5 model results, total carbon in the land-atmosphere-ocean system can be tracked and changes in this total must equal fossil fuel emissions to the system (see Box 6.4). Models used: Canadian Earth System Model 2 (CanESM2), Geophysical Fluid Dynamics Laboratory-Earth System Model 2G (GFDL-ESM2G), Geophysical Fluid Dynamics Laboratory-Earth System Model 2M (GFDL-ESM2M), Hadley Centre Global Environmental Model 2-Carbon Cycle(HadGEM2-CC), Hadley Centre Global Environmental Model 2-Earth System (HadGEM2-ES), Institute Pierre Simon Laplace-Coupled Model 5A-Low Resolution (IPSL-CM5A-LR), Institute Pierre Simon Laplace-Coupled Model 5A-Medium Resolution (IPSL-CM5A-MR), Institute Pierre Simon Laplace-Coupled Model 5B-Low Resolution (IPSL-CM5B-LR), Model for Interdisciplinary Research On Climate-Earth System Model (MIROC-ESM-CHEM), Model for Interdisciplinary Research On Climate-Earth System Model (MIROC-ESM), Max Planck Institute-Earth System Model-Low Resolution (MPI-ESM-LR), Norwegian Earth System Model 1 (Emissions capable) (NorESM1-ME), Institute for Numerical Mathematics Coupled Model 4 (INMCM4), Community Earth System Model 1-Biogeochemical (CESM1-BGC), Beijing Climate Center-Climate System Model 1.1 (BCC-CSM1.1). Not every model performed every scenario simulation. 
Sources of uncertainty for the permafrost carbon feedback include the physical thawing rates, the fraction of carbon that is released after being thawed and the time scales of release, possible mitigating nutrient feedbacks and the role of fine-scale processes such as spatial variability in permafrost degradation. It is also uncertain how much thawed carbon will decompose to $\mathrm{CO}_{2}$ or to $\mathrm{CH}_{4}$ (see Sections 6.4.7, 12.5.5.4 and 12.4.8.1).

\subsubsection{Future Ocean Acidification}

A fraction of $\mathrm{CO}_{2}$ emitted to the atmosphere dissolves in the ocean, reducing surface ocean $\mathrm{pH}$ and carbonate ion concentrations. The associated chemistry response to a given change in $\mathrm{CO}_{2}$ concentration is known with very high confidence. Overall, given evidence from Chapter 3 and model results from this chapter, it is virtually certain that the increased storage of carbon by the ocean will increase acidification in the future, continuing the observed trends of the past decades. Expected future changes are in line with what is measured at ocean time series stations (see Chapter 3). Multi-model projections using ocean process-based carbon cycle models discussed in AR4 demonstrate large decreases in $\mathrm{pH}$ and carbonate ion concentration $\left[\mathrm{CO}_{3}{ }^{2-}\right]$ during the 21 st century throughout the world oceans (Orr et al., 2005). The largest decrease in surface $\left[\mathrm{CO}_{3}{ }^{2-}\right]$ occur in the warmer low and mid-latitudes, which are naturally rich in this ion (Feely et al., 2009). However, it is the low $\Omega_{\mathrm{A}}$ waters in the high latitudes and in the upwelling regions that first become undersaturated with respect to aragonite (i.e., $\Omega_{A}<1$,
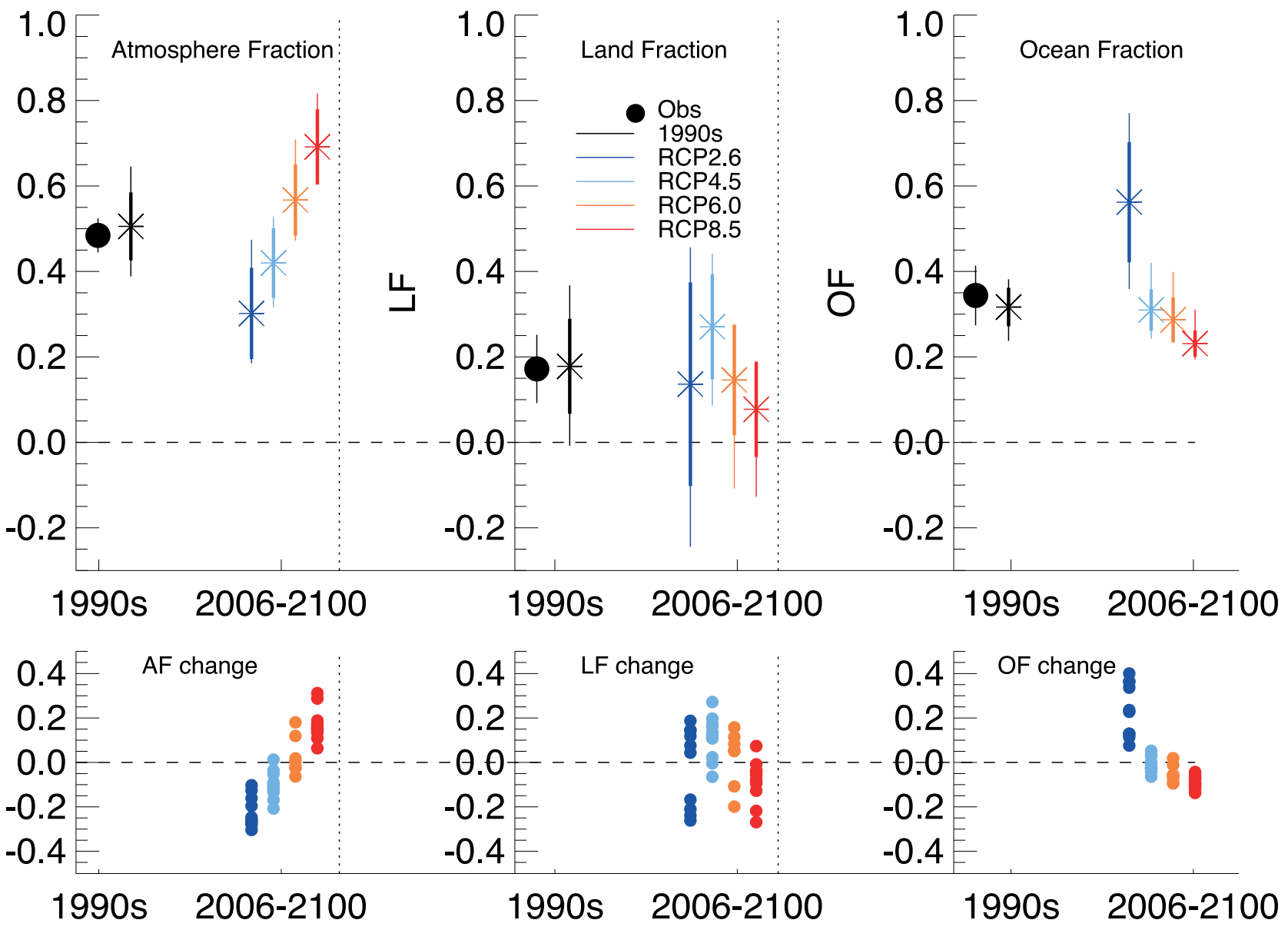

Figure 6.26 | Changes in atmospheric, land and ocean fraction of fossil fuel carbon emissions. The fractions are defined as the changes in storage in each component (atmosphere, land, ocean) divided by the compatible fossil fuel emissions derived from each CMIP5 simulation for the four RCP scenarios. Solid circles show the observed estimate based on Table 6.1 for the 1990s. The coloured bars denote the cumulative uptake fractions for the 21st century under the different RCP scenarios for each model. Multi-model mean values are shown as star symbols and the multi-model range (min-to-max) and standard deviation are shown by thin and thick vertical lines respectively. Owing to the difficulty of estimating land use emissions from the ESMs this figure uses a fossil fuel definition of airborne fraction, rather than the preferred definition of fossil and land use emissions discussed in Section 6.3.2.4. 21st century cumulative atmosphere, land and ocean fractions are shown here in preference to the more commonly shown instantaneous fractions because for RCP2.6 emissions reach and cross zero for some models and so an instantaneous definition of AF becomes singular at that point. Models used: Canadian Earth System Model 2 (CanESM2), Geophysical Fluid Dynamics Laboratory-Earth System Model 2G (GFDL-ESM2G), Geophysical Fluid Dynamics Laboratory-Earth System Model 2M (GFDL-ESM2M), Hadley Centre Global Environmental Model 2-Carbon Cycle (HadGEM2-CC), Hadley Centre Global Environmental Model 2-Earth System (HadGEM2-ES), Institute Pierre Simon Laplace-Coupled Model 5A-Low Resolution (IPSL-CM5A-LR), Institute Pierre Simon Laplace-Coupled Model 5A-Medium Resolution (IPSL-CM5A-MR), Institute Pierre Simon Laplace-Coupled Model 5B-Low Resolution (IPSL-CM5B-LR), Model for Interdisciplinary Research On Climate-Earth System Model (MIROC-ESM-CHEM), Model for Interdisciplinary Research On Climate-Earth System Model (MIROC-ESM), Max Planck Institute-Earth System Model-Low Resolution (MPI-ESM-LR), Norwegian Earth System Model 1 (Emissions capable) (NorESM1-ME), Institute for Numerical Mathematics Coupled Model 4 (INMCM4), Community Earth System Model 1-Biogeochemical (CESM1-BGC). Not every model performed every scenario simulation. 

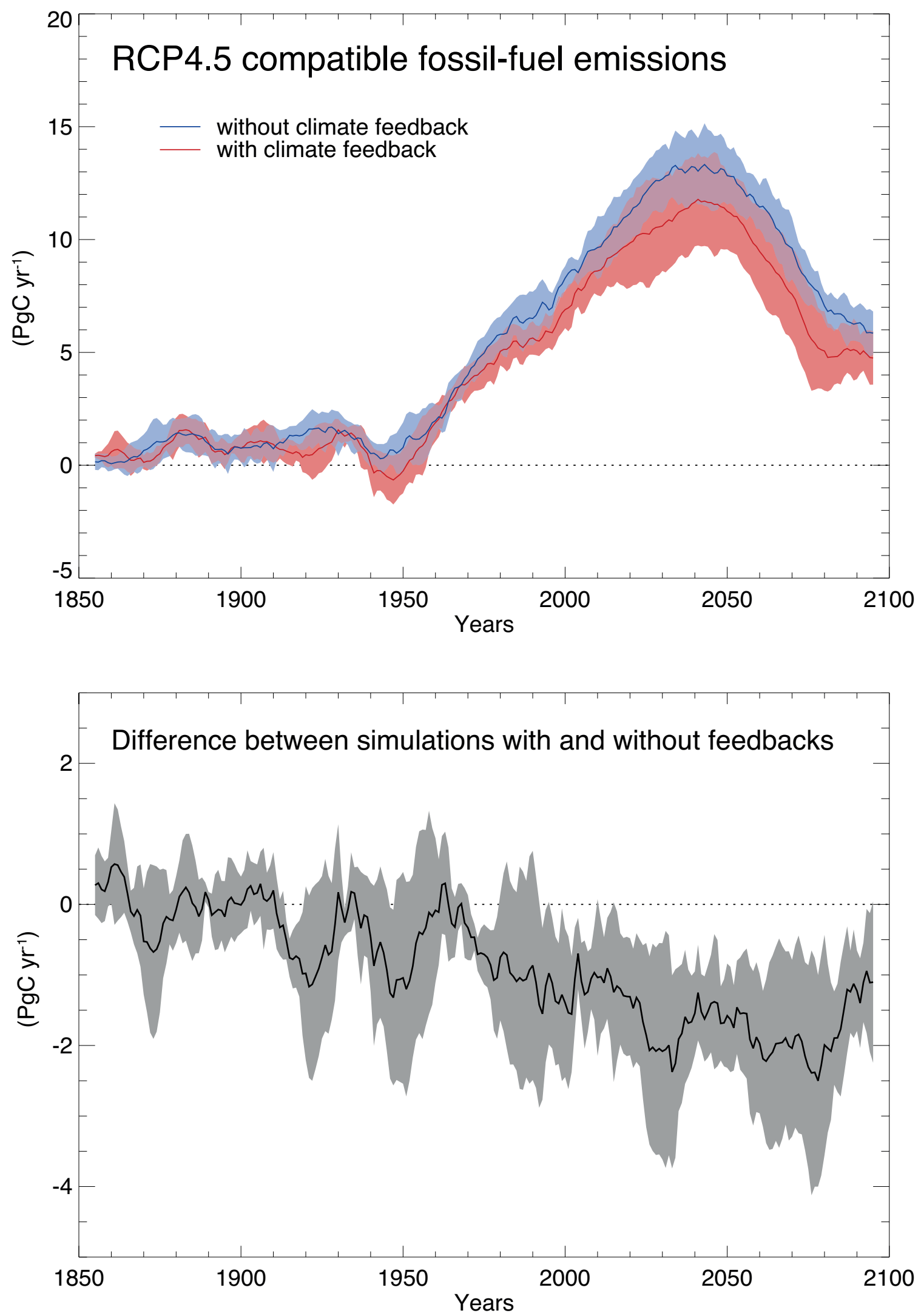

Figure 6.27 | Compatible fossil fuel emissions for the RCP4.5 scenario (top) in the presence (red) and absence (blue) of the climate feedback on the carbon cycle, and the difference between them (bottom). Multi-model mean, 10-year smoothed values are shown, with 1 standard deviation shaded. This shows the impact of climate change on the compatible fossil fuel $\mathrm{CO}_{2}$ emissions to achieve the RCP4.5 $\mathrm{CO}_{2}$ concentration pathway. Models used: Canadian Earth System Model 2 (CanESM2), Geophysical Fluid Dynamics Laboratory-Earth System Model 2M (GFDL-ESM2M), Hadley Centre Global Environmental Model 2-Earth System (HadGEM2-ES), Institute Pierre Simon Laplace-Coupled Model 5A-Low Resolution (IPSL-CM5A-LR) and Model for Interdisciplinary Research On Climate-Earth System Model (MIROC-ESM). 


\section{Frequently Asked Questions}

\section{FAQ 6.1 | Could Rapid Release of Methane and Carbon Dioxide from Thawing Permafrost or Ocean Warming Substantially Increase Warming?}

Permafrost is permanently frozen ground, mainly found in the high latitudes of the Arctic. Permafrost, including the sub-sea permafrost on the shallow shelves of the Arctic Ocean, contains old organic carbon deposits. Some are relicts from the last glaciation, and hold at least twice the amount of carbon currently present in the atmosphere as carbon dioxide $\left(\mathrm{CO}_{2}\right)$. Should a sizeable fraction of this carbon be released as methane and $\mathrm{CO}_{2}$, it would increase atmospheric concentrations, which would lead to higher atmospheric temperatures. That in turn would cause yet more methane and $\mathrm{CO}_{2}$ to be released, creating a positive feedback, which would further amplify global warming.

The Arctic domain presently represents a net sink of $\mathrm{CO}_{2}$-sequestering around $0.4 \pm 0.4 \mathrm{PgC}^{-1}$ in $^{-}$growing vegetation representing about $10 \%$ of the current global land sink. It is also a modest source of methane $\left(\mathrm{CH}_{4}\right)$ : between 15 and $\left.50 \mathrm{Tg}_{(\mathrm{CH}}\right) \mathrm{yr}^{-1}$ are emitted mostly from seasonally unfrozen wetlands corresponding to about $10 \%$ of the global wetland methane source. There is no clear evidence yet that thawing contributes significantly to the current global budgets of these two greenhouse gases. However, under sustained Arctic warming, modelling studies and expert judgments indicate with medium agreement that a potential combined release totalling up to $350 \mathrm{PgC}$ as $\mathrm{CO}_{2}$ equivalent could occur by the year 2100 .

Permafrost soils on land, and in ocean shelves, contain large pools of organic carbon, which must be thawed and decomposed by microbes before it can be released-mostly as $\mathrm{CO}_{2}$. Where oxygen is limited, as in waterlogged soils, some microbes also produce methane.

On land, permafrost is overlain by a surface 'active layer', which thaws during summer and forms part of the tundra ecosystem. If spring and summer temperatures become warmer on average, the active layer will thicken, making more organic carbon available for microbial decomposition. However, warmer summers would also result in greater uptake of carbon dioxide by Arctic vegetation through photosynthesis. That means the net Arctic carbon balance is a delicate one between enhanced uptake and enhanced release of carbon.

Hydrological conditions during the summer thaw are also important. The melting of bodies of excess ground ice may create standing water conditions in pools and lakes, where lack of oxygen will induce methane production. The complexity of Arctic landscapes under climate warming means we have low confidence in which of these different processes might dominate on

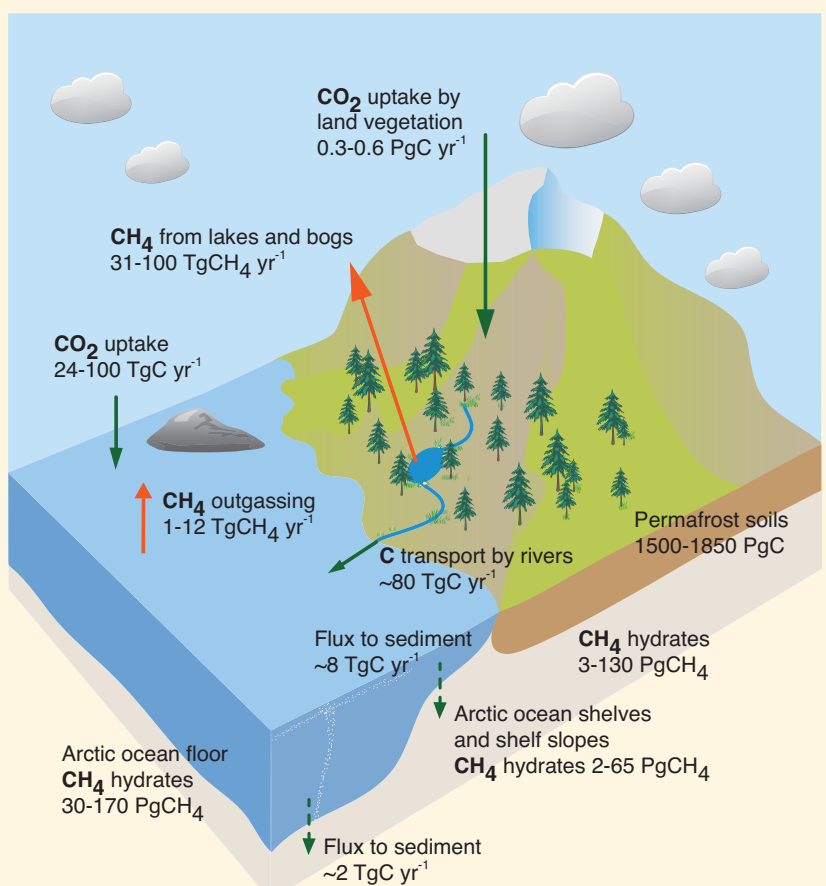

FAQ 6.1, Figure 1 | A simplified graph of current major carbon pools and flows in the Arctic domain, including permafrost on land, continental shelves and ocean. (Adapted from McGuire et al., 2009; and Tarnocai et al., 2009.) $\mathrm{TgC}=10^{12} \mathrm{gC}$, and $\mathrm{PgC}=10^{15} \mathrm{gC}$. ing takes time-in fact, the deeper Arctic permafrost can be seen as a relict of the last glaciation, which is still slowly eroding—so any significant loss of permafrost soil carbon will happen over long time scales.

Given enough oxygen, decomposition of organic matter in soil is accompanied by the release of heat by microbes (similar to compost), which, during summer, might stimulate further permafrost thaw. Depending on carbon and ice content of the permafrost, and the hydrological regime, this mechanism could, under warming, trigger relatively fast local permafrost degradation. (continued on next page) 


\section{FAQ 6.1 (continued)}

Modelling studies of permafrost dynamics and greenhouse gas emissions indicate a relatively slow positive feedback, on time scales of hundreds of years. Until the year 2100 , up to $250 \mathrm{PgC}$ could be released as $\mathrm{CO}_{2}$, and up to $5 \mathrm{Pg}$ as $\mathrm{CH}_{4}$. Given methane's stronger greenhouse warming potential, that corresponds to a further $100 \mathrm{PgC}$ of equivalent $\mathrm{CO}_{2}$ released until the year 2100. These amounts are similar in magnitude to other biogeochemical feedbacks, for example, the additional $\mathrm{CO}_{2}$ released by the global warming of terrestrial soils. However, current models do not include the full complexity of Arctic processes that occur when permafrost thaws, such as the formation of lakes and ponds.

Methane hydrates are another form of frozen carbon, occurring in deep permafrost soils, ocean shelves, shelf slopes and deeper ocean bottom sediments. They consist of methane and water molecule clusters, which are only stable in a specific window of low temperatures and high pressures. On land and in the ocean, most of these hydrates originate from marine or terrestrial biogenic carbon, decomposed in the absence of oxygen and trapped in an aquatic environment under suitable temperature-pressure conditions.

Any warming of permafrost soils, ocean waters and sediments and/or changes in pressure could destabilise those hydrates, releasing their $\mathrm{CH}_{4}$ to the ocean. During larger, more sporadic releases, a fraction of that $\mathrm{CH}_{4}$ might also be outgassed to the atmosphere. There is a large pool of these hydrates: in the Arctic alone, the amount of $\mathrm{CH}_{4}$ stored as hydrates could be more than 10 times greater than the $\mathrm{CH}_{4}$ presently in the global atmosphere.

Like permafrost thawing, liberating hydrates on land is a slow process, taking decades to centuries. The deeper ocean regions and bottom sediments will take still longer-between centuries and millennia to warm enough to destabilise the hydrates within them. Furthermore, methane released in deeper waters has to reach the surface and atmosphere before it can become climatically active, but most is expected to be consumed by microorganisms before it gets there. Only the $\mathrm{CH}_{4}$ from hydrates in shallow shelves, such as in the Arctic Ocean north of Eastern Siberia, may actually reach the atmosphere to have a climate impact.

Several recent studies have documented locally significant $\mathrm{CH}_{4}$ emissions over the Arctic Siberian shelf and from Siberian lakes. How much of this $\mathrm{CH}_{4}$ originates from decomposing organic carbon or from destabilizing hydrates is not known. There is also no evidence available to determine whether these sources have been stimulated by recent regional warming, or whether they have always existed-it may be possible that these $\mathrm{CH}_{4}$ seepages have been present since the last deglaciation. In any event, these sources make a very small contribution to the $\mathrm{global}^{\mathrm{CH}_{4}}$ budget-less than $5 \%$. This is also confirmed by atmospheric methane concentration observations, which do not show any substantial increases over the Arctic.

However modelling studies and expert judgment indicate that $\mathrm{CH}_{4}$ and $\mathrm{CO}_{2}$ emissions will increase under Arctic warming, and that they will provide a positive climate feedback. Over centuries, this feedback will be moderate: of a magnitude similar to other climate-terrestrial ecosystem feedbacks. Over millennia and longer, however, $\mathrm{CO}_{2}$ and $\mathrm{CH}_{4}$ releases from permafrost and shelves/shelf slopes are much more important, because of the large carbon and methane hydrate pools involved.

where $\Omega_{\mathrm{A}}=\left[\mathrm{Ca}^{+2}\right]\left[\mathrm{CO}_{3}{ }^{2-}\right] / \mathrm{K}_{\mathrm{sp}}$, where $\mathrm{K}_{\mathrm{sp}}$ is the solubility product for the metastable form of $\mathrm{CaCO}_{3}$ known as aragonite; a value of $\Omega_{A}<1$ thus indicates aragonite undersaturation). This aragonite undersaturation in surface waters is reached before the end of the $21 \mathrm{st}$ century in the Southern Ocean as highlighted in AR4, but occurs sooner and is more intense in the Arctic (Steinacher et al., 2009). Ten percent of Arctic surface waters are projected to become undersaturated when atmospheric $\mathrm{CO}_{2}$ reaches 428 ppm (by 2025 under all IPCC SRES scenarios). That proportion increases to $50 \%$ when atmospheric $\mathrm{CO}_{2}$ reaches 534 ppm (Steinacher et al., 2009). By 2100 under the A2 scenario, much of the Arctic surface is projected to become undersaturated with respect to calcite (Feely et al., 2009). Surface waters would then be corrosive to all $\mathrm{CaCO}_{3}$ minerals. These general trends are confirmed by the latest projections from the CMIP5 Earth System models (Figure 6.28 and 6.29). Between 1986-2005 and 2081-2100, decrease in global-mean surface $\mathrm{pH}$ is 0.065 (0.06 to 0.07 ) for RCP2.6, 0.145 (0.14 to 0.15$)$ for RCP4.5, 0.203 (0.20 to 0.21 ) for RCP6.0 and 0.31 (0.30 to 0.32 ) for RCP8.5 (range from CMIP5 models spread).

Surface $\mathrm{CaCO}_{3}$ saturation also varies seasonally, particularly in the high latitudes, where observed saturation is higher in summer and lower in winter (Feely et al., 1988; Merico et al., 2006; Findlay et al., 
2008). Future projections using ocean carbon cycle models indicate that undersaturated conditions will be reached first in winter (Orr et al., 2005). In the Southern Ocean, it is projected that wintertime undersaturation with respect to aragonite will begin when atmospheric $\mathrm{CO}_{2}$ will reach $450 \mathrm{ppm}$, within 1-3 decades, which is about $100 \mathrm{ppm}$ sooner ( $\sim 30$ years under the IS92a scenario) than for the annual mean undersaturation (McNeil and Matear, 2008). As well, aragonite undersaturation will be first reached during wintertime in parts $(10 \%)$ of the Arctic when atmospheric $\mathrm{CO}_{2}$ will reach $410 \mathrm{ppm}$, within a decade (Steinacher et al., 2009). Then, aragonite undersaturation will become widespread in these regions at atmospheric $\mathrm{CO}_{2}$ levels of $500-600$ ppm (Figure 6.28).

Although projected changes in $\mathrm{pH}$ are generally largest at the surface, the greatest $\mathrm{pH}$ changes in the subtropics occur between 200 and 300 $\mathrm{m}$ where subsurface increased loads of anthropogenic $\mathrm{CO}_{2}$ are similar to surface changes but the carbonate buffering capacity is lower (Orr, 2011). This more intense projected subsurface $\mathrm{pH}$ reduction is consistent with the observed subsurface changes in $\mathrm{pH}$ in the subtropical North Pacific (Dore et al., 2009; Byrne et al., 2010; Ishii et al., 2011). As

\section{a. Surface $\mathrm{pH}$}

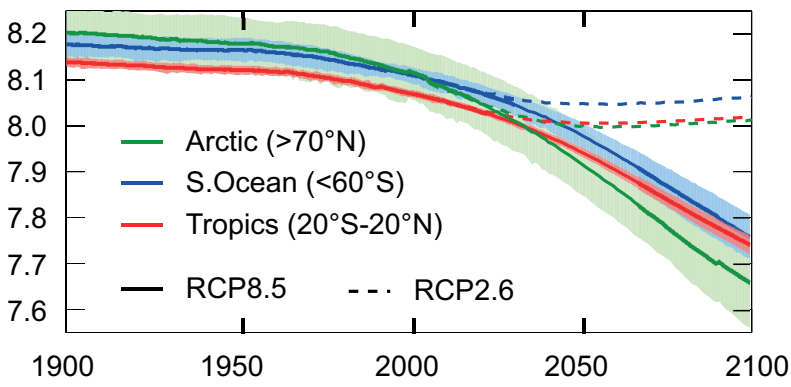

b. Surface pH in 2090s (RCP8.5, changes from 1990s)

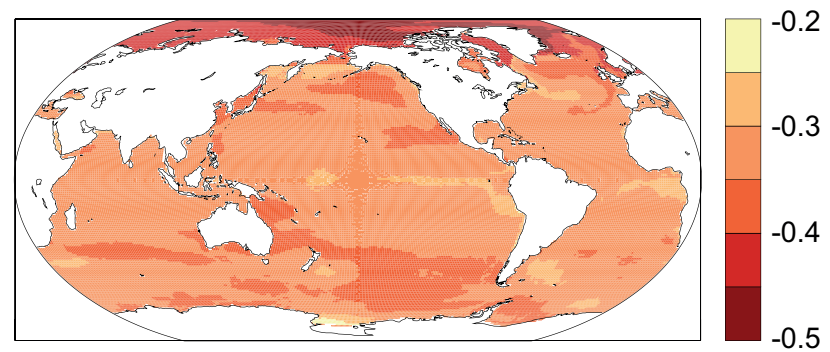

Figure 6.28| Projected ocean acidification from 11 CMIP5 Earth System Models under RCP8.5 (other RCP scenarios have also been run with the CMIP5 models): (a) Time series of surface pH shown as the mean (solid line) and range of models (filled), given as area-weighted averages over the Arctic Ocean (green), the tropical oceans (red) and the Southern Ocean (blue). (b) Maps of the median model's change in surface pH from 1850 to 2100. Panel (a) also includes mean model results from RCP2.6 (dashed lines). Over most of the ocean, gridded data products of carbonate system variables (Key et al., 2004) are used to correct each model for its present-day bias by subtracting the model-data difference at each grid cell following (Orr et al., 2005). Where gridded data products are unavailable (Arctic Ocean, all marginal seas, and the ocean near Indonesia), the results are shown without bias correction. The bias correction reduces the range of model projections by up to a factor of 4 , e.g., in panel (a) compare the large range of model projections for the Arctic (without bias correction) to the smaller range in the Southern Ocean (with bias correction). subsurface saturation states decline, the horizon separating undersaturated waters below from supersaturated waters above is projected to move upward (shoal). By 2100 under the RCP8.5 scenario, the median projection from 11 CMIP5 models is that this interface (aragonite saturation horizon) will shoal from $200 \mathrm{~m}$ up to $40 \mathrm{~m}$ in the subarctic Pacific, from $1000 \mathrm{~m}$ up to the surface in the Southern Ocean, and from $2850 \mathrm{~m}$ to $150 \mathrm{~m}$ in the North Atlantic (Figure 6.29), consistent with results from previous model comparison (Orr et al., 2005; Orr, 2011). Under the SRES A2 scenario, the volume of ocean with supersaturated waters is projected to decline from $42 \%$ in the preindustrial Era to $25 \%$ in 2100 (Steinacher et al., 2009). Yet even if atmospheric $\mathrm{CO}_{2}$ does not go above $450 \mathrm{ppm}$, most of the deep ocean volume is projected to become undersaturated with respect to both aragonite and calcite after several centuries (Caldeira and Wickett, 2005). Nonetheless, the most recent projections under all RCPs scenarios but RCP8.5 illustrate that limiting atmospheric $\mathrm{CO}_{2}$ will greatly reduce the level of ocean acidification that will be experienced (Joos et al., 2011).

In the open ocean, future reductions in surface ocean $\mathrm{pH}$ and $\mathrm{CaCO}_{3}$ (calcite and aragonite) saturation states are controlled mostly by the invasion of anthropogenic carbon. Other effects due to future climate change counteract less than $10 \%$ of the reductions in $\mathrm{CaCO}_{3}$ saturation induced by the invasion of anthropogenic carbon (Orr et al., 2005; McNeil and Matear, 2006; Cao et al., 2007). Warming dominates other effects from climate-change by reducing $\mathrm{CO}_{2}$ solubility and thus by enhancing $\left[\mathrm{CO}_{3}{ }^{2-}\right]$. An exception is the Arctic Ocean where reductions in $\mathrm{pH}$ and $\mathrm{CaCO}_{3}$ saturation states are projected to be exacerbated by effects from increased freshwater input due to sea ice melt, more precipitation, and greater air-sea $\mathrm{CO}_{2}$ fluxes due to less sea ice cover (Steinacher et al., 2009; Yamamoto et al., 2012). The projected effect of freshening is consistent with current observations of lower saturation states and lower $\mathrm{pH}$ values near river mouths and in areas under substantial fresh-water influence (Salisbury et al., 2008; Chierici and Fransson, 2009; Yamamoto-Kawai et al., 2009).

Regional ocean carbon cycle models project that some nearshore systems are also highly vulnerable to future $\mathrm{pH}$ decrease. In the California Current System, an eastern boundary upwelling system, observations and model results show that strong seasonal upwelling of carbonrich waters (Feely et al., 2008) renders surface waters as vulnerable to future ocean acidification as those in the Southern Ocean (Gruber et al., 2012). In the Northwestern European Shelf Seas, large spatiotemporal variability is enhanced by local effects from river input and organic matter degradation, exacerbating acidification from anthropogenic $\mathrm{CO}_{2}$ invasion (Artioli et al., 2012). In the Gulf of Mexico and East China Sea, coastal eutrophication, another anthropogenic perturbation, has been shown to enhance subsurface acidification as additional respired carbon accumulates at depth (Cai et al., 2011).

\subsubsection{Future Ocean Oxygen Depletion}

It is very likely that global warming will lead to declines in dissolved $\mathrm{O}_{2}$ in the ocean interior through warming-induced reduction in $\mathrm{O}_{2}$ solubility and increased ocean stratification. This will have implications for nutrient and carbon cycling, ocean productivity and marine habitats (Keeling et al., 2010). 


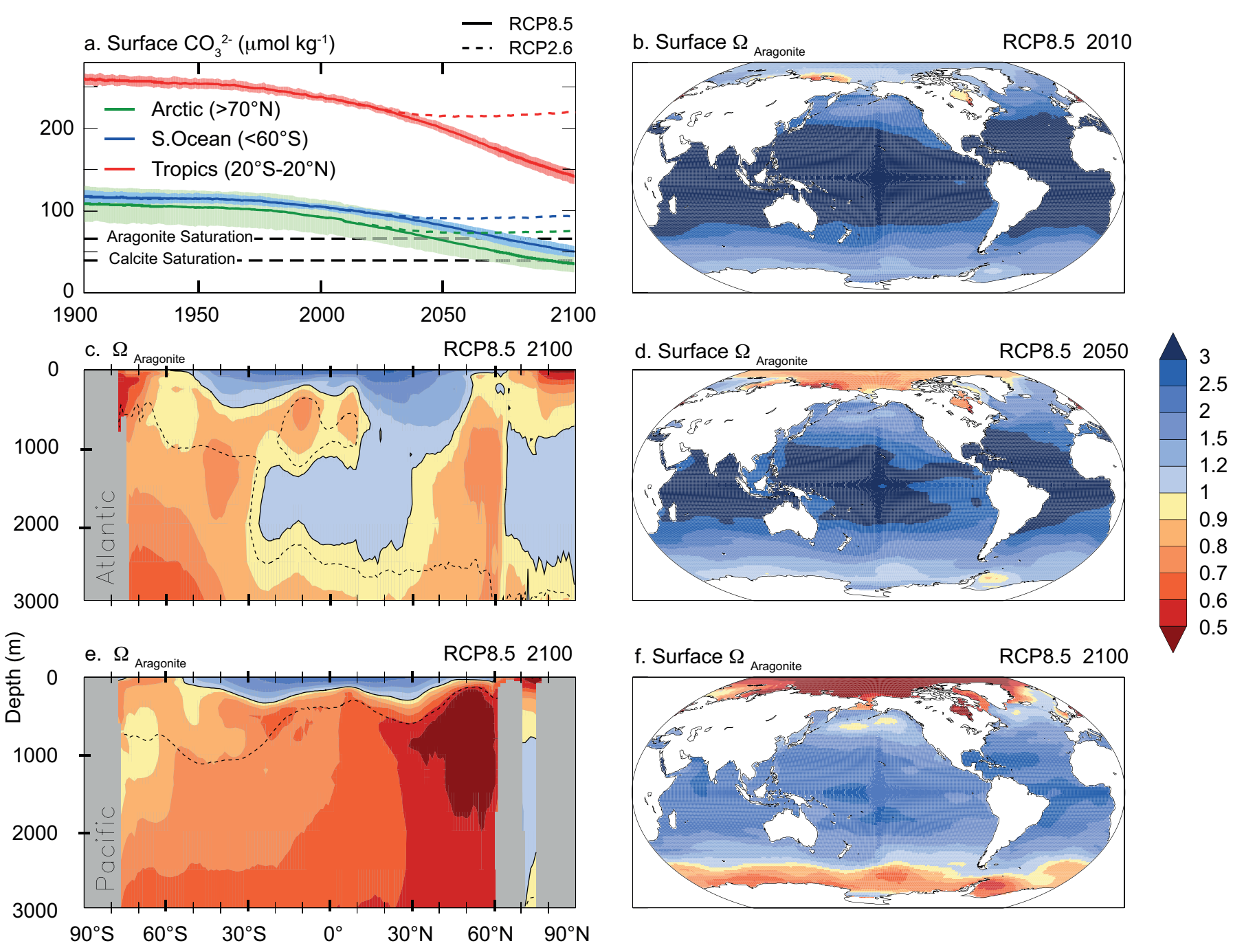

Figure 6.29 | Projected aragonite saturation state from 11 CMIP5 Earth System Models under RCP8.5 scenario: (a) time series of surface carbonate ion concentration shown as the mean (solid line) and range of models (filled), given as area-weighted averages over the Arctic Ocean (green), the tropical oceans (red), and the Southern Ocean (blue); maps of the median model's surface $\Omega_{A}$ in (b) 2010, (d) 2050 and (f) 2100; and zonal mean sections (latitude vs. depth) of $\Omega_{A}$ in 2100 over the (c) Atlantic and (e) Pacific, while the ASH is shown in 2010 (dotted line) as well as 2100 (solid line). Panel (a) also includes mean model results from RCP2.6 (dashed lines). As for Figure 6.28, gridded data products of carbonate system variables (Key et al., 2004) are used to correct each model for its present-day bias by subtracting the model-data difference at each grid cell following (Orr et al., 2005). Where gridded data products are unavailable (Arctic Ocean, all marginal seas, and the ocean near Indonesia), results are shown without bias correction.

Future changes in dissolved $\mathrm{O}_{2}$ have been investigated using models of various complexity (see references in Table 6.13). The global ocean dissolved oxygen will decline significantly under future scenarios (Cocco et al., 2013). Simulated declines in mean dissolved $\mathrm{O}_{2}$ concentration for the global ocean range from 6 to $12 \mu \mathrm{mol} \mathrm{kg}^{-1}$ by the year 2100 (Table

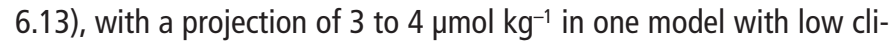
mate sensitivity (Frölicher et al., 2009). This general trend is confirmed by the latest projections from the CMIP5 Earth System models, with reductions in mean dissolved $\mathrm{O}_{2}$ concentrations from 1.5 to $4 \%$ (2.5 to $6.5 \mu \mathrm{mol} \mathrm{kg}^{-1}$ ) in 2090s relative to 1990s for all RCPs (Figure 6.30a).

Most modelling studies (Table 6.13) explain the global decline in dissolved oxygen by enhanced surface ocean stratification leading to reductions in convective mixing and deep water formation and by a contribution of 18 to $50 \%$ from ocean warming-induced reduction in solubility. These two effects are in part compensated by a small increase in $\mathrm{O}_{2}$ concentration from projected reductions in biological export production production (Bopp et al., 2001; Steinacher et al., 2010) or changes in ventilation age of the tropical thermocline (Gnanadesikan et al., 2007). The largest regional decreases in oxygen concentration $\left(\sim 20\right.$ to $100 \mu \mathrm{mol} \mathrm{kg}^{-1}$ ) are projected for the intermediate (200 to 400 $\mathrm{m}$ ) to deep waters of the North Atlantic, North Pacific and Southern Ocean for 2100 (Plattner et al., 2002; Matear and Hirst, 2003; Frölicher et al., 2009; Matear et al., 2010; Cocco et al., 2013), which is confirmed by the latest CMIP5 projections (Figure 6.30c and 6.30d).

It is as likely as not that the extent of open-ocean hypoxic (dissolved oxygen $<60$ to $80 \mu \mathrm{mol} \mathrm{kg}^{-1}$ ) and suboxic (dissolved oxygen $<5 \mu \mathrm{mol}$ $\mathrm{kg}^{-1}$ ) waters will increase in the coming decades. Most models show even some increase in oxygen in most $\mathrm{O}_{2}$-poor waters and thus a slight decrease in the extent of suboxic waters under the SRES-A2 scenario (Cocco et al., 2013), as well as under RCP8.5 scenario (see the model- 
Table 6.13 | Model configuration and projections for global marine $\mathrm{O}_{2}$ depletion by 2100 (adapted from Keeling et al. (2010).

\begin{tabular}{|c|c|c|c|c|}
\hline Study & $\begin{array}{l}\text { Ocean Carbon } \\
\text { Cycle Model }\end{array}$ & Forcing & $\begin{array}{l}\text { Mean }\left[\mathrm{O}_{2}\right] \text { Decrease } \\
\left(\mu \mathrm{mol} \mathrm{kg}^{-1}\right)^{\mathrm{a}, \mathrm{b}}\end{array}$ & $\begin{array}{c}\text { Solubility } \\
\text { Contribution (\%) }\end{array}$ \\
\hline Sarmiento et al. (1998) & GFDL & & $7 c$ & \\
\hline Plattner et al. (2002) & Bern 2D & SRES A1 & 12 & 35 \\
\hline Bopp et al. (2002) & IPSL & SRES A $2^{\mathrm{d}}$ & 4 & 25 \\
\hline Matear and Hirst (2003) & CSIRO & IS92a & 9 & 26 \\
\hline \multirow[t]{2}{*}{ Oschlies et al. (2008) } & UVic & SRES A2 & 9 & \\
\hline & UVic-variable C:N & SRES A2 & 12 & \\
\hline \multirow[t]{2}{*}{ Frölicher et al. (2009) } & \multirow[t]{2}{*}{ NCAR CSM1.4-CCCM } & SRES A2 & 4 & \multirow[t]{2}{*}{50} \\
\hline & & SRES B1 & 3 & \\
\hline Shaffer et al. (2009) & DCESS & SRES A2 & $10^{e}$ & \\
\hline
\end{tabular}

Notes:

a Assuming a total ocean mass of $1.48 \times 10^{21} \mathrm{~kg}$.

b Relative to pre-industrial baseline in 1750 .

c Model simulation ends at 2065.

d Radiative forcing of non- $\mathrm{CO}_{2} \mathrm{GHGs}$ is excluded from this simulation.

e For simulations with reduced ocean exchange.

CCCM = Coupled-Climate-Carbon Model; CSIRO = Commonwealth Scientific and Industrial Research Organisation; DCESS = Danish Center for Earth System Science; GFDL = Geophysical Fluid Dynamics Laboratory; IPSL = Institute Pierre Simon Laplace; NCAR = National Center for Atmospheric Research; IS92 = IPCC scenarios for 1992; SRES = Special Report on Emission Scenarios; UVic = University of Victoria.

mean increase of sub-surface $\mathrm{O}_{2}$ in large parts of the tropical Indian and Atlantic Oceans, Figure 6.30d). This rise in oxygen in most suboxic waters has been shown to be caused in one model study by an increased supply of oxygen due to lateral diffusion (Gnanadesikan et al., 2012). Given limitations of global ocean models in simulating today's $\mathrm{O}_{2}$ distribution (Cocco et al., 2013), as well as reproducing the measured changes in $\mathrm{O}_{2}$ concentrations over the past 50 years (see Chapter 3, and Stramma et al., 2012), the model projections are uncertain, especially concerning the evolution of $\mathrm{O}_{2}$ in and around oxygen minimum zones.

A number of biogeochemical ocean carbon cycle feedbacks, not yet included in most marine biogeochemical models (including CMIP5 models, see Section 6.3.2.5.6), could also impact future trends of ocean deoxygenation. For example, model experiments which include a $\mathrm{pCO}_{2}$ sensitive $\mathrm{C}: \mathrm{N}$ drawdown in primary production, as suggested by some mesocosm experiments (Riebesell et al., 2007), project future increases of up to $50 \%$ in the volume of the suboxic waters by 2100 (Oschlies et al., 2008; Tagliabue et al., 2011). In addition, future marine hypoxia could be amplified by changes in the $\mathrm{CaCO}_{3}$ to organic matter 'rain ratio' in response to rising $\mathrm{pCO}_{2}$ (Hofmann and Schellnhuber, 2009). Reduction in biogenic calcification due to ocean acidification would weaken the strength of $\mathrm{CaCO}_{3}$ mineral ballasting effect, which could lead organic material to be remineralized at a shallower depth exacerbating the future expansion of shallow hypoxic waters.

The modeled estimates do not take into account processes that are specific to the coastal ocean and may amplify deoxygenation. Recent observations for the period 1976-2000 have shown that dissolved $\mathrm{O}_{2}$ concentrations have declined at a faster rate in the coastal ocean $(-0.28$ $\left.\mu \mathrm{mol} \mathrm{kg}^{-1} \mathrm{yr}^{-1}\right)$ than the open ocean $\left(-0.02 \mu \mathrm{mol} \mathrm{kg}^{-1} \mathrm{y}^{-1}\right.$, and a faster rate than in the period 1951-1975, indicating a worsening of hypoxia (Gilbert et al., 2010). Hypoxia in the shallow coastal ocean (apart from continental shelves in Eastern Boundary Upwelling Systems) is largely eutrophication driven and is controlled by the anthropogenic flux of nutrients ( $\mathrm{N}$ and $\mathrm{P}$ ) and organic matter from rivers. If continued industrialisation and intensification of agriculture yield larger nutrient loads in the future, eutrophication should intensify (Rabalais et al., 2010), and further increase the coastal ocean deoxygenation.

On longer time scales beyond 2100, ocean deoxygenation is projected to increase with some models simulating a tripling in the volume of suboxic waters by 2500 (Schmittner et al., 2008). Ocean deoxygenation and further expansion of suboxic waters could persist on millennial time scales, with average dissolved $\mathrm{O}_{2}$ concentrations projected

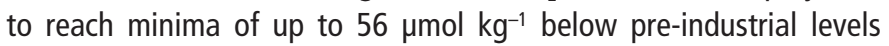
in experiments with high $\mathrm{CO}_{2}$ emissions and high climate sensitivity (Shaffer et al., 2009).

A potential expansion of hypoxic or suboxic water over large parts of the ocean is likely to impact the marine cycling of important nutrients, particularly nitrogen. The intensification of low oxygen waters has been suggested to lead to increases in water column denitrification and $\mathrm{N}_{2} \mathrm{O}$ emissions (e.g., Codispoti, 2010; Naqvi et al., 2010). Recent works, however, suggest that oceanic $\mathrm{N}_{2} \mathrm{O}$ production is dominated by nitrification with a contribution of $7 \%$ by denitrification (Freing et al., 2012), Figure 6.4c) and that ocean deoxygenation in response to anthropogenic climate change could leave $\mathrm{N}_{2} \mathrm{O}$ production relatively unchanged (Bianchi et al., 2012). 
a. Ocean oxygen content change (\%)

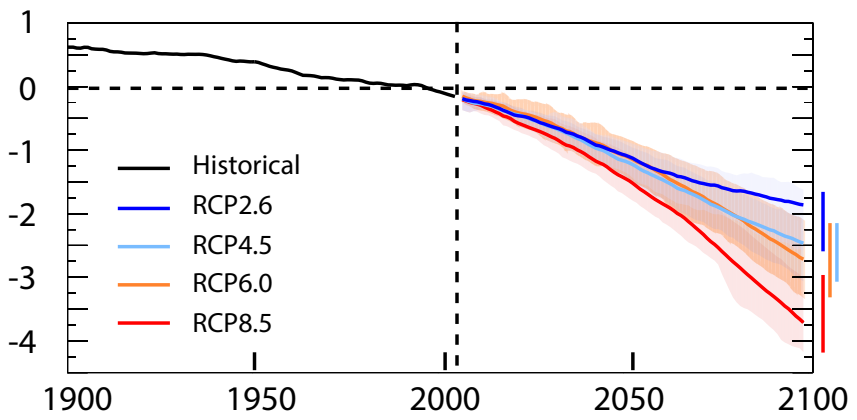

c. 2090 s, changes from 1990 s

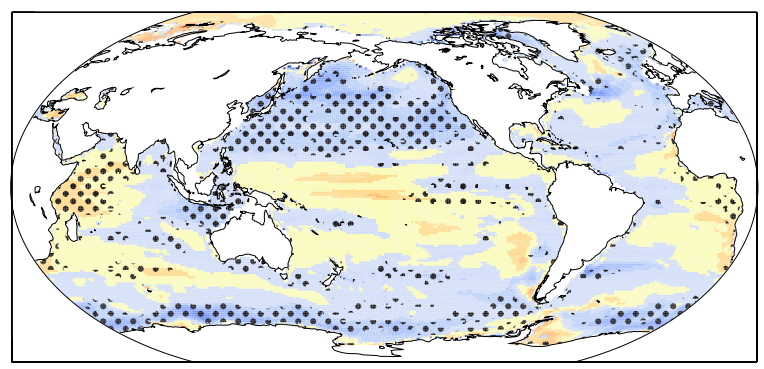

b. Oxygen concentrations (200-600m)

1990s

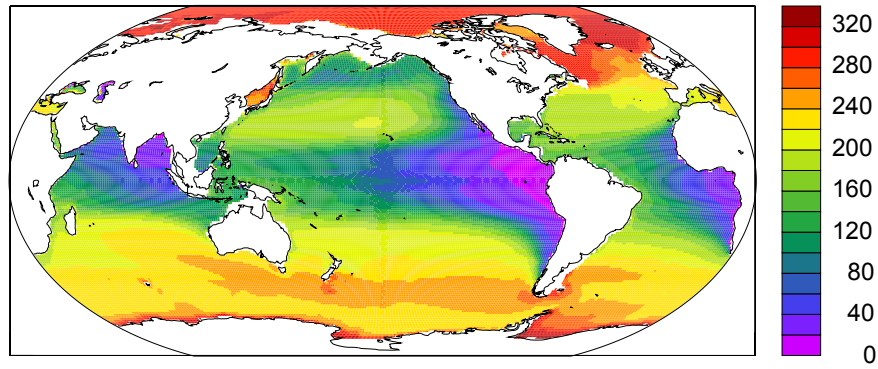

d. 2090s, changes from 1990s

RCP8.5

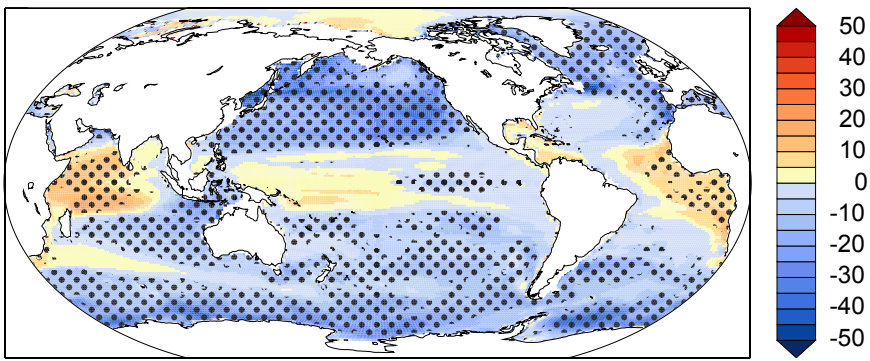

$\left(\mathrm{mmol} \mathrm{m}{ }^{-3}\right)$

Figure 6.30 | (a) Simulated changes in dissolved $\mathrm{O}_{2}$ (mean and model range as shading) relative to 1990s for RCP2.6, RCP4.5, RCP6.0 and RCP8.5. (b) Multi-model mean dissolved $\mathrm{O}_{2}\left(\mu \mathrm{mol} \mathrm{m}{ }^{-3}\right.$ ) in the main thermocline (200 to $600 \mathrm{~m}$ depth average) for the 1990s, and changes in 2090s relative to $1990 \mathrm{~s}$ for RCP2.6 (c) and RCP8.5 (d). To indicate consistency in the sign of change, regions are stippled where at least $80 \%$ of models agree on the sign of the mean change. These diagnostics are detailed in Cocco et al. (2013) in a previous model intercomparison using the SRES-A2 scenario and have been applied to CMIP5 models here. Models used: Community Earth System Model 1-Biogeochemical (CESM1-BGC), Geophysical Fluid Dynamics Laboratory-Earth System Model 2G (GFDL-ESM2G), Geophysical Fluid Dynamics Laboratory-Earth System Model 2M (GFDL-ESM2M), Hadley Centre Global Environmental Model 2-Earth System (HadGEM2-ES), Institute Pierre Simon Laplace-Coupled Model 5A-Low Resolution (IPSL-CM5A-LR), Institute Pierre Simon Laplace-Coupled Model 5A-Medium Resolution (IPSL-CM5A-MR), Max Planck Institute-Earth System Model-Low Resolution (MPI-ESM-LR), Max Planck Institute-Earth System Model-Medium Resolution (MPI-ESM-MR), Norwegian Earth System Model 1 (Emissions capable) (NorESM1).

\subsubsection{Future Trends in the Nitrogen Cycle and Impact on Carbon Fluxes}

\subsubsection{Projections for Formation of Reactive Nitrogen by Human Activity}

Since the 1970s, food production, industrial activity and fossil fuel combustion have resulted in the creation of more reactive nitrogen (Nr) than natural terrestrial processes (Section 6.1; Box 6.2, Figure 1). Building on the general description of the set of AR4 Special Report on Emission (SRES) scenarios, Erisman et al. (2008) estimated anthropogenic nitrogen fertiliser consumption throughout the 21st century. Five driving parameters (population growth, consumption of animal protein, agricultural efficiency improvement and additional biofuel production) are used to project future nitrogen demands for four scenarios (A1, B1, A2 and B2) (Figure 6.31). Assigning these drivers to these four SRES scenarios, they estimated a production of $\mathrm{Nr}$ for agricultural use of 90 to $190 \mathrm{TgN} \mathrm{yr}^{-1}$ by 2100, a range that spans from slightly less to almost twice as much current fertiliser consumption rates (Section 6.1, Figure 6.4a, Figure 1 in Box 6.2).

Despite the uncertainties and the non-inclusion of many important drivers, three of the scenarios generated by the Erisman et al. (2008) model point towards an increase in future production of reactive nitrogen. In particular, the A1 scenario which assumes a world with rapid economic growth, a global population that peaks mid-century and rapid introduction of new and more efficient technologies ends up as the potentially largest contributor to nitrogen use, as a result of large amounts of biofuels required and the fertiliser used to produce it. This increase in nitrogen use is assumed to be largely in line with the RCP2.6 scenario, where it appears to have rather limited adverse effects like increasing $\mathrm{N}_{2} \mathrm{O}$ emissions (van Vuuren et al., 2011).

$\mathrm{N}_{2} \mathrm{O}$ emissions are projected to increase from increased anthropogenic $\mathrm{Nr}$ production. It is thus likely that $\mathrm{N}_{2} \mathrm{O}$ emissions from soils will increase due to the increased demand for feed/food and the reliance of agriculture on nitrogen fertilisers. This is illustrated by the comparison of emissions from 1900 to those in 2000 and 2050, using the IAM IMAGE model that served to define the RCP2.6 pathway (Figure 6.32). The anthropogenic $\mathrm{N}_{2} \mathrm{O}$ emission map IN 2050 shown in Figure 6.32 is established from the RCP4.5 scenario; the RCP8.5 and RCP6 scenarios have much higher emissions, and RCP2.6 much lower (van Vuuren et al., 2011). A spatially explicit inventory of soil nitrogen budgets in livestock and crop production systems using the IMAGE model (Bouwman et al., 2011) shows that between 1900 and 1950, the global soil $\mathrm{Nr}$ budget surplus almost doubled to $36 \mathrm{TgN} \mathrm{yr}^{-1}$, and further increased to $138 \mathrm{TgN} \mathrm{yr}^{-1}$ between 1950 and 2000. The IMAGE model scenario from Bouwman et al. (2011) shown in Figure 6.32 portrays a world with a 


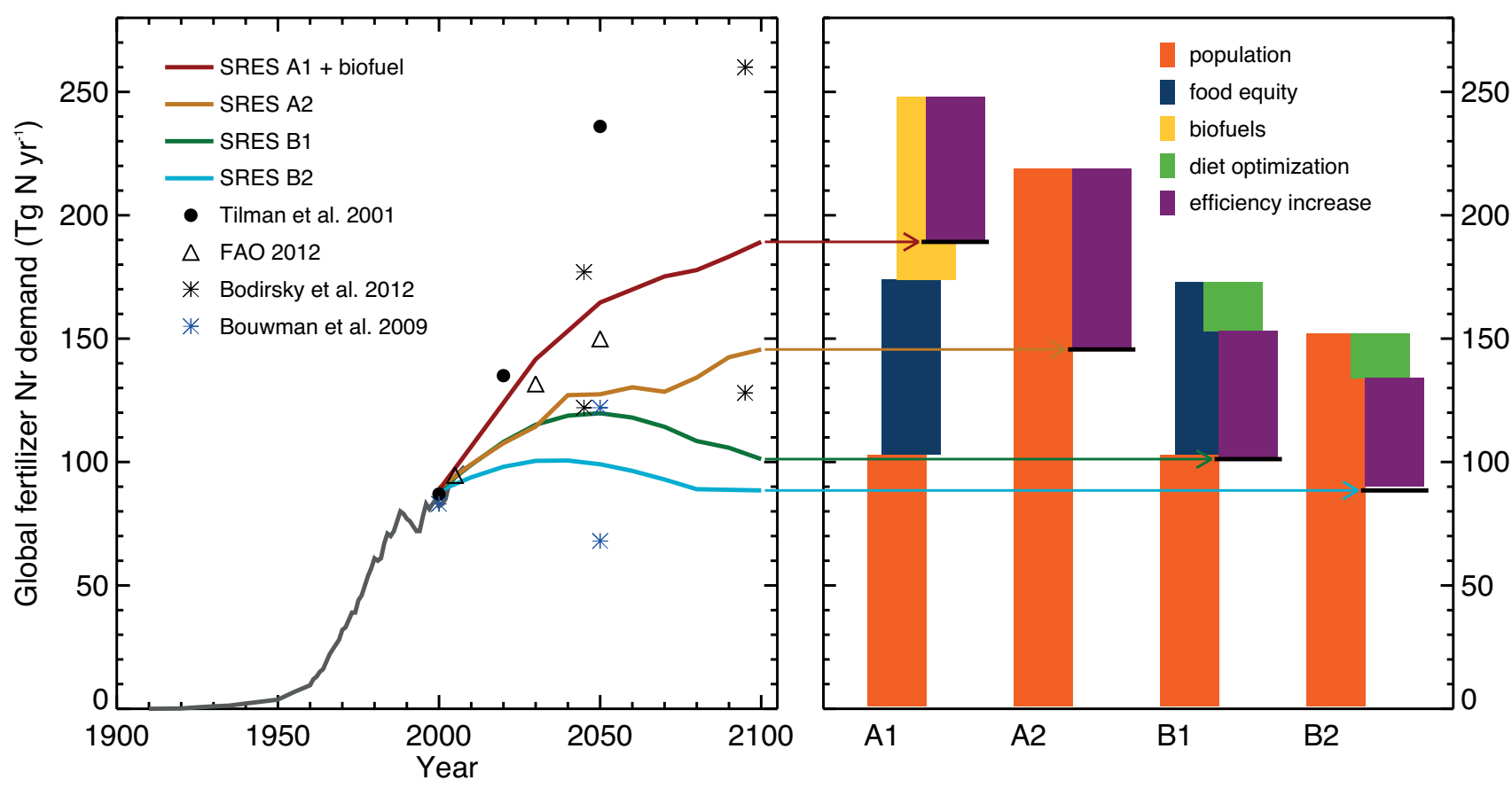

Figure 6.31 | Global nitrogen fertiliser consumption scenarios (left) and the impact of individual drivers on 2100 consumption (right). This resulting consumption is always the sum (denoted at the end points of the respective arrows) of elements increasing as well as decreasing nitrogen consumption. Other relevant estimates are presented for comparison. The A1, B1, A2 and B2 scenarios draw from the assumptions of the IPCC Special Report on Emission Scenarios (SRES) emission scenario storylines as explained in Erisman et al. (2008).

further increasing global crop production (+82\% for 2000-2050) and livestock production $(+115 \%)$. Despite the assumed rapid increase in nitrogen use efficiency in crop $(+35 \%)$ and livestock $(+35 \%)$ production, global agricultural $\mathrm{Nr}$ surpluses are projected to continue to increase $(+23 \%)$, and associated emissions of $\mathrm{N}_{2} \mathrm{O}$ to triple compared to 1900 levels.

Regional to global scale model simulations suggest a strong effect of climate variability on interannual variability of land $\mathrm{N}_{2} \mathrm{O}$ emissions (Tian et al., 2010; Zaehle et al., 2011; Xu-Ri et al., 2012). Kesik et al. (2006) found for European forests that higher temperatures and lower soil moisture will decrease future $\mathrm{N}_{2} \mathrm{O}$ emissions under scenarios of climate change, despite local increases of emission rates by up to $20 \%$. $\mathrm{Xu}$-Ri et al. (2012) show that local climate trends result in a spatially diverse pattern of increases and decreases of $\mathrm{N}_{2} \mathrm{O}$ emissions, which globally integrated result in a net climate response of $\mathrm{N}_{2} \mathrm{O}$ emissions of $1 \mathrm{TgN} \mathrm{yr}-1$ per $1{ }^{\circ} \mathrm{C}$ of land temperature warming. Using a further development of this model, Stocker et al. (2013) estimate increases in terrestrial $\mathrm{N}_{2} \mathrm{O}$ from a pre-industrial terrestrial source of $6.9 \mathrm{TgN}\left(\mathrm{N}_{2} \mathrm{O}\right)$

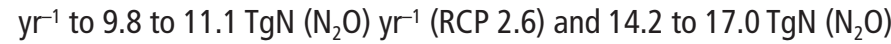

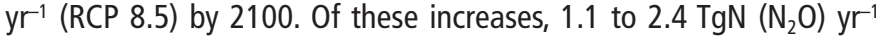
(RCP 2.6) or 4.7 to $7.7 \mathrm{TgN}\left(\mathrm{N}_{2} \mathrm{O}\right) \mathrm{yr}^{-1}$ (RCP 8.5) are due to the interacting effects of climate and $\mathrm{CO}_{2}$ on $\mathrm{N}_{2} \mathrm{O}$ emissions from natural and agricultural ecosystems. An independent modelling study suggested a climate change related increase of $\mathrm{N}_{2} \mathrm{O}$ emissions between 1860 and

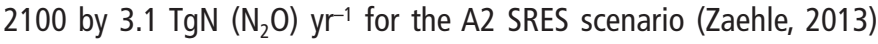
implying a slightly lower sensitivity of soil $\mathrm{N}_{2} \mathrm{O}$ emissions to climate of $0.5 \mathrm{TgN}\left(\mathrm{N}_{2} \mathrm{O}\right) \mathrm{yr}^{-1}$ per $1^{\circ} \mathrm{C}$ warming. While the present-day contribution of these climate-mediated effects on the radiative forcing from $\mathrm{N}_{2} \mathrm{O}$ is likely to be small $\left(0.016 \mathrm{~W} \mathrm{~m}^{-2}{ }^{\circ} \mathrm{C}^{-1}\right.$; Zaehle and Dalmonech,
2011). Modelling results (Stocker et al., 2013) suggest that the climate and $\mathrm{CO}_{2}$-related amplification of terrestrial $\mathrm{N}_{2} \mathrm{O}$ emissions imply a larger feedback of 0.03 to $0.05 \mathrm{~W} \mathrm{~m}^{-2}{ }^{\circ} \mathrm{C}^{-1}$ by 2100 .

With the continuing increases in the formation of $\mathrm{Nr}$ from anthropogenic activities will come increased $\mathrm{Nr}$ emissions and distribution of $\mathrm{Nr}$ by waters and the atmosphere. For the atmosphere, the main driver of future global nitrogen deposition is the emission trajectories of $\mathrm{NO}_{\mathrm{y}}$ and $\mathrm{NH}_{3}$. For all RCP scenarios except RCP2.6, nitrogen deposition is projected to remain relatively constant globally although there is a projected increase in $\mathrm{NH}_{x}$ deposition and decrease in $\mathrm{NO}_{y}$ deposition. On a regional basis, future decreases of $\mathrm{NH}_{\mathrm{x}}$ and $\mathrm{NOx}$ are projected in North America and northern Europe, and increases in Asia (Figure 6.33). Spatially, projected changes in total nitrogen deposition driven primarily by increases in $\mathrm{NH}_{x}$ emissions occur over large regions of the world for all RCPs, with generally the largest in RCP8.5 and the smallest in RCP2.6 (Figure 6.33) (Supplementary Material has RCP4.5 and RCP6.0). Previous IPCC scenarios (SRES A2 or IS92a) project a near doubling of atmospheric nitrogen deposition over some world biodiversity hotspots with half of these hotspots subjected to deposition rates greater than $15 \mathrm{kgN} \mathrm{ha}^{-1} \mathrm{yr}^{-1}$ (critical load threshold value) over at least $10 \%$ of their total area (Dentener et al., 2005; Phoenix et al., 2006; Bleeker et al., 2011).

Large uncertainties remain in our understanding and modelling of changes in $\mathrm{Nr}$ emissions, atmospheric transport and deposition processes, lead to low confidence in the projection of future $\mathrm{Nr}$ deposition fluxes, particularly in regions remote from anthropogenic emissions (Dentener et al., 2006). The large spread between atmospheric GCM models associated with precipitation projections confounds extraction 
of a climate signal in deposition projections (Langner et al., 2005; Hedegaard et al., 2008).

\subsubsection{Projected Changes in Sulphur Deposition}

Given the tight coupling between the atmospheric nitrogen and sulphur cycles, and the impact on climate (Section 7.3) this Chapter also presents scenarios for sulphur deposition. Deposition of $\mathrm{SO}_{\mathrm{x}}$ is projected to decrease in all RCP pathways (Figures 6.33 and 6.34). By contrast, scenarios established prior to RCPs indicated decreases of sulphur deposition in North America and Europe, but increases in South America, Africa, South and East Asia (Dentener et al., 2006; Tagaris et al., 2008). In all RCPs, sulphur deposition is lower by 2100 than in 2000 in all regions, with the largest decreases in North America, Europe and Asia (RCP2.6 and RCP 8.5 are seen in Figure 6.34; RCP4.5 and RCP6.0 are in the Supplementary Material) (Lamarque et al., 2011). Future hot spots of deposition are still evident in East and South East Asia, especially for RCP6.0.

Projected future increase of $\mathrm{Nr}$ input into terrestrial ecosystems also yields increased flux of $\mathrm{Nr}$ from rivers into coastal systems. As illustrated by the Global NEWS 2 model for 2050, by the base year 2000,

\section{$\mathrm{N}_{2} \mathrm{O}$ emissions $\left(\mathrm{kgN} \mathrm{km}^{-2} \mathrm{y}^{-1}\right)$}
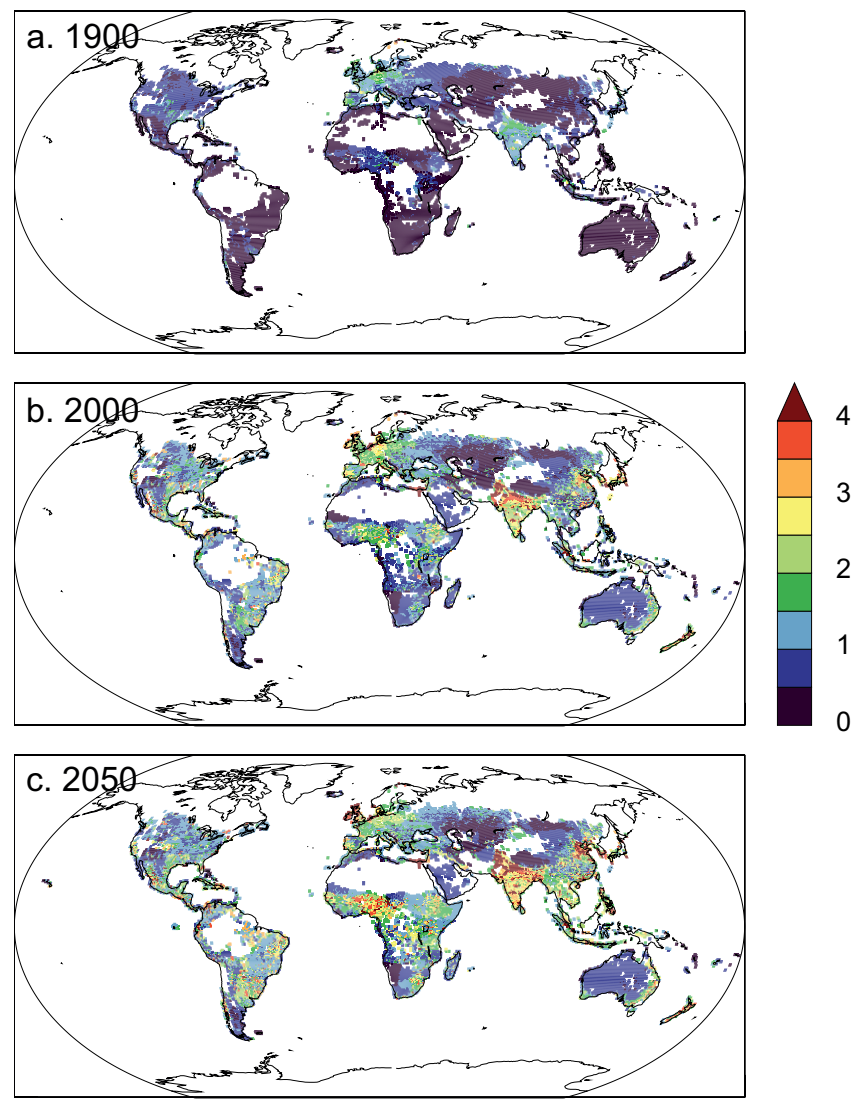

Figure 6.32 | $\mathrm{N}_{2} \mathrm{O}$ emissions in 1900, 2000 and projected to 2050 (Bouwman et al., 2011). This spatially explicit soil nutrient budget and nitrogen gas emission scenario was elaborated with the Integrated Model to Assess the Global Environment (IMAGE) model on the basis of the International Assessment of Agricultural Knowledge, Science and Technology for Development (IAASTD) baseline scenario (McIntyre et al., 2009). the discharge of dissolved inorganic nitrogen (DIN) to marine coastal waters was $>500 \mathrm{~kg} \mathrm{~N} \mathrm{~km}^{-2}$ of watershed area for most watershed systems downstream of either high population or extensive agricultural activity (Mayorga et al., 2010; Seitzinger et al., 2010). Additional information and the supporting figure are found in the Supplementary Material.

\subsubsection{Impact of Future Changes in Reactive Nitrogen on Carbon Uptake and Storage}

Anthropogenic $\mathrm{Nr}$ addition and natural nitrogen-cycle responses to global changes will have an important impact on the global carbon cycle. As a principal nutrient for plant growth, nitrogen can both limit future carbon uptake and stimulate it depending on changes in $\mathrm{Nr}$ availability. A range of global terrestrial carbon cycle models have been developed since AR4 that integrate nitrogen dynamics into the simulation of land carbon cycling (Thornton et al., 2007; Wang et al., 2007, 2010a; Sokolov et al., 2008; Xu-Ri and Prentice, 2008; Churkina et al., 2009; Jain et al., 2009; Fisher et al., 2010; Gerber et al., 2010; Zaehle and Friend, 2010; Esser et al., 2011). However, only two ESMs in CMIP5 (CESM1-BGC and NorESM1-ME) include a description of nitrogen-carbon interactions.

In response to climate warming, increased decomposition of soil organic matter increases nitrogen mineralisation, (high confidence) which can enhance $\mathrm{Nr}$ uptake and carbon storage by vegetation. Generally, higher $\mathrm{C}: \mathrm{N}$ ratio in woody vegetation compared to $\mathrm{C}: \mathrm{N}$ ratio of soil organic matter causes increased ecosystem carbon storage as increased $\mathrm{Nr}$ uptake shifts nitrogen from soil to vegetation (Melillo et al., 2011). In two studies (Sokolov et al., 2008; Thornton et al., 2009), this effect was strong enough to turn the carbon-climate interaction into a small negative feedback, that is, an increased land $\mathrm{CO}_{2}$ uptake in response to climate warming (positive $\gamma_{L}$ values in Figure 6.20), whereas in another study that described carbon-nitrogen interactions (Zaehle et al., 2010b) the carbon-climate interaction was reduced but remained positive, that is, decreased land $\mathrm{CO}_{2}$ uptake in response to climate change (negative $\gamma_{L}$ values in Figures $6.20,6.21$ and 6.22). The two CMIP5 ESMs which include terrestrial carbon-nitrogen interactions (Table 6.11) also simulate a small but positive climate-carbon feedback.

Consistent with the observational evidence (Finzi et al., 2006; Palmroth et al., 2006; Norby et al., 2010), modelling studies have shown a strong effect of $\mathrm{Nr}$ availability in limiting the response of plant growth and land carbon storage to elevated atmospheric $\mathrm{CO}_{2}$ (e.g., Sokolov et al., 2008; Thornton et al., 2009; Zaehle and Friend, 2010). These analyses are affected by the projected future trajectories of anthropogenic $\mathrm{Nr}$ deposition. The effects of $\mathrm{Nr}$ deposition counteract the nitrogen limitation of $\mathrm{CO}_{2}$ fertilisation (Churkina et al., 2009; Zaehle et al., 2010a). Estimates of the total net carbon storage on land due to $\mathrm{Nr}$ deposition between 1860 and 2100 range between 27 and $66 \mathrm{PgC}$ (Thornton et al., 2009; Zaehle et al., 2010a).

It is very likely that, at the global scale, nutrient limitation will reduce the global land carbon storage projected by CMIP5 carbon-cycle only models. Only two of the current CMIP5 ESM models explicitly consider carbon-nitrogen interactions (CESM1-BGC and NorESM1-ME). 
The effect of the nitrogen limitations on terrestrial carbon sequestration in the results of the other CMIP5 models may be approximated by comparing the implicit $\mathrm{Nr}$ requirement given plausible ranges of terrestrial C:N stoichiometry (Wang and Houlton, 2009) to plausible increases in terrestrial $\mathrm{Nr}$ supply due to increased biological nitrogen fixation (Wang and Houlton, 2009) and anthropogenic Nr deposition (Figure 6.35). For the ensemble of CMIP5 projections under the RCP 8.5 scenario, this implies a lack of available nitrogen of 1.3 to 13.1 $\mathrm{PgN}$ which would reduce terrestrial $\mathrm{C}$ sequestration by an average of $137 \mathrm{PgC}$ over the period 1860-2100, with a range of 41 to $273 \mathrm{PgC}$ among models. This represents an ensemble mean reduction in land carbon sequestration of $55 \%$, with a large spread across models (14 to $196 \%)$. Inferred reductions in ensemble-mean land carbon sink over the same period for RCPs 6.0, 4.5 and 2.6 are 109, 117 and 85 PgC, respectively. Between-model variation in these inferred reduced land carbon sinks is similar for all RCPs, with ranges of 57 to $162 \mathrm{PgC}, 38$ to $208 \mathrm{PgC}$, and 32 to $171 \mathrm{PgC}$ for RCPs 6.0, 4.5 and 2.6, respectively. The influence of nutrient addition for agriculture and pasture management is not addressed in this analysis. Results from the two CMIP5 models with explicit carbon-nitrogen interactions show even lower land carbon sequestration than obtained by this approximation method (Figure 6.35). More models with explicit carbon-nitrogen interactions are needed to understand between-model variation and construct an ensemble response.

The positive effect on land carbon storage due to climate-increased $\mathrm{Nr}$ mineralization is of comparable magnitude to the land carbon storage increase associated with increased anthropogenic Nr deposition. Models disagree, however, which of the two factors is more important, with both effects dependent on the choice of scenario. Crucially, the effect of nitrogen limitation on vegetation growth and carbon storage under elevated $\mathrm{CO}_{2}$ is the strongest effect of the natural and disturbed nitrogen cycle on terrestrial carbon dynamics (Bonan and Levis, 2010; Zaehle et al., 2010a). In consequence, the projected atmospheric $\mathrm{CO}_{2}$
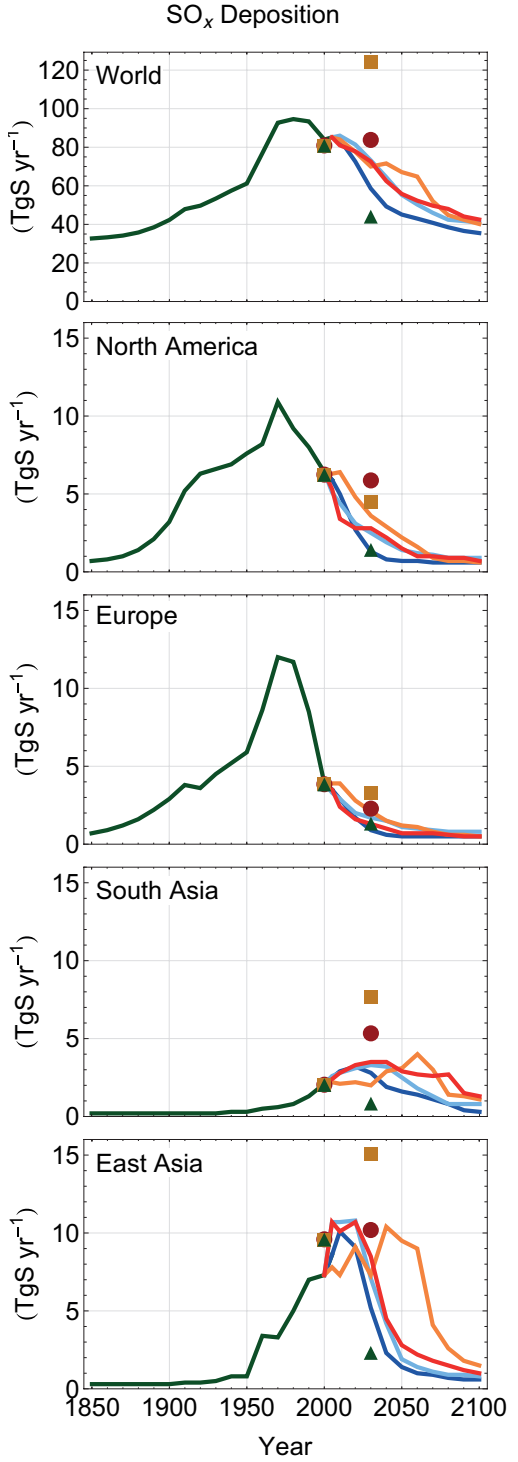

$\mathrm{NH}_{x}$ Deposition
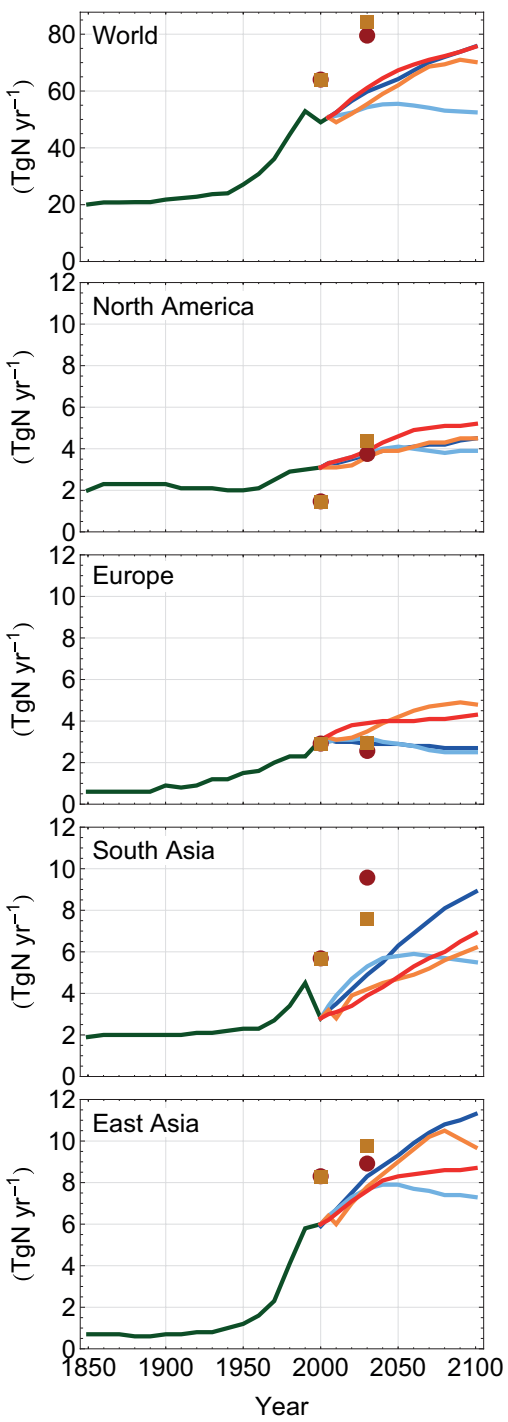
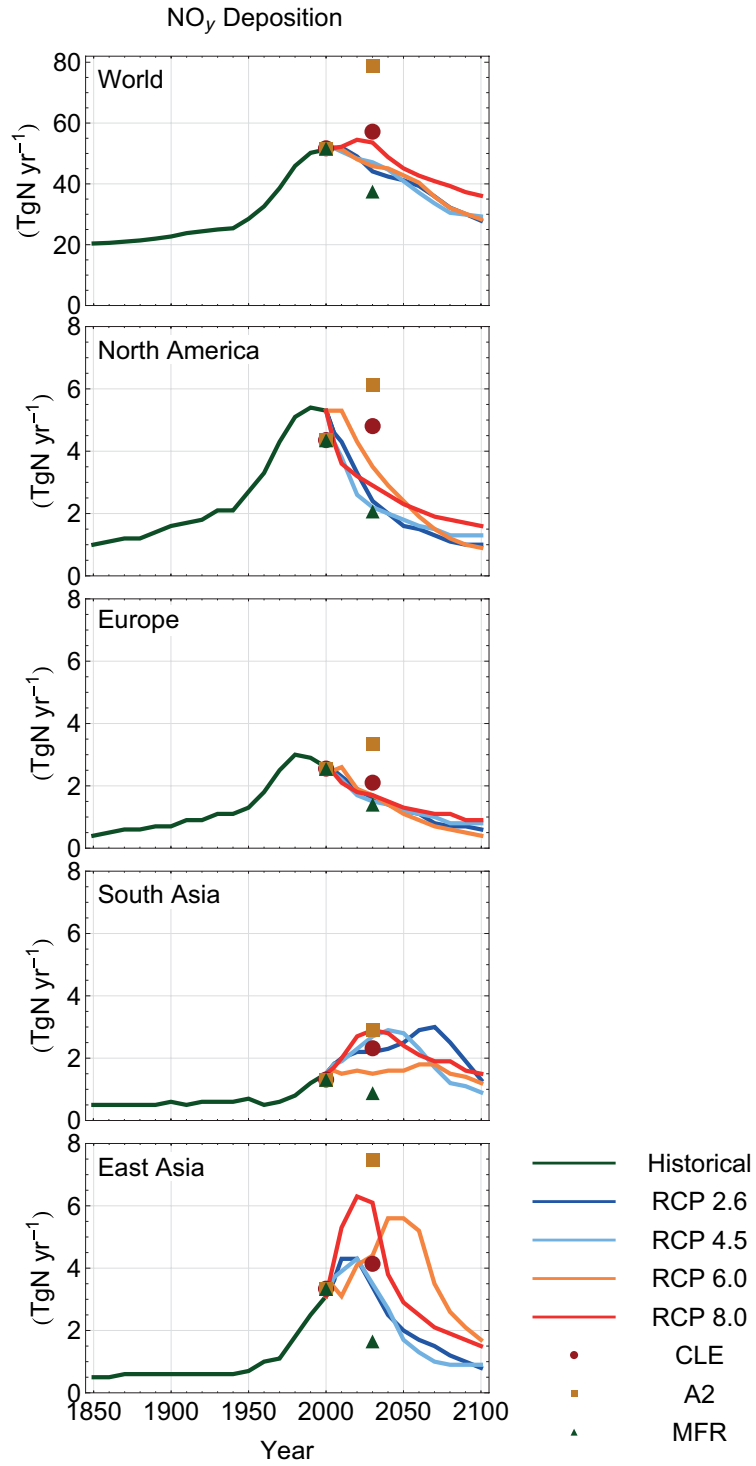

Figure 6.33 | Deposition of $\mathrm{SO}_{\mathrm{x}}$ (left, TgS yr-1), $\mathrm{NH}_{\mathrm{x}}$ (middle, $\mathrm{TgN} \mathrm{yr}^{-1}$ ) and $\mathrm{NO}_{\mathrm{y}}$ (right, $\mathrm{TgN} \mathrm{yr}^{-1}$ ) from 1850 to 2000 and projections of deposition to 2100 under the four RCP emission scenarios (Lamarque et al., 2011; van Vuuren et al., 2011). Also shown are the 2030 scenarios using the SRES B1/A2 energy scenario with assumed current legislation and maximum technically feasible air pollutant reduction controls (Dentener et al., 2006). 


$$
\mathrm{SO}_{\mathrm{x}} \text { deposition }\left(\mathrm{kgS} \mathrm{km}^{-2} \mathrm{y}^{-1}\right)
$$

1990s

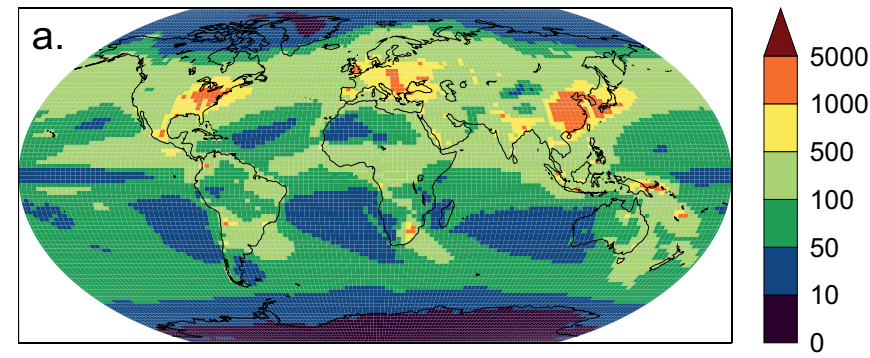

2090s, changes from 1990s
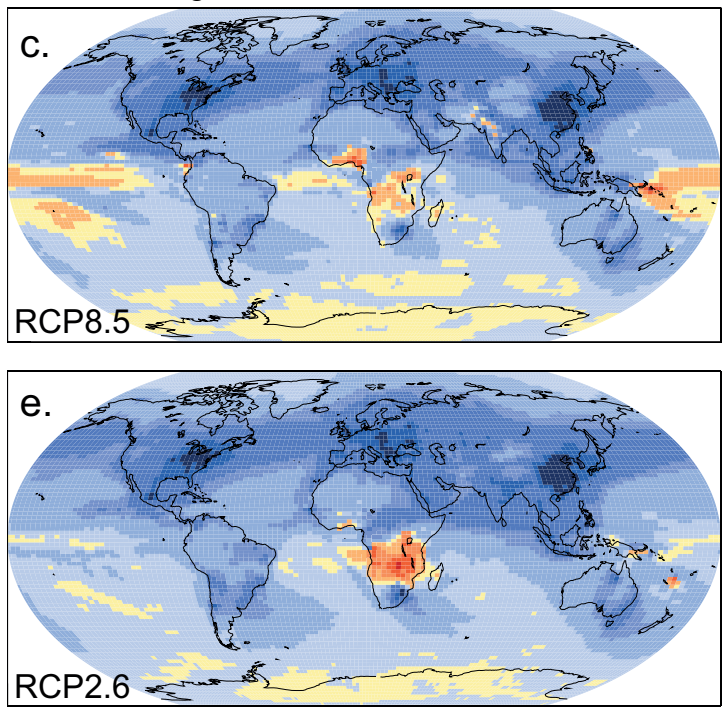

\section{$\mathrm{N}$ deposition $\left(\mathrm{kgN} \mathrm{km}^{-2} \mathrm{y}^{-1}\right)$}

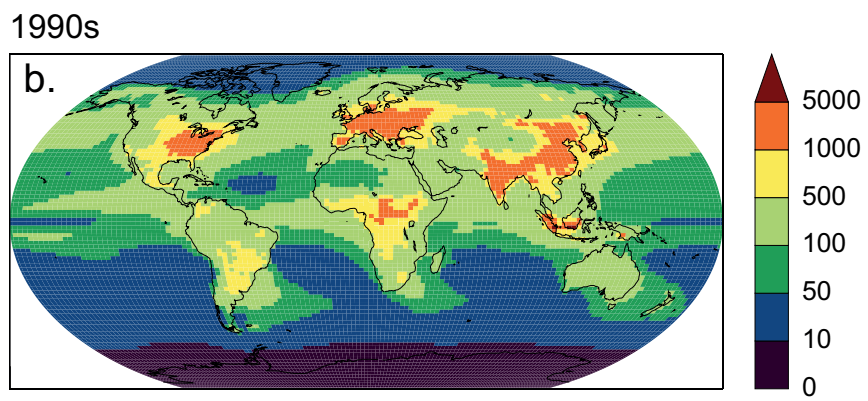

2090s, changes from 1990s
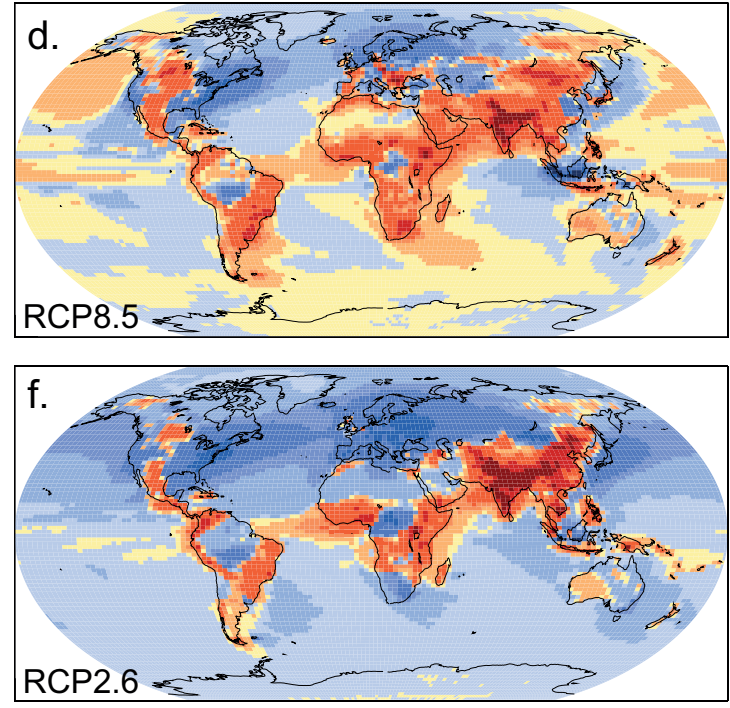

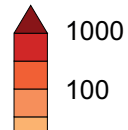

10

$-10$ $-100$

$-1000$

Figure 6.34 | Spatial variability of nitrogen and $\mathrm{SO}_{x}$ deposition in 1990s with projections to the 2090s (shown as difference relative to the $1990 \mathrm{~s}$ ), using the RCP2.6 and RCP8.5 scenarios, $\mathrm{kgN} \mathrm{km}^{-2} \mathrm{yr}^{-1}$, adapted from Lamarque et al. (2011). Note that no information on the statistical significance of the shown differences is available. This is of particular relevance for areas with small changes. The plots for all four of the RCP scenarios are in the Supplementary Material.

concentrations (and thus degree of climate change) in 2100 are higher in projections with models describing nitrogen limitations than in those same models without these interactions. The influence of current and future nitrogen deposition on the ocean sink for anthropogenic carbon is estimated to be rather small, with less than $5 \%$ of the ocean carbon sink in 2100 attributable to fertilisation from anthropogenic $\mathrm{Nr}$ deposition over the oceans (Reay et al., 2008).

None of the CMIP5 models include phosphorus as a limiting nutrient for land ecosystems, although this limitation and interactions with $\mathrm{Nr}$ availability are observed in many systems (Elser et al., 2007). Limitation by $\mathrm{Nr}$ availability alone may act as a partial surrogate for combined nitrogen-phosphorus limitation (Thornton et al., 2009; Section 6.4.8.2), but are likely to underestimate the overall nutrient limitation, especially in lowland tropical forest.

\subsubsection{Future Changes in Methane Emissions}

Future atmospheric $\mathrm{CH}_{4}$ concentrations are sensitive to changes in both emissions and $\mathrm{OH}$ oxidation. Atmospheric chemistry is not covered in this chapter and we assess here future changes in natural $\mathrm{CH}_{4}$ emissions in response to climate change (e.g., O'Connor et al., 2010; Figure 6.36). Projected increases in future fire occurrence (Section 6.4.8.1) suggest that $\mathrm{CH}_{4}$ from fires may increase (low confidence). Future changes in anthropogenic emissions due to anthropogenic alteration of wetlands (e.g., peatland drainage) may also be important but are not assessed here.

\subsubsection{Future Methane Emissions from Wetlands}

Overall, there is medium confidence that emissions of $\mathrm{CH}_{4}$ from wetlands are likely to increase in the future under elevated $\mathrm{CO}_{2}$ and warmer climate. Wetland extent is determined by geomorphology and soil moisture, which depends on precipitation, evapotranspiration, drainage and runoff. All of these may change in the future. Increasing temperature can lead to higher rates of evapotranspiration, reducing soil moisture and therefore affect wetland extent, and temporary increasing aeration of existing wetlands with further consequences to methane emissions. Regional projections of precipitation changes are especially uncertain (see Chapter 12). 
Direct effects on wetland $\mathrm{CH}_{4}$ emissions include: higher NPP under higher temperature and higher atmospheric $\mathrm{CO}_{2}$ concentrations leading to more substrate for methanogenesis (White et al., 2008); higher $\mathrm{CH}_{4}$ production rates under higher temperature; and changes in $\mathrm{CH}_{4}$ oxidation through changed precipitation that alters water table position (Melton et al., 2013). Wetland $\mathrm{CH}_{4}$ emissions are also affected by changes in wetland area which may either increase (due to thawing permafrost or reduced evapotranspiration) or decrease (due to reduced precipitation or increased evaporation) regionally. In most models, elevated $\mathrm{CO}_{2}$ has a stronger enhancement effect on $\mathrm{CH}_{4}$ emissions than climate change. However, large uncertainties exist concerning the lack of wetland specific plant functional types in most models and the lack of understanding how wetland plants will react to $\mathrm{CO}_{2}$ fertilisation (e.g., Berendse et al., 2001; Boardman et al., 2011; Heijmans et al., 2001, 2002a, 2002b).

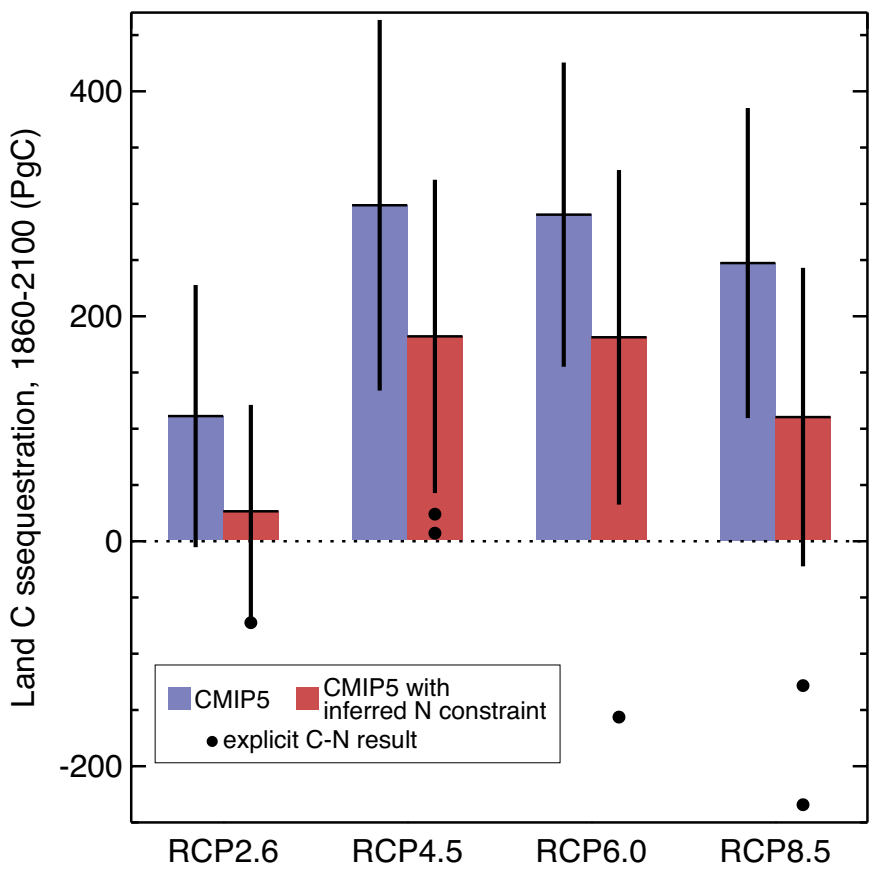

Figure 6.35 | Estimated influence of nitrogen availability on total land carbon sequestration over the period 1860-2100 (based on analysis method of Wang and Houlton (2009). Blue bars show, for each RCP scenario, the multi-model ensemble mean of land carbon sequestration, based on the carbon-only subset of CMIP5 models (Canadian Earth System Model 2 (CanESM2), Geophysical Fluid Dynamics Laboratory-Earth System Model 2 G (GFDL-ESM2G), Geophysical Fluid Dynamics Laboratory-Earth System Model 2M (GFDL-ESM2M), Hadley Centre Global Environmental Model 2-Carbon Cycle(HadGEM2-CC), Hadley Centre Global Environmental Model 2-Earth System (HadGEM2-ES), Institute Pierre Simon Laplace-Coupled Model 5A-Low Resolution (IPSLCM5A-LR), Institute Pierre Simon Laplace- Coupled Model 5A-Medium Resolution (IPSL-CM5A-MR), Institute Pierre Simon Laplace-Coupled Model 5B-Low Resolution (IPSL-CM5B-LR), Max Planck Institute-Earth System Model-Low Resolution (MPI-ESMLR): not all models produced results for all scenarios). Red bars show, for each scenario, the mean land carbon sequestration from the same ensemble of carbon-only models after correcting for inferred constraints on carbon uptake due to limited availability of nitrogen. Black bars show \pm one standard deviation around the means. Black symbols show individual model results from the two CMIP5 models with explicit carbon-nitrogen interactions (Community Earth System Model 1-Biogeochemical (CESM1-BGC) and Norwegian Earth System Model 1 (Emissions capable) (NorESM1-ME)). These two models have nearly identical representations of land carbon-nitrogen dynamics, and differences between them here (for RCP4.5 and RCP8.5, where both models contributed results) are due to differences in coupled system climate. All simulations shown here used prescribed atmospheric $\mathrm{CO}_{2}$ concentrations.
Since AR4, several modelling studies have attempted to quantify the sensitivity of global wetland $\mathrm{CH}_{4}$ emissions to environmental changes (see Figure 6.37). The studies cover a wide range of simulation results but there is high agreement between model results that the combined effect of $\mathrm{CO}_{2}$ increase and climate change by the end of the 21st century will increase wetland $\mathrm{CH}_{4}$ emissions. Using a common experimental protocol with spatially uniform changes in precipitation, temperature and $\mathrm{CO}_{2}$ ("WETCHIMP"; Melton et al., 2013) seven models predict that the effect of increased temperature alone (red bars in Figure 6.37) may cause an increase or decrease of wetland $\mathrm{CH}_{4}$ emissions, while the effect of increased precipitation alone (green bars in Figure 6.37) is always an increase, although generally small. The effect of increased atmospheric $\mathrm{CO}_{2}$ concentration (fertilisation of NPP; Box 6.3; blue bars in Figure 6.37) always resulted in an increase of emissions ( 22 to $162 \%)$. Other studies assessed the effects of temperature and precipitation together (orange bars in Figure 6.37) and often found an increase in wetland $\mathrm{CH}_{4}$ emissions (Eliseev et al., 2008; Gedney et al., 2004; Shindell et al., 2004; Volodin, 2008) although Ringeval et al. (2011) found a net decrease. The combined effect of climate and $\mathrm{CO}_{2}$ resulted in an increase of wetland $\mathrm{CH}_{4}$ emissions from $40 \%$ (Volodin (2008); fixed wetland area) to $68 \%$ (Ringeval et al., 2011); variable wetland area).

The models assessed here do not consider changes in soil hydrological properties caused by changes in organic matter content. Positive feedbacks from increased drainage due to organic carbon loss may

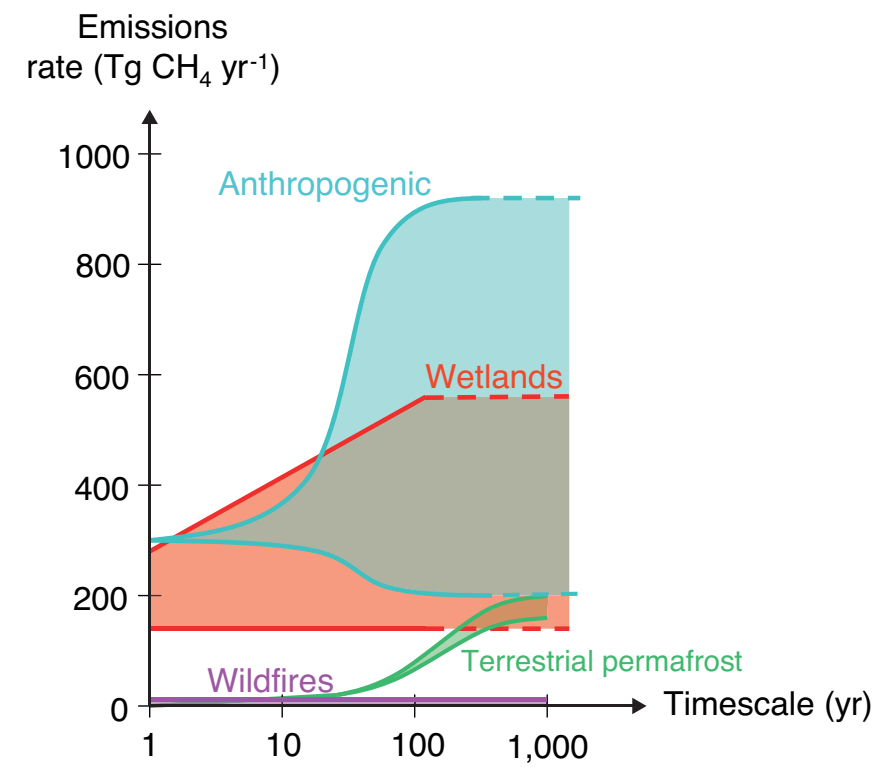

Figure 6.36 | Schematic synthesis of the magnitude and time scales associated with possible future $\mathrm{CH}_{4}$ emissions (adapted from O'Connor et al., 2010). Uncertainty in these future changes is large, and so this figure demonstrates the relative magnitude of possible future changes. Anthropogenic emissions starting at a present-day level of $300 \mathrm{Tg}\left(\mathrm{CH}_{4}\right) \mathrm{yr}^{-1}$ (consistent with Table 6.8) and increasing or decreasing according to RCP8.5 and RCP2.6 are shown for reference. Wetland emissions are taken as 140 to $280 \mathrm{Tg}\left(\mathrm{CH}_{4}\right) \mathrm{yr}^{-1}$ present day values (Table 6.8) and increasing by between 0 and $100 \%$ (Section 6.4.7.1; Figure 6.37). Permafrost emissions may become important during the 21 st century. $\mathrm{CH}_{4}$ release from marine hydrates and subsea permafrost may also occur but uncertainty is sufficient to prevent plotting emission rates here. Large $\mathrm{CH}_{4}$ hydrate release to the atmosphere is not expected during the 21st century. No quantitative estimates of future changes in $\mathrm{CH}_{4}$ emissions from wildfires exist, so plotted here are continued present-day emissions of 1 to $5 \mathrm{Tg}\left(\mathrm{CH}_{4}\right) \mathrm{yr}^{-1}$ (Table 6.8). 
accelerate peat decomposition rates (Ise et al., 2008). However, carbon accumulation due to elevated NPP in wetland and permafrost regions may to some extent offset $\mathrm{CH}_{4}$ emissions (Frolking and Roulet, 2007; Turetsky et al., 2007). None of the studies or models assessed here considers $\mathrm{CH}_{4}$ emissions from mangroves.

The models also do not agree in their simulations of present day wetland extent or $\mathrm{CH}_{4}$ emissions, and there are not adequate data sets to evaluate them thoroughly at the grid scale (typically $0.5^{\circ}$ ) (Melton et al., 2013). Hence despite high agreement between models of a strong positive response of wetland $\mathrm{CH}_{4}$ emission rates to increasing atmospheric $\mathrm{CO}_{2}$ we assign low confidence to quantitative projections of future wetland $\mathrm{CH}_{4}$ emissions.

Soil $\mathrm{CH}_{4}$ oxidation of about $30 \mathrm{Tg}\left(\mathrm{CH}_{4}\right) \mathrm{yr}^{-1}$ (Table 6.8) represents the smallest of the three sinks for atmospheric methane (see Table 6.8) but is also sensitive to future environmental changes. Soil $\mathrm{CH}_{4}$ oxidation is projected to increase by up to $23 \%$ under the SRES A1B due to rising atmospheric $\mathrm{CH}_{4}$ concentrations, higher soil temperature and lower soil moisture (Curry, 2007, 2009).

\subsubsection{Future Methane Emissions from Permafrost Areas}

Permafrost thaw may lead to increased drainage and a net reduction in lakes and wetlands, a process that has already begun to be seen in lakes in the discontinuous permafrost zone (Smith et al., 2005; Jones et al., 2011) and has been projected to continue under future scenarios (Avis et al., 2011). Alternatively, small lakes or ponds and wetland growth may occur in continuous permafrost areas underlain by ice-rich material subject to thermokarst (Christensen et al., 2004; Jorgenson et al., 2006; Plug and West, 2009; Jones et al., 2011).

There is high agreement between land surface models that permafrost extent is expected to reduce during the 21 st century, accompanying particularly rapid warming at high latitudes (Chapter 12). However, estimates vary widely as to the pace of degradation (Lawrence and Slater, 2005; Burn and Nelson, 2006; Lawrence et al., 2008). The LPJWHyMe model projected permafrost area loss of 30\% (SRES B1) and $47 \%$ (SRES A2) by 2100 (Wania, 2007). Marchenko et al. (2008) calculate that by $2100,57 \%$ of Alaska will lose permafrost within the top $2 \mathrm{~m}$. For the RCP scenarios, the CMIP5 multi-model ensemble shows a wide range of projections for permafrost loss: 15 to $87 \%$ under RCP4.5 and 30 to $99 \%$ under RCP8.5 (Koven et al., 2013).

Hydrological changes may lead to tradeoffs between the $\mathrm{CO}_{2}$ and $\mathrm{CH}_{4}$ balance of ecosystems underlain by permafrost, with methane production rates being roughly an order of magnitude less than rates of oxic decomposition to $\mathrm{CO}_{2}$ but $\mathrm{CH}_{4}$ having a larger greenhouse warming potential (Frolking and Roulet, 2007). The extent of permafrost thaw simulated by climate models has been used to estimate possible subsequent carbon release (Burke et al., 2013; Harden et al., 2012; Section 6.4.3.4) but few studies explicitly partition this into $\mathrm{CO}_{2}$ or $\mathrm{CH}_{4}$ release

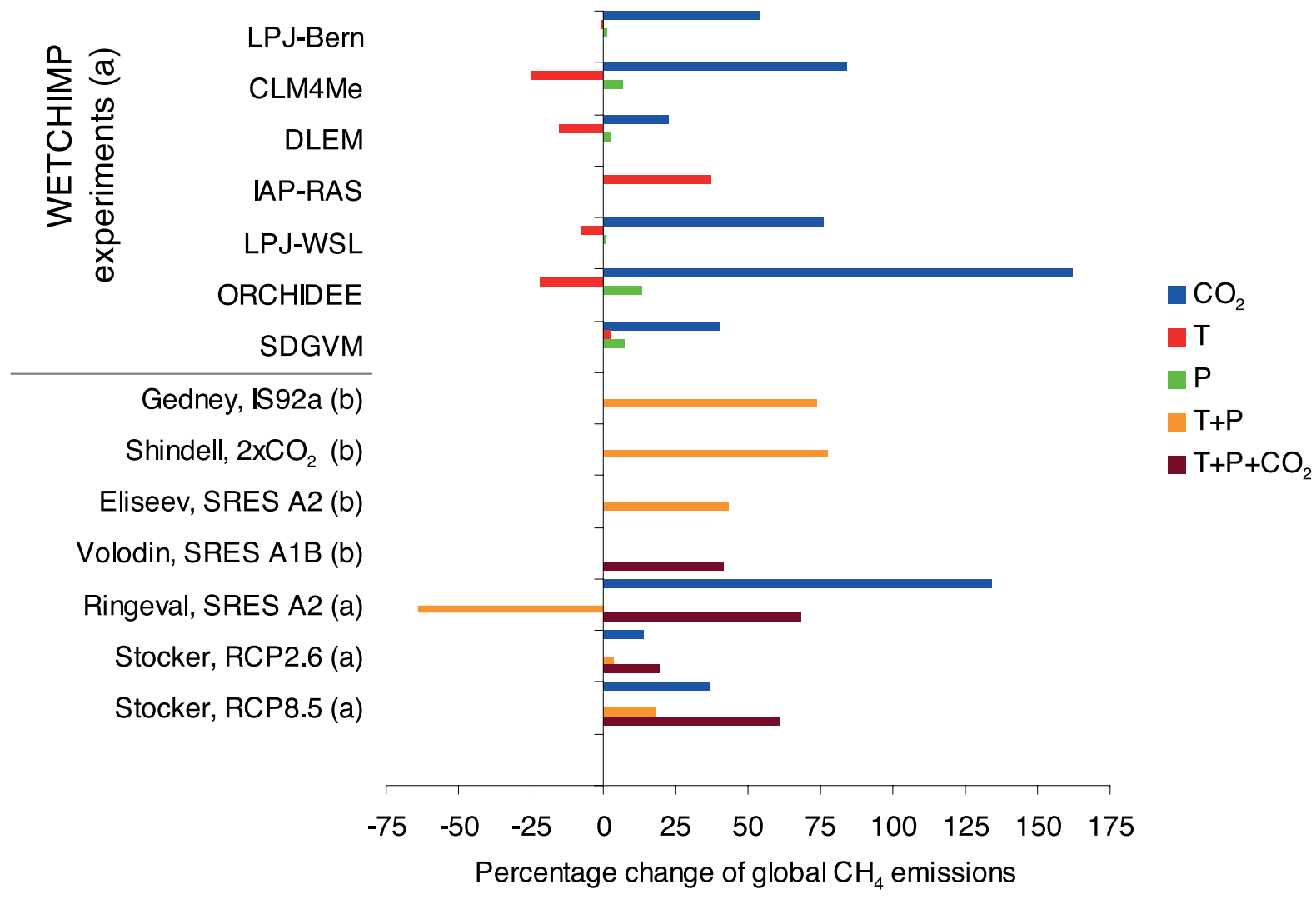

Figure 6.37 | Relative changes of global $\mathrm{CH}_{4}$ emissions from either pre-industrial (a) or present-day (b) conditions and environmental changes that reflect potential conditions in 2100. The first seven models took part in the WETCHIMP intercomparison project and were run under a common protocol (Melton et al., 2013). Bars represent $\mathrm{CH}_{4}$ emission changes associated with temperature-only changes $(T)$, precipitation only $(\mathrm{P}), \mathrm{CO}_{2}$ only $\left(\mathrm{CO}_{2}\right)$ or combinations of multiple factors. Other studies as listed in the figure used different future scenarios: Eliseev et al. (2008), Gedney et al. (2004), Ringeval et al. (2011), Shindell et al. (2004), Volodin (2008), Stocker et al. (2013). 
to the atmosphere. Schneider von Deimling et al. (2012) estimate cumulative $\mathrm{CH}_{4}$ emissions by 2100 between 131 and $533 \mathrm{Tg}\left(\mathrm{CH}_{4}\right)$ across the 4 RCPs. CMIP5 projections of permafrost thaw do not consider changes in pond or lake formation. Thawing of unsaturated Yedoma carbon deposits (which contain large, but uncertain amounts of organic carbon in permafrost in northeast Siberia; Schirrmeister et al., 2011) was postulated to produce significant $\mathrm{CH}_{4}$ emissions (Khvorostyanov et al., 2008), however more recent estimates with Yedoma carbon lability constrained by incubation observations (Dutta et al., 2006) argue for smaller emissions at 2100 (Koven et al., 2011).

\subsubsection{Future Methane Hydrate Emissions}

Substantial quantities of methane are believed to be stored within submarine hydrate deposits at continental margins (see also Section 6.1, FAQ 6.1). There is concern that warming of overlying waters may melt these deposits, releasing $\mathrm{CH}_{4}$ into the ocean and atmosphere systems. Overall, it is likely that subsequent emissions to the atmosphere caused by hydrate destabilisation would be in the form of $\mathrm{CO}_{2}$, due to $\mathrm{CH}_{4}$ oxidation in the water column.

Considering a potential warming of bottom waters by $1{ }^{\circ} \mathrm{C}, 3^{\circ} \mathrm{C}$ and $5^{\circ} \mathrm{C}$ during the next 100 years, Reagan and Moridis (2007) found that hydrates residing in a typical deep ocean setting $\left(4^{\circ} \mathrm{C}\right.$ and 1000 $\mathrm{m}$ depth) would be stable and in shallow low-latitude settings $\left(6^{\circ} \mathrm{C}\right.$ and $560 \mathrm{~m}$ ) any sea floor $\mathrm{CH}_{4}$ fluxes would be oxidized within the sediments. Only in cold-shallow Arctic settings $\left(0.4^{\circ} \mathrm{C}\right.$ and $\left.320 \mathrm{~m}\right)$ would $\mathrm{CH}_{4}$ fluxes exceed rates of benthic sediment oxidation. Simulations of heat penetration through the sediment by Fyke and Weaver (2006) suggest that changes in the gas hydrate stability zone will be small on century time scales except in high-latitude regions of shallow ocean shelves. In the longer term, Archer et al. (2009a) estimated that between 35 and $940 \mathrm{PgC}$ could be released over several thousand years in the future following a $3^{\circ} \mathrm{C}$ seafloor warming.

Using multiple climate models (Lamarque, 2008), predicted an upper estimate of the global sea floor flux of between 560 and $2140 \mathrm{Tg}\left(\mathrm{CH}_{4}\right)$ $\mathrm{yr}^{-1}$, mostly in the high latitudes. Hunter et al. (2013) also found 21st century hydrate dissociation in shallow Arctic waters and comparable in magnitude to Biastoch et al. (2011), although maximum $\mathrm{CH}_{4}$ sea floor fluxes were smaller than Lamarque (2008), with emissions from 330 to $450 \mathrm{Tg}\left(\mathrm{CH}_{4}\right) \mathrm{yr}^{-1}$ for RCP 4.5 to RCP8.5. Most of the sea floor flux of $\mathrm{CH}_{4}$ is expected to be oxidised in the water column into dissolved $\mathrm{CO}_{2}$. Mau et al. (2007) suggest only $1 \%$ might be released to the atmosphere but this fraction depends on the depth of water and ocean conditions. Elliott et al. (2011) demonstrated significant impacts of such sea floor release on marine hypoxia and acidity, although atmospheric $\mathrm{CH}_{4}$ release was small.

Observations of $\mathrm{CH}_{4}$ release along the Svalbard margin seafloor (Westbrook et al., 2009) suggest observed regional warming of $1^{\circ} \mathrm{C}$ during the last 30 years is driving hydrate disassociation, an idea supported by modelling (Reagan and Moridis, 2009). However, these studies do not consider subsea-permafrost hydrates suggested recently to be regionally significant sources of atmospheric $\mathrm{CH}_{4}$ (Shakhova et al., 2010). There was no positive excursion in the methane concentration recorded in ice cores from the largest known submarine landslide, the Storegga slide of Norway 8200 years ago. Large methane hydrate release due to marine landslides is unlikely as any given landslide could release only a tiny fraction of the global inventory (Archer, 2007).

There is low confidence in modelling abilities to simulate transient changes in hydrate inventories, but large $\mathrm{CH}_{4}$ release to the atmosphere during this century is unlikely.

\subsubsection{Other Drivers of Future Carbon Cycle Changes}

\subsubsection{Changes in Fire under Climate Change/Scenarios of Anthropogenic Fire Changes}

Regional studies for boreal regions suggest an increase in future fire risk (e.g., Amiro et al., 2009; Balshi et al., 2009; Flannigan et al., 2009a; Spracklen et al., 2009; Tymstra et al., 2007; Westerling et al., 2011; Wotton et al., 2010) with implications for carbon and nutrient storage (Certini, 2005). Kurz et al. (2008b) and Metsaranta et al. (2010) indicated that increased fire activity has the potential to turn the Canadian forest from a sink to a source of atmospheric $\mathrm{CO}_{2}$. Models predict spatially variable responses in fire activity, including strong increases and decreases, due to regional variations in the climate-fire relationship, and anthropogenic interference (Scholze et al., 2006; Flannigan et al., 2009b; Krawchuk et al., 2009; Pechony and Shindell, 2010; Kloster et al., 2012). Wetter conditions can reduce fire activity, but increased biomass availability can increase fire emissions (Scholze et al., 2006; Terrier et al., 2013). Using a land surface model and future climate projections from two GCMs, Kloster et al. (2012) projected fire carbon emissions in 2075-2099 that exceed present-day emissions by 17 to

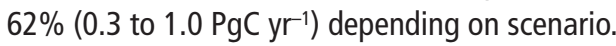

Future fire activity will also depend on anthropogenic factors especially related to land use change. For the Amazon it is estimated that at present $58 \%$ of the area is too humid to allow deforestation fires but climate change might reduce this area to $37 \%$ by 2050 (Le Page et al., 2010). Golding and Betts (2008) estimated that future Amazon forest vulnerability to fire may depend nonlinearly on combined climate change and deforestation.

\subsubsection{Other Biogeochemical Cycles and Processes Impacting Future Carbon Fluxes}

\subsection{Phosphorus}

On centennial time scales, the phosphoros $(\mathrm{P})$ limitation of terrestrial carbon uptake could become more severe than the nitrogen limitation because of limited phosphorus sources. Model simulations have shown a shift after 2100 from nitrogen to phosphorus limitation at high latitudes (Goll et al., 2012).

\subsection{Elevated surface ozone}

Plants are known to suffer damage due to exposure to levels of ozone $\left(\mathrm{O}_{3}\right)$ above about $40 \mathrm{ppb}$ (Ashmore, 2005). Model simulations of plant $\mathrm{O}_{3}$ damage on the carbon cycle have found a reduction in terrestrial carbon storage between 2005 and 2100 ranging from 4 to $140 \mathrm{PgC}$ (Felzer et al., 2005) and up to 260 PgC (Sitch et al., 2007). 


\subsection{Iron deposition to oceans}

Changes in iron deposition may have affected ocean carbon uptake in the past (Section 6.2.1.1), but future projections of iron deposition from desert dust over the ocean are uncertain, even about the sign of changes (Tegen et al., 2004; Mahowald et al., 2009). Tagliabue et al. (2008) found relatively little impact of varying aeolian iron input on ocean $\mathrm{CO}_{2}$ fluxes, but Mahowald et al. (2011) show projected changes in ocean productivity as large as those due to $\mathrm{CO}_{2}$ increases and climate change.

\subsection{Changes in the diffuse fraction of solar radiation at the surface}

Mercado et al. (2009) estimated that variations in the diffuse fraction, associated largely with the 'global dimming' period (Stanhill and Cohen, 2001), enhanced the land carbon sink by approximately $25 \%$ between 1960 and 1999. Under heavily polluted or dark cloudy skies, plant productivity may decline as the diffuse effect is insufficient to offset decreased surface irradiance (UNEP, 2011). Under future scenarios involving reductions in aerosol emissions (Figures 6.33 and 6.34), the diffuse-radiation enhancement of carbon uptake will decline.

\subsubsection{The Long-term Carbon Cycle and Commitments}

With very high confidence, the physical, biogeochemical carbon cycle in the ocean and on land will continue to respond to climate change and rising atmospheric $\mathrm{CO}_{2}$ concentrations created during the 21 st century. Long-term changes in vegetation structure and induced carbon storage potentially show larger changes beyond 2100 than during the $21 \mathrm{st}$ century as the long time scale response of tree growth and ecosystem migrations means that by 2100 only a part of the eventual committed change will be realized (Jones et al., 2009). Holocene changes in tree-line lagged changes in climate by centuries (MacDonald et al., 2008). Long-term 'commitments' to ecosystems migration also carry long-term committed effects to changes in terrestrial carbon storage (Jones et al., 2010; Liddicoat et al., 2013) and permafrost (0'Connor et al., 2010; Sections 6.4.3.3 and 6.4.7).

Warming of high latitudes is common to most climate models (Chapter 12) and this may enable increased productivity and northward expansion of boreal forest ecosystems into present tundra regions depending on nutrient availability (Kellomäki et al., 2008; Kurz et al., 2008a; MacDonald et al., 2008). CMIP5 simulations by two ESMs with dynamic vegetation for extended RCP scenarios to 2300 (Meinshausen et al., 2011) allow analysis of this longer term response of the carbon cycle. Increases in tree cover and terrestrial carbon storage north of $60^{\circ} \mathrm{N}$ are shown in Figure 6.38.
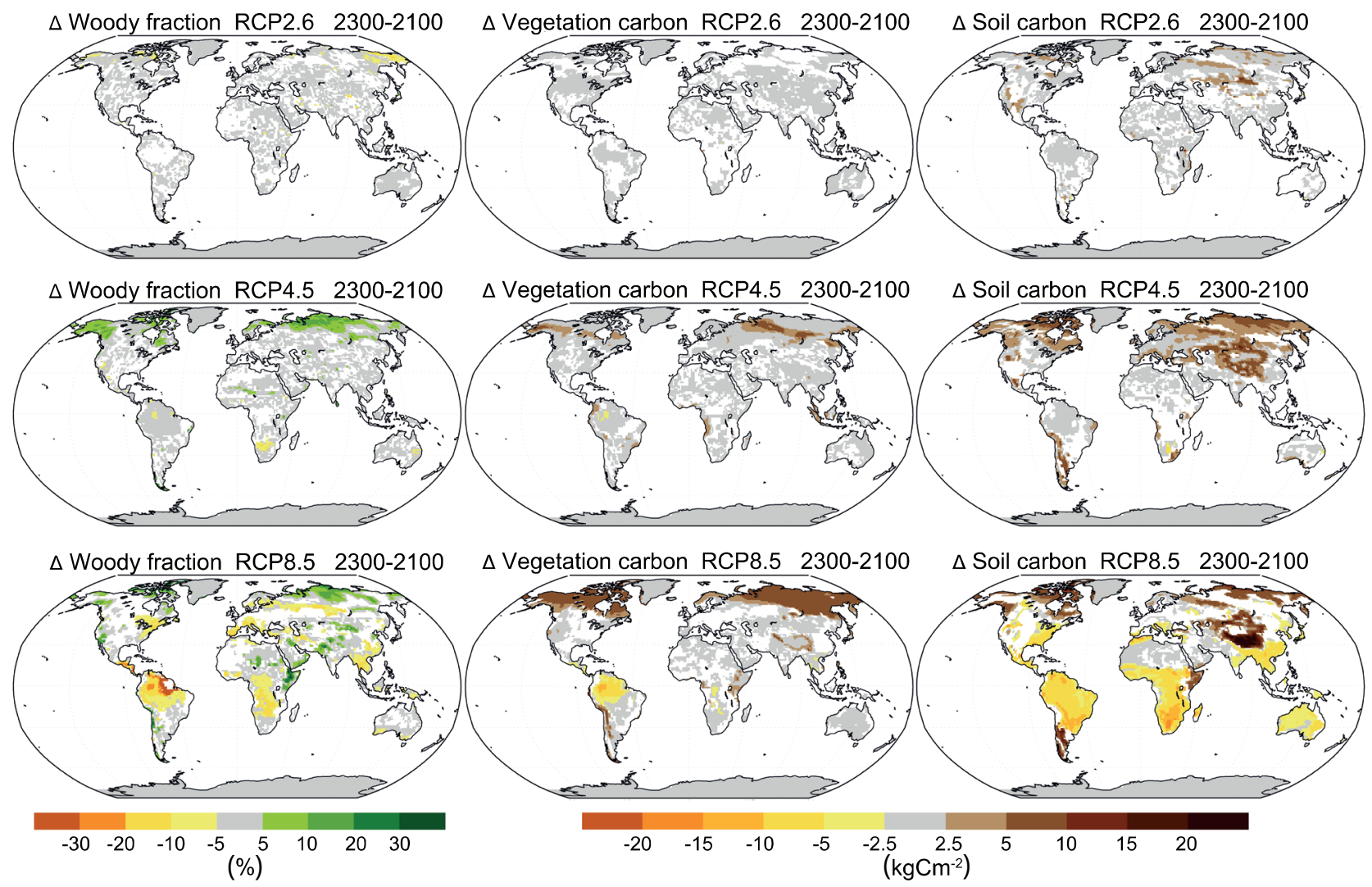

Figure 6.38 Maps of changes in woody cover fraction, \%, (left) and terrestrial carbon storage, $\mathrm{kg} \mathrm{C} \mathrm{m}^{-2}$ (vegetation carbon, middle; soil carbon, right) between years 2100 and 2300 averaged for two models, Hadley Centre Global Environmental Model 2-Earth System (HadGEM2-ES) and Max Planck Institute-Earth System Model (MPI-ESM), which simulate vegetation dynamics for three RCP extension scenarios 2.6 (top), 4.5 (middle), and 8.5 (bottom). Note the RCP6.0 extension was not a CMIP5 required simulation. Model results were interpolated on $1^{\circ} \times 1^{\circ}$ grid; white colour indicates areas where models disagree in sign of changes. Anthropogenic land use in these extension scenarios is kept constant at 2100 levels, so these results show the response of natural ecosystems to the climate change. 


\section{Frequently Asked Questions}

\section{FAQ 6.2 What Happens to Carbon Dioxide After It Is Emitted into the Atmosphere?}

Carbon dioxide $\left(\mathrm{CO}_{2}\right)$, after it is emitted into the atmosphere, is firstly rapidly distributed between atmosphere, the upper ocean and vegetation. Subsequently, the carbon continues to be moved between the different reservoirs of the global carbon cycle, such as soils, the deeper ocean and rocks. Some of these exchanges occur very slowly. Depending on the amount of $\mathrm{CO}_{2}$ released, between $15 \%$ and $40 \%$ will remain in the atmosphere for up to 2000 years, after which a new balance is established between the atmosphere, the land biosphere and the ocean. Geological processes will take anywhere from tens to hundreds of thousands of years-perhaps longer-to redistribute the carbon further among the geological reservoirs. Higher atmospheric $\mathrm{CO}_{2}$ concentrations, and associated climate impacts of present emissions, will, therefore, persist for a very long time into the future.

$\mathrm{CO}_{2}$ is a largely non-reactive gas, which is rapidly mixed throughout the entire troposphere in less than a year. Unlike reactive chemical compounds in the atmosphere that are removed and broken down by sink processes, such as methane, carbon is instead redistributed among the different reservoirs of the global carbon cycle and ultimately recycled back to the atmosphere on a multitude of time scales. FAQ 6.2, Figure 1 shows a simplified diagram of the global carbon cycle. The open arrows indicate typical timeframes for carbon atoms to be transferred through the different reservoirs.

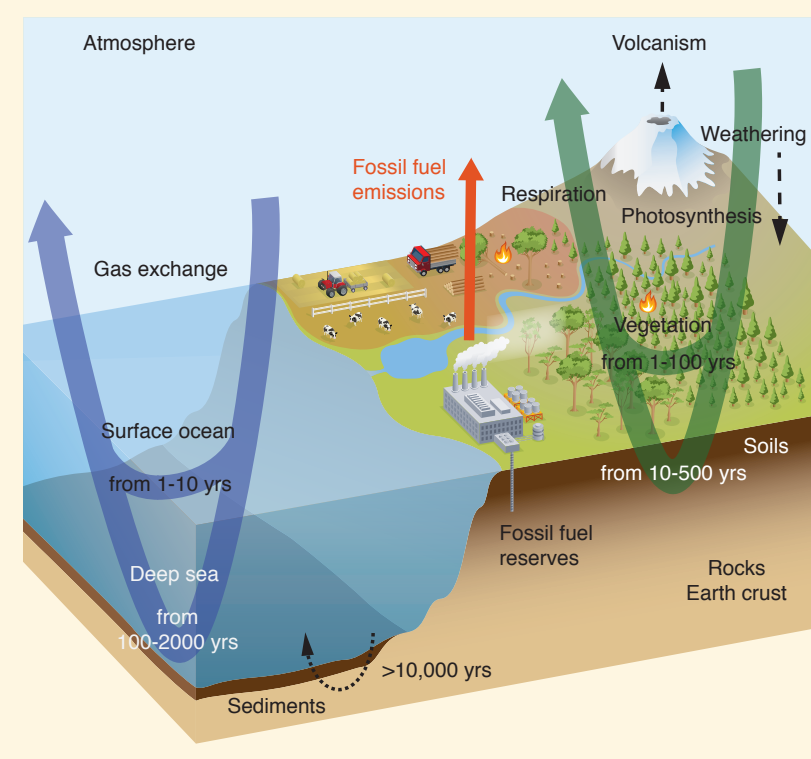

FAQ 6.2, Figure 1| Simplified schematic of the global carbon cycle showing the typical turnover time scales for carbon transfers through the major reservoirs.
Before the Industrial Era, the global carbon cycle was roughly balanced. This can be inferred from ice core measurements, which show a near constant atmospheric concentration of $\mathrm{CO}_{2}$ over the last several thousand years prior to the Industrial Era. Anthropogenic emissions of carbon dioxide into the atmosphere, however, have disturbed that equilibrium. As global $\mathrm{CO}_{2}$ concentrations rise, the exchange processes between $\mathrm{CO}_{2}$ and the surface ocean and vegetation are altered, as are subsequent exchanges within and among the carbon reservoirs on land, in the ocean and eventually, the Earth crust. In this way, the added carbon is redistributed by the global carbon cycle, until the exchanges of carbon between the different carbon reservoirs have reached a new, approximate balance.

Over the ocean, $\mathrm{CO}_{2}$ molecules pass through the air-sea interface by gas exchange. In seawater, $\mathrm{CO}_{2}$ interacts with water molecules to form carbonic acid, which reacts very quickly with the large reservoir of dissolved inorganic carbon-bicarbonate and carbonate ions-in the ocean. Currents and the formation of

sinking dense waters transport the carbon between the surface and deeper layers of the ocean. The marine biota also redistribute carbon: marine organisms grow organic tissue and calcareous shells in surface waters, which, after their death, sink to deeper waters, where they are returned to the dissolved inorganic carbon reservoir by dissolution and microbial decomposition. A small fraction reaches the sea floor, and is incorporated into the sediments.

The extra carbon from anthropogenic emissions has the effect of increasing the atmospheric partial pressure of $\mathrm{CO}_{2}$, which in turn increases the air-to-sea exchange of $\mathrm{CO}_{2}$ molecules. In the surface ocean, the carbonate chemistry quickly accommodates that extra $\mathrm{CO}_{2}$. As a result, shallow surface ocean waters reach balance with the atmosphere within 1 or 2 years. Movement of the carbon from the surface into the middle depths and deeper waters takes longer-between decades and many centuries. On still longer time scales, acidification by the invading $\mathrm{CO}_{2}$ dissolves carbonate sediments on the sea floor, which further enhances ocean uptake. However, current understanding suggests that, unless substantial ocean circulation changes occur, plankton growth remains roughly unchanged because it is limited mostly by environmental factors, such as nutrients and light, and not by the availability of inorganic carbon it does not contribute significantly to the ocean uptake of anthropogenic $\mathrm{CO}_{2}$. (continued on next page) 
FAQ 6.2 (continued)

On land, vegetation absorbs $\mathrm{CO}_{2}$ by photosynthesis and converts it into organic matter. A fraction of this carbon is immediately returned to the atmosphere as $\mathrm{CO}_{2}$ by plant respiration. Plants use the remainder for growth. Dead plant material is incorporated into soils, eventually to be decomposed by microorganisms and then respired back into the atmosphere as $\mathrm{CO}_{2}$. In addition, carbon in vegetation and soils is also converted back into $\mathrm{CO}_{2}$ by fires, insects, herbivores, as well as by harvest of plants and subsequent consumption by livestock or humans. Some organic carbon is furthermore carried into the ocean by streams and rivers.

An increase in atmospheric $\mathrm{CO}_{2}$ stimulates photosynthesis, and thus carbon uptake. In addition, elevated $\mathrm{CO}_{2} \mathrm{con}^{-}$ centrations help plants in dry areas to use ground water more efficiently. This in turn increases the biomass in vegetation and soils and so fosters a carbon sink on land. The magnitude of this sink, however, also depends critically on other factors, such as water and nutrient availability.

Coupled carbon-cycle climate models indicate that less carbon is taken up by the ocean and land as the climate warms constituting a positive climate feedback. Many different factors contribute to this effect: warmer seawater, for instance, has a lower $\mathrm{CO}_{2}$ solubility, so altered chemical carbon reactions result in less oceanic uptake of excess atmospheric $\mathrm{CO}_{2}$. On land, higher temperatures foster longer seasonal growth periods in temperate and higher latitudes, but also faster respiration of soil carbon.

The time it takes to reach a new carbon distribution balance depends on the transfer times of carbon through the different reservoirs, and takes place over a multitude of time scales. Carbon is first exchanged among the 'fast' carbon reservoirs, such as the atmosphere, surface ocean, land vegetation and soils, over time scales up to a few thousand years. Over longer time scales, very slow secondary geological processes-dissolution of carbonate sediments and sediment burial into the Earth's crust-become important.

FAQ 6.2, Figure 2 illustrates the decay of a large excess amount of $\mathrm{CO}_{2}$ (5000 PgC, or about 10 times the cumulative $\mathrm{CO}_{2}$ emitted so far since the beginning of the industrial Era) emitted into the atmosphere, and how it is redistributed among land and the ocean over time. During the first 200 years, the ocean and land take up similar amounts of carbon. On longer time scales, the ocean uptake dominates mainly because of its larger reservoir size $(\sim 38,000$ $\mathrm{PgC})$ as compared to land ( $4000 \mathrm{PgC})$ and atmosphere (589 PgC prior to the Industrial Era). Because of ocean chemistry the size of the initial input is important: higher emissions imply that a larger fraction of $\mathrm{CO}_{2}$ will remain in the atmosphere. After 2000 years, the atmosphere will still contain between $15 \%$ and $40 \%$ of those initial $\mathrm{CO}_{2}$ emissions. A further reduction by carbonate sediment dissolution, and reactions with igneous rocks, such as silicate weathering and sediment burial, will take anything from tens to hundreds of thousands of years, or even longer.

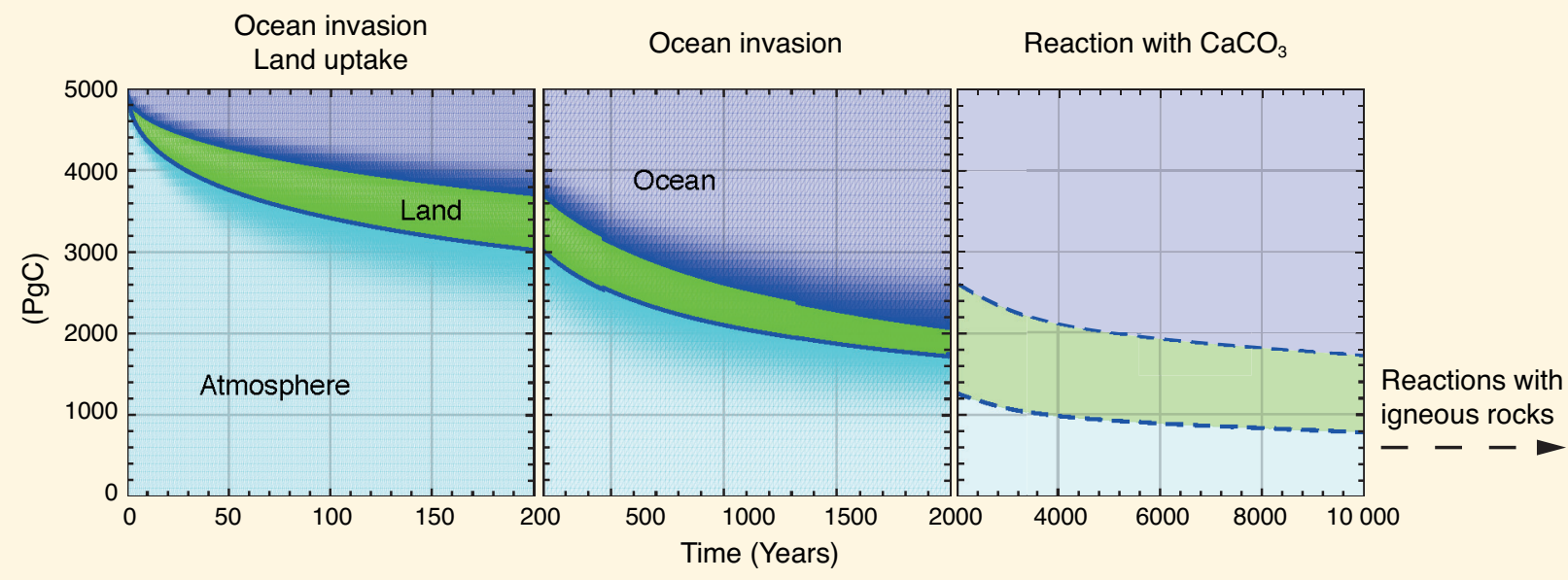

FAQ 6.2, Figure 2 | Decay of a $\mathrm{CO}_{2}$ excess amount of $5000 \mathrm{PgC}$ emitted at time zero into the atmosphere, and its subsequent redistribution into land and ocean as a function of time, computed by coupled carbon-cycle climate models. The sizes of the colour bands indicate the carbon uptake by the respective reservoir. The first two panels show the multi-model mean from a model intercomparison project (Joos et al., 2013). The last panel shows the longer term redistribution including ocean dissolution of carbonaceous sediments as computed with an Earth System Model of Intermediate Complexity (after Archer et al., 2009b). 
Increases in fire disturbance or insect damage may drive loss of forest in temperate regions (Kurz et al., 2008c), but this process is poorly represented or not accounted at all in models. Recent evidence from models (Huntingford et al., 2013) and studies on climate variability (Cox et al., 2013) suggests that large scale loss of tropical forest as previously projected in some models (Cox et al., 2004; Scholze et al., 2006) is unlikely, but depends strongly on the predicted future changes in regional temperature (Galbraith et al., 2010) and precipitation (Good et al., 2011, 2013), although both models here simulate reduced tree cover and carbon storage for the RCP8.5 scenario. ESMs also poorly simulate resilience of ecosystems to climate changes and usually do not account for possible existence of alternative ecosystem states such as tropical forest or savannah (Hirota et al., 2011).

Regional specific changes in ecosystem composition and carbon storage are uncertain but it is very likely that ecosystems will continue to change for decades to centuries following stabilisation of GHGs and climate change.

\subsection{Potential Effects of Carbon Dioxide Removal Methods and Solar Radiation Management on the Carbon Cycle}

\subsubsection{Introduction to Carbon Dioxide Removal Methods}

To slow or perhaps reverse projected increases in atmospheric $\mathrm{CO}_{2}$ (Section 6.4), several methods have been proposed to increase the removal of atmospheric $\mathrm{CO}_{2}$ and enhance the storage of carbon in land, ocean and geological reservoirs. These methods are categorized as 'Carbon Dioxide Removal (CDR)' methods (see Glossary). Another class of methods involves the intentional manipulation of planetary solar absorption to counter climate change, and is called the 'Solar Radiation Management (SRM)' (discussed in Chapter 7, Section 7.7; see Glossary). In this section, CDR methods are discussed from the aspect of the carbon cycle processes (Section 6.5.2) and their impacts and side effects on carbon cycle and climate (Section 6.5.3). A brief discussion on the indirect carbon cycle effects of SRM methods is given in Section 6.5.4. Most of the currently proposed CDR methods are summarized in Table 6.14 and some are illustrated schematically in Chapter 7 (Section 7.7; FAQ 7.3 Figure 1). Since some CDR methods might operate on large spatial scales they are also called 'Geoengineering' proposals (Keith, 2001). Removal of $\mathrm{CH}_{4}$ and $\mathrm{N}_{2} \mathrm{O}$ has also been proposed to reduce climate change (Stolaroff et al., 2012). While the science of geoengineering methods is assessed in this section (CDR) and Chapter 7 (SRM), the benefits and risks of SRM are planned to be assessed in Chapter 19 of AR5 WGII report. Further, Chapter 6 of AR5 WGIII report plans to assess the cost and socioeconomic implications of some CDR and SRM methods for climate stabilization pathways.

Large-scale industrial methods such as carbon capture and storage (CCS), biofuel energy production (without CCS) and reducing emissions from deforestation and degradation (REDD) cannot be called CDR methods since they reduce fossil fuel use or land use change $\mathrm{CO}_{2}$ emissions to the atmosphere but they do not involve a net removal of $\mathrm{CO}_{2}$ that is already in the atmosphere. However, direct air capture of $\mathrm{CO}_{2}$ using industrial methods (Table 6.14; and FAQ 7.3 Figure 1) will remove $\mathrm{CO}_{2}$ from the atmosphere and is thus considered as a $\mathrm{CDR}$ method. The distinction between CDR and mitigation (see Glossary) is not clear and there could be some overlap between the two.

Insofar as the CDR-removed $\mathrm{CO}_{2}$ is sequestered in a permanent reservoir, CDR methods could potentially reduce direct consequences of high $\mathrm{CO}_{2}$ levels, including ocean acidification (see Section 6.4.4) (Matthews et al., 2009). However, the effects of CDR methods that propose to manipulate carbon cycle processes are slow (see Box 6.1) and hence the consequent climate effects would be slow. The climate system has a less than 5 -years relaxation (e-folding) time scale for an assumed instantaneous reduction in radiative forcing to preindustrial levels (Held et al., 2010). While the climate effect of SRM could be rapid (Shepherd et al., 2009) given this time scale, at present, there is no known CDR method, including industrial direct air capture that can feasibly reduce atmospheric $\mathrm{CO}_{2}$ to pre-industrial levels within a similar time scale. Therefore, CDR methods do not present an option for rapidly preventing climate change when compared to SRM. It is likely that CDR would have to be deployed at large-scale for at least one century to be able to significantly reduce atmospheric $\mathrm{CO}_{2}$.

Important carbon cycle science considerations for evaluating CDR methods include the associated carbon storage capacity, the permanence of carbon storage and potential adverse side effects (Shepherd et al., 2009). Geological reservoirs could store several thousand $\mathrm{PgC}$ and the ocean may be able to store a few thousand $\mathrm{PgC}$ of anthropogenic carbon in the long-term (Metz et al., 2005; House et al., 2006; Orr, 2009) (see Box 6.1 and Archer et al., 2009b). The terrestrial biosphere may have a typical potential to store carbon equivalent to the cumulative historical land use loss of $180 \pm 80 \mathrm{PgC}$ (Table 6.1; Section 6.5.2.1).

In this assessment, we use "permanence" to refer to time scales larger than tens of thousands of years. CDR methods associated with either permanent or non-permanent carbon sequestration (see Table 6.14) have very different climate implications (Kirschbaum, 2003). Permanent sequestration methods have the potential to reduce the radiative forcing of $\mathrm{CO}_{2}$ over time. By contrast, non-permanent sequestration methods will release back the temporarily sequestered carbon as $\mathrm{CO}_{2}$ to the atmosphere, after some delayed time interval (Herzog et al., 2003). As a consequence, elevated levels of atmospheric $\mathrm{CO}_{2}$ and climate warming will only be delayed and not avoided by the implementation of non-permanent CDR methods (Figure 6.39). Nevertheless, $\mathrm{CDR}$ methods that could create a temporary $\mathrm{CO}_{2}$ removal (Table 6.14) may still have value (Dornburg and Marland, 2008) by reducing the cumulative impact of higher temperature.

Another important carbon cycle consequence of CDR methods is the 'rebound effect' (see Glossary). In the Industrial Era (since 1750) about half of the $\mathrm{CO}_{2}$ emitted into the atmosphere from fossil fuel emissions has been taken up by land and ocean carbon reservoirs (see Section 6.3 and Table 6.1). As for current $\mathrm{CO}_{2}$ emissions and the consequent $\mathrm{CO}_{2}$ rise, which are currently opposed by uptake of $\mathrm{CO}_{2}$ by natural reservoirs, any removal of $\mathrm{CO}_{2}$ from the atmosphere by $\mathrm{CDR}$ will be opposed by release of $\mathrm{CO}_{2}$ from natural reservoirs (Figure 6.40). It is thus virtually certain that the removal of $\mathrm{CO}_{2}$ by $\mathrm{CDR}$ will be partially offset by outgassing of $\mathrm{CO}_{2}$ from the ocean and land ecosystems. Therefore, return- 
Table 6.14 | Examples of CDR methods and their implications for carbon cycle and climate. The list is non-exhaustive. A 'rebound' effect and a thermal inertia of climate system are associated with all CDR methods.

\begin{tabular}{|c|c|c|c|c|c|}
\hline $\begin{array}{l}\text { Carbon Cycle } \\
\text { Process to } \\
\text { be Modified } \\
\text { Intentionally }\end{array}$ & CDR Method Name & $\begin{array}{l}\text { Nature of } \\
\text { CDR Removal } \\
\text { Process }\end{array}$ & Storage Location & Storage Form & $\begin{array}{l}\text { Some Carbon Cycle and } \\
\text { Climate Implications }\end{array}$ \\
\hline $\begin{array}{l}\text { Enhanced biological } \\
\text { production and } \\
\text { storage in ocean }\end{array}$ & $\begin{array}{l}\text { Ocean iron fertilisationk } \\
\text { Algae farming and buriall } \\
\text { Blue carbon (mangrove, kelp farming)m } \\
\text { Modifying ocean upwelling to bring } \\
\text { nutrients from deep ocean to surface } \\
\text { ocean }^{n}\end{array}$ & Biological & Ocean & $\begin{array}{l}\mathrm{k,n} \text { Inorganic } \\
\mathrm{l,m} \text { Organic }\end{array}$ & $\begin{array}{l}{ }^{k} \text { May lead to expanded regions with } \\
\text { low oxygen concentration, increased } \\
\mathrm{N}_{2} \mathrm{O} \text { production, deep ocean acidi- } \\
\text { fication and disruptions to marine } \\
\text { ecosystems and regional carbon cycle } \\
\text { "Disruptions to regional carbon cycle }\end{array}$ \\
\hline $\begin{array}{l}\text { Accelerated } \\
\text { weathering }\end{array}$ & $\begin{array}{l}\text { Enhanced weathering over land }{ }^{\circ} \\
\text { Enhanced weathering over ocean }\end{array}$ & Chemical & $\begin{array}{l}\text { ¿Soils and oceans } \\
\text { POcean }\end{array}$ & $0, p \mid$ Inorganic & $\begin{array}{l}\text { oPermanent removal; likely to change } \\
\text { pH of soils, rivers, and ocean } \\
\text { PPermanent removal; likely } \\
\text { to change pH of ocean }\end{array}$ \\
\hline Others & Direct-air capture with storage & Chemical & Ocean/geological formations & Inorganic & $\begin{array}{l}\text { Permanent removal if stored } \\
\text { in geological reservoirs }\end{array}$ \\
\hline
\end{tabular}

Notes

Superscripts in column 2 refer to the corresponding superscripts in columns 4,5 and 6 of the same row.

ing to pre-industrial $\mathrm{CO}_{2}$ levels would require permanently sequestering an amount of carbon equal to total anthropogenic $\mathrm{CO}_{2}$ emissions that have been released before the time of $C D R$, roughly twice as much the excess of atmospheric $\mathrm{CO}_{2}$ above pre-industrial level (Lenton and Vaughan, 2009; Cao and Caldeira, 2010b; Matthews, 2010).

\subsubsection{Carbon Cycle Processes Involved in Carbon Dioxide Removal Methods}

The CDR methods listed in Table 6.14 rely primarily on human management of carbon cycle processes to remove $\mathrm{CO}_{2}$ : (1) enhanced net biological uptake and subsequent sequestration by land ecosystems, (2) enhanced biological production in ocean and subsequent sequestration in the ocean and (3) accelerated chemical weathering reactions over land and ocean. The exceptional CDR method is industrial direct air capture of $\mathrm{CO}_{2}$, for example, relying on chemistry methods. $\mathrm{CO}_{2}$ removed by CDR is expected to be stored in organic form on land and in inorganic form in ocean and geological reservoirs (Table 6.14). This management of the carbon cycle however has other implications on ecosystems and biogeochemical cycles. The principle of different CDR methods listed in Table 6.14 is described below and the characteristics of some CDR methods are summarized in Table 6.15.

Some of the RCP scenarios used as a basis for future projections in this Assessment Report already include some CDR methods. To achieve the RCP2.6 $\mathrm{CO}_{2}$ peak and decline the IMAGE integrated assessment model simulates widespread implementation of BECCS technology to achieve globally negative emissions after around 2080 (see Section 6.4.3). RCP4.5 also assumes some use of BECCS to stabilise $\mathrm{CO}_{2}$ concentration by 2100 . Therefore it should be noted that potentials for CDR assessed in this section cannot be seen as additional potential for $\mathrm{CO}_{2}$ removal from the low $\mathrm{RCPs}$ as this is already included in those scenarios.

\subsubsection{Enhanced Carbon Sequestration by Land Ecosystems}

The key driver of these CDR methods is net primary productivity on land that currently produces biomass at a rate of approximately 50 to $60 \mathrm{PgC} \mathrm{yr}^{-1}$ (Nemani et al., 2003). The principle of these CDR methods is to increase net primary productivity and/or store a larger fraction of the biomass produced into ecosystem carbon pools with long turnover times, for example, under the form of wood or refractory organic matter in soils (Table 6.14). One variant is to harvest biomass for energy production and sequester the emitted $\mathrm{CO}_{2}$ (BECCS). BECCS technology has not been tested at industrial scale, but is commonly included in Integrated Assessment Models and future scenarios that aim to achieve low $\mathrm{CO}_{2}$ concentrations.

Estimates of the global potential for enhanced primary productivity over land are uncertain because the potential of any specific method will be severely constrained by competing land needs (e.g., agriculture, biofuels, urbanization and conservation) and sociocultural considerations. An order of magnitude of the upper potential of afforestation/ reforestation would be the restoration of all the carbon released by 


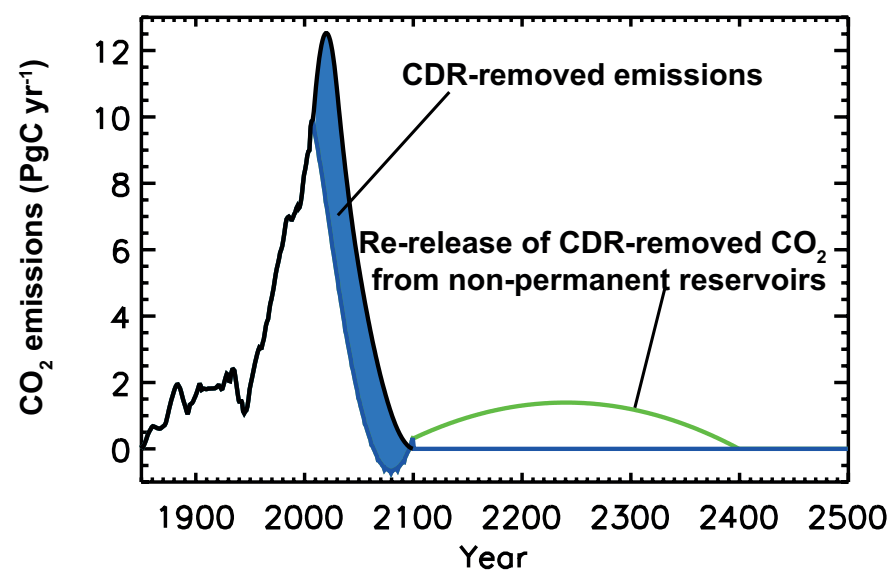

historical land use (180 $\pm 80 \mathrm{PgC}$; Table 6.1; Section 6.3.2.2). House et al. (2002) estimated that the atmospheric $\mathrm{CO}_{2}$ concentration by 2100 would be lowered by only about 40 to $70 \mathrm{ppm}$ in that scenario (accounting for the 'rebound' effect).

The capacity for enhancing the soil carbon content on agricultural and degraded lands was estimated by one study at 50 to $60 \%$ of the historical soil carbon released, that is 42 to $78 \mathrm{PgC}$ (Lal, 2004a). The proposed agricultural practices are the adoption of conservation tillage with cover crops and crop residue mulch, conversion of marginal lands into restorative land uses and nutrient cycling including the use of
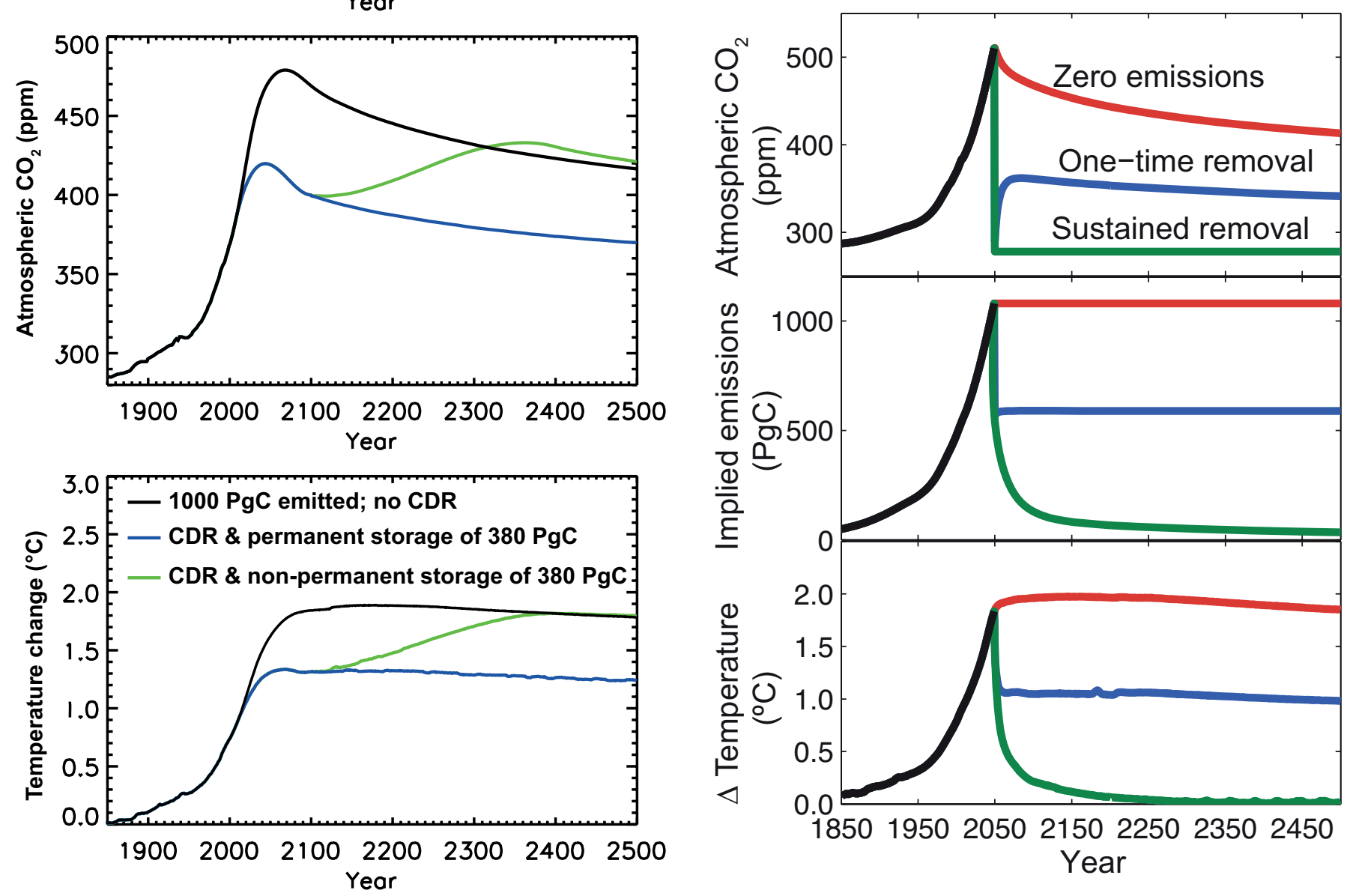

Figure 6.39 | Idealised model simulations (Matthews, 2010) to illustrate the effects of CDR methods associated with either permanent or non-permanent carbon sequestration. There is an emission of $1000 \mathrm{PgC}$ in the reference case (black line) between 1800 and 2100, corresponding approximately to RCP4.5 scenario (Section 6.4). Permanent sequestration of $380 \mathrm{PgC}$, assuming no leakage of sequestered carbon would reduce climate change (blue line, compared to black line). By contrast, a non-permanent sequestration CDR method where carbon will be sequestered and later on returned to the atmosphere in three centuries would not. In this idealised non-permanent sequestration example scenario, climate change would only be delayed but the eventual magnitude of climate change will be equivalent to the no-sequestration case (green line, compared to black). Figure adapted from Figure 5 of Matthews (2010).

Figure 6.40 | Idealised simulations with a simple global carbon cycle model (Cao and Caldeira, 2010b) to illustrate the 'rebound effect'. Effects of an instantaneous cessation of $\mathrm{CO}_{2}$ emissions in the year 2050 (amber line), one-time removal of the excess of atmospheric $\mathrm{CO}_{2}$ over pre-industrial levels (blue line) and removal of this excess of atmospheric $\mathrm{CO}_{2}$ followed by continued removal of all the $\mathrm{CO}_{2}$ that degasses from the ocean (green line) are shown. For the years 1850-2010 observed atmospheric $\mathrm{CO}_{2}$ concentrations are prescribed and $\mathrm{CO}_{2}$ emissions are calculated from $\mathrm{CO}_{2}$ concentrations and modeled carbon uptake. For the years 2011-2049, $\mathrm{CO}_{2}$ emissions are prescribed following the SRES A2 scenario. Starting from year 2050, $\mathrm{CO}_{2}$ emission is either set to zero or calculated from modeled $\mathrm{CO}_{2}$ concentrations and $\mathrm{CO}_{2}$ uptake. To a first approximation, a cessation of emissions would prevent further warming but would not lead to significant cooling on the century time scale. A one-time removal of excess atmospheric $\mathrm{CO}_{2}$ would eliminate approximately only half of the warming experienced at the time of the removal because of $\mathrm{CO}_{2}$ that outgases from the ocean (the rebound effect). To bring atmospheric $\mathrm{CO}_{2}$ back to pre-industrial levels permanently, would require the removal of all previously emitted $\mathrm{CO}_{2}$, that is, an amount equivalent to approximately twice the excess atmospheric $\mathrm{CO}_{2}$ above pre-industrial level. (Figure adapted from Cao and Caldeira, 2010b.) 
Table 6.15 | Characteristics of some CDR methods from peer-reviewed literature. Note that a variety of economic, environmental, and other constraints could also limit their implementation and net potential.

\begin{tabular}{|c|c|c|c|c|c|c|}
\hline $\begin{array}{l}\text { Carbon Dioxide } \\
\text { Removal Method }\end{array}$ & $\begin{array}{l}\text { Means of } \\
\text { Removing } \\
\mathrm{CO}_{2} \text { from } \\
\text { Atmosphere }\end{array}$ & $\begin{array}{l}\text { Carbon } \\
\text { Storage / } \\
\text { Form }\end{array}$ & $\begin{array}{l}\text { Time Scale of } \\
\text { Carbon Storage }\end{array}$ & $\begin{array}{l}\text { Physical Potential } \\
\text { of } \mathrm{CO}_{2} \text { Removed } \\
\text { in a Century }\end{array}$ & Reference & Unintended Side Effects \\
\hline $\begin{array}{l}\text { Biochar creation and } \\
\text { storage in soils }\end{array}$ & Biological & Land /organic & Decades to centuries & $130 \mathrm{PgC}$ & Woolf et al. (2010) & Same as above \\
\hline $\begin{array}{l}\text { Ocean-enhanced } \\
\text { upwelling bringing } \\
\text { more nutrients to } \\
\text { surface waters }\end{array}$ & Biological & $\begin{array}{l}\text { Ocean / } \\
\text { inorganic }\end{array}$ & Centuries to millennia & $\begin{array}{l}90 \mathrm{PgC} \\
1-2 \mathrm{PgC}\end{array}$ & $\begin{array}{l}\text { Oschlies et al. (2010a); } \\
\text { Lenton and Vaughan } \\
\text { (2009), Zhou and } \\
\text { Flynn (2005) }\end{array}$ & $\begin{array}{l}\text { Likely to cause changes to regional } \\
\text { ocean carbon cycle opposing } \mathrm{CO}_{2} \\
\text { removal, e.g., compensatory } \\
\text { downwelling in other regions }\end{array}$ \\
\hline $\begin{array}{l}\text { Land-based increased } \\
\text { weathering }\end{array}$ & Geochemical & $\begin{array}{l}\text { Ocean (and } \\
\text { some soils) / } \\
\text { inorganic }\end{array}$ & $\begin{array}{l}\text { Centuries to mil- } \\
\text { lennia for carbon- } \\
\text { ates, permanent for } \\
\text { silicate weathering }\end{array}$ & $\begin{array}{l}\text { No determined limit } \\
100 \mathrm{PgC}\end{array}$ & $\begin{array}{l}\text { Kelemen and Matter } \\
\text { (2008), Schuiling and } \\
\text { Krijgsman (2006) } \\
\text { Köhler et al. (2010) }\end{array}$ & $\begin{array}{l}\text { pH of soils and rivers will increase } \\
\text { locally, effects on terrestrial/ } \\
\text { freshwater ecosystems }\end{array}$ \\
\hline $\begin{array}{l}\text { Ocean-based } \\
\text { increased weathering }\end{array}$ & Geochemical & $\begin{array}{l}\text { Ocean / } \\
\text { inorganic }\end{array}$ & $\begin{array}{l}\text { Centuries to mil- } \\
\text { lennia for carbon- } \\
\text { ates, permanent for } \\
\text { silicate weathering }\end{array}$ & No determined limit & $\begin{array}{l}\text { Rau (2008), } \\
\text { Kheshgi (1995) }\end{array}$ & $\begin{array}{l}\text { Increased alkalinity effects } \\
\text { on marine ecosystems }\end{array}$ \\
\hline
\end{tabular}

Notes:

a Physical potential does not account for economic or environmental constraints of CDR methods; for example, the value of the physical potential for afforestation and reforestation does not consider the conflicts with land needed for agricultural production. Potentials for BECCS and biochar are highly speculative.

b If $2.5 \mathrm{tC} \mathrm{yr}^{-1}$ per hectare can be harvested on a sustainable basis (Kraxner et al., 2003) on about $4 \%$ ( 500 million hectares, about one tenth of global agricultural land area) of global land (13.4 billion hectares) for BECCS, approximately $1.25 \mathrm{PgC} \mathrm{yr}{ }^{-1}$ could be removed or about $125 \mathrm{PgC}$ in this century. Future $\mathrm{CO}_{2}$ concentration pathways, especially RCP2.6 and RCP4.5 include some $\mathrm{CO}_{2}$ removal by BECCS (Chapter 6 of AR5 WGIII) and hence the potentials estimated here cannot add on to existing model results (Section 6.4).

compost and manure. Recent estimates suggest a cumulative potential of 30 to $60 \mathrm{PgC}$ of additional storage over 25 to 50 years (Lal, 2004b).

Finally, biochar and biomass burial methods aim to store organic carbon into very long turnover time ecosystem carbon pools. The maximum sustainable technical potential of biochar cumulative sequestration is estimated at $130 \mathrm{PgC}$ over a century by one study (Woolf et al., 2010). The residence time of carbon converted to biochar and the additional effect of biochar on soil productivity are uncertain, and further research is required to assess the potential of this method (Shepherd et al., 2009).

\subsubsection{Enhanced Carbon Sequestration in the Ocean}

The principle here is to enhance the primary productivity of phytoplankton (biological pump; Section 6.1.1) so that a fraction of the extra organic carbon produced gets transported to the deep ocean. Some of the inorganic carbon in the surface ocean that is removed by the export of net primary productivity below the surface layer will be subsequently replaced by $\mathrm{CO}_{2}$ pumped from the atmosphere, thus removing atmospheric $\mathrm{CO}_{2}$. Ocean primary productivity is limited by nutrients (e.g., iron, nitrogen and phosphorus). Enhanced biological production in ocean CDR methods (Table 6.14) is obtained by adding nutrients that would otherwise be limiting (Martin, 1990). The expected increase in the downward flux of carbon can be partly sequestered as Dissolved Inorganic Carbon (DIC) after mineralization in the intermediate and deep waters. In other ocean-based CDR methods, algae and kelp farming and burial, carbon would be stored in organic form.

The effectiveness of ocean CDR through iron addition depends on the resulting increase of productivity and the fraction of this extra carbon exported to deep and intermediate waters, and its fate. Small-scale 
$\left(\sim 10 \mathrm{~km}^{2}\right)$ experiments (Boyd et al., 2007) have shown only limited transient effects of iron addition in removing atmospheric $\mathrm{CO}_{2}$. An increased productivity was indeed observed, but this effect was moderated either by other limiting elements, or by compensatory respiration from increased zooplankton grazing. Most of the carbon produced by primary productivity is oxidized (remineralized into DIC) in the surface layer, so that only a small fraction is exported to the intermediate and deep ocean (Lampitt et al., 2008) although some studies indicate little remineralization in the surface layer (Jacquet et al., 2008). A recent study (Smetacek et al., 2012) finds that at least half the extra carbon in plankton biomass generated by artificial iron addition sank far below a depth of $1000 \mathrm{~m}$, and that a substantial portion is likely to have reached the sea floor. There are some indications that sustained natural iron fertilisation may have a higher efficiency in exporting carbon from surface to intermediate and deep ocean than short term blooms induced by artificial addition of iron (Buesseler et al., 2004; Blain et al., 2007; Pollard et al., 2009). Thus, there is no consensus on the efficiency of iron fertilisation from available field experiments.

Using ocean carbon models (see Section 6.3.2.5.6), the maximum drawdown of atmospheric $\mathrm{CO}_{2}$ have been estimated from $15 \mathrm{ppm}$ (Zeebe and Archer, 2005) to 33 ppm (Aumont and Bopp, 2006) for an idealised continuous (over 100 years) global ocean iron fertilisation, which is technically unrealistic. In other idealised simulations of ocean fertilisation in the global ocean or only in the Southern Ocean (Joos et al., 1991; Peng and Broecker, 1991; Watson et al., 1994; Cao and Caldeira, 2010a), atmospheric $\mathrm{CO}_{2}$ was reduced by less than $100 \mathrm{ppm}$ for ideal conditions. Jin and Gruber (2003) obtained an atmospheric drawdown of more than $60 \mathrm{ppm}$ over 100 years from an idealised iron fertilisation scenario over the entire Southern Ocean. The radiative benefit from lower $\mathrm{CO}_{2}$ could be offset by a few percent to more than $100 \%$ from an increase in $\mathrm{N}_{2} \mathrm{O}$ emissions (Jin and Gruber, 2003). All the above estimates of maximum potential $\mathrm{CO}_{2}$ removal account for the rebound effect from oceans but not from the land (thus overestimate the atmospheric $\mathrm{CO}_{2}$ reduction).

One ocean CDR variant is to artificially supply more nutrients to the surface ocean in upwelling areas (Lovelock and Rapley, 2007; Karl and Letelier). The amount of carbon sequestered by these enhanced upwelling methods critically depends on their location (Yool et al., 2009). Idealised simulations suggest an atmospheric $\mathrm{CO}_{2}$ removal at a net rate of about $0.9 \mathrm{PgC} \mathrm{yr}^{-1}$ (Oschlies et al., 2010b). This oceanbased CDR method has not been tested in the field, unlike iron addition experiments.

\subsubsection{Accelerated Weathering}

The removal of $\mathrm{CO}_{2}$ by the weathering of silicate and carbonate minerals (Berner et al., 1983; Archer et al., 2009b) occurs on time scales from thousands to tens of thousands of years (see Box 6.1) and at a rate of $\sim 0.3 \mathrm{PgC} \mathrm{yr}^{-1}$ (Figure 6.1; Gaillardet et al., 1999; Hartmann et al., 2009). This rate is currently much too small to offset the rate at which fossil fuel $\mathrm{CO}_{2}$ is being emitted (Section 6.3).

The principle of accelerated weathering CDR on land is to dissolve artificially silicate minerals so drawdown of atmospheric $\mathrm{CO}_{2}$ and geochemical equilibrium restoration could proceed on a much faster (century) time scale. For instance, large amounts of silicate minerals such as olivine $\left(\left(\mathrm{Mg}, \mathrm{Fe}_{2} \mathrm{SiO}_{4}\right)\right.$ could be mined, crushed, transported to and distributed on agricultural lands, to remove atmospheric $\mathrm{CO}_{2}$ and form carbonate minerals in soils and/or bicarbonate ions that would be transported to the ocean by rivers (Schuiling and Krijgsman, 2006)I. Alternatively, $\mathrm{CO}_{2}$ removal by weathering reactions might be enhanced by exposing minerals such as basalt or olivine to elevated $\mathrm{CO}_{2}$, with potential $\mathrm{CO}_{2}$ removal rates exceeding $0.25 \mathrm{PgC} \mathrm{yr}^{-1}$ (Kelemen and Matter, 2008). In the idealised case where olivine could be spread as a fine powder over all the humid tropics, potential removal rates of up to $1 \mathrm{PgC} \mathrm{yr}^{-1}$ have been estimated, despite limitations by the saturation concentration of silicic acid (Köhler et al., 2010). For the United Kingdom, the potential from silicate resources was estimated to be more than 100 PgC (Renforth, 2012).

Fossil fuel $\mathrm{CO}_{2}$ released to the atmosphere leads to the addition of anthropogenic $\mathrm{CO}_{2}$ in the ocean (Section 6.3.2.5). This anthropogenic $\mathrm{CO}_{2}$ will eventually dissolve ocean floor carbonate sediments to reach geochemical equilibrium on a $10 \mathrm{kyr}$ time scale (Archer et al., 1997). The principle of ocean based weathering CDR methods is to accelerate this process. For instance, carbonate rocks could be crushed, reacted with $\mathrm{CO}_{2}$ (e.g., captured at power plants) to produce bicarbonate ions that would be released to the ocean (Rau and Caldeira, 1999; Caldeira and Rau, 2000; Rau, 2008). Alternatively, carbonate minerals could be directly released into the ocean (Kheshgi, 1995; Harvey, 2008). Strong bases, derived from silicate rocks, could also be released to ocean (House et al., 2007) to increase alkalinity and drawdown of atmospheric $\mathrm{CO}_{2}$. Carbonate minerals such as limestone could be heated to produce lime $\left(\mathrm{Ca}(\mathrm{OH})_{2}\right)$; this lime could be added to the ocean to increase alkalinity as well (Kheshgi, 1995). While the level of confidence is very high for the scientific understanding of weathering chemical reactions, it is low for its effects and risks at planetary scale (Section 6.5.3.3).

\subsubsection{Carbon Dioxide Removal by Direct Industrial Capture of Atmospheric Carbon Dioxide}

Direct Air Capture refers to the chemical process by which a pure $\mathrm{CO}_{2}$ stream is produced by capturing $\mathrm{CO}_{2}$ from ambient air. The captured $\mathrm{CO}_{2}$ could be sequestered in geological reservoirs or the deep ocean. At least three methods have been proposed to capture $\mathrm{CO}_{2}$ from the atmosphere: (1) adsorption on solids (Gray et al., 2008; Lackner, 2009, 2010; Lackner et al., 2012); (2) absorption into highly alkaline solutions (Stolaroff et al., 2008; Mahmoudkhani and Keith, 2009) and (3) absorption into moderate alkaline solution with a catalyst (Bao and Trachtenberg, 2006). The main limitation to direct air capture is the thermodynamic barrier due to the low concentration of $\mathrm{CO}_{2}$ in ambient air.

\subsubsection{Impacts of Carbon Dioxide Removal Methods on Carbon Cycle and Climate}

One impact common to all CDR methods is related to the thermal inertia of the climate system. Climate warming will indeed continue for at least decades after CDR is applied. Therefore, temperature (and climate change) will lag a CDR-induced decrease in atmospheric $\mathrm{CO}_{2}$ (Boucher et al., 2012). Modelling the impacts of CDR on climate change is still in its infancy. Some of the first studies (Wu et al., 2010; Cao et al., 2011) 
showed that the global hydrological cycle could intensify in response to a reduction in atmospheric $\mathrm{CO}_{2}$ concentrations.

\subsubsection{Impacts of Enhanced Land Carbon Sequestration}

In the case of land-based CDR, biomass in forests is a non-permanent ecosystem carbon pool and hence there is a risk that this carbon may return to the atmosphere, for example, by disturbances such as fire, or by future land use change. When considering afforestation/reforestation, it is also important to account for biophysical effects on climate that come together with carbon sequestration because afforestation/ reforestation changes the albedo (see Glossary), evapotranspiration and the roughness of the surface (Bonan, 2008; Bernier et al., 2011). Modelling studies show that afforestation in seasonally snow covered boreal and temperate regions will decrease the land surface albedo and have a net (biophysical plus biogeochemical) warming effect, whereas afforestation in low latitudes (Tropics) is likely to enhance latent heat flux from evapotranspiration and have a net cooling effect (Bonan et al., 1992; Betts, 2000; Bala et al., 2007; Montenegro et al., 2009; Bathiany et al., 2010). Consequently, the location of land ecosystem based CDR methods needs to be considered carefully when evaluating their effects on climate (Bala et al., 2007; Arora and Montenegro, 2011; Lee et al., 2011; Pongratz et al., 2011b). In addition CDR in land ecosystems is likely to increase $\mathrm{N}_{2} \mathrm{O}$ emissions (Li et al., 2005). Enhanced biomass production may also require more nutrients (fertilisers) which are associated with fossil fuel $\mathrm{CO}_{2}$ emission from industrial fertiliser production and $\mathrm{Nr}$ impacts. Biochar-based $\mathrm{CDR}$ could reduce $\mathrm{N}_{2} \mathrm{O}$ emissions but may increase $\mathrm{CO}_{2}$ and $\mathrm{CH}_{4}$ emissions from agricultural soils (Wang et al., 2012b). Addition of biochar could also promote a rapid loss of forest humus and soil carbon in some ecosystems during the first decades (Wardle et al., 2008).

\subsubsection{Impacts of Enhanced Carbon Sequestration in the Ocean}

In the case of ocean-based CDR using fertilisation, adding macronutrients such as nitrogen and phosphate in the fertilised region could lead to a decrease in production 'downstream' of the fertilised region (Gnanadesikan et al., 2003; Gnanadesikan and Marinov, 2008; Watson et al., 2008). Gnanadesikan et al. (2003) simulated a decline in export production of $30 \mathrm{tC}$ for every ton removed from the atmosphere. A sustained global-ocean iron fertilisation for SRES A2 $\mathrm{CO}_{2}$ emission scenario was also found to acidify the deep ocean ( $\mathrm{pH}$ decrease of about 0.1 to 0.2 ) while mitigating surface $\mathrm{pH}$ change by only 0.06 (Cao and Caldeira, 2010a). Other environmental risks associated with ocean fertilisation include expanded regions with low oxygen concentration (Oschlies et al., 2010a), increased $\mathrm{N}_{2} \mathrm{O}$ emission (Jin and Gruber, 2003), increased production of dimethylsulphide (DMS), isoprene, $\mathrm{CO}, \mathrm{N}_{2} \mathrm{O}$, $\mathrm{CH}_{4}$ and other non- $\mathrm{CO}_{2} \mathrm{GHGs}$ (Oschlies et al., 2010a) and possible disruptions to marine ecosystems (Denman, 2008).

In the case of enhanced ocean upwelling CDR methods there could be disturbance to the regional carbon balances, since the extra-upwelling will be balanced by extra-downwelling at another location. Along with growth-supporting nutrients, enhanced concentrations of DIC will also be brought to surface waters and partially offset the removal of $\mathrm{CO}_{2}$ by increased biological pump. Further, in case artificially enhanced upwelling would be stopped, atmospheric $\mathrm{CO}_{2}$ concentrations could rise rapidly because carbon removed from the atmosphere and stored in soils in the cooler climate caused by artificial upwelling could be rapidly released back (Oschlies et al., 2010b). The level of confidence on the impacts of the enhanced upwelling is low.

\subsubsection{Impact of Enhanced Weathering}

In the case of weathering-based $\mathrm{CDR}$, the $\mathrm{pH}$ and carbonate mineral saturation of soils, rivers and ocean surface waters will increase where CDR is implemented. Köhler et al. (2010) simulated that the pH of the Amazon river would rise by 2.5 units if the dissolution of olivine in the entire Amazon basin was used to remove $0.5 \mathrm{PgC} \mathrm{yr}^{-1}$ from the atmosphere. In the marine environment, elevated $\mathrm{pH}$ and increased alkalinity could potentially counteract the effects of ocean acidification, which is beneficial. Changes in alkalinity could also modify existing ecosystems. There is uncertainty in our understanding of the net effect on ocean $\mathrm{CO}_{2}$ uptake but there will be a partial offset of the abiotic effect by calcifying species. As for other CDR methods, the confidence level on the carbon cycle impacts of enhanced weathering is low.

\subsubsection{Impacts of Solar Radiation Management on the Carbon Cycle}

Solar radiation management (SRM) methods aim to reduce incoming solar radiation at the surface (discussed in Section 7.7 and in AR5, WG2, Chapter 19). Balancing reduced outgoing radiation by reduced incoming radiation may be able to cool global mean temperature but may lead to a less intense global hydrological cycle (Bala et al., 2008) with regionally different climate impacts (Govindasamy et al., 2003; Matthews and Caldeira, 2007; Robock et al., 2008; Irvine et al., 2010; Ricke et al., 2010). Therefore, SRM will not prevent the effects of climate change on the carbon and other biogeochemical cycles.

SRM could reduce climate warming but will not interfere with the direct biogeochemical effects of elevated $\mathrm{CO}_{2}$ on the carbon cycle. For example, ocean acidification caused by elevated $\mathrm{CO}_{2}$ (Section 6.4.4) and the $\mathrm{CO}_{2}$ fertilisation of productivity (Box 6.3) will not be altered by SRM (Govindasamy et al., 2002; Naik et al., 2003; Matthews and Caldeira, 2007). Similarly, SRM will not interfere with the stomatal response of plants to elevated $\mathrm{CO}_{2}$ (the $\mathrm{CO}_{2}$-physiological effect) that leads to a decline in evapotranspiration, causing land temperatures to warm and runoff to increase (Gedney et al., 2006; Betts et al., 2007; Matthews and Caldeira, 2007; Piao et al., 2007; Cao et al., 2010; Fyfe et al., 2013).

However, due to carbon-climate feedbacks (Section 6.4), the implementation of SRM could affect the carbon cycle. For instance, carbon uptake by land and ocean could increase in response to SRM by reducing the negative effects of climate change on carbon sinks (Matthews and Caldeira, 2007). For instance, for the SRES A2 scenario with SRM, a lower $\mathrm{CO}_{2}$ concentration of $110 \mathrm{ppm}$ by year 2100 relative to a baseline case without SRM has been simulated by Matthews and Caldeira (2007). Land carbon sinks may be enhanced by increasing the amount of diffuse relative to direct radiation (Mercado et al., 2009) if SRM causes the fraction of diffuse light to increase (e.g., injection of aerosols into the stratosphere). However, reduction of total incoming solar radiation could decrease terrestrial $\mathrm{CO}_{2}$ sinks as well. 


\subsubsection{Synthesis}

CDR methods are intentional large scale methods to remove atmospheric $\mathrm{CO}_{2}$ either by managing the carbon cycle or by direct industrial processes (Table 6.14). In contrast to SRM methods, CDR methods that manage the carbon cycle are unlikely to present an option for rapidly preventing climate change. The maximum (idealised) potential for atmospheric $\mathrm{CO}_{2}$ removal by individual $\mathrm{CDR}$ methods is compiled in Table 6.15. In this compilation, note that unrealistic assumptions about the scale of deployment, such as fertilising the entire global ocean, are used, and hence large potentials are simulated. The 'rebound effect' in the natural carbon cycle is likely to diminish the effectiveness of all the CDR methods (Figure 6.40). The level of confidence on the effects of both CDR and SRM methods on carbon and other biogeochemical cycles is very low.

\section{Acknowledgements}

We wish to acknowledge Anna Peregon (LSCE, France) for investing countless hours compiling and coordinating input from all of the Chapter 6 Lead Authors. She was involved in the production of every aspect of the chapter and we could not have completed our task on time without her help. We also thank Brett Hopwood (ORNL, USA) for skilful and artistic edits of several graphical figures representing the global biogeochemical cycles in the Chapter 6 Introduction. We also thank Silvana Schott (Max Planck Institute for Biogeochemistry, Germany) for graphics artwork for several of the figures in Chapter 6. 


\section{References}

Achard, F., H. D. Eva, P. Mayaux, H.-J. Stibig, and A. Belward, 2004: Improved estimates of net carbon emissions from land cover change in the tropics for the 1990s. Global Biogeochem. Cycles, 18, GB2008.

Adair, E. C., P. B. Reich, S. E. Hobbie, and J. M. H. Knops, 2009: Interactive effects of time, $\mathrm{CO}_{2}, \mathrm{~N}$, and diversity on total belowground carbon allocation and ecosystem carbon storage in a grassland community. Ecosystems, 12, 10371052.

Adkins, J. F., K. McIntyre, and D. P. Schrag, 2002: The salinity, temperature and $0^{180} 0$ of the glacial deep ocean. Science, 298, 1769-1773.

Ahn, J. and E. J. Brook, 2008: Atmospheric $\mathrm{CO}_{2}$ and climate on millennial time scales during the last glacial period. Science, 322, 83-85.

Ahn, J., et al., 2012: Atmospheric $\mathrm{CO}_{2}$ over the last 1000 years: A high resolution record from the West Antarctic Ice Sheet (WAIS) Divide ice core. Global Biogeochem. Cycles, 26, GB2027.

Ainsworth, E. A. and S. P. Long, 2004: What have we learned from 15 years of free-air $\mathrm{CO}_{2}$ enrichment (FACE)? A meta-analytic review of the responses of photosynthesis, canopy properties and plant production to rising $\mathrm{CO}_{2}$. New Phytologist, 165, 351-372.

Ainsworth, E. A., C. R. Yendrek, S. Sitch, W. J. Collins, and L. D. Emberson, 2012: The effects of tropospheric ozone on net primary productivity and implications for climate change. Annu. Rev. Plant Biol., 63, 637-661.

Allan, W., H. Struthers, and D. C. Lowe, 2007: Methane carbon isotope effects caused by atomic chlorine in the marine boundary layer: Global model results compared with Southern Hemisphere measurements. J. Geophys. Res. Atmos., 112, D04306.

Amiro, B. D., A. Cantin, M. D. Flannigan, and W. J. de Groot, 2009: Future emissions from Canadian boreal forest fires. Can. J. Forest Res., 39, 383-395.

Anderson, R. F., M. Q. Fleisher, Y. Lao, and G. Winckler, 2008: Modern $\mathrm{CaCO}_{3}$ preservation in equatorial Pacific sediments in the context of late-Pleistocene glacial cycles. Mar. Chem., 111, 30-46.

Andreae, M. O. and P. Merlet, 2001: Emission of trace gases and aerosols from biomass burning. Global Biogeochem. Cycles, 15, 955-966.

Andres, R. J., J. S. Gregg, L. Losey, G. Marland, and T. A. Boden, 2011: Monthly, global emissions of carbon dioxide from fossil fuel consumption. Tellus B, 63, 309-327.

Andres, R. J., et al., 2012: A synthesis of carbon dioxide emissions from fossil-fuel combustion. Biogeosciences, 9, 1845-1871.

Aranjuelo, I., et al., 2011: Maintenance of $C$ sinks sustains enhanced $C$ assimilation during long-term exposure to elevated $\left[\mathrm{CO}_{2}\right]$ in Mojave Desert shrubs. Oecologia, 167, 339-354.

Archer, D., 2007: Methane hydrate stability and anthropogenic climate change. Biogeosciences, 4, 521-544.

Archer, D. and E. Maier-Reimer, 1994: Effect of deep-sea sedimentary calcite preservation on atmospheric $\mathrm{CO}_{2}$ concentration. Nature, 367, 260-263.

Archer, D. and V. Brovkin, 2008: The millennial atmospheric lifetime of anthropogenic $\mathrm{CO}_{2}$. Clim. Change, 90, 283-297.

Archer, D., H. Kheshgi, and E. Maier-Reimer, 1997: Multiple timescales for neutralization of fossil fuel $\mathrm{CO}_{2}$. Geophys. Res. Lett., 24, 405-408.

Archer, D., H. Kheshgi, and E. Maier-Reimer, 1998: Dynamics of fossil fuel $\mathrm{CO}_{2}$ neutralization by marine $\mathrm{CaCO}_{3}$. Global Biogeochem. Cycles, 12, 259-276.

Archer, D., B. Buffett, and V. Brovkin, 2009a: Ocean methane hydrates as a slow tipping point in the global carbon cycle. Proc. Natl. Acad. Sci. U.S.A., 106, 2059620601.

Archer, D., A. Winguth, D. Lea, and N. Mahowald, 2000: What caused the glacial/ interglacial atmospheric $\mathrm{pCO}_{2}$ cycles? Rev. Geophys., 38, 159-189.

Archer, D., et al., 2009b: Atmospheric lifetime of fossil fuel carbon dioxide. Annu. Rev. Earth Planet. Sci., 37, 117-134.

Archer, D. E., P. A. Martin, J. Milovich, V. Brovkin, G.-K. Plattner, and C. Ashendel, 2003: Model sensitivity in the effect of Antarctic sea ice and stratification on atmospheric $\mathrm{pCO}_{2}$. Paleoceanography, 18, 1012.

Archibald, S., D. P. Roy, B. W. van Wilgen, and R. J. Scholes, 2009: What limits fire? An examination of drivers of burnt area in Southern Africa. Global Change Biol., $15,613-630$

Arneth, A., et al., 2010: Terrestrial biogeochemical feedbacks in the climate system. Nature Geosci., 3, 525-532.

Arora, V. K., and G. J. Boer, 2010: Uncertainties in the 20th century carbon budget associated with land use change. Global Change Biol., 16, 3327-3348.
Arora, V. K., and A. Montenegro, 2011: Small temperature benefits provided by realistic afforestation efforts. Nature Geosci., 4, 514-518.

Arora, V. K., et al., 2011: Carbon emission limits required to satisfy future representative concentration pathways of greenhouse gases. Geophys. Res. Lett., 38, L05805.

Arora, V. K., et al., 2013: Carbon-concentration and carbon-climate feedbacks in CMIP5 Earth system models. J. Clim., 26, 5289-5314.

Artioli, Y., et al., 2012: The carbonate system in the North Sea: Sensitivity and model validation. J. Mar. Syst., 102-104, 1-13.

Ashmore, M. R., 2005: Assessing the future global impacts of ozone on vegetation. Plant Cell Environ., 28, 949-964.

Assmann, K. M., M. Bentsen, J. Segschneider, and C. Heinze, 2010: An isopycnic ocean carbon cycle model. Geosci. Model Dev., 3, 143-167.

Aufdenkampe, A. K., et al., 2011: Rivering coupling of biogeochemical cycles between land, oceans and atmosphere. Front. Ecol. Environ., 9, 23-60.

Aumont, 0., and L. Bopp, 2006: Globalizing results from ocean in situ iron fertilization studies. Global Biogeochem. Cycles, 20, GB2017.

Avis, C. A., A. J. Weaver, and K. J. Meissner, 2011: Reduction in areal extent of highlatitude wetlands in response to permafrost thaw. Nature Geosci., 4, 444-448.

Ayres, R. U., W. H. Schlesinger, and R. H. Socolow, 1994: Human impacts on the carbon and nitrogen cycles.In: Industrial Ecology and Global Change [R. H. Socolow, C. Andrews, F. Berkhout and V. Thomas (eds.)]. Cambridge University Press, Cambridge, United Kingdom, and New York, NY, USA, pp. 121-155.

Bacastow, R. B., and C. D. Keeling, 1979: Models to predict future atmospheric $\mathrm{CO}_{2}$ concentrations. In: Workshop on the Global Effects of Carbon Dioxide from Fossil Fuels. United States Department of Energy, Washington, DC, pp. 72-90.

Baccini, A., et al., 2012: Estimated carbon dioxide emissions from tropical deforestation improved by carbon-density maps. Nature Clim. Change, 2, 182185.

Bader, M., E. Hiltbrunner, and C. Körner, 2009: Fine root responses of mature deciduous forest trees to free air carbon dioxide enrichment (FACE). Funct. Ecol., 23, 913-921.

Baker, A., S. Cumberland, and N. Hudson, 2008: Dissolved and total organic and inorganic carbon in some British rivers. Area, 40, 117-127.

Baker, D. F., et al., 2006: TransCom 3 inversion intercomparison: Impact of transport model errors on the interannual variability of regional $\mathrm{CO}_{2}$ fluxes, 1988-2003. Global Biogeochem. Cycles, 20, GB1002.

Bala, G., P. B. Duffy, and K. E. Taylor, 2008: Impact of geoengineering schemes on the global hydrological cycle. Proc. Natl. Acad. Sci. U.S.A., 105, 7664-7669.

Bala, G., K. Caldeira, M. Wickett, T. J. Phillips, D. B. Lobell, C. Delire, and A. Mirin, 2007: Combined climate and carbon-cycle effects of large-scale deforestation. Proc. Natl. Acad. Sci. U.S.A., 104, 6550-6555.

Baldocchi, D. D., et al., 2001: FLUXNET: A new tool to study the temporal and spatial variability of ecosystem-scale carbon dioxide, water vapor and energy flux densities. Bull. Am. Meteorol. Soc., 82, 2415-2435.

Ballantyne, A. P., C. B. Alden, J. B. Miller, P. P. Tans, and J. W. C. White, 2012: Increase in observed net carbon dioxide uptake by land and oceans during the last 50 years. Nature, 488, 70-72.

Balshi, M. S., A. D. McGuire, P. Duffy, M. D. Flannigan, D. W. Kicklighter, and J. Melillo, 2009: Vulnerability of carbon storage in North American boreal forests to wildfires during the 21st century. Global Change Biol., 15, 1491-1510.

Bao, L. H., and M. C. Trachtenberg, 2006: Facilitated transport of $\mathrm{CO}_{2}$ across a liquid membrane: Comparing enzyme, amine, and alkaline. J. Membr. Sci., 280, 330334.

Barnard, R., P. W. Leadley, and B. A. Hungate, 2005: Global change, nitrification, and denitrification: A review. Global Biogeochem. Cycles, 19, GB1007.

Barnes, R. T., and P. A. Raymond, 2009: The contribution of agricultural and urban activities to inorganic carbon fluxes within temperate watersheds. Chem. Geol., 266, 318-327.

Barnosky, A. D., 2008: Colloquium Paper: Megafauna biomass tradeoff as a driver of Quaternary and future extinctions. Proc. Natl. Acad. Sci. U.S.A., 105, 1154311548.

Bastviken, D., J. Cole, M. Pace, and L. Tranvik, 2004: Methane emissions from lakes: Dependence of lake characteristics, two regional assessments, and a global estimate. Global Biogeochem. Cycles, 18, GB4009. 
Bastviken, D., L. J. Tranvik, J. A. Downing, P. M. Crill, and A. Enrich-Prast, 2011 Freshwater methane emissions offset the continental carbon sink. Science, 331, 50.

Bathiany, S., M. Claussen, V. Brovkin, T. Raddatz, and V. Gayler, 2010: Combined biogeophysical and biogeochemical effects of large-scale forest cover changes in the MPI earth system model. Biogeosciences, 7, 1383-1399.

Batjes, N. H., 1996: Total carbon and nitrogen in the soils of the world. Eur. J. Soil Sci., 47, 151-163.

Battin, T. J., S. Luyssaert, L. A. Kaplan, A. K. Aufdenkampe, A. Richter, and L. J. Tranvik, 2009: The boundless carbon cycle Nature Geosci., 2, 598-600.

Beaugrand, G., M. Edwards, and L. Legendre, 2010: Marine biodiversity, ecosystem functioning, and carbon cycles. Proc. Natl. Acad. Sci. U.S.A., 107, 10120-10124.

Beaulieu, J. J., et al., 2011: Nitrous oxide emission from denitrification in stream and river networks. Proc. Natl. Acad. Sci. U.S.A., 108, 214-219.

Beer, C., et al., 2010: Terrestrial gross carbon dioxide uptake: Global distribution and covariation with climate. Science, 329, 834-838.

Bellassen, V., G. Le Maire, J. F. Dhote, P. Ciais, and N. Viovy, 2010: Modelling forest management within a global vegetation model. Part 1: Model structure and general behaviour. Ecol. Model., 221, 2458-2474.

Bellassen, V., N. Viovy, S. Luyssaert, G. Le Maire, M.-J. Schelhaas, and P. Ciais, 2011 Reconstruction and attribution of the carbon sink of European forests between 1950 and 2000. Global Change Biol., 17, 3274-3292.

Bennington, V., G. A. McKinley, S. Dutkiewicz, and D. Ullman, 2009: What does chlorophyll variability tell us about export and air-sea $\mathrm{CO}_{2}$ flux variability in the North Atlantic? Global Biogeochem. Cycles, 23, GB3002.

Berendse, F., et al., 2001: Raised atmospheric $\mathrm{CO}_{2}$ levels and increased $\mathrm{N}$ deposition cause shifts in plant species composition and production in Sphagnum bogs. Global Change Biol., 7, 591-598.

Bergamaschi, P., et al., 2009: Inverse modeling of global and regional $\mathrm{CH}_{4}$ emissions using SCIAMACHY satellite retrievals. J. Geophys. Res., 114, D22301.

Berger, W. H., 1982: Increase of carbon dioxide in the atmosphere during deglaciation: The coral-reef hypothesis. Naturwissenschaften, 69, 87-88.

Berner, R. A., 1992: Weathering, plants, and the long-term carbon-cycle. Geochim. Cosmochim. Acta, 56, 3225-3231.

Berner, R. A., A. C. Lasaga, and R. M. Garrels, 1983: The carbonate-silicate geochemical cycle and its effect on atmospheric carbon dioxide over the past 100 million years. Am. J. Sci., 283, 641-683.

Bernier, P. Y., R. L. Desjardins, Y. Karimi-Zindashty, D. E. Worth, A. Beaudoin, Y. Luo, and S. Wang, 2011: Boreal lichen woodlands: A possible negative feedback to climate change in Eastern North America. Agr. Forest Meteorol., 151, 521-528.

Betts, R. A., 2000: Offset of the potential carbon sink from boreal forestation by decreases in surface albedo. Nature, 408, 187-190.

Betts, R. A., et al., 2007: Projected increase in continental runoff due to plant responses to increasing carbon dioxide. Nature, 448, 1037-1041.

Bianchi, D., J. P. Dunne, J. L. Sarmiento, and E. D. Galbraith, 2012: Data-based estimates of suboxia, denitrification and $\mathrm{N}_{2} \mathrm{O}$ production in the ocean and their sensitivity to dissolved $\mathrm{O}_{2}$. Global Biogeochem. Cycles, 26, GB2009.

Biastoch, A., et al., 2011: Rising Arctic Ocean temperatures cause gas hydrate destabilization and ocean acidification. Geophys. Res. Lett., 38, L08602.

Billings, S. A., S. M. Schaeffer, and R. D. Evans, 2002: Trace N gas losses and N mineralization in Mojave desert soils exposed to elevated $\mathrm{CO}_{2}$. Soil Biol. Biochem., 34, 1777-1784.

Bird, M. I., J. Lloyd, and G. D. Farquhar, 1996: Terrestrial carbon storage from the last glacial maximum to the present. Chemosphere, 33, 1675-1685.

Blain, S., et al., 2007: Effect of natural iron fertilization on carbon sequestration in the Southern Ocean. Nature, 446, 1070-1074.

Blake, D. R., E. W. Mayer, S. C. Tyler, Y. Makide, D. C. Montague, and F. S. Rowland, 1982: Global increase in atmospheric methane concentrations between 1978 and 1980. Geophys. Res. Lett., 9, 477-480.

Bleeker, A., W. K. Hicks, F. Dentener, and J. Galloway, 2011: Nitrogen deposition as a threat to the World's protected areas under the Convention on Biological Diversity. Environ. Pollut., 159, 2280-2288.

Bloom, A. A., J. Lee-Taylor, S. Madronich, D. J. Messenger, P. I. Palmer, D. S. Reay, and A. R. McLeod, 2010: Global methane emission estimates from ultraviolet irradiation of terrestrial plant foliage. New Phytologist, 187, 417-425.

Blunier, T., J. Chappellaz, J. Schwander, B. Stauffer, and D. Raynaud, 1995: Variations in atmospheric methane concentration during the Holocene epoch. Nature, 374 $46-49$.
Boardman, C. P., V. Gauci, J. S. Watson, S. Blake, and D. J. Beerling, 2011: Contrasting wetland $\mathrm{CH}_{4}$ emission responses to simulated glacial atmospheric $\mathrm{CO}_{2}$ in temperate bogs and fens. New Phytologist, 192, 898-911.

Bock, M., J. Schmitt, L. Moller, R. Spahni, T. Blunier, and H. Fischer, 2010: Hydrogen isotopes preclude marine hydrate $\mathrm{CH}_{4}$ emissions at the onset of DansgaardOeschger events. Science, 328, 1686-1689.

Boden, T., G. Marland, and R. Andres, 2011: Global $\mathrm{CO}_{2}$ emissions from fossilfuel burning, cement manufacture, and gas flaring: 1751-2008 (accessed at 2011.11.10). Oak Ridge National Laboratory, U. S. Department of Energy, Carbon Dioxide Information Analysis Center, Oak Ridge, TN, U.S.A., doi:10.3334/ CDIAC/00001_V2011, http://cdiac.ornl.gov/trends/emis/overview_2008.html.

Bonan, G. B., 2008: Ecological Climatology: Concepts and Applications. Cambridge University Press, New York, NY, USA.

Bonan, G. B., and S. Levis, 2010: Quantifying carbon-nitrogen feedbacks in the Community Land Model (CLM4). Geophys. Res. Lett., 37, L07401.

Bonan, G. B., D. Pollard, and S. L. Thompson, 1992: Effects of boreal forest vegetation on global climate. Nature, 359, 716-718.

Bond-Lamberty, B., and A. Thomson, 2010: Temperature-associated increases in the global soil respiration record. Nature, 464, 579-U132.

Booth, B. B. B., et al., 2012: High sensitivity of future global warming to land carbon cycle processes. Environ. Res. Lett., 7, 024002.

Bopp, L., K. E. Kohfeld, C. Le Quéré, and O. Aumont, 2003: Dust impact on marine biota and atmospheric $\mathrm{CO}_{2}$ during glacial periods. Paleoceanography, 18, 1046.

Bopp, L., C. Le Quéré, M. Heimann, A. C. Manning, and P. Monfray, 2002: Climateinduced oceanic oxygen fluxes: Implications for the contemporary carbon budget. Global Biogeochem. Cycles, 16, 1022.

Bopp, L., et al., 2001: Potential impact of climate change on marine export production. Global Biogeochem. Cycles, 15, 81-99.

Boucher, 0., et al., 2012: Reversibility in an Earth System model in response to $\mathrm{CO}_{2}$ concentration changes. Environ. Res. Lett., 7, 024013.

Bousquet, P., D. A. Hauglustaine, P. Peylin, C. Carouge, and P. Ciais, 2005: Two decades of $\mathrm{OH}$ variability as inferred by an inversion of atmospheric transport and chemistry of methyl chloroform. Atmos. Chem. Phys., 5, 2635-2656.

Bousquet, P., P. Peylin, P. Ciais, C. Le Quéré, P. Friedlingstein, and P. P. Tans, 2000: Regional changes in carbon dioxide fluxes of land and oceans since 1980. Science, 290, 1342-1346.

Bousquet, P., et al., 2006: Contribution of anthropogenic and natural sources to atmospheric methane variability. Nature, 443, 439-443.

Bousquet, P., et al., 2011: Source attribution of the changes in atmospheric methane for 2006-2008. Atmos. Chem. Phys., 11, 3689-3700.

Bouttes, N., D. Paillard, D. M. Roche, V. Brovkin, and L. Bopp, 2011: Last Glacial Maximum $\mathrm{CO}_{2}$ and $\mathrm{d}^{13} \mathrm{C}$ successfully reconciled. Geophys. Res. Lett., 38, L02705.

Bouttes, N., et al., 2012: Impact of oceanic processes on the carbon cycle during the last termination. Clim. Past, 8, 149-170.

Bouwman, A. F., et al., 2013: Global trends and uncertainties in terrestrial denitrification and $\mathrm{N}_{2} \mathrm{O}$ emissions. Philos. Trans. R. Soc. London Ser. B, 368, 20130112.

Bouwman, L., et al., 2011: Exploring global changes in nitrogen and phosphorus cycles in agriculture induced by livestock production over the 1900-2050 period. Proc. Natl. Acad. Sci. U.S.A., doi:10.1073/pnas.1012878108.

Boyd, P. W., et al., 2007: Mesoscale iron enrichment experiments 1993-2005: Synthesis and future directions. Science, 315, 612-617.

Bozbiyik, A., M. Steinacher, F. Joos, T. F. Stocker, and L. Menviel, 2011: Fingerprints of changes in the terrestrial carbon cycle in response to large reorganizations in ocean circulation. Clim. Past, 7, 319-338.

Brenninkmeijer, C. A. M., et al., 2007: Civil Aircraft for the regular investigation of the atmosphere based on an instrumented container: The new CARIBIC system. Atmos. Chem. Phys., 7, 4953-4976.

Bridgham, S. D., J. P. Megonigal, J. K. Keller, N. B. Bliss, and C. Trettin, 2006: The carbon balance of North American wetlands. Wetlands, 26, 889-916.

Broecker, W. S., and T.-H. Peng, 1986: Carbon cycle: 1985 glacial to interglacial changes in the operation of the global carbon cycle. Radiocarbon, 28, 309-327.

Broecker, W. S., E. Clark, D. C. McCorkle, T.-H. Peng, I. Hajdas, and G. Bonani, 1999: Evidence for a reduction in the carbonate ion content of the deep sea during the course of the Holocene. Paleoceanography, 14, 744-752.

Brovkin, V., A. Ganopolski, D. Archer, and S. Rahmstorf, 2007: Lowering of glacial atmospheric $\mathrm{CO}_{2}$ in response to changes in oceanic circulation and marine biogeochemistry. Paleoceanography, 22, PA4202. 
Brovkin, V., J. H. Kim, M. Hofmann, and R. Schneider, 2008: A lowering effect of reconstructed Holocene changes in sea surface temperatures on the atmospheric $\mathrm{CO}_{2}$ concentration. Global Biogeochem. Cycles, 22, GB1016.

Brovkin, V., T. Raddatz, C. H. Reick, M. Claussen, and V. Gayler, 2009: Global biogeophysical interactions between forest and climate. Geophys. Res. Lett., 36, L07405.

Brovkin, V., S. Sitch, W. von Bloh, M. Claussen, E. Bauer, and W. Cramer, 2004: Role of land cover changes for atmospheric $\mathrm{CO}_{2}$ increase and climate change during the last 150 years. Global Change Biol., 10, 1253-1266.

Brovkin, V., J. Bendtsen, M. Claussen, A. Ganopolski, C. Kubatzki, V. Petoukhov, and A. Andreev, 2002: Carbon cycle, vegetation, and climate dynamics in the Holocene: Experiments with the CLIMBER-2 model. Global Biogeochem. Cycles, 16, 1139.

Brovkin, V., et al., 2010: Sensitivity of a coupled climate-carbon cycle model to large volcanic eruptions during the last millennium. Tellus $B, 62,674-681$.

Brown, J. R., et al., 2011: Effects of multiple global change treatments on soil $\mathrm{N}_{2} \mathrm{O}$ fluxes. Biogeochemistry, 109, 85-100.

Brzezinski, M. A., et al., 2002: A switch from $\mathrm{Si}(\mathrm{OH})_{4}$ to $\mathrm{NO}_{3}$ depletion in the glacial Southern Ocean. Geophys. Res. Lett., 29, 1564.

Buesseler, K. O., J. E. Andrews, S. M. Pike, and M. A. Charette, 2004: The effects of iron fertilization on carbon sequestration in the Southern Ocean. Science, 304, 414-417.

Burke, E. J., C. D. Jones, and C. D. Koven, 2013: Estimating the permafrost-carbonclimate response in the CMIP5 climate models using a simplified approach. J. Clim., 26, 4897-4909.

Burn, C. R., and F. E. Nelson, 2006: Comment on "A projection of severe near-surface permafrost degradation during the 21 st century" by David M. Lawrence and Andrew G. Slater. Geophys. Res. Lett., 33, L21503.

Butterbach-Bahl, K., and M. Dannenmann, 2011: Denitrification and associated soil $\mathrm{N}_{2} \mathrm{O}$ emissions due to agricultural activities in a changing climate. Curr. Opin. Environ. Sustain., 3, 389-395.

Byrne, R. H., S. Mecking, R. A. Feely, and X. W. Liu, 2010: Direct observations of basinwide acidification of the North Pacific Ocean. Geophys. Res. Lett., 37, L02601.

Cadule, P., et al., 2010: Benchmarking coupled climate-carbon models against longterm atmospheric $\mathrm{CO}_{2}$ measurements. Global Biogeochem. Cycles, 24, GB2016.

Cai, W.-J., et al., 2011: Acidification of subsurface coastal waters enhanced by eutrophication. Nature Geosci, 4, 766-770.

Caldeira, K., and G. H. Rau, 2000: Accelerating carbonate dissolution to sequester carbon dioxide in the ocean: Geochemical implications. Geophys. Res. Lett., 27, 225-228.

Caldeira, K., and M. E. Wickett, 2005: Ocean model predictions of chemistry changes from carbon dioxide emissions to the atmosphere and ocean. J. Geophys. Res. Oceans, 110, c09504.

Canadell, J. G., and M. R. Raupach, 2008: Managing forests for climate change mitigation. Science, 320, 1456-1457.

Canadell, J. G., et al., 2007a: Saturation of the terrestrial carbon sink. In: Terrestrial Ecosystems in a Changing World. [J. G. Canadell, D. Pataki and L. Pitelka (eds.)]. The IGBP Series. Springer-Verlag, Berlin and Heidelberg, Germany, pp. 59-78,

Canadell, J. G., et al., 2007b: Contributions to accelerating atmospheric $\mathrm{CO}_{2}$ growth from economic activity, carbon intensity, and efficiency of natural sinks. Proc. Natl. Acad. Sci. U.S.A., 104, 18,866-18,870.

Canfield, D. E., A. N. Glazer, and P. G. Falkowski, 2010: The evolution and future of Earth's nitrogen cycle. Science, 330, 192-196.

Cao, L., and K. Caldeira, 2010a: Can ocean iron fertilization mitigate ocean acidification? Clim. Change, 99, 303-311.

Cao, L., and K. Caldeira, 2010b: Atmospheric carbon dioxide removal: Long-term consequences and commitment. Environ. Res. Lett., 5, 024011.

Cao, L., K. Caldeira, and A. K. Jain, 2007: Effects of carbon dioxide and climate change on ocean acidification and carbonate mineral saturation. Geophys. Res. Lett., 34, L05607.

Cao, L., G. Bala, and K. Caldeira, 2011: Why is there a short-term increase in global precipitation in response to diminished $\mathrm{CO}_{2}$ forcing? Geophys. Res. Lett., 38, L06703.

Cao, L., G. Bala, K. Caldeira, R. Nemani, and G. Ban-Weiss, 2010: Importance of carbon dioxide physiological forcing to future climate change. Proc. Natl. Acad. Sci. U.S.A., 107, 9513-9518.

Carcaillet, C., et al., 2002: Holocene biomass burning and global dynamics of the carbon cycle. Chemosphere, 49, 845-863.

Certini, G., 2005: Effects of fire on properties of forest soils: A review. Oecologia, 143, 1-10.
Chambers, J. Q., J. I. Fisher, H. Zeng, E. L. Chapman, D. B. Baker, and G. C. Hurtt, 2007: Hurricane Katrina's carbon footprint on U.S. Gulf Coast forests. Science, 318, 1107.

Chantarel, A. M., J. M. G. Bloor, N. Deltroy, and J.-F. Soussana, 2011: Effects of climate change drivers on nitrous oxide fluxes in an upland temperate grassland. Ecosystems, 14, 223-233.

Chapuis-Lardy, L., N. Wrage, A. Metay, J. L. Chotte, and M. Bernoux, 2007: Soils, a sink for $\mathrm{N}_{2} \mathrm{O}$ ? A review. Global Change Biol., 13, 1-17.

Chen, Y. H., and R. G. Prinn, 2006: Estimation of atmospheric methane emissions between 1996 and 2001 using a three-dimensional global chemical transport model. J. Geophys. Res. Atmos., 111, D10307.

Chhabra, A., K. R. Manjunath, S. Panigrahy, and J. S. Parihar, 2013: Greenhouse gas emissions from Indian livestock. Clim. Change, 117, 329-344.

Chierici, M., and A. Fransson, 2009: Calcium carbonate saturation in the surface water of the Arctic Ocean: Undersaturation in freshwater influenced shelves. Biogeosciences, 6, 2421-2431.

Christensen, T. R., et al., 2004: Thawing sub-arctic permafrost: Effects on vegetation and methane emissions. Geophys. Res. Lett., 31, L04501.

Churkina, G., V. Brovkin, W. von Bloh, K. Trusilova, M. Jung, and F. Dentener, 2009: Synergy of rising nitrogen depositions and atmospheric $\mathrm{CO}_{2}$ on land carbon uptake moderately offsets global warming. Global Biogeochem. Cycles, 23, GB4027.

Ciais, P., P. Rayner, F. Chevallier, P. Bousquet, M. Logan, P. Peylin, and M. Ramonet, 2010: Atmospheric inversions for estimating $\mathrm{CO}_{2}$ fluxes: methods and perspectives. Clim. Change, 103, 69-92(24).

Ciais, P., et al., 2012: Large inert carbon pool in the terrestrial biosphere during the Last Glacial Maximum. Nature Geosci, 5, 74-79.

Ciais, P., et al., 2008: Carbon accumulation in European forests. Nature Geosci., 1, 425-429.

Ciais, P., et al., 2005: Europe-wide reduction in primary productivity caused by the heat and drought in 2003. Nature, 437, 529-533.

Clark, D. B., D. A. Clark, and S. F. Oberbauer, 2010: Annual wood production in a tropical rain forest in NE Costa Rica linked to climatic variation but not to increasing $\mathrm{CO}_{2}$. Global Change Biol., 16, 747-759.

Claussen, M., et al., 2002: Earth system models of intermediate complexity: Closing the gap in the spectrum of climate system models. Clim. Dyn., 18, 579-586.

Cocco, V., et al., 2013: Oxygen and indicators of stress for marine life in multi-model global warming projections. Biogeosciences, 10, 1849-1868.

Codispoti, L. A., 2007: An oceanic fixed nitrogen sink exceeding $400 \mathrm{Tg} \mathrm{N} \mathrm{a}^{-1}$ vs the concept of homeostasis in the fixed-nitrogen inventory. Biogeosciences, 4, 233-253.

Codispoti, L. A., 2010: Interesting Times for Marine $\mathrm{N}_{2} \mathrm{O}$. Science, 327, 1339-1340.

Cole, J. J., et al., 2007: Plumbing the global carbon cycle: Integrating inland waters into the terrestrial carbon budget. Ecosystems, 10, 171-184.

Collins, W. J., et al., 2011: Development and evaluation of an Earth-System modelHadGEM2. Geosci. Model Dev., 4, 1051-1075.

Conrad, R., 1996: Soil microorganisms as controllers of atmospheric trace gases $\left(\mathrm{H}_{2}\right.$ $\mathrm{CO}, \mathrm{CH}_{4}, \mathrm{OCS}, \mathrm{N}_{2} \mathrm{O}$, and NO). Microbiol. Rev., 60, 609-640.

Conway, T., and P. Tans, 2011: Global $\mathrm{CO}_{2}$. National Oceanic and Atmospheric Administration, Earth System Research Library, Silver Spring, MD, USA.

Conway, T. J., P. P. Tans, L. S. Waterman, K. W. Thoning, D. R. Kitzis, K. A. Masarie, and N. Zhang, 1994: Evidence for interannual variability of the carbon cycle from the National Oceanic and Atmospheric Administration Climate Monitoring and Diagnostics Laboratory Global Air Sampling Network. J. Geophys. Res. Atmos. 99, 22831-22855.

Corbière, A., N. Metzl, G. Reverdin, C. Brunet, and A. Takahashi, 2007: Interannual and decadal variability of the oceanic carbon sink in the North Atlantic subpolar gyre. Tellus $B, 59,168-178$.

Cox, P., and C. Jones, 2008: Climate change. Illuminating the modern dance of climate and $\mathrm{CO}_{2}$. Science, 321, 1642-1644.

Cox, P. M., 2001: Description of the TRIFFID dynamic global vegetation model. Technical Note 24. Hadley Centre, Met Office, Exeter, Devon, UK.

Cox, P. M., R. A. Betts, M. Collins, P. P. Harris, C. Huntingford, and C. D. Jones, 2004: Amazonian forest dieback under climate-carbon cycle projections for the 21st century. Theor. Appl. Climatol., 78, 137-156.

Cox, P. M., D. Pearson, B. B. Booth, P. Friedlingstein, C. Huntingford, C. D. Jones, and C. M. Luke, 2013: Sensitivity of tropical carbon to climate change constrained by carbon dioxide variability. Nature, 494, 341-344. 
Crévoisier, C., D. Nobileau, A. M. Fiore, R. Armante, A. Chédin, and N. A. Scott, 2009: Tropospheric methane in the tropics - first year from IASI hyperspectral infrared observations. Atmos. Chem. Phys., 9, 6337-6350.

Crutzen, P. J., A. R. Mosier, K. A. Smith, and W. Winiwarter, 2008: $\mathrm{N}_{2} \mathrm{O}$ release from agro-biofuel production negates global warming reduction by replacing fossi fuels. Atmos. Chem. Phys., 8, 389-395.

Cunnold, D. M., et al., 2002: In situ measurements of atmospheric methane at GAGE/ AGAGE sites during 1985-2000 and resulting source inferences. J. Geophys. Res. Atmos., 107, ACH20-1, CiteID 4225.

Curry, C. L., 2007: Modeling the soil consumption of methane at the global scale. Global Biogeochem. Cycles, 21, GB4012.

Curry, C. L., 2009: The consumption of atmospheric methane by soil in a simulated future climate. Biogeosciences, 6, 2355-2367.

Daniau, A. L., et al., 2012: Predictability of biomass burning in response to climate changes. Global Biogeochem. Cycles, 26, Gb4007.

Davidson, E. A., 2009: The contribution of manure and fertilizer nitrogen to atmospheric nitrous oxide since 1860. Nature Geosci., 2, 659-662.

Davidson, E. A., et al., 2012: Excess nitrogen in the U.S. environnement: Trends, risks, and solutions. Issues of Ecology, Report number 15. Ecological Society of America, Washington, DC.

Dawes, M. A., S. Hättenschwiler, P. Bebi, F. Hagedorn, I. T. Handa, C. Körner, and C. Rixen, 2011: Species-specific tree growth responses to 9 years of $\mathrm{CO}_{2}$ enrichment at the alpine treeline. J. Ecol., 99, 383-394.

De Klein, $\mathrm{C}$., et al., 2007: $\mathrm{N}_{2} \mathrm{O}$ emissions from managed soils, and $\mathrm{CO}_{2}$ emissions from lime and urea application. In: 2006 IPCC Guidelines for National Greenhouse Gas Inventories, Vol. 4 [M. Gytarsky, T. Higarashi, W. Irving, T. Krug and J. Penman (eds.)]. Intergovernmental Panel on Climate Change, Geneva, Switzerland, pp. 11.1-11.54.

DeFries, R., and C. Rosenzweig, 2010: Toward a whole-landscape approach for sustainable land use in the tropics. Proc. Natl. Acad. Sci. U.S.A., 107, 1962719632.

DeFries, R. S., R. A. Houghton, M. C. Hansen, C. B. Field, D. L. Skole, and J. Townshend, 2002: Carbon emissions from tropical deforestation and regrowth based on satellite observations for the 1980s and 1990s. Proc. Natl. Acad. Sci. U.S.A., 99 14256-14261.

Delmas, R. J., J.-M. Ascencio, and M. Legrand, 1980: Polar ice evidence that atmospheric $\mathrm{CO}_{2} 20,000-y r$ BP was $50 \%$ of present. Nature, 284, 155-157.

Denman, K. L., 2008: Climate change, ocean processes and ocean iron fertilization. Mar. Ecol. Prog. Ser., 364, 219-225.

Denman, K. L., et al., 2007: Couplings between changes in the climate system and biogeochemistry. In: Climate Change 2007: The Physical Science Basis. Contribution of Working Group I to the Fourth Assessment Report of the Intergovernmental Panel on Climate Change [Solomon, S., D. Qin, M. Manning, Z. Chen, M. Marquis, K. B. Averyt, M. Tignor and H. L. Miller (eds.)] Cambridge University Press, Cambridge, United Kingdom and New York, NY, USA, 499-587.

Dentener, F., W. Peters, M. Krol, M. van Weele, P. Bergamaschi, and J. Lelieveld, 2003: Interannual variability and trend of $\mathrm{CH}_{4}$ lifetime as a measure for $\mathrm{OH}$ changes in the 1979-1993 time period. J. Geophys. Res. Atmos., 108, 4442.

Dentener, F., et al., 2005: The impact of air pollutant and methane emission controls on tropospheric ozone and radiative forcing: CTM calculations for the period 1990-2030. Atmos. Chem. Phys., 5, 1731-1755.

Dentener, F., et al., 2006: The global atmospheric environment for the next generation. Environ. Sci. Technol., 40, 3586-3594.

Deutsch, C., J. L. Sarmiento, D. M. Sigman, N. Gruber, and J. P. Dunne, 2007: Spatia coupling of nitrogen inputs and losses in the ocean. Nature, 445, 163-167.

Dickens, G. R., 2003: A methane trigger for rapid warming? Science, 299, 1017.

Dlugokencky, E., and P. P. Tans, 2013a: Recent $\mathrm{CO}_{2}$, NOAA, ESRS. Retrieved from www.esrl.noaa.gov/gmd/ccgg/trends/global.html, accessed 01-02-2013.

Dlugokencky, E., and P. P. Tans, 2013b: Globally averaged marine surface annual mean data, NOAA/ESRL. Retrieved from www.esrl.noaa.gov/gmd/ccgg/trends/, accessed 01-02-2013.

Dlugokencky, E. J., E. G. Nisbet, R. Fisher, and D. Lowry, 2011: Global atmospheric methane: Budget, changes and dangers. Philos. Trans. R. Soc. London Ser. A, 369, 2058-2072.

Dlugokencky, E. J., P. M. Lang, A. M. Crotwell, and K. A. Masarie, 2012: Atmospheric methane dry air mole fractions from the NOAA ESRL Carbon Cycle Cooperative Global Air Sampling Network, 1983-2011, version 2012-09-24. Version 201008-12 ed.
Dlugokencky, E. J., S. Houweling, L. Bruhwiler, K. A. Masarie, P. M. Lang, J. B. Miller and P. P. Tans, 2003: Atmospheric methane levels off: Temporary pause or a new steady-state? Geophys. Res. Lett., 30, 1992.

Dlugokencky, E. J., et al., 2009: Observational constraints on recent increases in the atmospheric $\mathrm{CH}_{4}$ burden. Geophys. Res. Lett., 36, L18803.

Dolman, A. J., et al., 2012: An estimate of the terrestrial carbon budget of Russia using inventory based, eddy covariance and inversion methods. Biogeosciences, 9, 5323-5340.

Doney, S. C., et al., 2009: Mechanisms governing interannual variability in upperocean inorganic carbon system and air-sea $\mathrm{CO}_{2}$ fluxes: Physical climate and atmospheric dust. Deep-Sea Res. Pt. II, 56, 640-655.

Dore, J. E., R. Lukas, D. W. Sadler, M. J. Church, and D. M. Karl, 2009: Physical and biogeochemical modulation of ocean acidification in the central North Pacific. Proc. Natl. Acad. Sci. U.S.A., 106, 12235-12240.

Dornburg, V., and G. Marland, 2008: Temporary storage of carbon in the biosphere does have value for climate change mitigation: A response to the paper by Miko Kirschbaum. Mitigat. Adapt. Strat. Global Change, 13, 211-217.

Duce, R. A., et al., 2008: Impacts of atmospheric anthropogenic nitrogen on the open ocean. Science, 320, 893-897.

Dueck, T. A., et al., 2007: No evidence for substantial aerobic methane emission by terrestrial plants: $\mathrm{A}^{13} \mathrm{C}$-labelling approach. New Phytologist, 175, 29-35.

Dufresne, J.-L., et al., 2013: Climate change projections using the IPSL-CM5 Earth System Model: From CMIP3 to CMIP5. Clim. Dyn., 40, 2123-2165.

Dukes, J. S., et al., 2005: Responses of grassland production to single and multiple global environmental changes. PloS Biol., 3, 1829-1837.

Dunne, J. P., et al., 2012: GFDL's ESM2 global coupled climate-carbon Earth System Models Part I: Physical formulation and baseline simulation characteristics. J. Clim., 25, 6646-6665.

Dunne, J. P., et al., 2013: GFDL's ESM2 global coupled climate-carbon Earth System Models. Part II: Carbon system formation and baseline simulation characteristics. J. Clim., 26, 2247-2267.

Dutaur, L., and L. V. Verchot, 2007: A global inventory of the soil $\mathrm{CH}_{4}$ sink. Global Biogeochem. Cycles, 21, GB4013.

Dutta, K., E. A. G. Schuur, J. C. Neff, and S. A. Zimov, 2006: Potential carbon release from permafrost soils of Northeastern Siberia. Global Change Biol., 12, 23362351.

Eby, M., K. Zickfeld, A. Montenegro, D. Archer, K. J. Meissner, and A. J. Weaver, 2009: Lifetime of anthropogenic climate change: Millennial time scales of potential $\mathrm{CO}_{2}$ and surface temperature perturbations. J. Clim., 22, 2501-2511.

Eby, M., et al., 2013: Historical and idealized climate model experiments: An EMIC intercomparison. Clim. Past, 9, 1-30.

EDGAR4-database, 2009: Emission Database for Global Atmospheric Research (EDGAR), release version 4.0. http://edgar.jrc.ec.europa.eu, 2009. European Commission. Joint Research Centre (JRC) / Netherlands Environmental Assessment Agency (PBL).

Elberling, B., H. H. Christiansen, and B. U. Hansen, 2010: High nitrous oxide production from thawing permafrost. Nature Geosci., 3, 332-335.

Eliseev, A. V., I. I. Mokhov, M. M. Arzhanov, P. F. Demchenko, and S. N. Denisov, 2008: Interaction of the methane cycle and processes in wetland ecosystems in a climate model of intermediate complexity. Izvestiya Atmos. Ocean. Phys., 44, 139-152.

Elliott, S., M. Maltrud, M. Reagan, G. Moridis, and P. Cameron-Smith, 2011: Marine methane cycle simulations for the period of early global warming. J. Geophys. Res. Biogeosci., 116, G01010.

Elser, J. J., et al., 2007: Global analysis of nitrogen and phosphorus limitation of primary producers in freshwater, marine and terrestrial ecosystems. Ecol. Lett., 10, 1135-1142.

Elsig, J., et al., 2009: Stable isotope constraints on Holocene carbon cycle changes from an Antarctic ice core. Nature, 461, 507-510.

Emerson, S., and J. I. Hedges, 1988: Processes controlling the organic carbon content of open ocean sediments. Paleoceanography, 3, 621-634.

EPA, 2006: Global anthropogenic non- $\mathrm{CO}_{2}$ greenhouse gas emissions. United States Environmental Protection Agency (US EPA, Washington, DC) Report EPA430-R-06-003. Retrieved from http://nepis.epa.gov/EPA/html/DLwait.htm?url=/ Adobe/PDF/2000ZL5G.PDF.

EPA, 2010: Methane and nitrous oxide emissions from natural sources. United States Environmental Protection Agency (EPA) Report. Washington, DC. http://www. epa.gov/outreach/pdfs/Methane-and-Nitrous-Oxide-Emissions-From-NaturalSources.pdf 
EPA, 2011a: Global anthropogenic non- $\mathrm{CO}_{2}$ greenhouse gas emissions: 1990-2030, United States Environmental Protection Agency (US EPA) Report. Washington, DC. http://www.epa.gov/climatechange/Downloads/EPAactivities/EPA_Global_ NonC02_Projections_Dec2012.pdf

EPA, 2011b: Reactive nitrogen in the United States: An analysis of inputs, flows, consequences, andmanagementoptions. ReportEPA-SAB-11-013,Washington,DC, 140 pp. http://yosemite.epa.gov/sab/sabproduct.nsf/WebBOARD/INCFullReport/ \$File/Final\%20INC\%20Report_8_19_11\%28without\%20signatures\%29.pdf

Erisman, J. W., M. S. Sutton, J. N. Galloway, Z. Klimont, and W. Winiwarter, 2008: A century of ammonia synthesis. Nature Geosci, 1, 1-4.

Erisman, J. W., J. Galloway, S. Seitzinger, A. Bleeker, and K. Butterbach-Bahl, 2011: Reactive nitrogen in the environment and its effect on climate change. Curr. Opin. Environ. Sustain., 3, 281-290.

Esser, G., J. Kattge, and A. Sakalli, 2011: Feedback of carbon and nitrogen cycles enhances carbon sequestration in the terrestrial biosphere. Global Change Biol., $17,819-842$.

Etheridge, D. M., L. P. Steele, R. L. Langenfelds, R. J. Francey, J.-M. Barnola, and V. I. Morgan, 1996: Natural and anthropogenic changes in atmospheric $\mathrm{CO}_{2}$ over the last 1000 years from air in Antarctic ice and firn. J. Geophys. Res., 101, $4115-4128$.

Etiope, G., K. R. Lassey, R. W. Klusman, and E. Boschi, 2008: Reappraisal of the fossil methane budget and related emission from geologic sources. Geophys. Res. Lett., 35, L09307.

Evans, C. D., D. T. Monteith, and D. M. Cooper, 2005: Long-term increses in surface water dissolved organic carbon: Observations, possible causes and environmental impacts. Environ. Pollut., 137, 55-71.

Falloon, P., C. Jones, M. Ades, and K. Paul, 2011: Direct soil moisture controls of future global soil carbon changes: An important source of uncertainty. Global Biogeochem. Cycles, 25, GB3010.

Fan, S.-M., T. L. Blaine, and J. L. Sarmiento, 1999: Terrestrial carbon sink in the Northern Hemisphere estimated from the atmospheric $\mathrm{CO}_{2}$ difference between Manna Loa and the South Pole since 1959. Tellus B, 51, 863-870.

FAO, 2005: Global Forest Resource Assessment 2005. Progress toward sustainable forest management. FAO Forestry Paper 147. Food and Agriculture Organization of the United Nations, Rome, Italy, pp. 129-147.

FAO, 2010: Global Forest Resources Assessment 2010. Main report. FAO Forestry Paper 163, Food and Agriculture Organization of the United Nations, Rome, Italy, $340 \mathrm{pp}$.

Feely, R. A., S. C. Doney, and S. R. Cooley, 2009: Ocean acidification: Present conditions and future changes in a high- $\mathrm{CO}_{2}$ world. Oceanography, 22, 36-47.

Feely, R. A., C. L. Sabine, J. M. Hernandez-Ayon, D. Ianson, and B. Hales, 2008: Evidence for upwelling of corrosive "acidified" water onto the continental shelf. Science, 320, 1490-1492.

Feely, R. A., R. H. Byrne, J. G. Acker, P. R. Betzer, C.-T. A. Chen, J. F. Gendron, and M. F. Lamb, 1988: Winter-summer variations of calcite and aragonite saturation in the northeast Pacific. Mar. Chem., 25, 227-241.

Feely, R. A., T. Takahashi, R. Wanninkhof, M. J. McPhaden, C. E. Cosca, S. C. Sutherland, and M. E. Carr, 2006: Decadal variability of the air-sea $\mathrm{CO}_{2}$ fluxes in the equatorial Pacific Ocean. J. Geophys. Res. Oceans, 111, C08590.

Felzer, B., et al., 2005: Past and future effects of ozone on carbon sequestration and climate change policy using a global biogeochemical model. Clim. Change, 73, 345-373.

Ferretti, D. F., et al., 2005: Unexpected changes to the global methane budget over the past 2000 years. Science, 309, 1714-1717.

Findlay, H. S., T. Tyrrell, R. G. J. Bellerby, A. Merico, and I. Skjelvan, 2008: Carbon and nutrient mixed layer dynamics in the Norwegian Sea. Biogeosciences, 5, $1395-1410$.

Findlay, S. E. G., 2005: Increased carbon transport in the Hudson River: Unexpected consequence of nitrogen deposition? Front. Ecol. Environ., 3, 133-137.

Finzi, A. C., et al., 2006: Progressive nitrogen limitation of ecosystem processes under elevated $\mathrm{CO}_{2}$ in a warm-temperate forest. Ecology, 87, 15-25.

Finzi, A. C., et al., 2007: Increases in nitrogen uptake rather than nitrogen-use efficiency support higher rates of temperate forest productivity under elevated $\mathrm{CO}_{2}$. Proc. Natl. Acad. Sci. U.S.A., 104, 14014-14019.

Fischer, H., et al., 2008: Changing boreal methane sources and constant biomass burning during the last termination. Nature, 452, 864-867.
Fisher, J. B., S. Sitch, Y. Malhi, R. A. Fisher, C. Huntingford, and S. Y. Tan, 2010: Carbon cost of plant nitrogen acquisition: A mechanistic, globally applicable model of plant nitrogen uptake, retranslocation, and fixation. Global Biogeochem. Cycles, 24, GB1014.

Flannigan, M. D., B. Stocks, M. Turetsky, and M. Wotton, 2009a: Impacts of climate change on fire activity and fire management in the circumboreal forest. Global Change Biol., 15, 549-560.

Flannigan, M. D., M. A. Krawchuk, W. J. de Groot, B. M. Wotton, and L. M. Gowman, 2009b: Implications of changing climate for global wildland fire. Int. J. Wildland Fire, 18, 483-507.

Fleming, E. L., C. H. Jackman, R. S. Stolarski, and A. R. Douglass, 2011: A model study of the impact of source gas changes on the stratosphere for 1850-2100. Atmos. Chem. Phys., 11, 8515-8541.

Flückiger, J., A. Dällenbach, T. Blunier, B. Stauffer, T. F. Stocker, D. Raynaud, and J.-M. Barnola, 1999: Variations in atmospheric $\mathrm{N}_{2} \mathrm{O}$ concentration during abrupt climate changes. Science, 285, 227-230.

Flückiger, J., et al., 2002: High-resolution Holocene $\mathrm{N}_{2} \mathrm{O}$ ice core record and its relationship with $\mathrm{CH}_{4}$ and $\mathrm{CO}_{2}$. Global Biogeochem. Cycles, 16, 1-10.

Flückiger, J., et al., 2004: $\mathrm{N}_{2} \mathrm{O}$ and $\mathrm{CH}_{4}$ variations during the last glacial epoch: Insight into global processes. Global Biogeochem. Cycles, 18, GB1020.

Foley, J. A., C. Monfreda, N. Ramankutty, and D. Zaks, 2007: Our share of the planetary pie. Proc. Natl. Acad. Sci. U.S.A., 104, 12585-12586.

Foley, J. A., et al., 2011: Solutions for a cultivated planet. Nature, 478, 337-342.

Fowler, D., et al., 2013: The global nitrogen cycle in the 21 th century. Philos. Trans. $R$. Soc. London Ser. B, 368, 20130165.

Francey, R. J., et al., 2013: Atmospheric verification of anthropogenic $\mathrm{CO}_{2}$ emission trends. Nature Clim. Change, 3, 520-524.

Frank, D. C., J. Esper, C. C. Raible, U. Buntgen, V. Trouet, B. Stocker, and F. Joos, 2010: Ensemble reconstruction constraints on the global carbon cycle sensitivity to climate. Nature, 463, 527-U143.

Frankenberg, C., et al., 2011: Global column-averaged methane mixing ratios from 2003 to 2009 as derived from SCIAMACHY: Trends and variability. J. Geophys. Res., 116, D04302.

Frankenberg, C., et al., 2008: Tropical methane emissions: A revised view from SCIAMACHY onboard ENVISAT. Geophys. Res. Lett., 35, L15811.

Freing, A., D. W. R. Wallace, and H. W. Bange, 2012: Global oceanic production of nitrous oxide. Philos. Trans. R. Soc. London Ser. B, 367, 1245-1255.

Friedli, H., H. Lötscher, H. Oeschger, U. Siegenthaler, and B. Stauffer, 1986: Ice core record of the ${ }^{13} \mathrm{C}^{12} \mathrm{C}$ ratio of atmospheric $\mathrm{CO}_{2}$ in the past two centuries. Nature, $324,237-238$.

Friedlingstein, P., and I. C. Prentice, 2010: Carbon-climate feedbacks: A review of model and observation based estimates. Curr. Opin. Environ. Sustain., 2, 251257.

Friedlingstein, P., J. L. Dufresne, P. M. Cox, and P. Rayner, 2003: How positive is the feedback between climate change and the carbon cycle? Tellus B, 55, 692-700.

Friedlingstein, P., et al., 2010: Update on $\mathrm{CO}_{2}$ emissions. Nature Geosci, 3, 811-812.

Friedlingstein, P., et al., 2006: Climate-carbon cycle feedback analysis: Results from the C4MIP model intercomparison. J. Clim., 19, 3337-3353.

Friis, K., A. Körtzinger, J. Patsch, and D. W. R. Wallace, 2005: On the temporal increase of anthropogenic $\mathrm{CO}_{2}$ in the subpolar North Atlantic. Deep-Sea Res. Pt. I, 52, 681-698.

Frölicher, T. L., F. Joos, and C. C. Raible, 2011: Sensitivity of atmospheric $\mathrm{CO}_{2}$ and climate to explosive volcanic eruptions. Biogeosciences, 8, 2317-2339.

Frölicher, T. L., F. Joos, C. C. Raible, and J. L. Sarmiento, 2013: Atmospheric $\mathrm{CO}_{2}$ response to volcanic eruptions: The role of ENSO, season, and variability. Global Biogeochem. Cycles, 27, 239-251.

Frölicher, T. L., F. Joos, G. K. Plattner, M. Steinacher, and S. C. Doney, 2009: Natural variability and anthropogenic trends in oceanic oxygen in a coupled carbon cycle-climate model ensemble. Global Biogeochem. Cycles, 23, GB1003.

Frolking, S., and N. T. Roulet, 2007: Holocene radiative forcing impact of northern peatland carbon accumulation and methane emissions. Global Change Biol., 13, 1079-1088.

Fuller, D. Q., et al., 2011: The contribution of rice agriculture and livestock pastoralism to prehistoric methane levels: An archaeological assessment. The Holocene, 21, 743-759.

Fung, I., M. Prather, J. John, J. Lerner, and E. Matthews, 1991: Three-dimensional model synthesis of the global methane cycle. J. Geophys. Res., 96, 13033-13065.

Fyfe, J. C., and O. A. Saenko, 2006: Simulated changes in the extratropical Southern Hemisphere winds and currents. Geophys. Res. Lett., 33, L06701. 
Fyfe, J. C., J. N. S. Cole, V. K. Arora, and J. F. Scinocca, 2013: Biogeochemical carbon coupling influences global precipitation in geoengineering experiments. Geophys. Res. Lett., 40, 651-655.

Fyke, J. G., and A. J. Weaver, 2006: The effect of potential future climate change on the marine methane hydrate stability zone. J. Clim., 19, 5903-5917.

Gaillard, M. J., et al., 2010: Holocene land-cover reconstructions for studies on land cover-climate feedbacks. Clim. Past, 6, 483-499.

Gaillardet, J., B. Dupre, P. Louvat, and C. J. Allegre, 1999: Global silicate weathering and $\mathrm{CO}_{2}$ consumption rates deduced from the chemistry of large rivers. Chem. Geol., 159, 3-30.

Galbraith, D., P. E. Levy, S. Sitch, C. Huntingford, P. Cox, M. Williams, and P. Meir, 2010: Multiple mechanisms of Amazonian forest biomass losses in three dynamic global vegetation models under climate change. New Phytologist, 187, 647-665.

Galloway, J. N., J. D. Aber, J. W. Erisman, S. P. Seitzinger, R. W. Howarth, E. B. Cowling, and B. J. Cosby, 2003: The nitrogen cascade. BioScience, 53, 341-356.

Galloway, J. N., et al., 2008: Transformation of the nitrogen cycle: Recent trends, questions, and potential solutions. Science, 320, 889.

Galloway, J. N., et al., 2004: Nitrogen cycles: Past, present and future. Biogeochemistry, 70, 153-226.

Gao, H., et al., 2012: Intensive and extensive nitrogen loss from intertidal permeable sediments of the Wadden Sea Limnol. Oceanogr., 57, 185-198.

Gärdenäs, A. l., et al., 2011: Knowledge gaps in soil carbon and nitrogen interactions-From molecular to global scale. Soil Biol. Biochem., 43, 702-717.

GEA, 2006: Energy resources and potentials. In: Global Energy Assessment-Toward a Sustainable Future. Cambridge University Press, Cambridge, United Kingdom, and New York, NY, USA, 425-512.

Gedalof, Z., and A. A. Berg, 2010: Tree ring evidence for limited direct $\mathrm{CO}_{2}$ fertilization of forests over the 20th century. Global Biogeochem. Cycles, 24, Gb3027.

Gedney, N., P. M. Cox, and C. Huntingford, 2004: Climate feedback from wetland methane emissions. Geophys. Res. Lett., 31, L20503.

Gedney, N., P. M. Cox, R. A. Betts, O. Boucher, C. Huntingford, and P. A. Stott, 2006: Detection of a direct carbon dioxide effect in continental river runoff records. Nature, 439, 835-838.

Gerber, S., L. O. Hedin, M. Oppenheimer, S. W. Pacala, and E. Shevliakova, 2010: Nitrogen cycling and feedbacks in a global dynamic land model. Global Biogeochem. Cycles, 24, GB1001.

Gerber, S., F. Joos, P. Brugger, T. F. Stocker, M. E. Mann, S. Sitch, and M. Scholze, 2003 Constraining temperature variations over the last millennium by comparing simulated and observed atmospheric $\mathrm{CO}_{2}$. Clim. Dyn., 20, 281-299.

Gervois, S., P. Ciais, N. de Noblet-Ducoudre, N. Brisson, N. Vuichard, and N. Viovy, 2008: Carbon and water balance of European croplands throughout the 20th century. Global Biogeochem. Cycles, 22, GB003018.

Gilbert, D., N. N. Rabalais, R. J. Diaz, and J. Zhang, 2010: Evidence for greater oxygen decline rates in the coastal ocean than in the open ocean. Biogeosciences, 7, 2283-2296.

Gloor, M., J. L. Sarmiento, and N. Gruber, 2010: What can be learned about carbon cycle climate feedbacks from the $\mathrm{CO}_{2}$ airborne fraction? Atmos. Chem. Phys., 10, 7739-7751.

Gloor, M., et al., 2012: The carbon balance of South America: A review of the status, decadal trends and main determinants. Biogeosciences, 9, 5407-5430.

Gloor, M., et al., 2009: Does the disturbance hypothesis explain the biomass increase in basin-wide Amazon forest plot data? Global Change Biol., 15, 2418-2430.

Gnanadesikan, A., and I. Marinov, 2008: Export is not enough: Nutrient cycling and carbon sequestration. Mar. Ecol. Prog. Ser., 364, 289-294.

Gnanadesikan, A., J. L. Sarmiento, and R. D. Slater, 2003: Effects of patchy ocean fertilization on atmospheric carbon dioxide and biological production. Global Biogeochem. Cycles, 17, 1050.

Gnanadesikan, A., J. L. Russell, and F. Zeng, 2007: How does ocean ventilation change under global warming? Ocean Sci., 3, 43-53.

Gnanadesikan, A., J. P. Dunne, and J. John, 2012: Understanding why the volume of suboxic waters does not increase over centuries of global warming in an Earth System Model. Biogeosciences, 9, 1159-1172.

Goldewijk, K. K., 2001: Estimating global land use change over the past 300 years: The HYDE Database. Global Biogeochem. Cycles, 15, 417-433.

Goldewijk, K. K., A. Beusen, G. van Drecht, and M. de Vos, 2011: The HYDE 3.1 spatially explicit database of human-induced global land-use change over the past 12,000 years. Global Ecol. Biogeogr., 20, 73-86.
Golding, N., and R. Betts, 2008: Fire risk in Amazonia due to climate change in the HadCM3 climate model: Potential interactions with deforestation. Global Biogeochem. Cycles, 22, GB4007.

Goll, D. S., et al., 2012: Nutrient limitation reduces land carbon uptake in simulations with a model of combined carbon, nitrogen and phosphorus cycling. Biogeosciences, 9, 3547-3569.

Good, P., C. Jones, J. Lowe, R. Betts, and N. Gedney, 2013: Comparing tropical forest projections from two generations of Hadley Centre Earth System Models, HadGEM2-ES and HadCM3LC. J. Clim., 26, 495-511.

Good, P., C. Jones, J. Lowe, R. Betts, B. Booth, and C. Huntingford, 2011: Quantifying environmental drivers of future tropical forest extent. J. Clim., 24, 1337-1349.

Govindasamy, B., K. Caldeira, and P. B. Duffy, 2003: Geoengineering Earth's radiation balance to mitigate climate change from a quadrupling of $\mathrm{CO}_{2}$. Global Planet. Change, 37, 157-168.

Govindasamy, B., S. Thompson, P. B. Duffy, K. Caldeira, and C. Delire, 2002: Impact of geoengineering schemes on the terrestrial biosphere. Geophys. Res. Lett., 29, 2061.

Graven, H. D., N. Gruber, R. Key, S. Khatiwala, and X. Giraud, 2012: Changing controls on oceanic radiocarbon: New insights on shallow-to-deep ocean exchange and anthropogenic $\mathrm{CO}_{2}$ uptake. J. Geophys. Res. Oceans, 117, C10005.

Gray, M. L., K. J. Champagne, D. Fauth, J. P. Baltrus, and H. Pennline, 2008: Performance of immobilized tertiary amine solid sorbents for the capture of carbon dioxide. Int. J. Greenh. Gas Control, 2, 3-8.

Gregg, J. S., R. J. Andres, and G. Marland, 2008: China: Emissions pattern of the world leader in $\mathrm{CO}_{2}$ emissions from fossil fuel consumption and cement production. Geophys. Res. Lett., 35, L08806.

Gregory, J. M., C. D. Jones, P. Cadule, and P. Friedlingstein, 2009: Quantifying carbon cycle feedbacks. J. Clim., 22, 5232-5250.

Groszkopf, T., et al., 2012: Doubling of marine dinitrogen-fixation rates based on direct measurements. Nature, 488, 361-364.

Gruber, N., and J. N. Galloway, 2008: An Earth-system perspective of the global nitrogen cycle. Nature, 451, 293-296.

Gruber, N., C. Hauri, Z. Lachkar, D. Loher, T. L. Frölicher, and G. K. Plattner, 2012: Rapid progression of ocean acidification in the California Current System. Science, $337,220-223$.

Gruber, N., et al., 2009: Oceanic sources, sinks, and transport of atmospheric $\mathrm{CO}_{2}$. Global Biogeochem. Cycles, 23, GB1005.

Gurney, K. R., and W. J. Eckels, 2011: Regional trends in terrestrial carbon exchange and their seasonal signatures. Tellus $B, 63,328-339$.

Hamilton, S. K., A. L. Kurzman, C. Arango, L. Jin, and G. P. Robertson, 2007: Evidence for carbon sequestration by agricultural liming. Global Biogeochem. Cycles, 21, GB2021.

Hansell, D. A., C. A. Carlson, D. J. Repeta, and R. Schlitzer, 2009: Dissolved organic matter in the ocean: A controversy stimulates new insights. Oceanography, 22, 202-211.

Hansen, M. C., S. V. Stehman, and P. V. Potapov, 2010: Quantification of global gross forest cover loss. Proc. Natl. Acad. Sci. U.S.A., 107, 8650-8655.

Harden, J. W., et al., 2012: Field information links permafrost carbon to physical vulnerabilities of thawing. Geophys. Res. Lett., 39, L15704.

Harris, N. L., et al., 2012: Baseline map of carbon emissions from deforestation in tropical regions. Science, 336, 1573-1576.

Harrison, K. G., 2000: Role of increased marine silica input on paleo-pCO, levels. Paleoceanography, 15, 292-298.

Hartmann, J., N. Jansen, H. H. Dürr, S. Kempe, and P. Köhler, 2009: Global $\mathrm{CO}_{2}$ consumption by chemical weathering: What is the contribution of highly active weathering regions? Global Planet. Change, 69, 185-194.

Harvey, L. D. D., 2008: Mitigating the atmospheric $\mathrm{CO}_{2}$ increase and ocean acidification by adding limestone powder to upwelling regions. J. Geophys. Res., $113, \mathrm{C} 04028$.

Haverd, V., et al., 2013: The Australian terrestrial carbon budget. Biogeosciences, $10,851-869$.

Hedegaard, G. B., J. Brandt, J. H. Christensen, L. M. Frohn, C. Geels, K. M. Hansen, and M. Stendel, 2008: Impacts of climate change on air pollution levels in the Northern Hemisphere with special focus on Europe and the Arctic. Atmos. Chem. Phys., 8, 3337-3367.

Heijmans, M. M. P. D., W. J. Arp, and F. Berendse, 2001: Effects of elevated $\mathrm{CO}_{2}$ and vascular plants on evapotranspiration in bog vegetation. Global Change Biol., 7, 817-827. 
Heijmans, M. M. P. D., H. Klees, and F. Berendse, 2002a: Competition between Sphagnum magellanicum and Eriophorum angustifolium as affected by raised $\mathrm{CO}_{2}$ and increased $\mathrm{N}$ deposition. Oikos, 97, 415-425.

Heijmans, M. M. P. D., H. Klees, W. de Visser, and F. Berendse, 2002b: Response of a Sphagnum bog plant community to elevated $\mathrm{CO}_{2}$ and $\mathrm{N}$ supply. Plant Ecol., $162,123-134$.

Hein, R., P. J. Crutzen, and M. Heimann, 1997: An inverse modeling approach to investigate the global atmospheric methane cycle. Global Biogeochem. Cycles, 11, 43-76.

Held, I. M., M. Winton, K. Takahashi, T. Delworth, F. Zeng, and G. K. Vallis, 2010: Probing the fast and slow components of global warming by returning abruptly to preindustrial forcing. J. Clim., 23, 2418-2427.

Herridge, D. F., M. B. Peoples, and R. M. Boddey, 2008: Global inputs of biological nitrogen fixation in agricultural systems. Plant Soil, 311, 1-18.

Herzog, H., K. Caldeira, and J. Reilly, 2003: An issue of permanence: Assessing the effectiveness of temporary carbon storage. Clim. Change, 59, 293-310.

Hibbard, K. A., G. A. Meehl, P. M. Cox, and P. Friedlingstein, 2007: A strategy for climate change stabilization experiments. EOS Trans. Am. Geophys. Union, 88, 217-221.

Hickler, T., B. Smith, I. C. Prentice, K. Mjöfors, P. Miller, A. Arneth, and M. T. Sykes, 2008: $\mathrm{CO}_{2}$ fertilization in temperate FACE experiments not representative of boreal and trophical forests. Global Change Biol., 14, 1531-1542.

Hietz, P., B. L. Turner, W. Wanek, A. Richter, C. A. Nock, and S. J. Wright, 2011: Longterm change in the nitrogen cycle of tropical forests. Science, 334, 664-666.

Higgins, P. A. T., and J. Harte, 2012: Carbon cycle uncertainty increases climate change risks and mitigation challenges. J. Clim., 25, 7660-7668.

Hirota, M., M. Holmgren, E. H. Van Nes, and M. Scheffer, 2011: Global resilience of tropical forest and savanna to critical transitions. Science, 334, 232-235.

Hirsch, A. I., A. M. Michalak, L. M. Bruhwiler, W. Peters, E. J. Dlugokencky, and P. P. Tans, 2006: Inverse modeling estimates of the global nitrous oxide surface flux from 1998 to 2001. Global Biogeochem. Cycles, 20, GB1008.

Hodson, E. L., B. Poulter, N. E. Zimmermann, C. Prigent, and J. O. Kaplan, 2011: The El Nino-Southern Oscillation and wetland methane interannual variability. Geophys. Res. Lett., 38, L08810.

Hoelzemann, J. J., M. G. Schultz, G. P. Brasseur, C. Granier, and M. Simon, 2004: Global Wildland Fire Emission Model (GWEM): Evaluating the use of global area burnt satellite data. J. Geophys. Res. Atmos., 109, D14S04.

Hofmann, M., and H.-J. Schellnhuber, 2009: Oceanic acidification affects marine carbon pump and triggers extended marine oxygen holes. Proc. Natl. Acad. Sci. U.S.A., 106, 3017-3022.

Holland, E. A., J. Lee-Taylor, C. D. Nevison, and J. Sulzman, 2005: Global N cycle: Fluxes and $\mathrm{N}_{2} \mathrm{O}$ mixing ratios originating from human activity. Data set. Oak Ridge National Laboratory Distributed Active Archive Center, Oak Ridge National Laboratory, Oak Ridge, TN. Retrieved from http://www.daac.ornl.gov

Hönisch, B., N. G. Hemming, D. Archer, M. Siddall, and J. F. McManus, 2009: Atmospheric carbon dioxide concentration across the mid-Pleistocene transition. Science, 324, 1551-1554.

Hooijer, A., S. Page, J. G. Canadell, M. Silvius, J. Kwadijk, H. Wösten, and J. Jauhiainen, 2010: Current and future $\mathrm{CO}_{2}$ emissions from drained peatlands in Southeast Asia. Biogeosciences, 7, 1505-1514.

Hopcroft, P. O., P. J. Valdes, and D. J. Beerling, 2011: Simulating idealized DansgaardOeschger events and their potential impacts on the global methane cycle. Quat. Sci. Rev., 30, 3258-3268.

Houghton, R. A., 2003: Revised estimates of the annual net flux of carbon to the atmosphere from changes in land use and land management 1850-2000. Tellus $B, 55,378-390$.

Houghton, R. A., 2010: How well do we know the flux of $\mathrm{CO}_{2}$ from land-use change? Tellus B, 62, 337-351.

Houghton, R. A., et al., 2012: Carbon emissions from land use and land-cover change. Biogeosciences, 9, 5125-5142.

House, J. I., I. C. Prentice, and C. Le Quéré, 2002: Maximum impacts of future reforestation or deforestation on atmospheric $\mathrm{CO}_{2}$. Global Change Biol., 8, 1047-1052.

House, K. Z., D. P. Schrag, C. F. Harvey, and K. S. Lackner, 2006: Permanent carbon dioxide storage in deep-sea sediments. Proc. Natl. Acad. Sci. U.S.A., 103, 14255.

House, K. Z., C. H. House, D. P. Schrag, and M. J. Aziz, 2007: Electrochemical acceleration of chemical weathering as an energetically feasible approach to mitigating anthropogenic climate change. Environ. Sci. Technol., 41, 8464-8470.
Hsu, J., and M. J. Prather, 2010: Global long-lived chemical modes excited in a 3-D chemistry transport model: Stratospheric $\mathrm{N}_{2} \mathrm{O}, \mathrm{NOy}, \mathrm{O}_{3}$ and $\mathrm{CH}_{4}$ chemistry. Geophys. Res. Lett., 37, L07805.

Huang, J., et al., 2008: Estimation of regional emissions of nitrous oxide from 1997 to 2005 using multinetwork measurements: A chemical transport model, and an inverse method. J. Geophys. Res., 113, D17313.

Huber, C., et al., 2006: Isotope calibrated Greenland temperature record over Marine Isotope Stage 3 and its relation to $\mathrm{CH}_{4}$. Earth Planet. Sci. Lett., 243, 504-519.

Hunter, S. J., A. M. Haywood, D. S. Goldobin, A. Ridgwell, and J. G. Rees, 2013: Sensitivity of the global submarine hydrate inventory to scenarious of future climate change. Earth Planet. Sci. Lett., 367, 105-115.

Huntingford, C., J. A. Lowe, B. B. B. Booth, C. D. Jones, G. R. Harris, L. K. Gohar, and P. Meir, 2009: Contributions of carbon cycle uncertainty to future climate projection spread. Tellus $B, 61,355-360$.

Huntingford, $C$., et al., 2013: Simulated resilience of tropical rainforests to $\mathrm{CO}_{2-}$ induced climate change. Nature Geosci., 6, 268-273.

Hurtt, G. C., et al., 2011: Harmonization of land-use scenarios for the period 15002100: 600 years of global gridded annual land-use transitions, wood harvest, and resulting secondary lands. Clim. Change, 109, 117-161.

Huybers, P., and C. Langmuir, 2009: Feedback between deglaciation, volcanism, and atmospheric $\mathrm{CO}_{2}$. Earth Planet. Sci. Lett., 286, 479-491.

Indermühle, A., et al., 1999: Holocene carbon-cycle dynamics based on $\mathrm{CO}_{2}$ trapped in ice at Taylor Dome, Antarctica. Nature, 398, 121-126.

Irvine, P. J., A. Ridgwell, and D. J. Lunt, 2010: Assessing the regional disparities in geoengineering impacts. Geophys. Res. Lett., 37, L18702.

Ise, T., A. L. Dunn, S. C. Wofsy, and P. R. Moorcroft, 2008: High sensitivity of peat decomposition to climate change through water-table feedback. Nature Geosci., $1,763-766$.

Ishii, M., N. Kosugi, D. Sasano, S. Saito, T. Midorikawa, and H. Y. Inoue, 2011: Ocean acidification off the south coast of Japan: A result from time series observations of $\mathrm{CO}_{2}$ parameters from 1994 to 2008. J. Geophys. Res. Oceans, 116, $\mathrm{C} 06022$.

Ishii, M., et al., 2009: Spatial variability and decadal trend of the oceanic $\mathrm{CO}_{2}$ in the western equatorial Pacific warm/fresh water. Deep-Sea Res. Pt. II, 56, 591-606.

Ishijima, K., T. Nakazawa, and S. Aoki, 2009: Variations of atmospheric nitrous oxide concentration in the northern and western Pacific. Tellus B, 61, 408-415.

Ito, A., and J. E. Penner, 2004: Global estimates of biomass burning emissions based on satellite imagery for the year 2000. J. Geophys. Res., 109, D14S05.

Ito, A., and M. Inatomi, 2012: Use of a process-based model for assessing the methane budgets of global terrestrial ecosystems and evaluation of uncertainty. Biogeosciences, 9, 759-773.

ludicone, D., et al., 2011: Water masses as a unifying framework for understanding the Southern Ocean Carbon Cycle. Biogeosciences, 8, 1031-1052.

Iversen, T., et al., 2013: The Norwegian Earth System Model, NorESM1-M. Part 2: Climate response and scenario projections. Geosci. Model Dev., 6, 389-415.

Jaccard, S. L., and E. D. Galbraith, 2012: Large climate-driven changes of oceanic oxygen concentrations during the last deglaciation. Nature Geosci., 5, 151-156.

Jaccard, S. L., G. H. Haug, D. M. Sigman, T. F. Pedersen, H. R. Thierstein, and U. R?hl, 2005: Glacial/interglacial changes in subarctic North Pacific stratification. Science, 308, 1003-1006.

Jacobson, A. R., S. E. Mikaloff Fletcher, N. Gruber, J. L. Sarmiento, and M. Gloor, 2007: A joint atmosphere-ocean inversion for surface fluxes of carbon dioxide: 2 . Regional results. Global Biogeochem. Cycles, 21, GB1020.

Jacquet, S. H. M., N. Savoye, F. Dehairs, V. H. Strass, and D. Cardinal, 2008: Mesopelagic carbon remineralization during the European Iron Fertilization Experiment. Global Biogeochem. Cycles, 22, 1-9.

Jain, A., X. J. Yang, H. Kheshgi, A. D. McGuire, W. Post, and D. Kicklighter, 2009: Nitrogen attenuation of terrestrial carbon cycle response to global environmental factors. Global Biogeochem. Cycles, 23, GB4028.

Jin, X., and N. Gruber, 2003: Offsetting the radiative benefit of ocean iron fertilization by enhancing $\mathrm{N}_{2} \mathrm{O}$ emissions. Geophys. Res. Lett., 30, 24, 2249.

Jones, C., S. Liddicoat, and J. Lowe, 2010: Role of terrestrial ecosystems in determining $\mathrm{CO}_{2}$ stabilization and recovery behaviour. Tellus $B, 62,682-699$.

Jones, C., M. Collins, P. M. Cox, and S. A. Spall, 2001: The carbon cycle response to ENSO: A coupled climate-carbon cycle model study. J. Clim., 14, 4113-4129.

Jones, C., J. Lowe, S. Liddicoat, and R. Betts, 2009: Committed terrestrial ecosystem changes due to climate change. Nature Geosci., 2, 484-487.

Jones, C., et al., 2013: 21 th Century compatible $\mathrm{CO}_{2}$ emissions and airborne fraction simulated by CMIP5 Earth System models under 4 Representative Concentration Pathways. J. Clim., 26, 4398-4413. 
Jones, C. D., and P. M. Cox, 2001: Modeling the volcanic signal in the atmospheric $\mathrm{CO}_{2}$ record. Global Biogeochem. Cycles, 15, 453-465.

Jones, C. D., and P. Falloon, 2009: Sources of uncertainty in global modelling of future soil organic carbon storage. In: Uncertainties in Environmental Modelling and Consequences for Policy Making [P. Bavaye, J. Mysiak and M. Laba (eds.)]. Springer Science+Business Media, New York, NY, USA and Heidelberg, Germany, pp. 283-315.

Jones, C. D., P. M. Cox, and C. Huntingford, 2006: Impact of climate carbon cycle feedbacks on emission scenarios to achieve stabilization. In:Avoiding Dangerous Climate Change [H. J. Schellnhuber, W. Cramer, N. Nakicenovic, T. Wigley and G. Yohe (eds.)]. Cambridge University Press, Cambridge, United Kingdom, and New York, NY, USA, pp. 323-332.

Jones, C. D., et al., 2011: The HadGEM2-ES implementation of CMIP5 centennial simulations. Geosci. Model Dev. 4, 543-570.

Joos, F., and R. Spahni, 2008: Rates of change in natural and anthropogenic radiative forcing over the past 20,000 years. Proc. Natl. Acad. Sci. U.S.A., 105, 1425-1430.

Joos, F., J. L. Sarmiento, and U. Siegenthaler, 1991: Estimates of the effect of Southern-Ocean iron fertilization on atmospheric $\mathrm{CO}_{2}$ concentrations. Nature, $349,772-775$

Joos, F., T. L. Frölicher, M. Steinacher, and G.-K. Plattner, 2011: Impact of climate change mitigation on ocean acidification projections. In: Ocean Acidification [J. P. Gattuso and L. Hansson (eds.)]. Oxford University Press, Oxford, United Kingdom, and New York, NY, USA, pp. 273-289.

Joos, F., S. Gerber, I. C. Prentice, B. L. Otto-Bliesner, and P. J. Valdes, 2004: Transient simulations of Holocene atmospheric carbon dioxide and terrestrial carbon since the Last Glacial Maximum. Global Biogeochem. Cycles, 18, Gb2002.

Joos, F., et al., 2013: Carbon dioxide and climate impulse response functions for the computation of greenhouse gas metrics: A multi-model analysis. Atmos. Chem. Phys., 13, 2793-2825.

Jorgenson, M. T., Y. L. Shur, and E. R. Pullman, 2006: Abrupt increase in permafrost degradation in Arctic Alaska. Geophys. Res. Lett., 33, L02503.

Jung, M., et al., 2007: Assessing the ability of three land ecosystem models to simulate gross carbon uptake of forests from boreal to Mediterranean climate in Europe. Biogeosciences, 4, 647-656.

Jung, M., et al., 2011: Global patterns of land-atmosphere fluxes of carbon dioxide, latent heat, and sensible heat derived from eddy covariance, satellite, and meteorological observations. J. Geophys. Res. Biogeosci., 116, G00J07.

Jungclaus, J. H., et al., 2010: Climate and carbon-cycle variability over the last millennium. Clim. Past, 6, 723-737.

Kai, F. M., S. C. Tyler, J. T. Randerson, and D. R. Blake, 2011: Reduced methane growth rate explained by decreased Northern Hemisphere microbial sources. Nature, 476, 194-197.

Kanakidou, M., et al., 2012: Atmospheric fluxes of organic N and P to the global ocean. Global Biogeochem. Cycles, 26, GB3026.

Kaplan, J. O., G. Folberth, and D. A. Hauglustaine, 2006: Role of methane and biogenic volatile organic compound sources in late glacial and Holocene fluctuations of atmospheric methane concentrations. Global Biogeochem. Cycles, 20, Gb2016.

Kaplan, J. O., I. C. Prentice, W. Knorr, and P. J. Valdes, 2002: Modeling the dynamics of terrestrial carbon storage since the Last Glacial Maximum. Geophys. Res. Lett., 29, 31-1-31-4.

Kaplan, J. O., K. M. Krumhardt, E. C. Ellis, W. F. Ruddiman, C. Lemmen, and K. Klein Goldewijk, 2011: Holocene carbon emissions as a result of anthropogenic land cover change. Holocene, 21, 775-791.

Karl, D. M., and R. M. Letelier, 2008: Nitrogen fixation-enhanced carbon sequestration in low nitrate, low chlorophyll seascapes. Mar. Ecol. Prog. Ser., 364, 257-268.

Kato, E., T. Kinoshita, A. Ito, M. Kawamiya, and Y. Yamagata, 2013: Evaluation of spatially explicit emission scenario of land-use change and biomass burning using a process-based biogeochemical model. J. Land Use Sci, , 8, 104-122.

Keeling, C. D., 1960: The concentration and isotopic abundances of carbon dioxide in the atmosphere. Tellus $B, 12,200-203$.

Keeling, C. D., S. C. Piper, and M. Heimann, 1989: A three dimensional model of atmospheric $\mathrm{CO}_{2}$ transport based on observed winds: 4. Mean annual gradients and interannual variations. In: Aspects of Climate Variability in the Pacific and the Western Americas [D. H. Peterson (ed.)]. Geophysical Monograph Series, Vol. 55. American Geophysical Union, Washington, DC, pp. 305-363.

Keeling, C. D., R. B. Bacastow, A. E. Bainbridge, C. A. Ekdahl, P. R. Guenther, L. S Waterman, and J. F. S. Chin, 1976: Atmospheric carbon-dioxide variations at Mauna-Loa Observatory, Hawaii. Tellus, 28, 538-551.
Keeling, C. D. S. C. Piper, R. B. Bacastow, M. Wahlen, T. P. Whorf, M. Heimann, and H. A. Meijer, 2005: Atmospheric $\mathrm{CO}_{2}$ and ${ }^{13} \mathrm{CO}_{2}$ exchange with the terrestrial biosphere and oceans from 1978 to 2000: Observations and carbon cycle implications. In: A History of Atmospheric $\mathrm{CO}_{2}$ and Its Effects on Plants, Animals, and Ecosystems [J. R. Ehleringer, T. E. Cerling and M. D. Dearing (eds.)]. Springer Science+Business Media, New York, NY, USA, and Heidelberg, Germany, pp. $83-113$.

Keeling, R. F., and S. R. Shertz, 1992: Seasonal and interannual variations in atmospheric oxygen and implications for the global carbon cycle. Nature, 358 723-727.

Keeling, R. F., S. C. Piper, and M. Heimann, 1996: Global and hemispheric $\mathrm{CO}_{2}$ sinks deduced from changes in atmospheric $\mathrm{O}_{2}$ concentration. Nature, 381, 218-221.

Keeling, R. F., A. Körtzinger, and N. Gruber, 2010: Ocean deoxygenation in a warming world. Annu. Rev. Mar. Sci. , 2, 199-229.

Keenan, T. F., et al., 2012: Terrestrial biosphere model performance for inter-annual variability of land-atmosphere $\mathrm{CO}_{2}$ exchange. Global Change Biol., 18, 19711987.

Keith, D. W., 2001: Geoengineering. Nature, 409, 420.

Keith, D. W., M. Ha-Duong, and J. K. Stolaroff, 2006: Climate strategy with $\mathrm{CO}_{2}$ capture from the air. Clim. Change, 74, 17-45.

Kelemen, P. B., and J. Matter, 2008: In situ carbonation of peridotite for $\mathrm{CO}_{2}$ storage. Proc. Natl. Acad. Sci. U.S.A., 105, 17295-17300.

Kellomäki, S., H. Peltola, T. Nuutinen, K. T. Korhonen, and H. Strandman, 2008: Sensitivity of managed boreal forests in Finland to climate change, with implications for adaptive management. Philos. Trans. R. Soc. London Ser. B, 363, 2341-2351.

Keppler, F., J. T. G. Hamilton, M. Bra?? and T. Röckmann, 2006: Methane emissions from terrestrial plants under aerobic conditions. Nature, 439, 187-191.

Kesik, M., et al., 2006: Future scenarios of $\mathrm{N}_{2} \mathrm{O}$ and $\mathrm{NO}$ emissions from European forest soils. J. Geophys. Res. Biogeosci., 111, G02018.

Key, R. M., et al., 2004: A global ocean carbon climatology: Results from Global Data Analysis Project (GLODAP). Global Biogeochem. Cycles, 18, GB4031.

Khalil, M. A. K., and R. A. Rasmussen, 1989: Climate-induced feedbacks for the global cycles of methane and nitrous oxide. Tellus $B, 41,554-559$.

Khalil, M. A. K., C. L. Butenhoff, and R. A. Rasmussen, 2007: Atmospheric methane: Trends and cycles of sources and sinks. Environ. Sci. Technol., 41, 2131-2137.

Khatiwala, S., F. Primeau, and T. Hall, 2009: Reconstruction of the history of anthropogenic $\mathrm{CO}_{2}$ concentrations in the ocean. Nature, 462, 346-349.

Kheshgi, H. S., 1995: Sequestering atmospheric carbon-dioxide by increasing ocean alkalinity. Energy, 20, 915-922.

Khvorostyanov, D., P. Ciais, G. Krinner, and S. Zimov, 2008: Vulnerability of east Siberia's frozen carbon stores to future warming. Geophys. Res. Lett., 35, L10703.

Kim, J. H., et al., 2004: North Pacific and North Atlantic sea-surface temperature variability during the Holocene. Quat. Sci. Rev., 23, 2141-2154.

King, A. W., D. J. Hayes, D. N. Huntzinger, T. O. West, and W. M. Post, 2012: North America carbon dioxide sources and sinks: Magnitude, attribution, and uncertainty. Front. Ecol. Environ., 10, 512-519.

Kirschbaum, M. U. F., 2003: Can trees buy time? An assessment of the role of vegetation sinks as part of the global carbon cycle. Clim. Change, 58, 47-71.

Kirschbaum, M. U. F., and A. Walcroft, 2008: No detectable aerobic methane efflux from plant material, nor from adsorption/desorption processes. Biogeosciences, 5, 1551-1558.

Kleinen, T., V. Brovkin, and R. J. Schuldt, 2012: A dynamic model of wetland extent and peat accumulation: Results for the Holocene. Biogeosciences, 9, 235-248.

Kleinen, T., V. Brovkin, W. von Bloh, D. Archer, and G. Munhoven, 2010: Holocene carbon cycle dynamics. Geophys. Res. Lett., 37, L02705.

Kloster, S., N. M. Mahowald, J. T. Randerson, and P. J. Lawrence, 2012: The impacts of climate, land use, and demography on fires during the 21st century simulated by CLM-CN. Biogeosciences, 9, 509-525.

Knorr, W., 2009: Is the airborne fraction of anthropogenic emissions increasing? Geophys. Res. Lett., 36, L21710.

Kohfeld, K. E., and A. Ridgwell, 2009: Glacial-interglacial variability in atmospheric $\mathrm{CO}_{2}$. In: Surface Ocean-Lower Atmospheres Processes [C. Le Quéré and E. S. Saltzman (eds.)]. American Geophysical Union, Washington, DC, pp. 251-286.

Köhler, P., J. Hartmann, and D. A. Wolf-Gladrow, 2010: Geoengineering potential of artificially enhanced silicate weathering of olivine. Proc. Natl. Acad. Sci. U.S.A., 107, 20228-20233. 
Köhler, P., H. Fischer, G. Munhoven, and R. E. Zeebe, 2005: Quantitative interpretation of atmospheric carbon records over the last glacial termination. Global Biogeochem. Cycles, 19, GB4020.

Konijnendijk, T. Y. M., S. L. Weber, E. Tuenter, and M. van Weele, 2011: Methane variations on orbital timescales: A transient modeling experiment. Clim. Past, 7, 635-648.

Koven, C. D., W. J. Riley, and A. Stern, 2013: Analysis of permafrost thermal dynamics and response to climate change in the CMIP5 Earth System Models. J. Clim., 26, 1877-1900.

Koven, C. D., et al., 2011: Permafrost carbon-climate feedbacks accelerate global warming. Proc. Natl. Acad. Sci. U.S.A., 108, 14769-14774.

Krawchuk, M. A., M. A. Moritz, M.-A. Parisien, J. Van Dorn, and K. Hayhoe, 2009: Global pyrogeography: The current and future distribution of wildfire. PLOS ONE, 4, e5102.

Kraxner, F., S. Nilsson, and M. Obersteiner, 2003: Negative emissions from BioEnergy use, carbon capture and sequestration (BECS) - the case of biomass production by sustainable forest management from semi-natural temperate forests. Biomass Bioenerg., 24, 285-296.

Krinner, G., et al., 2005: A dynamic global vegetation model for studies of the coupled atmosphere-biosphere system. Global Biogeochem. Cycles, 19, GB1015.

Krishnamurthy, A., J. K. Moore, N. Mahowald, C. Luo, S. C. Doney, K. Lindsay, and C. S. Zender, 2009: Impacts of increasing anthropogenic soluble iron and nitrogen deposition on ocean biogeochemistry. Global Biogeochem. Cycles, 23, GB3016.

Kroeze, C., A. Mosier, and L. Bouwman, 1999: Closing the global $\mathrm{N}_{2} \mathrm{O}$ budget: $\mathrm{A}$ retrospective analysis 1500-1994. Global Biogeochem. Cycles, 13, 1-8.

Kroeze, C., L. Bouwman, and C. P. Slomp, 2007: Sinks for $\mathrm{N}_{2} \mathrm{O}$ at the Earth's surface. In: Greenhouse Gas Sinks [D. S. Raey, M. Hewitt, J. Grace and K. A. Smith (eds.)]. CAB International, pp. 227-243.

Kroeze, C., E. Dumont, and S. P. Seitzinger, 2010: Future trends in emissions of $\mathrm{N}_{2} \mathrm{O}$ from rivers and estuaries. J. Integrat. Environ. Sci, 7, 71-78.

Kurahashi-Nakamura, T., A. Abe-Ouchi, Y. Yamanaka, and K. Misumi, 2007: Compound effects of Antarctic sea ice on atmospheric $\mathrm{pCO}_{2}$ change during glacial-interglacial cycle. Geophys. Res. Lett., 34, L20708.

Kurz, W. A., G. Stinson, and G. Rampley, 2008a: Could increased boreal forest ecosystem productivity offset carbon losses from increased disturbances? Philos. Trans. R. Soc. London Ser. B, 363, 2261-2269.

Kurz, W. A., G. Stinson, G. J. Rampley, C. C. Dymond, and E. T. Neilson, 2008b: Risk of natural disturbances makes future contribution of Canada's forests to the global carbon cycle highly uncertain. Proc. Natl. Acad. Sci. U.S.A., 105, 1551-1555.

Kurz, W. A., et al., 2008c: Mountain pine beetle and forest carbon feedback to climate change. Nature, 452, 987-990.

Kwon, E. Y., F. Primeau, and J. L. Sarmiento, 2009: The impact of remineralization depth on the air-sea carbon balance. Nature Geosci. , 2, 630-635.

Lackner, K. S., 2009: Capture of carbon dioxide from ambient air. Eur. Phys. J. Spec. Topics, 176, 93-106.

Lackner, K. S., 2010: Washing carbon out of the air. Sci. Am., 302, 66-71.

Lackner, K. S., S. Brennan, J. M. Matter, A.-H. A. Park, A. Wright, and B. van der Zwaan, 2012: The urgency of the development of $\mathrm{CO}_{2}$ capture from ambient air. Proc. Natl. Acad. Sci. U.S.A., 109, 13156-13162.

Lal, R., 2004a: Soil carbon sequestration impacts on global climate change and food security. Science, 304, 1623-1627.

Lal, R., 2004b: Soil carbon sequestration to mitigate climate change. Geoderma, $123,1-22$.

Lamarque, J.-F., 2008: Estimating the potential for methane clathrate instability in the $1 \%-\mathrm{CO}_{2}$ IPCC AR-4 simulations. Geophys. Res. Lett., 35, L19806.

Lamarque, J.-F., et al., 2010: Historical (1850-2000) gridded anthropogenic and biomass burning emissions of reactive gases and aerosols: Methodology and application. Atmos. Chem. Phys., 10, 7017-7039.

Lamarque, J.-F., et al., 2013: The Atmospheric Chemistry and Climate Model Intercomparison Project (ACCMIP): Overview and description of models, simulations and climate diagnostics. Geosci. Model Dev., 6, 179-206.

Lamarque, J. F., et al., 2011: Global and regional evolution of short-lived radiativelyactive gases and aerosols in the Representative Concentration Pathways. Clim. Change, 109, 191-212.

Lampitt, R. S., et al., 2008: Ocean fertilization: A potential means of geoengineering? Philos. Trans. R. Soc. London Ser. A, 366, 3919-3945.

Langenfelds, R. L., R. J. Francey, B. C. Pak, L. P. Steele, J. Lloyd, C. M. Trudinger, and C. E. Allison, 2002: Interannual growth rate variations of atmospheric $\mathrm{CO}_{2}$ and its $\mathrm{d}^{13} \mathrm{C}_{1} \mathrm{H}_{2}, \mathrm{CH}_{4}$, and $\mathrm{CO}$ between 1992 and 1999 linked to biomass burning. Global
Biogeochem. Cycles, 16, 1048.

Langner, J., R. Bergstrom, and V. Foltescu, 2005: Impact of climate change on surface ozone and deposition of sulphur and nitrogen in Europe. Atmos. Environ., 39, $1129-1141$.

Larsen, K. S., et al., 2011: Reduced N cycling in response to elevated $\mathrm{CO}_{2}$, warming, and drought in a Danish heathland: Synthesizing results of the CLIMAITE project after two years of treatments. Global Change Biol., 17, 1884-1899.

Lassey, K. R., D. C. Lowe, and A. M. Smith, 2007: The atmospheric cycling of radiomethane and the "fossil fraction" of the methane source. Atmos. Chem. Phys., 7, 2141-2149.

Law, R. M., R. J. Matear, and R. J. Francey, 2008: Comment on "Saturation of the Southern Ocean $\mathrm{CO}_{2}$ sink due to recent climate change". Science, 319, 570a.

Lawrence, D., et al., 2011: Parameterization improvements and functional and structural advances in version 4 of the Community Land Model. J. Adv. Model. Earth Syst., 3, M03001, 27 pp.

Lawrence, D. M., and A. G. Slater, 2005: A projection of severe near-surface permafrost degradation during the 21st century. Geophys. Res. Lett., 32, L24401.

Lawrence, D. M., A. G. Slater, V. E. Romanovsky, and D. J. Nicolsky, 2008: Sensitivity of a model projection of near-surface permafrost degradation to soil column depth and representation of soil organic matter. J. Geophys. Res. Earth Surf., 113, F02011.

Le Page, Y., G. R. van der Werf, D. C. Morton, and J. M. C. Pereira, 2010: Modeling firedriven deforestation potential in Amazonia under current and projected climate conditions. J. Geophys. Res. Biogeosci., 115, G03012.

Le Quéré, C., T. Takahashi, E. T. Buitenhuis, C. Rodenbeck, and S. C. Sutherland, 2010: Impact of climate change and variability on the global oceanic sink of $\mathrm{CO}_{2}$. Global Biogeochem. Cycles, 24, GB4007.

Le Quéré, C., et al., 2007: Saturation of the southern ocean $\mathrm{CO}_{2}$ sink due to recent climate change. Science, 316, 1735-1738.

Le Quéré, C., et al., 2009: Trends in the sources and sinks of carbon dioxide. Nature Geosci., 2, 831-836.

Le Quéré, C., et al., 2013: The global carbon budget 1959-2011. Earth Syst. Sci. Data, 5, 165-186.

LeBauer, D. S., and K. K. Treseder, 2008: Nitrogen limitation of net primary productivity in terrestrial ecosystems is globally distributed. Ecology, 89, 371-379.

Lee, X., et al., 2011: Observed increase in local cooling effect of deforestation at higher latitudes. Nature, 479, 384-387.

Lemmen, C., 2009: World distribution of land cover changes during Pre- and Protohistoric Times and estimation of induced carbon releases. Geomorphol. Relief Proc. Environ., 4, 303-312.

Lenton, A., and R. J. Matear, 2007: Role of the Southern Annular Mode (SAM) in Southern Ocean $\mathrm{CO}_{2}$ uptake. Global Biogeochem. Cycles, 21, Gb2016.

Lenton, T. M., and C. Britton, 2006: Enhanced carbonate and silicate weathering accelerates recovery from fossil fuel $\mathrm{CO}_{2}$ perturbations. Global Biogeochem. Cycles, 20, Gb3009.

Lenton, T. M., and N. E. Vaughan, 2009: The radiative forcing potential of different climate geoengineering options. Atmos. Chem. Phys., 9, 5539-5561.

Lepistö, A., P. Kortelainen, and T. Mattsson, 2008: Increased organic C and N leaching in a northern boreal river basin in Finland. Global Biogeochem. Cycles, 22, GB3029.

LeQuere, C., T. Takahashi, E. T. Buitenhuis, C. Rodenbeck, and S. C. Sutherland, 2010: Impact of climate change and variability on the global oceanic sink of $\mathrm{CO2}$. Global Biogeochem. Cycles, 24.

Leuzinger, S., Y. Q. Luo, C. Beier, W. Dieleman, S. Vicca, and C. Körner, 2011: Do global change experiments overestimate impacts on terrestrial ecosystems? Trends Ecol. Evol., 26, 236-241.

Levin, I., et al., 2010: Observations and modelling of the global distribution and longterm trend of atmospheric ${ }^{14} \mathrm{CO}_{2}$. Tellus $B, 62,26-46$.

Levin, I., et al., 2012: No inter-hemispheric ${ }^{13} \mathrm{CH}_{4}$ trend observed. Nature, 486, E3E4.

Levine, J. G., E. W. Wolff, P. O. Hopcroft, and P. J. Valdes, 2012: Controls on the tropospheric oxidizing capacity during an idealized Dansgaard-Oeschger event, and their implications for the rapid rises in atmospheric methane during the last glacial period. Geophys. Res. Lett., 39, L12805.

Levine, J. G., et al., 2011: Reconciling the changes in atmospheric methane sources and sinks between the Last Glacial Maximum and the pre-industrial era. Geophys. Res. Lett., 38, L23804. 
Levy, P. E., M. G. R. Cannell, and A. D. Friend, 2004: Modelling the impact of future changes in climate, $\mathrm{CO}_{2}$ concentration and land use on natural ecosystems and the terrestrial carbon sink. Global Environ. Change, 14, 21-30.

Lewis, S. L., P. M. Brando, O. L. Phillips, G. M. van der Heijden, and D. Nepstad, 2011: The 2010 Amazon drought. Science, 331, 554.

Lewis, S. L., et al., 2009: Increasing carbon storage in intact African tropical forests. Nature, 457, 1003-1006.

Li, C., S. Frolking, and K. Butterbach-Bahl, 2005: Carbon sequestration can increase nitrous oxide emissions. Clim. Change, 72, 321-338.

Liberloo, M., et al., 2009: Coppicing shifts $\mathrm{CO}_{2}$ stimulation of poplar productivity to above-ground pools: A synthesis of leaf to stand level results from the POP/ EUROFACE experiment. New Phytologist, 182, 331-346.

Liddicoat, S., C. Jones, and E. Robertson, 2013: $\mathrm{CO}_{2}$ emissions determined by HadGEM2-ES to be compatible with the Representative Concentration Pathway scenarious and their extension. J. Clim., 26, 4381-4397.

Lohila, A., M. Aurela, J. Hatakka, M. Pihlatie, K. Minkkinen, T. Penttilä, and T. Laurila, 2010: Responses of $\mathrm{N}_{2} \mathrm{O}$ fluxes to temperature, water table and $\mathrm{N}$ deposition in a northern boreal fen. Eur. J. Soil Sci., 61, 651-661.

Long, M. C., K. Lindsay, S. Peacock, J. K. Moore, and S. C. Doney, 2013: Twentiethcentury oceanic carbon uptake and storage in CESM1(BGC). J. Clim., 26, 67756800.

Loose, B., and P. Schlosser, 2011: Sea ice and its effect on $\mathrm{CO}_{2}$ flux between the atmosphere and the Southern Ocean interior. J. Geophys. Res. Oceans, 116, C11.

Loulergue, L., et al., 2008: Orbital and millennial-scale features of atmospheric $\mathrm{CH}_{4}$ over the past 800,000 years. Nature, 453, 383-386.

Lourantou, A., and N. Metzl, 2011: Decadal evolution of carbon sink within a strong bloom area in the subantarctic zone. Geophys. Res. Lett., 38, L23608.

Lourantou, A., J. Chappellaz, J.-M. Barnola, V. Masson-Delmotte, and D. Raynaud, 2010a: Changes in atmospheric $\mathrm{CO}_{2}$ and its carbon isotopic ratio during the penultimate deglaciation. Quat. Sci. Rev., 29, 1983-1992.

Lourantou, A., et al., 2010b: Constraint of the $\mathrm{CO}_{2}$ rise by new atmospheric carbon isotopic measurements during the last deglaciation. Global Biogeochem. Cycles, 24, GB2015.

Lovelock, J. E., and C. G. Rapley, 2007: Ocean pipes could help the Earth to cure itself. Nature, 449, 403-403.

Lovenduski, N. S., N. Gruber, and S. C. Doney, 2008: Towards a mechanistic understanding of the decadal trends in the Southern Ocean carbon sink. Global Biogeochem. Cycles, 22, GB3016.

Lovenduski, N. S., N. Gruber, S. C. Doney, and I. D. Lima, 2007: Enhanced $\mathrm{CO}_{2}$ outgassing in the Southern Ocean from a positive phase of the Southern Annular Mode. Global Biogeochem. Cycles, 21, Gb2026.

Lucht, W., et al., 2002: Climatic control of the high-latitude vegetation greening trend and Pinatubo effect. Science, 296, 1687-1689.

Luo, Y., D. Hui, and D. Zhang, 2006: Elevated carbon dioxide stimulates net accumulations of carbon and nitrogen in terrestrial ecosystems: A meta-analysis. Ecology, 87, 53-63.

Luo, Y., et al., 2004: Progressive nitrogen limitation of ecosystem responses to rising atmospheric carbon dioxide. BioScience, 54, 731-739.

Lüthi, D., et al., 2008: High-resolution carbon dioxide concentration record 650,000800,000 years before present. Nature, 453, 379-382.

Luyssaert, S., et al., 2010: The European carbon balance. Part 3: Forests. Global Change Biol., 16, 1429-1450.

Luyssaert, S., et al., 2012: The European land and inland water $\mathrm{CO}_{2}, \mathrm{CO}, \mathrm{CH}_{4}$ and $\mathrm{N}_{2} \mathrm{O}$ balance between 2001 and 2005. Biogeosciences, 9, 3357-3380.

MacDonald, G. M., K. V. Kremenetski, and D. W. Beilman, 2008: Climate change and the northern Russian treeline zone. Philos. Trans. R. Soc. London Ser. B, 363, 2285-2299.

6 MacDougall, A. H., C. A. Avis, and A. J. Weaver, 2012: Significant contribution to climate warming from the permafrost carbon feedback. Nature Geosci., 5, 719-721.

MacFarling-Meure, C., et al., 2006: Law Dome $\mathrm{CO}_{2}, \mathrm{CH}_{4}$ and $\mathrm{N}_{2} \mathrm{O}$ ice core records extended to 2000 years BP. Geophys. Res. Lett., 33, L14810.

Magnani, F., et al., 2007: The human footprint in the carbon cycle of temperate and boreal forests. Nature, 447, 848-850.

Mahmoudkhani, M., and D. W. Keith, 2009: Low-energy sodium hydroxide recovery for $\mathrm{CO}_{2}$ capture from atmospheric air - Thermodynamic analysis. Int. J. Greenh. Gas Cont., 3, 376-384.
Mahowald, N., et al., 1999: Dust sources and deposition during the last glacial maximum and current climate: A comparison of model results with paleodata from ice cores and marine sediments. J. Geophys. Res. Atmos, 104, 1589515916.

Mahowald, N., et al., 2011: Desert dust and anthropogenic aerosol interactions in the Community Climate System Model coupled-carbon-climate model. Biogeosciences, 8, 387-414.

Mahowald, N. M., D. R. Muhs, S. Levis, P. J. Rasch, M. Yoshioka, C. S. Zender, and C. Luo, 2006: Change in atmospheric mineral aerosols in response to climate: Last glacial period, preindustrial, modern, and doubled carbon dioxide climates. J. Geophys. Res. Atmos., 111, D10202.

Mahowald, N. M., et al., 2009: Atmospheric iron deposition: Global ddistribution, variability, and human perturbations. Annu. Rev. Mar. Sci, 1, 245-278.

Mahowald, N. M., et al., 2010: Observed 20th century desert dust variability: Impact on climate and biogeochemistry. Atmos. Chem. Phys., 10, 10875-10893.

Maier-Reimer, E., I. Kriest, J. Segschneider, and P. Wetzel, 2005: The HAMburg Ocean Carbon Cycle model HAMOCC 5.1 - Technical description, Release 1.1. MaxPlanck Institute for Meteorology, Hamburg, Germany.

Manning, A. C., and R. F. Keeling, 2006: Global oceanic and land biotic carbon sinks from the Scripps atmospheric oxygen flask sampling network. Tellus $B, 58$, 95-116.

Marchenko, S. S., V. Romanovsky, and G. S. Tipenko, 2008: Numerical modeling of spatial permafrost dynamics in Alaska, Proceedings of the Ninth International Conference on Permafrost, University of Alaska Fairbanks, June 29-July 3, 2008, 1125-1130.

Marland, G., and R. M. Rotty, 1984: Carbon dioxide emissions from fossil fuels: A procedure for estimation and results for 1950-1982. Tellus B, 36, 232-261.

Marlon, J. R., et al., 2008: Climate and human influences on global biomass burning over the past two millennia. Nature Geosci, 1, 697-702.

Marlon, J. R., et al., 2012: Long-term perspective on wildfires in the western USA. Proc. Natl. Acad. Sci. U.S.A., 109, E535-E543.

Martin, J. H., 1990: Glacial-interglacial $\mathrm{CO}_{2}$ change: The iron hypothesis. Paleoceanography, 5, 1-13.

Masarie, K. A., and P. P. Tans, 1995: Extension and integration of atmospheric carbondioxide data into a globally consistent measurement record. J. Geophys. Res. Atmos., 100, 11593-11610.

Mason Earles, J., S. Yeh, and K. E. Skog, 2012: Timing of carbon emissions from global forest clearance. Nature Clim. Change, 2, 682-685.

Matear, R. J., and B. I. McNeil, 2003: Decadal accumulation of anthropogenic $\mathrm{CO}_{2}$ in the Southern Ocean: A comparison of CFC-age derived estimates to multiplelinear regression estimates. Global Biogeochem. Cycles, 17, 1113.

Matear, R. J., and A. C. Hirst, 2003: Long-term changes in dissolved oxygen concentrations in the ocean caused by protracted global warming. Global Biogeochem. Cycles, 17, 1125.

Matear, R. J., A. C. Hirst, and B. I. McNeil, 2000: Changes in dissolved oxygen in the Southern Ocean with climate change. Geochem. Geophys. Geosyst., 1, 1050.

Matear, R. J., Y.-P. Wang, and A. Lenton, 2010: Land and ocean nutrient and carbon cycle interactions. Curr. Opin. Environ. Sustain., 2, 258-263.

Matsumoto, K., 2007: Biology-mediated temperature control on atmospheric $\mathrm{pCO}_{2}$ and ocean biogeochemistry. Geophys. Res. Lett., 34, L20605.

Matsumoto, K., J. L. Sarmiento, and M. A. Brzezinski, 2002: Silicic acid leakage from the Southern Ocean: A possible explanation for glacial atmospheric $\mathrm{pCO}_{2}$. Global Biogeochem. Cycles, 16, 1031.

Matsumoto, K., et al., 2004: Evaluation of ocean carbon cycle models with databased metrics. Geophys. Res. Lett., 31, L007303.

Matthews, H. D., 2006: Emissions targets for $\mathrm{CO}_{2}$ stabilization as modified by carbon cycle feedbacks. Tellus $B, 58,591-602$.

Matthews, H. D., 2010: Can carbon cycle geoengineering be a useful complement to ambitious climate mitigation? Carbon Management, 1, 135-144.

Matthews, H. D., and K. Caldeira, 2007: Transient climate-carbon simulations of planetary geoengineering. Proc. Natl. Acad. Sci. U.S.A., 104, 9949-9954.

Matthews, H. D., A. J. Weaver, and K. J. Meissner, 2005: Terrestrial carbon cycle dynamics under recent and future climate change. J. Clim., 18, 1609-1628.

Matthews, H. D., L. Cao, and K. Caldeira, 2009: Sensitivity of ocean acidification to geoengineered climate stabilization. Geophys. Res. Lett., 36, L10706.

Mau, S., D. Valentine, J. Clark, J. Reed, R. Camilli, and L. Washburn, 2007: Dissolved methane distributions and air-sea flux in the plume of a massive seep field, Coal Oil Point, California. Geophys. Res. Lett., 34, L22603. 
Mayorga, E., et al., 2010: Global nutrient export from WaterSheds 2 (NEWS 2): Model development and implementation. Environ. Model. Software, 25, 837-853.

McCarthy, H. R., et al., 2010: Re-assessment of plant carbon dynamics at the Duke free-air $\mathrm{CO}_{2}$ enrichment site: Interactions of atmospheric $\mathrm{CO}_{2}$ with nitrogen and water availability over stand development. New Phytologist, 185, 514-528.

McGuire, A. D., et al., 2009: Sensitivity of the carbon cycle in the Arctic to climate change. Ecol. Monogr., 79, 523-555.

McGuire, A. D., et al., 2012: An assessment of the carbon balance of Arctic tundra: Comparisons among observations, process models, and atmospheric inversions. Biogeosciences, 9, 3185-3204.

McInerney, F. A., and S. L. Wing, 2011: The Paleocene-Eocene thermal maximum: A perturbation of carbon cycle, climate, and biosphere with implications for the future. Annu. Rev. Earth Planet. Sci., 39, 489-516.

McIntyre, B. D., H. R. Herren, J. Wakhungu, and R. T. Watson, 2009: International assessment of agricultural knowledge, science and technology for development (IAASTD): Global report. International Assessment of Agricultural Knowledge, Science and Technology for Development, $590 \mathrm{pp}$.

McKinley, G. A., A. R. Fay, T. Takahashi, and N. Metzl, 2011: Convergence of atmospheric and North Atlantic carbon dioxide trends on multidecadal timescales. Nature Geosci., 4, 606-610.

McKinley, G. A., et al., 2006: North Pacific carbon cycle response to climate variability on seasonal to decadal timescales. J. Geophys. Res. Oceans, 111, C07s06.

McNeil, B. I., and R. J. Matear, 2006: Projected climate change impact on oceanic acidification. Carbon Bal. Manag., 1.

McNeil, B. I., and R. J. Matear, 2008: Southern Ocean acidification: A tipping point at 450-ppm atmospheric $\mathrm{CO}_{2}$. Proc. Natl. Acad. Sci. U.S.A., 105, 18860-18864.

McNeil, B. I., R. J. Matear, R. M. Key, J. L. Bullister, and J. L. Sarmiento, 2003: Anthropogenic $\mathrm{CO}_{2}$ uptake by the ocean based on the global chlorofl uorocarbon data set. Science, 299, 235-239.

Medlyn, B. E., 2011: Comment on "Drought-induced reductions in global terrestrial net primary production from 2000 through 2009". Science, 333, 1093.

Meehl, G. H., et al., 2007: Global Climate Projections. In: Climate Change 2007: The Physical Science Basis. Contribution of Working Group I to the Fourth Assessment Report of the Intergovernmental Panel on Climate Change [Solomon, S., D. Qin, M. Manning, Z. Chen, M. Marquis, K. B. Averyt, M. Tignor and H. L. Miller (eds.)] Cambridge University Press, Cambridge, United Kingdom and New York, NY, USA, pp. 747-846.

Meinshausen, M., et al., 2011: The RCP greenhouse gas concentrations and their extensions from 1765 to 2300. Clim. Change, 109, 213-241.

Melillo, J. M., et al., 2011: Soil warming, carbon-nitrogen interactions, and forest carbon budgets. Proc. Natl. Acad. Sci. U.S.A., 108, 9508-9512.

Melton, J. R., et al., 2013: Present state of global wetland extent and wetland methane modelling: Conclusions from a model intercomparison project (WETCHIMP). Biogeosciences, 10, 753-788.

Menviel, L., and F. Joos, 2012: Toward explaining the Holocene carbon dioxide and carbon isotope records: Results from transient ocean carbon cycle-climate simulations. Paleoceanography, 27, PA1207.

Menviel, L., F. Joos, and S. P. Ritz, 2012: Simulating atmospheric $\mathrm{CO}_{2}, \mathrm{C}^{13}$ and the marine carbonate cycle during the last Glacial-Interglacial cycle: Possible role for a deepening of the mean remineralization depth and an increase in the oceanic nutrient inventory. Quat. Sci. Rev., 56, 46-68.

Menviel, L., A. Timmermann, A. Mouchet, and 0. Timm, 2008: Meridional reorganizations of marine and terrestrial productivity during Heinrich events. Paleoceanography, 23, PA1203.

Mercado, L. M., N. Bellouin, S. Sitch, O. Boucher, C. Huntingford, M. Wild, and P. M. Cox, 2009: Impact of changes in diffuse radiation on the global land carbon sink. Nature, 458, 1014-1017.

Merico, A., T. Tyrrell, and T. Cokacar, 2006: Is there any relationship between phytoplankton seasonal dynamics and the carbonate system? J. Mar. Syst., 59, 120-142.

Metsaranta, J. M., W. A. Kurz, E. T. Neilson, and G. Stinson, 2010: Implications of future disturbance regimes on the carbon balance of Canada's managed forest (2010-2100). Tellus B, 62, 719-728.

Metz, B., O. Davidson, H. C. De Coninck, M. Loss, and L. A. Meyer, 2005: IPCC Special Report on Carbon Dioxide Capture and Storage Cambridge University Press, Cambridge, United Kingdom, and New York, NY, USA, 442 pp.,

Metzl, N., 2009: Decadal increase of oceanic carbon dioxide in Southern Indian Ocean surface waters (1991-2007). Deep-Sea Res. Pt. II, 56, 607-619.
Metzl, N., et al., 2010: Recent acceleration of the sea surface $\mathrm{fCO}_{2}$ growth rate in the North Atlantic subpolar gyre (1993-2008) revealed by winter observations. Global Biogeochem. Cycles, 24, GB4004.

Mieville, A., et al., 2010: Emissions of gases and particles from biomass burning during the 20th century using satellite data and an historical reconstruction. Atmos. Environ., 44, 1469-1477.

Mikaloff-Fletcher, S. E., et al., 2006: Inverse estimates of anthropogenic $\mathrm{CO}_{2}$ uptake, transport, and storage by the ocean. Global Biogeochem. Cycles, 20, GB2002.

Minschwaner, K., R. J. Salawitch, and M. B. McElroy, 1993: Absorption of solar radiation by $\mathrm{O}_{2}$ : Implications for $\mathrm{O}_{3}$ and lifetimes of $\mathrm{N}_{2} \mathrm{O}, \mathrm{CFCl}_{3}$, and $\mathrm{CF}_{2} \mathrm{Cl}_{2}$. J. Geophys. Res. Atmos., 98, 10543-10561.

Mischler, J. A., et al., 2009: Carbon and hydrogen isotopic composition of methane over the last 1000 years. Global Biogeochem. Cycles, 23, GB4024.

Mitchell, L. E., E. J. Brook, T. Sowers, J. R. McConnell, and K. Taylor, 2011: Multidecadal variability of atmospheric methane, 1000-1800 C.E. J. Geophys. Res. Biogeosci., 116, G02007.

Miyama, T., and M. Kawamiya, 2009: Estimating allowable carbon emission for $\mathrm{CO}_{2}$ concentration stabilization using a GCM-based Earth system model. Geophys. Res. Lett., 36, L19709.

Monnin, E., et al., 2001: Atmospheric $\mathrm{CO}_{2}$ concentrations over the last glacial termination. Science, 291, 112-114.

Monnin, E., et al., 2004: Evidence for substantial accumulation rate variability in Antarctica during the Holocene through synchronization of $\mathrm{CO}_{2}$ in the Taylor Dome, Dome C and DML ice cores. Earth Planet. Sci. Lett., 224, 45-54.

Monteil, G., S. Houweling, E. J. Dlugockenky, G. Maenhout, B. H. Vaughn, J. W. C. White, and T. Rockmann, 2011: Interpreting methane variations in the past two decades using measurements of $\mathrm{CH}_{4}$ mixing ratio and isotopic composition. Atmos. Chem. Phys., 11, 9141-9153.

Monteith, D. T., et al., 2007: Dissolved organic carbon trends resulting from changes in atmospheric deposition chemistry. Nature, 450, 537-U539.

Montenegro, A., V. Brovkin, M. Eby, D. Archer, and A. J. Weaver, 2007: Long term fate of anthropogenic carbon. Geophys. Res. Lett., 34, L19707.

Montenegro, A., M. Eby, Q. Z. Mu, M. Mulligan, A. J. Weaver, E. C. Wiebe, and M. S. Zhao, 2009: The net carbon drawdown of small scale afforestation from satellite observations. Global Planet. Change, 69, 195-204.

Montzka, S. A., M. Krol, E. Dlugokencky, B. Hall, P. Joeckel, and J. Lelieveld, 2011: Small interannual variability of global atmospheric hydroxyl. Science, 331, 67-69.

Mooney, S. D., et al., 2011: Late Quaternary fire regimes of Australasia. Quat. Sci. Rev., 30, 28-46.

Morford, S. L., B. Z. Houlton, and R. A. Dahlgren, 2011: Increased forest ecosystem carbon and nitrogen storage from nitrogen rich bedrock. Nature, 477, 78-81.

Morino, I., et al., 2011: Preliminary validation of column-averaged volume mixing ratios of carbon dioxide and methane retrieved from GOSAT short-wavelength infrared spectra. Atmos. Measure. Techn., 3, 5613-5643.

Mosier, A., C. Kroeze, C. Nevison, O. Oenema, S. Seitzinger, and O. van Cleemput, 1998: Closing the global $\mathrm{N}_{2} \mathrm{O}$ budget: Nitrous oxide emissions through the agricultural nitrogen cycle - OECD/IPCC/IEA phase II development of IPCC guidelines for national greenhouse gas inventory methodology. Nutr. Cycl. Agroecosyst., 52, 225-248.

Mosier, A. R., J. A. Morgan, J. Y. King, D. R. LeCain, and D. G. Milchunas, 2002: Soilatmosphere exchange of $\mathrm{CH}_{4}, \mathrm{CO}_{2}, \mathrm{NOx}$, and $\mathrm{N}_{2} \mathrm{O}$ in the Colorado shortgrass steppe under elevated $\mathrm{CO}_{2}$. Plant Soil, 240, 201-211.

Moss, R. H., et al., 2010: The next generation of scenarios for climate change research and assessment. Nature, 463, 747-756.

Munhoven, G., 2002: Glacial-interglacial changes of continental weathering: Estimates of the related $\mathrm{CO}_{2}$ and $\mathrm{HCO}^{3-}$ flux variations and their uncertainties. Global Planet. Change, 33, 155-176.

Murata, A., Y. Kumamoto, S. Watanabe, and M. Fukasawa, 2007: Decadal increases of anthropogenic $\mathrm{CO}_{2}$ in the South Pacific subtropical ocean along 32 degrees $\mathrm{S}$. J. Geophys. Res. Oceans, 112, C05033.

Murata, A., Y. Kumamoto, K.-i. Sasaki, S. Watanabe, and M. Fukasawa, 2009: Decadal increases of anthropogenic $\mathrm{CO}_{2}$ along 149 degrees $\mathrm{E}$ in the western North Pacific. J. Geophys. Res. Oceans, 114, C04018.

Murata, A., Y. Kumamoto, K. Sasaki, S. Watanabe, and M. Fukasawa, 2010: Decadal increases in anthropogenic $\mathrm{CO}_{2}$ along 20 degrees $\mathrm{S}$ in the South Indian Ocean. J. Geophys. Res. Oceans, 115, C12055.

Myneni, R. B., et al., 2001: A large carbon sink in the woody biomass of Northern forests. Proc. Natl. Acad. Sci. U.S.A., 98, 14784-14789. 
Nabuurs, G. J., et al., 2008: Hotspots of the European forests carbon cycle. Forest Ecol. Manage., 256, 194-200.

Naegler, T., and I. Levin, 2009: Observation-based global biospheric excess radiocarbon inventory 1963-2005. J. Geophys. Res., 114, D17302.

Naik, V., D. J.Wuebbles, E. H. De Lucia, and J.A. Foley, 2003: Influence of geoengineered climate on the terrestrial biosphere. Environ. Manage., 32, 373-381.

Naqvi, S. W. A., H. W. Bange, L. Farias, P. M. S. Monteiro, M. I. Scranton, and J. Zhang, 2010: Coastal hypoxia/anoxia as a source of $\mathrm{CH}_{4}$ and $\mathrm{N}_{2} \mathrm{O}$. Biogeosciences, 7 , 2159-2190.

Neef, L., M. van Weele, and P. van Velthoven, 2010: Optimal estimation of the present-day global methane budget. Global Biogeochem. Cycles, 24, GB4024.

Neftel, A., H. Oeschger, J. Schwander, B. Stauffer, and R. Zumbrunn, 1982: Ice core sample measurements give atmospheric $\mathrm{CO}_{2}$ content during the past $40,000 \mathrm{yr}$. Nature, 295, 220-223.

Nemani, R. R., et al., 2003: Climate-driven increases in global terrestrial net primary production from 1982 to 1999. Science, 300, 1560-1563.

Nevison, C. D., et al., 2011: Exploring causes of interannual variability in the seasonal cycles of tropospheric nitrous oxide. Atmos. Chem. Phys., 11, 3713-3730.

Nevle, R. J., and D. K. Bird, 2008: Effects of syn-pandemic fire reduction and reforestation in the tropical Americas on atmospheric $\mathrm{CO}_{2}$ during European conquest. Palaeogeogr. Palaeoclimatol. Palaeoecol. 264, 25-38.

Nevle, R. J., D. K. Bird, W. F. Ruddiman, and R. A. and Dull, 2011: Neotropical human landscape interactions, fire, and atmospheric $\mathrm{CO}_{2}$ during European conquest. Holocene, 21, 853-864.

Newingham, B. A., C. H. Vanier, T. N. Charlet, K. Ogle, S. D. Smith, and R. S. Nowak, 2013: No cumulative effect of ten years of elevated $\mathrm{CO}_{2}$ on perennial plant biomass components in the Mojave Desert. Global Change Biol., 19, 2168-2181.

Nisbet, R. E. R., et al., 2009: Emission of methane from plants. Proc. R. Soc. Ser. B, $276,1347-1354$

Norby, R. J., 1998: Nitrogen deposition: A component of global change analysis. New Phytologist, 139, 189-200.

Norby, R. J., J. M. Warren, C. M. Iversen, B. E. Medlyn, and R. E. McMurtrie, 2010: $\mathrm{CO}_{2}$ enhancement of forest productivity constrained by limited nitrogen availability. Proc. Natl. Acad. Sci. U.S.A., 107, 19368-19373.

Norby, R. J., et al., 2005: Forest response to elevated $\mathrm{CO}_{2}$ is conserved across a broad range of productivity. Proc. Natl. Acad. Sci. U.S.A., 102, 18052-18056.

Nowak, R. S., D. S. Ellsworth, and S. D. Smith, 2004: Functional responses of plants to elevated atmospheric $\mathrm{CO}_{2}$ - do photosynthetic and productivity data from FACE experiments support early predictions? New Phytologist, 162, 253-280.

O'Connor, F. M., et al., 2010: Possible role of wetlands, permafrost, and methane hydrates in the methane cycle under future climate change: A review. Rev. Geophys., 48, RG4005.

Oh, N.-H., and P. A. Raymond, 2006: Contribution of agricultural liming to riverine bicarbonate export and $\mathrm{CO}_{2}$ sequestration in the Ohio River basin. Global Biogeochem. Cycles, 20, GB3012.

Oleson, K. W., et al., 2010: Technical description of version 4.0 of the Community Land Model (CLM), NCAR Technical Note NCAR/TN-478+STR, National Center for Atmospheric Research, Boulder, CO, USA, $257 \mathrm{pp}$.

Olivier, J., J. Aardenne, F. Dentener, L. Ganzeveld, and J. Peters, 2005: Recent trends in global greenhouse emissions: Regional trends 1970-2000 and spatial distribution of key sources in 2000. Environ. Sci., 2, 81-99.

Olivier, J. G. J., and G. Janssens-Maenhout, 2012: Part III: Greenhouse gas emissions: 1. Shares and trends in greenhouse gas emissions; 2 . Sources and Methods; Total greenhouse gas emissions. In: $\mathrm{CO}_{2}$ Emissions from Fuel Combustion, 2012 Edition. International Energy Agency (IEA), Paris, France, III.1-III.51.

Olofsson, J., and T. Hickler, 2008: Effects of human land-use on the global carbon cycle during the last 6,000 years. Veget. Hist. Archaeobot., 17, 605-615.

Olsen, A., et al., 2006: Magnitude and origin of the anthropogenic $\mathrm{CO}_{2}$ increase and ${ }^{13} \mathrm{C}$ Suess effect in the Nordic seas since 1981. Global Biogeochem. Cycles, 20 GB3027.

Opdyke, M. R., N. E. Ostrom, and P. H. Ostrom, 2009: Evidence for the predominance of denitrification as a source of $\mathrm{N}_{2} \mathrm{O}$ in temperate agricultural soils based on isotopologue measurements. Global Biogeochem. Cycles, 23, Gb4018.

Orr, F. M. J., 2009: Onshore geologic storage of $\mathrm{CO}_{2}$. Science, 325, 1656-1658.

Orr, J. C., 2011: Recent and future changes in ocean carbonate chemistry. In: Ocean Acidification [J.-P. Gattuso and L. Hansson (eds.)]. Oxford University Press, Oxford, United Kingdom, and New York, NY, USA, pp. 41-66.

Orr, J. C., et al., 2001: Estimates of anthropogenic carbon uptake from four threedimensional global ocean models. Global Biogeochem. Cycles, 15, 43-60.
Orr, J. C., et al., 2005: Anthropogenic ocean acidification over the twenty-first century and its impact on calcifying organisms. Nature, 437, 681-686.

Oschlies, A., 2001: Model-derived estimates of new production: New results point towards lower values. Deep-Sea Res. Pt. II, 48, 2173-2197.

Oschlies, A., K. G. Schulz, U. Riebesell, and A. Schmittner, 2008: Simulated 21st century's increase in oceanic suboxia by $\mathrm{CO}_{2}$ enhanced biotic carbon export. Global Biogeochem. Cycles, 22, GB4008.

Oschlies, A., W. Koeve, W. Rickels, and K. Rehdanz, 2010a: Side effects and accounting aspects of hypothetical large-scale Southern Ocean iron fertilization. Biogeosciences, 7, 4017-4035.

Oschlies, A., M. Pahlow, A. Yool, and R. J. Matear, 2010b: Climate engineering by artificial ocean upwelling: Channelling the sorcerer's apprentice. Geophys. Res. Lett., 37, L04701.

Otto, D., D. Rasse, J. Kaplan, P. Warnant, and L. Francois, 2002: Biospheric carbon stocks reconstructed at the Last Glacial Maximum: Comparison between general circulation models using prescribed and computed sea surface temperatures. Global Planet. Change, 33, 117-138.

Pacala, S. W., et al., 2001: Consistent land- and atmosphere-based U.S. carbon sink estimates. Science, 292, 2316-2320.

Page, S. E., J. O. Rieley, and C. J. Banks, 2011: Global and regional importance of the tropical peatland carbon pool. Global Change Biol., 17, 798-818.

Page, S. E., F. Siegert, J. O. Rieley, H.-D. V. Boehm, A. Jaya, and S. Limin, 2002: The amount of carbon released from peat and forest fires in Indonesia during 1997. Nature, 420, 61-65.

Palmroth, S., et al., 2006: Aboveground sink strength in forests controls the allocation of carbon below ground and its $\left[\mathrm{CO}_{2}\right]$-induced enhancement. Proc. Natl. Acad. Sci. U.S.A., 103, 19362-19367.

Pan, Y. D., et al., 2011: A large and persistent carbon sink in the world's forests. Science, 333, 988-993.

Papa, F., C. Prigent, F. Aires, C. Jimenez, W. B. Rossow, and E. Matthews, 2010: Interannual variability of surface water extent at the global scale, 1993-2004. J. Geophys. Res.Atmos., 115, D12111.

Parekh, P., F. Joos, and S. A. Müller, 2008: A modeling assessment of the interplay between aeolian iron fluxes and iron-binding ligands in controlling carbon dioxide fluctuations during Antarctic warm events. Paleoceanography, 23, PA4202.

Park, G.-H., et al., 2010: Variability of global net air-sea $\mathrm{CO}_{2}$ fluxes over the last three decades using empirical relationships. Tellus $B, 62,352-368$.

Park, S., et al., 2012: Trends and seasonal cycles in the isotopic composition of nitrous oxide since 1940. Nature Geosci., 5, 261-265.

Patra, P. K., et al., 2013: The carbon budget of South Asia. Biogeosciences, 10, 513527.

Patra, P. K., et al., 2011: TransCom model simulations of $\mathrm{CH}_{4}$ and related species: Linking transport, surface flux and chemical loss with $\mathrm{CH}_{4}$ variability in the troposphere and lower stratosphere. Atmos. Chem. Phys., 11, 12813-12837.

Pechony, 0., and D. T. Shindell, 2010: Driving forces of global wildfires over the past millennium and the forthcoming century. Proc. Natl. Acad. Sci. U.S.A., 107, 19167-19170.

Peng, T.-H., and W. S. Broecker, 1991: Dynamic limitations on the Antarctic iron fertilization strategy. Nature, 349, 227-229.

Peng, T.-H., R. Wanninkhof, J. L. Bullister, R. A. Feely, and T. Takahashi, 1998: Quantification of decadal anthropogenic $\mathrm{CO}_{2}$ uptake in the ocean based on dissolved inorganic carbon measurements. Nature, 396, 560-563.

Peng, T. H., R. Wanninkhof, and R. A. Feely, 2003: Increase of anthropogenic $\mathrm{CO}_{2}$ in the Pacific Ocean over the last two decades. Deep-Sea Res. Pt. II, 50, 3065-3082.

Peñuelas, J., J. G. Canadell, and R. Ogaya, 2011: Increased water-use-efficiency during the 20th century did not translate into enhanced tree growth. Global Ecol. Biogeogr., 20, 597-608.

Pérez, F. F., M. Vázquez-Rodríguez, E. Louarn, X. A. Padin, H. Mercier, and A. F. Rios, 2008: Temporal variability of the anthropogenic $\mathrm{CO}_{2}$ storage in the Irminger Sea. Biogeosciences, 5, 1669-1679.

Perrin, A.-S., A. Probst, and J.-L. Probst, 2008: Impact of nitrogenous fertilizers on carbonate dissolution in small agricultural catchments: Implications for weathering $\mathrm{CO}_{2}$ uptake at regional and global scales. Geochim. Cosmochim. Acta, 72, 3105-3123.

Pershing, A. J., L. B. Christensen, N. R. Record, G. D. Sherwood, and P. B. Stetson, 2010: The impact of whaling on the ocean carbon cycle: Why bigger was better. PLoS ONE, 5, e12444. 
Peters, G. P., et al., 2013: The challenge to keep global warming below $2^{\circ} \mathrm{C}$. Nature Clim. Change, 3, 4-6.

Petit, J. R., et al., 1999: Climate and atmospheric history of the past 420,000 years from the Vostok ice core, Antarctica. Nature, 399, 429-436.

Petrenko, V. V., et al., 2009: ${ }^{14} \mathrm{CH}_{4}$ Measurements in Greenland ice: Investigating Last Glacial Termination $\mathrm{CH}_{4}$ sources. Science, 324, 506-508.

Peylin, P., et al., 2005: Multiple constraints on regional $\mathrm{CO}_{2}$ flux variations over land and oceans. Global Biogeochem. Cycles, 19, GB1011.

Peylin, P., et al., 2013: Global atmospheric carbon budget: Results from an ensemble of atmospheric $\mathrm{CO}_{2}$ inversions. Biogeosci. Discuss., 10, 5301-5360.

Pfeil, G. B., et al., 2013: A uniform, quality controlled Surface Ocean $\mathrm{CO}_{2}$ Atlas (SOCAT). Earth Syst. Sci. Data, 5, 125-143.

Phoenix, G. K., et al., 2006: Atmospheric nitrogen deposition in world biodiversity hotspots: The need for a greater global perspective in assessing $\mathrm{N}$ deposition impacts. Global Change Biol., 12, 470-476.

Piao, S., et al., 2011: Contribution of climate change and rising $\mathrm{CO}_{2}$ to terrestrial carbon balance in East Asia: A multi-model analysis. Global Planet. Change, 75, 133-142.

Piao, S., et al., 2013: Evaluation of terrestrial carbon cycle models for their response to climate variability and $\mathrm{CO}_{2}$ trends. Global Change Biol., 19, 2117-2132..

Piao, S. L., P. Friedlingstein, P. Ciais, L. M. Zhou, and A. P. Chen, 2006: Effect of climate and $\mathrm{CO}_{2}$ changes on the greening of the Northern Hemisphere over the past two decades. Geophys. Res. Lett., 33, L23402.

Piao, S. L., P. Friedlingstein, P. Ciais, N. de Noblet-Ducoudré, D. Labat, and S. Zaehle, 2007: Changes in climate and land use have a larger direct impact than rising $\mathrm{CO}_{2}$ on global river runoff trends. Proc. Natl. Acad. Sci. U.S.A., 104, 15242-15247.

Piao, S. L., P. Ciais, P. Friedlingstein, N. de Noblet-Ducoudré, P. Cadule, N. Viovy, and T. Wang, 2009a: Spatiotemporal patterns of terrestrial carbon cycle during the 20th century. Global Biogeochem. Cycles, 23, Gb4026.

Piao, S. L., J. Y. Fang, P. Ciais, P. Peylin, Y. Huang, S. Sitch, and T. Wang, 2009b: The carbon balance of terrestrial ecosystems in China. Nature, 458, 1009-U82.

Piao, S. L., et al., 2012: The carbon budget of terrestrial ecosystems in East Asia over the last two decades. Biogeosciences, 9, 3571-3586.

Pison, I., P. Bousquet, F. Chevallier, S. Szopa, and D. Hauglustaine, 2009: Multi-species inversion of $\mathrm{CH}_{4}, \mathrm{CO}$ and $\mathrm{H}_{2}$ emissions from surface measurements. Atmos. Chem. Phys., 9, 5281-5297.

Plattner, G.-K., et al., 2008: Long-term climate commitments projected with climatecarbon cycle models. J. Clim., 21, 2721-2751.

Plattner, G. K., F. Joos, and T. Stocker, 2002: Revision of the global carbon budget due to changing air-sea oxygen fluxes. Global Biogeochem. Cycles, 16, 1096.

Plug, L. J., and J. J. West, 2009: Thaw lake expansion in a two-dimensional coupled model of heat transfer, thaw subsidence, and mass movement. J. Geophys. Res., 114, F01002.

Pollard, R. T., et al., 2009: Southern Ocean deep-water carbon export enhanced by natural iron fertilization. Nature, 457, 577-580.

Pongratz, J., C. H. Reick, T. Raddatz, and M. Claussen, 2009: Effects of anthropogenic land cover change on the carbon cycle of the last millennium. Global Biogeochem. Cycles, 23, Gb4001.

Pongratz, J., K. Caldeira, C. H. Reick, and M. Claussen, 2011a: Coupled climatecarbon simulations indicate minor global effects of wars and epidemics on atmospheric $\mathrm{CO}_{2}$ between $\mathrm{AD} 800$ and 1850. Holocene, 21, 843-851.

Pongratz, J., C. H. Reick, T. Raddatz, K. Caldeira, and M. Claussen, 2011 b: Past land use decisions have increased mitigation potential of reforestation. Geophys. Res. Lett., 38, L15701.

Poulter, B., et al., 2010: Net biome production of the Amazon Basin in the 21st century. Global Change Biol., 16, 2062-2075.

Power, M. J., et al., 2013: Climatic control of the biomass-burning decline in the Americas after AD 1500. Holocene, 23, 3-13.

Power, M. J., et al., 2008: Changes in fire regimes since the Last Glacial Maximum: An assessment based on a global synthesis and analysis of charcoal data. Clim. Dyn., 30, 887-907.

Prather, M. J., C. D. Holmes, and J. Hsu, 2012: Reactive greenhouse gas scenarios: Systematic exploration of uncertainties and the role of atmospheric chemistry. Geophys. Res. Lett., 39, L09803.

Prentice, I. C., and S. P. Harrison, 2009: Ecosystem effects of $\mathrm{CO}_{2}$ concentration: Evidence from past climates. Clim. Past, 5, 297-307.
Prentice, I. C., et al., 2001: The carbon cycle and atmospheric carbon dioxide. In: Climate Change 2001: The Scientific Basis. Contribution of Working Group I to the Third Assessment Report of the Intergovernmental Panel on Climate Change [J. T. Houghton, Y. Ding, D. J. Griggs, M. Noquer, P. J. van der Linden, X. Dai, K. Maskell and C. A. Johnson (eds.)]. Cambridge University Press, Cambridge, United Kingdom and New York, NY, USA, pp. 183-237.

Prinn, R. G., et al., 2001: Evidence for substantial variations of atmospheric hydroxyl radicals in the past two decades. Science, 292, 1882-1888.

Prinn, R. G., et al., 2005: Evidence for variability of atmospheric hydroxyl radicals over the past quarter century. Geophys. Res. Lett., 32, L07809.

Prinn, R. G., et al., 2000: A history of chemically and radiatively important gases in air deduced from ALE/GAGE/AGAGE. J. Geophys. Res. Atmos., 105, 17751-17792.

Quinton, J. N., G. Govers, K. Van Oost, and R. D. Bardgett, 2010: The impact of agricultural soil erosion on biogeochemical cycling. Nature Geosci., 3, 311-314.

Rabalais, N. N., R. J. Diaz, L. A. Levin, R. E. Turner, D. Gilbert, and J. Zhang, 2010: Dynamics and distribution of natural and human-caused hypoxia. Biogeosciences, 7, 585-619.

Raddatz, T. J., et al., 2007: Will the tropical land biosphere dominate the climatecarbon cycle feedback during the twenty-first century? Clim. Dyn., 29, 565-574.

Rafelski, L. E., S. C. Piper, and R. F. Keeling, 2009: Climate effects on atmospheric carbon dioxide over the last century. Tellus $B, 61,718-731$.

Ramankutty, N., and J. A. Foley, 1999: Estimating historical changes in global land cover: Croplands from 1700 to 1992. Global Biogeochem. Cycles, 13, 997-1027.

Ramankutty, N., C. Delire, and P. Snyder, 2006: Feedbacks between agriculture and climate: An illustration of the potential unintended consequences of human land use activities. Global Planet. Change, 54, 79-93.

Randerson, J. T., et al., 2009: Systematic assessment of terrestrial biogeochemistry in coupled climate-carbon models. Global Change Biol., 15, 2462-2484.

Rau, G. H., 2008: Electrochemical splitting of calcium carbonate to increase solution alkalinity: Implications for mitigation of carbon dioxide and ocean acidity. Environ. Sci. Technol., 42, 8935-8940.

Rau, G. H., and K. Caldeira, 1999: Enhanced carbonate dissolution: A means of sequestering waste $\mathrm{CO}_{2}$ as ocean bicarbonate. Energ. Conv. Manage., 40, $1803-$ 1813.

Raupach, M. R., 2013: The exponential eigenmodes of the carbon-climate system, and their implications for ratios of responses to forcings Earth Syst. Dyn., 4, $31-49$.

Raupach, M. R., J. G. Canadell, and C. Le Quéré, 2008: Anthropogenic and biophysical contributions to increasing atmospheric $\mathrm{CO}_{2}$ growth rate and airborne fraction. Biogeosciences, 5, 1601-1613.

Ravishankara, A. R., J. S. Daniel, and R. W. Portmann, 2009: Nitrous oxide $\left(\mathrm{N}_{2} \mathrm{O}\right)$ : The dominant ozone-depleting substance emitted in the 21 st century. Science, 326 , 123-125.

Raymond, P. A., and J. J. Cole, 2003: Increase in the export of alkalinity from North America's largest river. Science, 301, 88-91.

Raymond, P. A., N.-H. Oh, R. E. Turner, and W. Broussard, 2008: Anthropogenically enhanced fluxes of water and carbon from the Mississippi River. Nature, 451, 449-452.

Rayner, P. J., R. M. Law, C. E. Allison, R. J. Francey, C. M. Trudinger, and C. PickettHeaps, 2008: Interannual variability of the global carbon cycle (1992-2005) inferred by inversion of atmospheric $\mathrm{CO}_{2}$ and ${ }^{13} \mathrm{CO}_{2}$ measurements. Global Biogeochem. Cycles, 22, GB3008.

Reagan, M. T., and G. J. Moridis, 2007: Oceanic gas hydrate instability and dissociation under climate change scenarios. Geophys. Res. Lett., 34, L22709.

Reagan, M. T., and G. J. Moridis, 2009: Large-scale simulation of methane hydrate dissociation along the West Spitsbergen Margin. Geophys. Res. Lett., 36, L23612.

Reay, D. S., F. Dentener, P. Smith, J. Grace, and R. A. Feely, 2008: Global nitrogen deposition and carbon sinks. Nature Geosci., 1, 430-437.

Renforth, P., 2012: The potential of enhanced weathering in the UK. Int. J. Greenh. Gas Cont., 10, 229-243.

Revelle, R., and H. E. Suess, 1957: Carbon dioxide exchange between atmosphere and ocean and the question of an increase of atmospheric $\mathrm{CO}_{2}$ during the past decades. Tellus, 9, 18-27.

Rhee, T. S., A. J. Kettle, and M. O. Andreae, 2009: Methane and nitrous oxide emissions from the ocean: A reassessment using basin-wide observations in the Atlantic. J. Geophys. Res., 114, D12304.

Ricke, K. L., M. G. Morgan, and M. R. Allen, 2010: Regional climate response to solarradiation management. Nature Geosci., 3, 537-541. 
Ridgwell, A., and R. E. Zeebe, 2005: The role of the global carbonate cycle in the regulation and evolution of the Earth system. Earth Planet. Sci. Lett., 234, 299315.

Ridgwell, A., and J. C. Hargreaves, 2007: Regulation of atmospheric $\mathrm{CO}_{2}$ by deep-sea sediments in an Earth system model. Global Biogeochem. Cycles, 21, Gb2008.

Ridgwell, A. J., 2001: Glacial-interglacial perturbations in the global carbon cycle. PhD Thesis, University of East Anglia, Norwich, United Kingdom, 134 pp.

Ridgwell, A. J., A. J. Watson, M. A. Maslin, and J. 0. Kaplan, 2003: Implications of coral reef buildup for the controls on atmospheric $\mathrm{CO}_{2}$ since the Last Glacial Maximum. Paleoceanography, 18, 1083.

Riebesell, U., A. Körtzinger, and A. Oschlies, 2009: Sensitivities of marine carbon fluxes to ocean change. Proc. Natl. Acad. Sci. U.S.A., 106, 20602-20609.

Riebesell, U., et al., 2007: Enhanced biological carbon consumption in a high $\mathrm{CO}_{2}$ ocean. Nature, 450, 545-548.

Rigby, M., et al., 2008: Renewed growth of atmospheric methane. Geophys. Res. Lett., 35, L22805.

Ringeval, B., P. Friedlingstein, C. Koven, P. Ciais, N. de Noblet-Ducoudre, B. Decharme, and P. Cadule, 2011: Climate- $\mathrm{CH}_{4}$ feedback from wetlands and its interaction with the climate- $\mathrm{CO}_{2}$ feedback. Biogeosciences, 8, 2137-2157.

Robock, A., L. Oman, and G. L. Stenchikov, 2008: Regional climate responses to geoengineering with tropical and Arctic $\mathrm{SO}_{2}$ injections. J. Geophys. Res., 113 D16101.

Röckmann, T., and I. Levin, 2005: High-precision determination of the changing isotopic composition of atmospheric $\mathrm{N}_{2} \mathrm{O}$ from 1990 to 2002. J. Geophys. Res. Atmos., 110, D21304.

Rödenbeck, C., S. Houweling, M. Gloor, and M. Heimann, 2003: $\mathrm{CO}_{2}$ flux history 1982-2001 inferred from atmospheric data using a global inversion of atmospheric transport. Atmos. Chem. Phys., 3, 1919-1964.

Rosamond, M. S., S. J. Thuss, and S. L. Schiff, 2012: Dependence of riverine nitrous oxide emissions on dissolved oxygen levels. Nature Geosci, , 5, 715-718.

Roth, R., and F. Joos, 2012: Model limits on the role of volcanic carbon emissions in regulating glacial-interglacial $\mathrm{CO}_{2}$ variations. Earth Planet. Sci. Lett., 329-330, 141-149.

Röthlisberger, R., M. Bigler, E. W. Wolff, F. Joos, E. Monnin, and M. A. Hutterli, 2004: Ice core evidence for the extent of past atmospheric $\mathrm{CO}_{2}$ change due to iron fertilisation. Geophys. Res. Lett., 31, L16207.

Rotty, R. M., 1983: Distribution of and changes in industrial carbon-cycle production. J. Geophys. Res. Oceans, 88, 1301-1308.

Roy, T., et al., 2011: Regional impacts of climate change and atmospheric $\mathrm{CO}_{2}$ on future ocean carbon uptake: A multimodel linear feedback analysis. J. Clim., 24, 2300-2318.

Rubasinghege, G., S. N. Spak, C. O. Stanier, G. R. Carmichael, and V. H. Grassian, 2011: Abiotic mechanism for the formation of atmospheric nitrous oxide from ammonium nitrate. Environ. Sci. Technol. , 45, 2691-2697.

Ruddiman, W. F., 2003: The anthropogenic greenhouse era began thousands of years ago. Clim. Change, 61, 261-293.

Ruddiman, W. F., 2007: The early anthropogenic hypothesis: Challenges and responses. Rev. Geophys., 45, RG4001.

Sabine, C. L., R. A. Feely, F. J. Millero, A. G. Dickson, C. Langdon, S. Mecking, and D. Greeley, 2008: Decadal changes in Pacific carbon. J. Geophys. Res. Oceans, 113 C07021.

Sabine, C. L., et al., 2004: The oceanic sink for anthropogenic $\mathrm{CO}_{2}$. Science, 305, 367-371.

Salisbury, J., M. Green, C. Hunt, and J. Campbell, 2008: Coastal acidification by rivers: A threat to shellfish? EOS Trans. AGU, 89, 513.

Sallée, J.-B., R. J. Matear, S. R. Rintoul, and A. Lenton, 2012: Localized subduction of anthropogenic carbon dioxide in the Southern Hemisphere oceans. Nature Geosci., 5, 579-584.

Samanta, A., M. H. Costa, E. L. Nunes, S. A. Viera, L. Xu, and R. B. Myneni, 2011: Comment on "Drought-induced reduction in global terrestrial net primary production from 2000 through 2009". Science, 333, 1093.

Sanderson, M. G., 1996: Biomass of termites and their emissions of methane and carbon dioxide: A global database. Global Biogeochem. Cycles, 10, 543-557.

Sapart, C. J., et al., 2012: Natural and anthropogenic variations in methane sources during the past two millennia. Nature, 490, 85-88.

Sarmiento, J. L., and N. Gruber, 2006: Ocean Biogeochemical Dynamics. Princeton University Press, Princeton, NJ, USA.

Sarmiento, J. L., J. C. Orr, and U. Siegenthaler, 1992: A perturbation simulation of $\mathrm{CO}_{2}$ uptake in an Ocean General Circulation Model. J. Geophys. Res., 97, 3621-3645.
Sarmiento, J. L., T. M. C. Hughes, R. J. Stouffer, and S. Manabe, 1998: Simulated response of the ocean carbon cycle to anthropogenic climate warming. Nature, 393, 245-249.

Sarmiento, J. L., P. Monfray, E. Maier-Reimer, O. Aumont, R. Murnane, and J. C. Orr, 2000: Sea-air $\mathrm{CO}_{2}$ fluxes and carbon transport: A comparison of three ocean general circulation models. Global Biogeochem. Cycles, 14, 1267-1281.

Sarmiento, J. L., et al., 2010: Trends and regional distributions of land and ocean carbon sinks. Biogeosciences, 7, 2351-2367.

Savolainen, I., S. Monni, and S. Syri, 2009: The mitigation of methane emissions from the industrialised countries can explain the atmospheric concentration level-off. Int. J. Energ. Clean Environ., 10, 193-201.

Schaefer, K., T. Zhang, L. Bruhwiler, and A. P. Barrett, 2011: Amount and timing of permafrost carbon release in response to climate warming. Tellus $B, 63,165-$ 180.

Scheffer, M., V. Brovkin, and P. M. Cox, 2006: Positive feedback between global warming and atmospheric $\mathrm{CO}_{2}$ concentration inferred from past climate change. Geophys. Res. Lett., 33, L10702.

Schilt, A., M. Baumgartner, T. Blunier, J. Schwander, R. Spahni, H. Fischer, and T. F. Stocker, 2010a: Glacial-interglacial and millennial-scale variations in the atmospheric nitrous oxide concentration during the last 800,000 years. Quat. Sci. Rev., 29, 182-192.

Schilt, A., et al., 2010b: Atmospheric nitrous oxide during the last 140,000 years. Earth Planet. Sci. Lett., 300, 33-43.

Schirrmeister, L., G. Grosse, S. Wetterich, P. P. Overduin, J. Strauss, E. A. G. Schuur, and H.-W. Hubberten, 2011: Fossil organic matter characteristics in permafrost deposits of the northeast Siberian Arctic. J. Geophys. Res., 116, G00M02.

Schmitt, J., et al., 2012: Carbon isotope constraints on the deglacial $\mathrm{CO}_{2}$ rise from ice cores. Science, 336, 711-714.

Schmittner, A., and E. D. Galbraith, 2008: Glacial greenhouse-gas fluctuations controlled by ocean circulation changes. Nature, 456, 373-376.

Schmittner, A., A. Oschlies, H. D. Matthews, and E. D. Galbraith, 2008: Future changes in climate, ocean circulation, ecosystems, and biogeochemical cycling simulated for a business-as-usual $\mathrm{CO}_{2}$ emission scenario until year $4000 \mathrm{AD}$. Global Biogeochem. Cycles, 22, GB1013.

Schmittner, A., N. M. Urban, K. Keller, and D. Matthews, 2009: Using tracer observations to reduce the uncertainty of ocean diapycnal mixing and climatecarbon cycle projections. Global Biogeochem. Cycles, 23, GB4009.

Schneider von Deimling, T. S., M. Meinshausen, A. Levermann, V. Huber, K. Frieler, D. M. Lawrence, and V. Brovkin, 2012: Estimating the near-surface permafrostcarbon feedback on global warming. Biogeosciences, 9, 649-665.

Scholze, M., W. Knorr, N. W. Arnell, and I. C. Prentice, 2006: A climate-change risk analysis for world ecosystems. Proc. Natl. Acad. Sci. U.S.A., 103, 13116-13120.

Schuiling, R. D., and P. Krijgsman, 2006: Enhanced weathering: An effective and cheap tool to sequester $\mathrm{CO}_{2}$. Clim. Change, 74, 349-354.

Schultz, M. G., et al., 2007: Emission data sets and methodologies for estimating emissions. REanalysis of the TROpospheric chemical composition over the past 40 years. A long-term global modeling study of tropospheric chemistry funded under the 5th EU framework programme EU-Contract EVK2-CT-2002-00170.

Schulze, E. D., S. Luyssaert, P. Ciais, A. Freibauer, and I. A. Janssens, 2009: Importance of methane and nitrous oxide for Europe's terrestrial greenhouse-gas balance. Nature Geosci., 2, 842-850.

Schulze, E. D., et al., 2010: The European carbon balance. Part 4: Integration of carbon and other trace-gas fluxes. Global Change Biol., 16, 1451-1469.

Schurgers, G., U. Mikolajewicz, M. Gröger, E. Maier-Reimer, M. Vizcaino, and A. Winguth, 2006: Dynamics of the terrestrial biosphere, climate and atmospheric $\mathrm{CO}_{2}$ concentration during interglacials: A comparison between Eemian and Holocene. Clim. Past, 2, 205-220.

Schuster, U., and A. J. Watson, 2007: A variable and decreasing sink for atmospheric $\mathrm{CO}_{2}$ in the North Atlantic. J. Geophys. Res. Oceans, 112, C11006.

Schuster, U., et al., 2009: Trends in North Atlantic sea-surface $\mathrm{fCO}_{2}$ from 1990 to 2006. Deep-Sea Res. Pt. II, 56, 620-629.

Schuster, U., et al., 2013: An assessment of the Atlantic and Arctic sea-air $\mathrm{CO}_{2}$ fluxes, 1990-2009. Biogeosciences, 10, 607-627.

Schwalm, C. R., et al., 2010: A model-data intercomparison of $\mathrm{CO}_{2}$ exchange across North America: Results from the North American Carbon Program site synthesis. J. Geophys. Res., 115, G0OH05.

Seitzinger, S. P., and C. Kroeze, 1998: Global distribution of nitrous oxide production and $\mathrm{N}$ inputs in freshwater and coastal marine ecosystems. Global Biogeochem. Cycles, 12, 93-113. 
Seitzinger, S. P., J. A. Harrison, E. Dumont, A. H. W. Beusen, and A. F. Bouwman, 2005: Sources and delivery of carbon, nitrogen, and phosphorus to the coastal zone: An overview of Global Nutrient Export from Watersheds (NEWS) models and their application. Global Biogeochem. Cycles, 19, Gb4s01.

Seitzinger, S. P., et al., 2010: Global river nutrient export: A scenario analysis of past and future trends. Global Biogeochem. Cycles, 24, GB0A08.

Sentman, L. T., E. Shevliakova, R. J. Stouffer, and S. Malyshev, 2011: Time scales of terrestrial carbon response related to land-use application: Implications for initializing an Earth System Model. Earth Interactions, 15, 1-16.

Shackleton, N. J., 2000: The 100,000-year ice-age cycle identified and found to lag temperature, carbon dioxide, and orbital eccentricity. Science, 289, 1897-1902.

Shaffer, G., 2010: Long-term effectiveness and consequences of carbon dioxide sequestration. Nature Geosci., 3, 464-467.

Shaffer, G., S. M. Olsen, and J. O. P. Pedersen, 2009: Long-term ocean oxygen depletion in response to carbon dioxide emission from fossil fuels. Nature Geosci., 2, 105-109.

Shakhova, N., I. Semiletov, A. Salyuk, V. Yusupov, D. Kosmach, and O. Gustafsson, 2010: Extensive methane venting to the atmosphere from sediments of the East Siberian Arctic shelf. Science, 327, 1246-1250.

Shallcross, D. E., M. A. K. Khalil, and C. L. Butenhoff, 2007: The atmospheric methane sink. In: Greenhouse Gas Sinks [D. Reay (ed.)] CAB International, pp. 171-183.

Shepherd, J., et al., 2009: Geoengineering the climate: Science, governance and uncertainty. Report of the Royal Society, London, $98 \mathrm{pp}$.

Shevliakova, E., et al., 2009: Carbon cycling under 300 years of land use change: Importance of the secondary vegetation sink. Global Biogeochem. Cycles, 23, GB2022.

Shindell, D. T., B. P. Walter, and G. Faluvegi, 2004: Impacts of climate change on methane emissions from wetlands. Geophys. Res. Lett., 31, L21202.

Siegenthaler, U., et al., 2005a: Supporting evidence from the EPICA Dronning Maud Land ice core for atmospheric $\mathrm{CO}_{2}$ changes during the past millennium. Tellus $B, 57,51-57$.

Siegenthaler, U., et al., 2005b: Stable carbon cycle-climate relationship during the late Pleistocene. Science, 310, 1313-1317.

Sigman, D. M., M. P. Hain, and G. H. Haug, 2010: The polar ocean and glacial cycles in atmospheric $\mathrm{CO}_{2}$ concentration. Nature, 466, 47-55.

Simpson, I. J., F. S. Rowland, S. Meinardi, and D. R. Blake, 2006: Influence of biomass burning during recent fluctuations in the slow growth of global tropospheric methane. Geophys. Res. Lett., 33, L22808.

Simpson, I. J., et al., 2012: Long-term decline of global atmospheric ethane concentrations and implications for methane. Nature, 488, 490-494.

Singarayer, J. S., P. J. Valdes, P. Friedlingstein, S. Nelson, and D. J. Beerling, 2011: Late Holocene methane rise caused by orbitally controlled increase in tropical sources. Nature, 470, 82-85.

Singh, B. K., R. D. Bardgett, P. Smith, and D. S. Reay, 2010: Microorganisms and climate change: Terrestrial feedbacks and mitigation options. Nature Rev. Microbiol., 8, 779-790.

Sitch, S., P. M. Cox, W. J. Collins, and C. Huntingford, 2007: Indirect radiative forcing of climate change through ozone effects on the land-carbon sink. Nature, 448, 791-794.

Sitch, S., et al., 2003: Evaluation of ecosystem dynamics, plant geography and terrestrial carbon cycling in the LPJ Dynamic Global Vegetation Model. Global Change Biol., 9, 161-185.

Sitch, S., et al., 2008: Evaluation of the terrestrial carbon cycle, future plant geography and climate-carbon cycle feedbacks using five Dynamic Global Vegetation Models (DGVMs). Global Change Biol., 14, 2015-2039.

Skinner, L. C., S. Fallon, C. Waelbroeck, E. Michel, and S. Barker, 2010: Ventilation of the deep Southern ocean and deglacial $\mathrm{CO}_{2}$ rise. Science, 328, 1147-1151.

Smetacek, V., et al., 2012: Deep carbon export from a Southern Ocean iron-fertilized diatom bloom. Nature, 487, 313-319.

Smith, B., I. C. Prentice, and M. T. Sykes, 2001a: Representation of vegetation dynamics in the modelling of terrestrial ecosystems: Comparing two contrasting approaches within European climate space. Global Ecol. Biogeogr., 10, 621-637.

Smith, K. A., A. R. Mosier, P. J. Crutzen, and W. Winiwarter, 2012: The role of $\mathrm{N}_{2} \mathrm{O}$ derived from crop-based biofuels, and from agriculture in general, in Earth's climate. Philos. Trans. R. Soc. London B, 367, 1169-1174.

Smith, L. C., Y. Sheng, G. M. MacDonald, and L. D. Hinzman, 2005: Disappearing Arctic lakes. Science, 308, 1429.
Smith, S. V., W. H. Renwick, R. W. Buddemeier, and C. J. Crossland, 2001 b: Budgets of soil erosion and deposition for sediments and sedimentary organic carbon across the conterminous United States. Global Biogeochem. Cycles, 15, 697707.

Sokolov, A. P., D. W. Kicklighter, J. M. Melillo, B. S. Felzer, C. A. Schlosser, and T. W. Cronin, 2008: Consequences of considering carbon-nitrogen interactions on the feedbacks between climate and the terrestrial carbon cycle. J. Clim., 21, 3776-3796.

Sowers, T., 2006: Late quaternary atmospheric $\mathrm{CH}_{4}$ isotope record suggests marine clathrates are stable. Science, 311, 838-840.

Sowers, T., R. B. Alley, and J. Jubenville, 2003: Ice core records of atmospheric $\mathrm{N}_{2} \mathrm{O}$ covering the last 106,000 years. Science, 301, 945-948.

Spahni, R., et al., 2011: Constraining global methane emissions and uptake by ecosystems. Biogeosciences, 8, 1643-1665.

Spracklen, D. V., L. J. Mickley, J. A. Logan, R. C. Hudman, R. Yevich, M. D. Flannigan, and A. L. Westerling, 2009: Impacts of climate change from 2000 to 2050 on wildfire activity and carbonaceous aerosol concentrations in the western United States. J. Geophys. Res. Atmos., 114, D20301.

Stallard, R. F., 1998: Terrestrial sedimentation and the carbon cycle: Coupling weathering and erosion to carbon burial. Global Biogeochem. Cycles, 12, 231257.

Stanhill, G., and S. Cohen, 2001: Global dimming: A review of the evidence for a widespread and significant reduction in global radiation with discussion of its probable causes and possible agricultural consequences. Agr. Forest Meteorol., 107, 255-278.

Steinacher, M., F. Joos, T. L. Frölicher, G.-K. Plattner, and S. C. Doney, 2009: Imminent ocean acidification in the Arctic projected with the NCAR global coupled carbon cycle-climate model. Biogeosciences, 6, 515-533.

Steinacher, M., et al., 2010: Projected 21st century decrease in marine productivity: A multi-model analysis. Biogeosciences, 7, 979-1005.

Stephens, B. B., and R. F. Keeling, 2000: The influence of Antarctic sea ice on glacialinterglacial $\mathrm{CO}_{2}$ variations. Nature, 404, 171-174.

Stephens, B. B., et al., 2007: Weak northern and strong tropical land carbon uptake from vertical profiles of atmospheric $\mathrm{CO}_{2}$. Science, 316, 1732-1735.

Stevenson, D. S., et al., 2006: Multimodel ensemble simulations of present-day and near-future tropospheric ozone. J. Geophys. Res., 111, D08301.

Stocker, B. D., K. Strassmann, and F. Joos, 2011: Sensitivity of Holocene atmospheric $\mathrm{CO}_{2}$ and the modern carbon budget to early human land use: Analyses with a process-based model. Biogeosciences, 8, 69-88.

Stocker, B. D., et al., 2013: Multiple greenhouse gas feedbacks from the land biosphere under future climate change scenarious. Nature Clim. Change, 3, 666672.

Stöckli, R., et al., 2008: Use of FLUXNET in the Community Land Model development. J. Geophys. Res.Biogeosci., 113, G01025.

Stolaroff, J. K., D. W. Keith, and G. V. Lowry, 2008: Carbon dioxide capture from atmospheric air using sodium hydroxide spray. Environ. Sci. Technol., 42, 27282735.

Stolaroff, J. K., S. Bhattacharyya, C. A. Smith, W. L. Bourcier, P. J. Cameron-Smith, and R. D. Aines, 2012: Review of methane mitigation technologies with application to rapid release of methane from the Arctic. Environ. Sci. Technol., 46, 6455-6469.

Stramma, L., A. Oschlies, and S. Schmidtko, 2012: Mismatch between observed and modeled trends in dissolved upper-ocean oxygen over the last 50 years. Biogeosciences, 9, 4045-4057.

Strassmann, K. M., F. Joos, and G. Fischer, 2008: Simulating effects of land use changes on carbon fluxes: Past contributions to atmospheric $\mathrm{CO}_{2}$ increases and future commitments due to losses of terrestrial sink capacity. Tellus $B, 60$, 583-603.

Stuiver, M., and P. D. Quay, 1981: Atmospheric ${ }^{14} \mathrm{C}$ changes resulting from fossil-fuel $\mathrm{CO}_{2}$ release and cosmic-ray flux variability. Earth Planet. Sci. Lett., 53, 349-362.

Suchet, P. A., and J. L. Probst, 1995: A Global model for present-day atmospheric soil $\mathrm{CO}_{2}$ consumption by chemical erosion of continental rocks $\left(\mathrm{GEM}-\mathrm{CO}_{2}\right)$. Tellus $B_{\text {, }}$ $47,273-280$.

Sugimoto, A., T. Inoue, N. Kirtibutr, and T. Abe, 1998: Methane oxidation by termite mounds estimated by the carbon isotopic composition of methane. Global Biogeochem. Cycles, 12, 595-605.

Sundquist, E. T., 1986: Geologic analogs: Their value and limitations in carbon dioxide research. In: The Changing Carbon Cycle [J. R. Trabalka and D. E. Reichle (eds.)], Springer-Verlag, New York, pp. 371-402. 
Sundquist, E. T, 1990: Influence of deep-sea benthic processes on atmospheric $\mathrm{CO}_{2}$. Philos. Trans. R. Soc. London Series A, 331, 155-165.

Suntharalingam, P., et al., 2012: Quantifying the impact of anthropogenic nitrogen deposition on oceanic nitrous oxide. Geophys. Res. Lett., 39, L07605.

Sussmann, R., F. Forster, M. Rettinger, and P. Bousquet, 2012: Renewed methane increase for five years (2007-2011) observed by solar FTIR spectrometry. Atmos. Chem. Phys., 112, 4885-4891.

Sutka, R. L., N. E. Ostrom, P. H. Ostrom, J. A. Breznak, H. Gandhi, A. J. Pitt, and F. Li, 2006: Distinguishing nitrous oxide production from nitrification and denitrification on the basis of isotopomer abundances. Appl. Environ. Microbiol, 72, 638-644.

Sutton, M. A., D. D. Simpson, P. E. Levy, R. I. Smith, S. Reis, M. Van Oijen, and W. De Vries, 2008: Uncertainties in the relationship between atmospheric nitrogen deposition and forest carbon sequestration. Global Change Biol., 14, 20572063.

Sutton, M. A., et al., 2011: The European Nitrogen Assessment - Sources, Effects and Policy Perspectives. Cambridge University Press, Cambridge, United Kingdom, and New York, NY, USA, 664 pp.

Syakila, A., and C. Kroeze, 2011: The global $\mathrm{N}_{2} \mathrm{O}$ budget revisited. Greenh. Gas Measure. Manage., 1, 17-26.

Syakila, A., C. Kroeze, and C. P. Slomp, 2010: Neglecting sinks for $\mathrm{N}_{2} \mathrm{O}$ at the earth's surface: Does it matter? J. Integrat. Environ. Sci., 7, 79-87.

Syvitski, J. P. M., C. J. Vörösmarty, A. J. Kettner, and P. Green, 2005: Impact of humans on the flux of terrestrial sediment to the global coastal ocean. Science, $\mathbf{3 0 8}$, 376-380.

Tagaris, E., K.-J. Liao, K. Manomaiphiboon, J.-H. Woo, S. He, P. Amar, and A. G. Russell, 2008: Impacts of future climate change and emissions reductions on nitrogen and sulfur deposition over the United States. Geophys. Res. Lett., 35, L08811.

Tagliabue, A., L. Bopp, and O. Aumont, 2008: Ocean biogeochemistry exhibits contrasting responses to a large scale reduction in dust deposition. Biogeosciences, 5, 11-24.

Tagliabue, A., L. Bopp, and M. Gehlen, 2011: The response of marine carbon and nutrient cycles to ocean acidification: Large uncertainties related to phytoplankton physiological assumptions. Global Biogeochem. Cycles, 25, GB3017.

Takahashi, T., S. C. Sutherland, R. A. Feely, and R. Wanninkhof, 2006: Decadal change of the surface water $\mathrm{pCO}_{2}$ in the North Pacific: A synthesis of 35 years of observations. J. Geophys. Res. Oceans, 111, C07s05.

Takahashi, T., J. Olafsson, J. G. Goddard, D. W. Chipman, and S. C. Sutherland, 1993: Seasonal variation of $\mathrm{CO}_{2}$ and nutrients in the high-latitude surface oceans-A comparative study. Global Biogeochem. Cycles, 7, 843-878.

Takahashi, T., et al., 2009: Climatological mean and decadal change in surface ocean $\mathrm{pCO}_{2}$, and net sea-air $\mathrm{CO}_{2}$ flux over the global oceans. Deep-Sea Res. Pt. II, $\mathbf{5 6}$ 554-577.

Tan, K., et al., 2010: Application of the ORCHIDEE global vegetation model to evaluate biomass and soil carbon stocks of Qinghai-Tibetan grasslands. Global Biogeochem. Cycles, 24, GB1013.

Tanhua, T., A. Körtzinger, K. Friis, D. W. Waugh, and D. W. R. Wallace, 2007: An estimate of anthropogenic $\mathrm{CO}_{2}$ inventory from decadal changes in oceanic carbon content. Proc. Natl. Acad. Sci. U.S.A., 104, 3037-3042.

Tans, P. P., T. J. Conway, and T. Nakazawa, 1989: Latitudinal distribution of the sources and sinks of atmospheric carbon dioxide derived from surface observations and an atmospheric transport model. J. Geophys. Res. Atmos., 94, 5151-5172.

Tarnocai, C., J. G. Canadell, E. A. G. Schuur, P. Kuhry, G. Mazhitova, and S. Zimov, 2009: Soil organic carbon pools in the northern circumpolar permafrost region. Global Biogeochem. Cycles, 23, Gb2023.

Taucher, J., and A. Oschlies, 2011: Can we predict the direction of marine primary production change under global warming? Geophys. Res. Lett., 38, L02603.

Taylor, K. E., R. J. Stouffer, and G. A. Meehl, 2012: An overview of CMIP5 and the experiment design. Bull. Am. Meteorol. Soc., 93, 485-498.

Tegen, I., M. Werner, S. P. Harrison, and K. E. Kohfeld, 2004: Relative importance of climate and land use in determining present and future global soil dust emission. Geophys. Res. Lett., 31, L05105.

Terazawa, K., S. Ishizuka, T. Sakata, K. Yamada, and M. Takahashi, 2007: Methane emissions from stems of Fraxinus mandshurica var. japonica trees in a floodplain forest. Soil Biology and Biochemistry, 39, 2689-2692.

Terrier, A., M. P. Girardin, C. Périé, P. Legendre, and Y. Bergeron, 2013: Potential changes in forest composition could reduce impacts of climate change on boreal wildfires. Ecol. Appl., 23, 21-35.
Thomas, $\mathrm{H}$. , et al., 2007: Rapid decline of the $\mathrm{CO}_{2}$ buffering capacity in the North Sea and implications for the North Atlantic Ocean. Global Biogeochem. Cycles, 21, GB4001.

Thompson, D. W. J., and S. Solomon, 2002: Interpretation of recent Southern Hemisphere climate change. Science, 296, 895-899.

Thomson, A. M., et al., 2010: Climate mitigation and food production in tropical landscapes. Special feature: Climate mitigation and the future of tropical landscapes. Proc. Natl. Acad. Sci. U.S.A., 107, 19633-19638.

Thornton, P. E., J.-F. Lamarque, N. A. Rosenbloom, and N. M. Mahowald, 2007: Influence of carbon-nitrogen cycle coupling on land model response to $\mathrm{CO}_{2}$ fertilization and climate variability. Global Biogeochem. Cycles, 21, Gb4018.

Thornton, P. E., et al., 2009: Carbon-nitrogen interactions regulate climate-carbon cycle feedbacks: Results from an atmosphere-ocean general circulation model. Biogeosciences, 6, 2099-2120.

Tian, H., X. Xu, M. Liu, W. Ren, C. Zhang, G. Chen, and C. Lu, 2010: Spatial and temporal patterns of $\mathrm{CH}_{4}$ and $\mathrm{N}_{2} \mathrm{O}$ fluxes in terrestrial ecosystems of North America during 1979-2008: Application of a global biogeochemistry model. Biogeosciences, 7, 2673-2694.

Tilman, D., C. Balzer, J. Hill, and B. L. Befort, 2011: Global food demand and the sustainable intensification of agriculture. Proc. Natl. Acad. Sci. U.S.A., 108, 20260-20264.

Tjiputra, J. F., A. Olsen, K. Assmann, B. Pfeil, and C. Heinze, 2012: A model study of the seasonal and long-term North Atlantic surface $\mathrm{pCO}_{2}$ variability. Biogeosciences, 9, 907-923.

Todd-Brown, K., F. M. Hopkins, S. N. Kivlin, J. M. Talbot, and S. D. Allison, 2012: A framework for representing microbial decomposition in coupled climate models. Biogeoschemistry, 109, 19-33.

Toggweiler, J. R., 1999: Variation of atmospheric $\mathrm{CO}_{2}$ by ventilation of the ocean's deepest water. Paleoceanography, 14, 571-588.

Toggweiler, J. R., J. L. Russell, and S. R. Carson, 2006: Midlatitude westerlies, atmospheric $\mathrm{CO}_{2}$, and climate change during the ice ages. Paleoceanography, 21, PA2005.

Tranvik, L. J., et al., 2009: Lakes and reservoirs as regulators of carbon cycling and climate. Limnol. Oceanogr., 54, 2298-2314.

Trudinger, C. M., I. G. Enting, P. J. Rayner, and R. J. Francey, 2002: Kalman filter analysis of ice core data - 2. Double deconvolution of $\mathrm{CO}_{2}$ and $213 \mathrm{C}$ measurements. J. Geophys. Res., 107, D20.

Turetsky, M. R., R. K. Wieder, D. H. Vitt, R. J. Evans, and K. D. Scott, 2007: The disappearance of relict permafrost in boreal north America: Effects on peatland carbon storage and fluxes. Global Change Biol., 13, 1922-1934.

Tymstra, C., M. D. Flannigan, O. B. Armitage, and K. Logan, 2007: Impact of climate change on area burned in Alberta's boreal forest. Int. J. Wildland Fire, 16, 153 160.

Tyrrell, T., J. G. Shepherd, and S. Castle, 2007: The long-term legacy of fossil fuels. Tellus B, 59, 664-672.

Ullman, D. J., G. A. McKinley, V. Bennington, and S. Dutkiewicz, 2009: Trends in the North Atlantic carbon sink: 1992-2006. Global Biogeochem. Cycles, 23, Gb4011.

UNEP, 2011: Integrated assessment of black carbon and tropospheric ozone: Summary for decision makers. United Nations Environment Programme and World Meterological Association, $38 \mathrm{pp}$.

Valsala, V., S. Maksyutov, M. Telszewski, S. Nakaoka, Y. Nojiri, M. Ikeda, and R. Murtugudde, 2012: Climate impacts on the structures of the North Pacific airsea $\mathrm{CO}_{2}$ flux variability. Biogeosciences, 9, 477-492.

van der Werf, G. R., et al., 2004: Continental-scale partitioning of fire emissions during the 1997 to $2001 \mathrm{El}$ Niño/La Niña period. Science, 303, 73-76.

van der Werf, G. R., et al., 2009: $\mathrm{CO}_{2}$ emissions from forest loss. Nature Geosci., 2, 737-738.

van der Werf, G. R., et al., 2010: Global fire emissions and the contribution of deforestation, savanna, forest, agricultural, and peat fires (1997-2009). Atmos. Chem. Phys., 10, 11707-11735.

van derWerf, G. R., et al., 2008: Climate regulation of fire emissions and deforestation in equatorial Asia Proc. Natl. Acad. Sci. U.S.A., 105, 20350-20355.

van Groenigen, K. J., C. W. Osenberg, and B. A. Hungate, 2011: Increased soil emissions of potent greenhouse gases under increased atmospheric $\mathrm{CO}_{2}$. Nature, 475, 214-216.

van Huissteden, J., C. Berrittella, F. J. W. Parmentier, Y. Mi, T. C. Maximov, and A. J. Dolman, 2011: Methane emissions from permafrost thaw lakes limited by lake drainage. Nature Clim. Change, 1, 119-123. 
van Minnen, J. G., K. Klein Goldewijk, E. Stehfest, B. Eickhout, G. van Drecht, and R. Leemans, 2009: The importance of three centuries of land-use change for the global and regional terrestrial carbon cycle. Clim. Change, 97, 123-144.

van Vuuren, D. P., L. F. Bouwman, S. J. Smith, and F. Dentener, 2011: Global projections for anthropogenic reactive nitrogen emissions to the atmosphere:An assessment of scenarios in the scientific literature. Curr. Opin. Environ. Sustain., 3, 359-369.

Verdy, A., S. Dutkiewicz, M. J. Follows, J. Marshall, and A. Czaja, 2007: Carbon dioxide and oxygen fluxes in the Southern Ocean: Mechanisms of interannual variability. Global Biogeochem. Cycles, 21, Gb2020.

Vigano, I., H. van Weelden, R. Holzinger, F. Keppler, A. McLeod, and T. Röckmann, 2008: Effect of UV radiation and temperature on the emission of methane from plant biomass and structural components. Biogeosciences, 5, 937-947.

Vitousek, P. M., S. Porder, B. Z. Houlton, and O. A. Chadwick, 2010: Terrestrial phosphorus limitation: Mechanisms, implications, and nitrogen-phosphorus interactions. Ecol. Appl., 20, 5-15.

Vitousek, P. M., D. N. L. Menge, S. C. Reed, and C. C. Cleveland, 2013: Biological nitrogen fixation: Rates, patterns, and ecological controls in terrestrial ecosystems. Philos. Trans. R. Soc. London B,368, 20130119.

Volk, C. M., et al., 1997: Evaluation of source gas lifetimes from stratospheric observations. J. Geophys. Res.: Atmos., 102, 25543-25564.

Volodin, E. M., 2008: Methane cycle in the INM RAS climate model. Izvestiya Atmos. Ocean. Phys., 44, 153-159.

Voss, M., H. W. Bange, J. W. Dippner, J. J. Middelburg, J. P. Montoya, and B. Ward, 2013: The marine nitrogen cycle: Recent discoveries, uncertainties and the potential relevance of climate change. Philos. Trans. R. Soc. London B, 368, 20130121.

Voss, M., et al., 2011: Nitrogen processes in coastal and marine ecosystems. In: The European Nitrogen Assessment: Sources, Effects, and Policy Perspectives. [M. A. Sutton, C. M. Howard, J. W. Erisman, G. Billen, A. Bleeker, P. Grennfelt, H. van Grinsven and B. Grizetti (eds.)]. Cambridge University Press, Cambridge, United Kingdom, and New York, NY, USA, pp. 147-176.

Voulgarakis, A., et al., 2013: Analysis of present day and future $\mathrm{OH}$ and methane lifetime in the ACCMIP simulations. Atmos. Chem. Phys., 13, 2563-2587.

Waelbroeck, C., et al., 2009: Constraints on the magnitude and patterns of ocean cooling at the Last Glacial Maximum. Nature Geosci., 2, 127-132.

Wakita, M., S. Watanabe, A. Murata, N. Tsurushima, and M. Honda, 2010: Decadal change of dissolved inorganic carbon in the subarctic western North Pacific Ocean. Tellus $B, 62,608-620$.

Walker, J. C. G., and J. F. Kasting, 1992: Effects of fuel and forest conservation on future levels of atmospheric carbon dioxide. Palaeogeogr. Palaeoclimat. Palaeoecol. (Global Planet. Change Sect.), 97, 151-189.

Walter Anthony, K. M., P. Anthony, G. Grosse, and J. Chanton, 2012: Geologic methane seeps along boundaries of Arctic permafrost thaw and melting glaciers. Nature Geosci., 5, 419-426.

Walter, K. M., L. C. Smith, and F. Stuart Chapin, 2007: Methane bubbling from northern lakes: Present and future contributions to the global methane budget. Philos. Trans. R. Soc. A, 365, 1657-1676.

Walter, K. M., S. A. Zimov, J. P. Chanton, D. Verbyla, and F. S. I. Chapin, 2006: Methane bubbling from Siberian thaw lakes as a positive feedback to climate warming. Nature, 443, 71-75.

Wang, D., S. A. Heckathorn, X. Wang, and S. M. Philpott, 2012a: A meta-analysis of plant physiological and growth responses to temperature and elevated $\mathrm{CO}_{2}$. Oecologia, 169, 1-13.

Wang, J., X. Pan, Y. Liu, X. Zhang, and Z. Xiong, 2012b: Effects of biochar amendment in two soils on greenhouse gas emissions and crop production. Plant Soil, 360, 287-298.

Wang, Y.-P., and B. Z. Houlton, 2009: Nitrogen constraints on terrestrial carbon uptake: Implications for the global carbon-climate feedback. Geophys. Res. Lett., 36, L24403.

Wang, Y. P., B. Z. Houlton, and C. B. Field, 2007: A model of biogeochemical cycles of carbon, nitrogen, and phosphorus including symbiotic nitrogen fixation and phosphatase production. Global Biogeochem. Cycles, 21, GB1018.

Wang, Y. P., R. M. Law, and B. Pak, 2010a: A global model of carbon, nitrogen and phosphorus cycles for the terrestrial biosphere. Biogeosciences, 7, 2261-2282.

Wang, Z., J. Chappellaz, K. Park, and J. E. Mak, 2010b: Large variations in Southern Hemisphere biomass burning during the last 650 years. Science, 330, 16631666.

Wang, Z. P., X. G. Han, G. G. Wang, Y. Song, and J. Gulledge, 2008: Aerobic methane emission from plants in the Inner Mongolia steppe. Environ. Sci. Technol., 42, 62-68.
Wania, R., 2007: Modelling Northern Peatland Land Surface Processes, Vegetation Dynamics and Methane Emissions. Ph.D. Thesis, Bristol, UK.

Wania, R., I. Ross, and I. C. Prentice, 2009: Integrating peatlands and permafrost into a dynamic global vegetation model: 1 . Evaluation and sensitivity of physical land surface processes. Global Biogeochem. Cycles, 23, GB3014.

Wanninkhof, R., S. C. Doney, J. L. Bullister, N. M. Levine, M. Warner, and N. Gruber, 2010: Detecting anthropogenic $\mathrm{CO}_{2}$ changes in the interior Atlantic Ocean between 1989 and 2005. J. Geophys. Res. Oceans, 115, C11028.

Wanninkhof, R., et al., 2013: Global ocean carbon uptake: Magnitude, variability and trends. Biogeosciences, 10, 1983-2000.

Wardle, D. A., M.-C. Nilsson, and O. Zackrisson, 2008: Fire-derived charcoal causes loss of forest humus. Science, 320, 629.

Watanabe, S., et al., 2011: MIROC-ESM 2010: Model description and basic results of CMIP5-20c3m experiments. Geosci. Model Dev., 4, 845-872.

Watson, A. J., and A. C. N. Garabato, 2006: The role of Southern Ocean mixing and upwelling in glacial-interglacial atmospheric $\mathrm{CO}_{2}$ change. Tellus $B, 58,73-87$.

Watson, A. J., D. C. E. Bakker, A. J. Ridgwell, P. W. Boyd, and C. S. Law, 2000: Effect of iron supply on Southern Ocean $\mathrm{CO}_{2}$ uptake and implications for glacial atmospheric $\mathrm{CO}_{2}$. Nature, 407, 730-733.

Watson, A. J., P. W. Boyd, S. M. Turner, T. D. Jickells, and P. S. Liss, 2008: Designing the next generation of ocean iron fertilization experiments. Mar. Ecol. Prog. Ser., 364, 303-309.

Watson, A. J., et al., 1994: Minimal effect of iron fertilization on sea-surface carbondioxide concentartions. Nature, 371, 143-145.

Watson, A. J., et al., 2009: Tracking the variable North Atlantic sink for atmospheric $\mathrm{CO}_{2}$. Science, 326, 1391-1393.

Waugh, D. W., T. M. Hall, B. I. McNeil, R. Key, and R. J. Matear, 2006: Anthropogenic $\mathrm{CO}_{2}$ in the oceans estimated using transit time distributions. Tellus $B, 58,376-$ 389.

Wecht, K. J., et al., 2012:Validation of TES methane with HIPPO aircraft observations: Implications for inverse modeling of methane sources. Atmos. Chem. Phys., 12, 1823-1832.

Westbrook, G. K., et al., 2009: Escape of methane gas from the seabed along the West Spitsbergen continental margin. Geophys. Res. Lett., 36, L15608.

Westerling, A. L., M. G. Turner, E. A. H. Smithwick, W. H. Romme, and M. G. Ryan, 2011: Continued warming could transform Greater Yellowstone fire regimes by mid-21st century. Proc. Natl. Acad. Sci. U.S.A., 108, 13165-13170.

White, J. R., R. D. Shannon, J. F. Weltzin, J. Pastor, and S. D. Bridgham, 2008: Effects of soil warming and drying on methane cycling in a northern peatland mesocosm study. J. Geophys. Res. Biogeosci, 113, G00A06.

Wiedinmyer, C., S. K. Akagi, R. J. Yokelson, L. K. Emmons, J. A. Al-Saadi, J. J. Orlando, and A. J. Soja, 2011: The Fire INventory from NCAR (FINN): A high resolution global model to estimate the emissions from open burning. Geosci. Model Dev., 4, 625-641.

Williams, C. A., G. J. Collatz, J. Masek, and S. N. Goward, 2012a: Carbon consequences of forest disturbance and recovery across the conterminous United States. Global Biogeochem. Cycles, 26, GB1005.

Williams, J., and P. J. Crutzen, 2010: Nitrous oxide from aquaculture. Nature Geosci, 3,143 .

Williams, J. E., A. Strunk, V. Huijnen, and M. van Weele, 2012b: The application of the Modified Band Approach for the calculation of on-line photodissociation rate constants in TM5: Implications for oxidative capacity. Geosci. Model Dev. $5,15-35$.

Wise, M., et al., 2009: Implications of limiting $\mathrm{CO}_{2}$ concentrations for land Uue and energy. Science, 324, 1183-1186.

Woodward, F. I., and M. R. Lomas, 2004: Simulating vegetation processes along the Kalahari transect. Global Change Biol., 10, 383-392.

Woolf, D., J. E. Amonette, F. A. Street-Perrott, J. Lehmann, and S. Joseph, 2010: Sustainable biochar to mitigate global climate change. Nature Commun., 1, 1-9.

Worden, J., et al., 2012: Profiles of $\mathrm{CH}_{4}, \mathrm{HDO}, \mathrm{H}_{2} \mathrm{O}$, and $\mathrm{N}_{2} \mathrm{O}$ with improved lower tropospheric vertical resolution from Aura TES radiances. Atmos. Measure. Techn., 5, 397-411

Worrall, F., T. Burt, and R. Shedden, 2003: Long term records of riverine dissolved organic matter. Biogeochemistry, 64, 165-178.

Wotton, B. M., C. A. Nock, and M. D. Flannigan, 2010: Forest fire occurrence and climate change in Canada. Int. J. Wildland Fire, 19, 253-271.

Wu, P. L., R. Wood, J. Ridley, and J. Lowe, 2010: Temporary acceleration of the hydrological cycle in response to a $\mathrm{CO}_{2}$ rampdown. Geophys. Res. Lett., 37, L12705. 
Wu, T., et al., 2013: Global Carbon budgets simulated by the Beijing Climate Center Climate System Model for the last Century. J. Geophys. Res. Atmos., doi:10.1002/ jgrd.50320, in press.

Wurzburger, N., J. P. Bellenger, A. M. L. Kraepiel, and L. O. Hedin, 2012: Molybdenum and phosphorus interact to constrain asymbiotic nitrogen fixation in tropical forests. PLOS ONE, 7, e33710.

$\mathrm{Xu}-\mathrm{Ri}$, and I. C. Prentice, 2008: Terrestrial nitrogen cycle simulation with a dynamic global vegetation model. Global Change Biol., 14, 1745-1764.

Xu-Ri, I. C. Prentice, R. Spahni, and H. S. Niu, 2012: Modelling terrestrial nitrous oxide emissions and implications for climate feedback. New Phytologist, 196, 472-488.

Yamamoto-Kawai, M., F. A. McLaughlin, E. C. Carmack, S. Nishino, and K. Shimada, 2009: Aragonite undersaturation in the Arctic Ocean: Effects of ocean acidification and sea ice melt. Science, 326, 1098-1100.

Yamamoto, A., M. Kawamiya, A. Ishida, Y. Yamanaka, and S. Watanabe, 2012: Impact of rapid sea-ice reduction in the Arctic Ocean on the rate of ocean acidification. Biogeosciences, 9, 2365-2375.

Yan, X., H. Akiyama, K. Yagi, and H. Akimoto, 2009: Global estimations of the inventory and mitigation potential of methane emissions from rice cultivation conducted using the 2006 Intergovernmental Panel on Climate Change Guidelines. Global Biogeochem. Cycles, 23, GB2002.

Yang, X., T. K. Richardson, and A. K. Jain, 2010: Contributions of secondary forest and nitrogen dynamics to terrestrial carbon uptake. Biogeosciences, 7, 3041-3050.

Yevich, R., and J. A. Logan, 2003: An assessment of biofuel use and burning of agricultural waste in the developing world. Global Biogeochem. Cycles, 17, 1095.

Yool, A., J. G. Shepherd, H. L. Bryden, and A. Oschlies, 2009: Low efficiency of nutrient translocation for enhancing oceanic uptake of carbon dioxide. J. Geophys. Res. Oceans, 114, C08009.

Yoshikawa-Inoue, H. Y., and M. Ishii, 2005: Variations and trends of $\mathrm{CO}_{2}$ in the surface seawater in the Southern Ocean south of Australia between 1969 and 2002. Tellus $B, 57,58-69$.

Yoshikawa, C., M. Kawamiya, T. Kato, Y. Yamanaka, and T. Matsuno, 2008: Geographical distribution of the feedback between future climate change and the carbon cycle. J. Geophys. Res. Biogeosci., 113, G03002.

Young, P., et al., 2013: Pre-industrial to end 21st century projections of tropospheric ozone from the Atmospheric Chemistry and Climate Model Intercomparison Project (ACCMIP). Atmos. Chem. Phys., 4, 2063-2090.

Yu, J., W. S. Broecker, H. Elderfield, Z. Jin, J. McManus, and F. Zhang, 2010: Loss of carbon from the deep sea since the Last Glacial Maximum. Science, 330 1084-1087.

Yu, Z., 2011: Holocene carbon flux histories of the world's peatlands: Global carboncycle implications. Holocene, 21, 761-774.

Zaehle, S., 2013: Terrestrial nitrogen-carbon cycle interactions at the global scale, Philos. Trans. R. Soc. London B, 368, 20130125.

Zaehle, S., and A. D. Friend, 2010: Carbon and nitrogen cycle dynamics in the 0-CN land surface model: 1 . Model description, site-scale evaluation, and sensitivity to parameter estimates. Global Biogeochem. Cycles, 24, GB1005.

Zaehle, S., and D. Dalmonech, 2011: Carbon-nitrogen interactions on land at global scales: Current understanding in modelling climate biosphere feedbacks. Curr. Opin. Environ. Sustain., 3, 311-320.

Zaehle, S., P. Friedlingstein, and A. D. Friend, 2010a: Terrestrial nitrogen feedbacks may accelerate future climate change. Geophys. Res. Lett., 37, L01401.

Zaehle, S., P. Ciais, A. D. Friend, and V. Prieur, 2011: Carbon benefits of anthropogenic reactive nitrogen offset by nitrous oxide emissions. Nature Geosci., 4, 601-605.

Zaehle, S., A. D. Friend, P. Friedlingstein, F. Dentener, P. Peylin, and M. Schulz, 2010b: Carbon and nitrogen cycle dynamics in the 0-CN land surface model: 2. Role of the nitrogen cycle in the historical terrestrial carbon balance. Global Biogeochem. Cycles, 24, GB1006.

Zak, D. R., K. S. Pregitzer, M. E. Kubiske, and A. J. Burton, 2011: Forest productivity under elevated $\mathrm{CO}_{2}$ and $\mathrm{O}_{3}$ : Positive feedbacks to soil $\mathrm{N}$ cycling sustain decadelong net primary productivity enhancement by $\mathrm{CO}_{2}$. Ecol. Lett., 14, 1220-1226.

Zech, R., Y. Huang, M. Zech, R. Tarozo, and W. Zech, 2011: High carbon sequestration in Siberian permafrost loess-paleosoils during glacials. Clim. Past, 7, 501-509.

Zeebe, R. E., and D. Wolf-Gladrow, 2001: $\mathrm{CO}_{2}$ in Seawater: Equilibrium, Kinetics, Isotopes. Elsevier Science, Amsterdam, Netherlands, and Philadelphia, PA, USA.

Zeebe, R. E., and D. Archer, 2005: Feasibility of ocean fertilization and its impact on future atmospheric $\mathrm{CO}_{2}$ levels. Geophys. Res. Lett., 32, L09703.
Zeng, N., 2003: Glacial-interglacial atmospheric $\mathrm{CO}_{2}$ change -The glacial burial hypothesis. Adv. Atmos. Sci., 20, 677-693.

Zhang, Q., Y. P. Wang, A. J. Pitman, and Y. J. Dai, 2011: Limitations of nitrogen and phosphorous on the terrestrial carbon uptake in the 20th century. Geophys. Res. Lett., 38, L22701.

Zhao, M., and S. W. Running, 2010: Drought-induced reduction in global terrestrial net primary production from 2000 through 2009. Science, 329, 940-943.

Zhou, S., and P. C. Flynn, 2005: Geoengineering downwelling ocean currents: A cost assessment. Clim. Change, 71, 203-220.

Zhuang, Q. L., et al., 2006: $\mathrm{CO}_{2}$ and $\mathrm{CH}_{4}$ exchanges between land ecosystems and the atmosphere in northern high latitudes over the 21st century. Geophys. Res. Lett., 33, L17403.

Zickfeld, K., M. Eby, H. D. Matthews, A. Schmittner, and A. J. Weaver, 2011: Nonlinearity of carbon cycle feedbacks. J. Clim., 24, 4255-4275.

Zimov, N. S., S. A. Zimov, A. E. Zimova, G. M. Zimova, V. I. Chuprynin, and F. S. Chapin, 2009: Carbon storage in pernafrost and soils of the mammoth tundra-steppe biome: Role in the global carbon budget. Geophys. Res. Lett., 36, L02502. 